\title{
Inference of ecology from the ontogeny of microfossils
}

by

\section{Peter Neil Schweitzer}

M.S. University of Kansas, 1986

B.S. University of Maryland, 1979

Submitted in partial fulfillment of the requirements for the degree of

Doctor of Philosophy

at the

\section{MASSACHUSETTS INSTITUTE OF TECHNOLOGY \\ and the \\ WOODS HOLE OCEANOGRAPHIC INSTITUTION}

June 1989

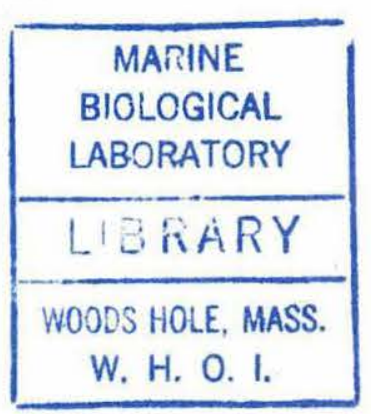

(C) Peter N. Schweitzer 1989

The author hereby grants to MIT and to WHOI permission to reproduce and to distribute copies of this thesis document in whole or in part.

Signature of Author.

Joint Program in Oceanography Massachusetts Institute of Technology Woods Hole Oceanographic Institution December 2, 1989

Certified by

G.P. Lohmann Associate Scientist Thesis Supervisor

Accepted by .

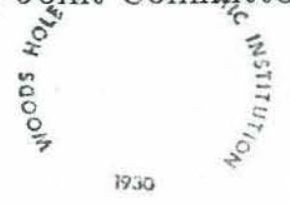


This work comprises three detailed studies of ontogeny and ecology. In the first chapter, four living species of the ostracode genus Cyprideis were studied both morphologically and ecologically to determine whether differences in age at maturity are correlated with heterochrony as expected; accelerated maturity should yield generalized morphology and small size, while delayed maturity should produce specialized morphology and large size. Two of the four species show the expected pattern, the other two do not. Cyprideis does not support the generalization that life-history evolution causes heterochrony, and casts doubt on the inference of life-history evolution from heterochrony where the data are drawn exclusively from extinct forms.

In the second chapter, populations of Globorotalia menardii and G. tumida were subjected to careful morphological analysis; the stable-isotopic composition of the growth stages revealed that both species inhabit the upper fifty meters of the ocean, descending to deeper water $(75-100 \mathrm{~m})$ for the emplacement of an enveloping calcite crust.

The third chapter shows a simple relationship between proloculus size and rate of chamber expansion in the polar planktonic foraminifer Neogloboquadrina pachyderma. The consequences for morphology of variations in ontogeny can be used to suggest ways of selecting specimens that minimize ontogenetic variations in shell chemistry. 


\section{Contents}

1 Life-history and the evolution of ontogeny in the ostracode genus Cyprideis 11

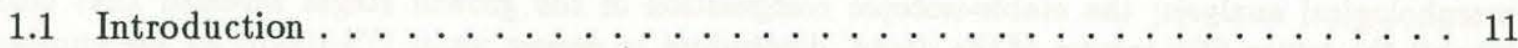

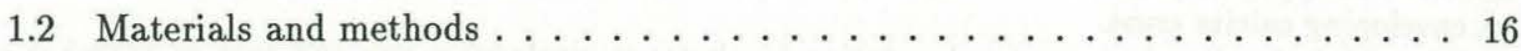

1.2.1 Material used to characterize size and shape . . . . . . . . . 17

1.2.2 Regular sampling of living populations . . . . . . . . . . . . 18

1.2.3 Quantitative description and analysis of shape variation . . . . . . . 20 20

1.2.4 Detection of heterochrony . . . . . . . . . . . . . . 22

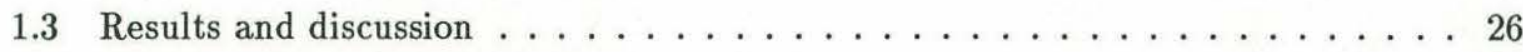

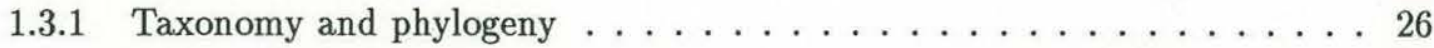

1.3.2 Ecology and life-history . . . . . . . . . . . . . . . . . . 29

1.3.3 Sources of intraspecific variation . . . . . . . . . . 36

1.3.4 Morphological relationships among species . . . . . . . . . . . 69

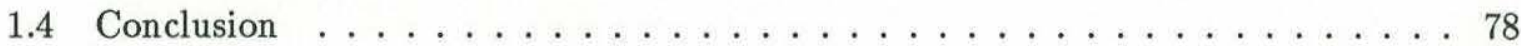

1.5 Literature cited . . . . . . . . . . . . . . . . . . . . . 81

1.6 Appendix A. Sample localities . . . . . . . . . . . . . . . 84

1.7 Appendix B. Counts of specimens sampled from Sippewissett Marsh . . . . . 86

2 Ontogeny and habitat of modern menardiiform planktonic foraminifera 91

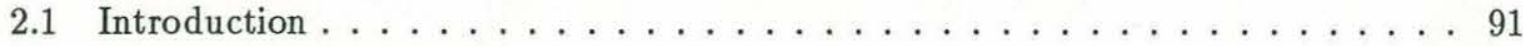

2.2 Materials and methods . . . . . . . . . . . . . . . . 93

2.2 .1 Sources of studied material $\ldots \ldots \ldots \ldots . \ldots \ldots$

2.2 .2 Sampling procedures . . . . . . . . . . . . . . . 93

2.2.3 Measurement of foraminiferal morphology . . . . . . . . . . . . . . . . . 94

2.2.4 Measurement of stable-isotopic composition . . . . . . . . . . . . . . . . 94 
2.3 Results . . . . . . . . . . . . . . . . . . . 97

2.3 .1 Taxonomy . . . . . . . . . . . . . . . . . . 97

2.3.2 Morphological changes of ontogeny . . . . . . . . . . . . . 98

2.3.3 Ontogenetic changes in isotopic composition . . . . . . . . . . . . 109

2.3.4 Geographic variations in isotopic composition . . . . . . . . . . 110

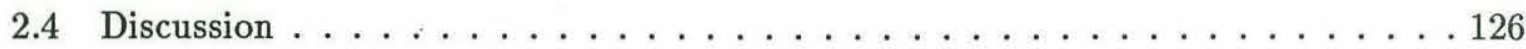

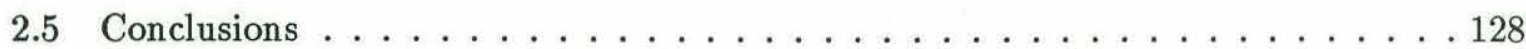

2.6 Literature cited . . . . . . . . . . . . . . . . . . . 129

3 Size and shape in isotopic analysis of the planktonic foraminifer Neogloboquadrina pachyderma: Ontogenetic considerations $\quad 131$

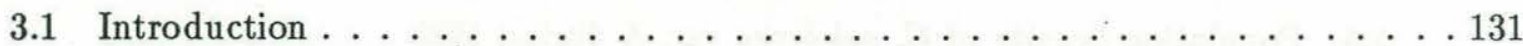

3.2 Materials and methods . . . . . . . . . . . . . . . . . . . 134

3.2.1 Measurement of foraminiferal ontogeny . . . . . . . . . . . 134

3.3 Results. . . . . . . . . . . . . . . . . . . 137

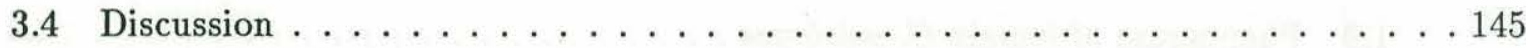

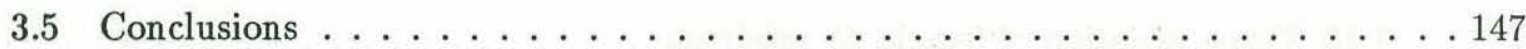

3.6 Literature cited . . . . . . . . . . . . . . . . . . . . . . 148

3.7 Appendix A. Computer programs for the measurement of foraminiferal ontogeny 149 


\section{List of Figures}

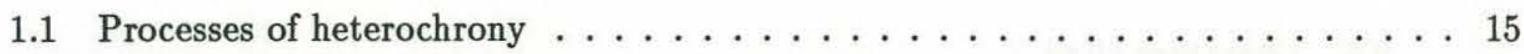

1.2 Population density of C. margarita during $1988 \ldots \ldots \ldots \ldots \ldots$

1.3 Population density of $C$. mexicana during $1988 \ldots \ldots \ldots \ldots \ldots \ldots$

1.4 Population density of $C$. ovata during $1988 \ldots \ldots \ldots \ldots$

1.5 Population density of C. salebrosa var. A during $1988 \ldots \ldots \ldots \ldots$

1.6 Temperature of the water when samples were taken. . . . . . . . . 35

1.7 Seasonal variation in shape of $C$ margarita $\ldots \ldots \ldots \ldots \ldots$

1.8 Detail of seasonal variation in shape of $C$. margarita . . . . . . . . . . 44

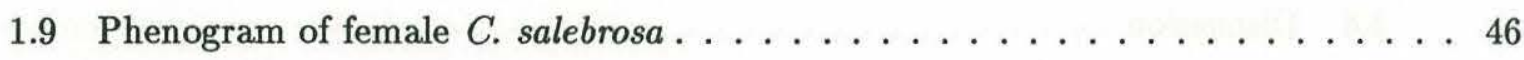

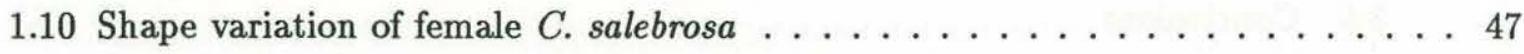

1.11 Detail of shape variation of female C. salebrosa . . . . . . . . . . . 48

1.12 Varieties of C. salebrosa . . . . . . . . . . . . . . . 49

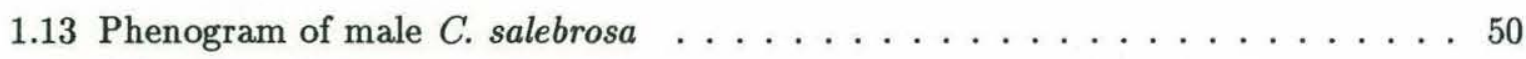

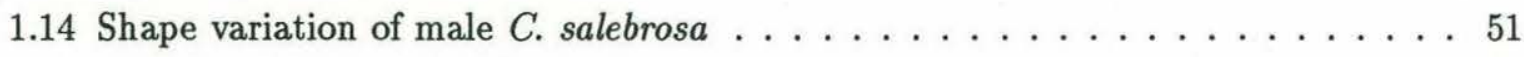

1.15 Detail of shape variation of male $C$. salebrosa . . . . . . . . . . . 52

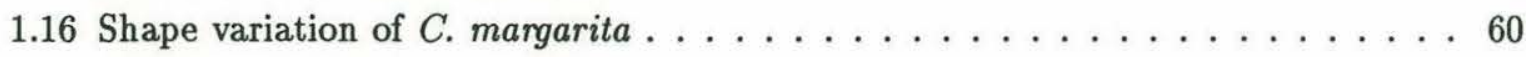

1.17 Seasonal variability in shape of $C$ margarita $\ldots \ldots \ldots \ldots$

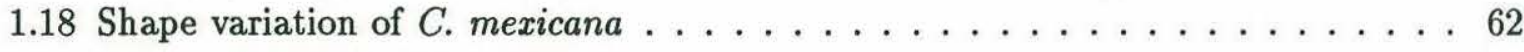

1.19 Seasonal variability in shape of $C$ mexicana . . . . . . . . . 63

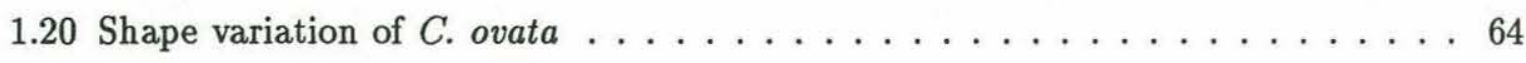

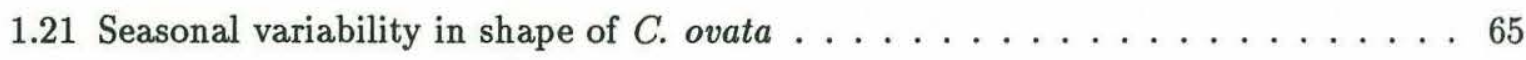

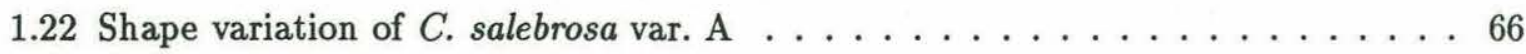

1.23 Seasonal variability in shape of . salebrosa var. A . . . . . . . . . 67

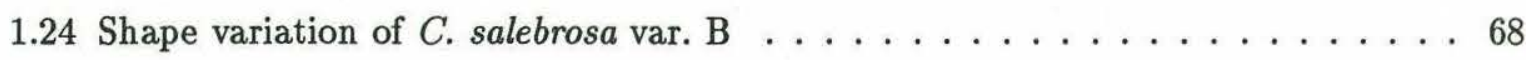


1.25 Growth of Cyprideis species . . . . . . . . . . . . . . . . . . 72

1.26 Growth curves of Cyprideis . . . . . . . . . . . . . 73

1.27 Shape variation among species of Cyprideis . . . . . . . . . . 74

1.28 Phenogram of Cyprideis species . . . . . . . . . . . . . 75

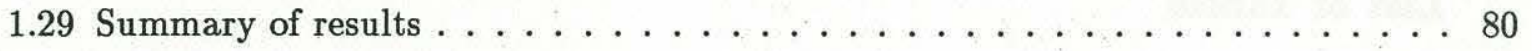

2.1 Test weight $v s$ size in G. menardii . . . . . . . . . . . . . . 100

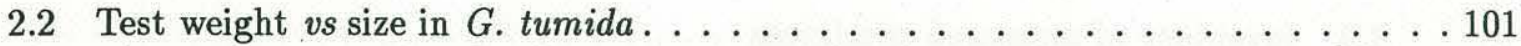

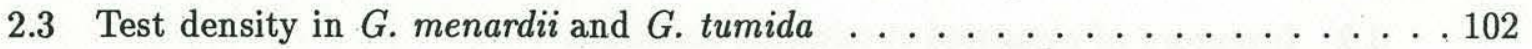

2.4 Test density $v s$ size in $G$. menardii . . . . . . . . . . . . . . . . 103

2.5 Test density $v s$ size in G. tumida . . . . . . . . . . . . . . . . . . 104

2.6 Axial compression of the test during ontogeny: crusted specimens . . . . . . . 105

2.7 Axial compression of the test during ontogeny: noncrusted specimens . . . . . 106

2.8 Geographic variation in size distribution of $G$. tumida . . . . . . . . . . 107

2.9 Geographic variation in size distribution of $G$. menardii . . . . . . . . . . 108

2.10 Isotopic composition of whole shells of $G$. menardii . . . . . . . . . . . 114

2.11 Isotopic composition of whole shells of G. tumida $\ldots \ldots \ldots \ldots$

2.12 Isotopic composition of added chambers and crust in G. menardii . . . . . . . 118

2.13 Isotopic composition of added chambers and crust in G. tumida . . . . . . . . 119

2.14 Isotopic composition of $G$. menardii at the Sierra Leone Rise . . . . . . . 121

2.15 Isotopic composition of G. tumida at the Sierra Leone Rise . . . . . . . . . 122

2.16 Isotopic composition of G. menardii at the Bermuda Rise . . . . . . . . . . . 124

2.17 Isotopic composition of $G$. tumida at the Bermuda Rise . . . . . . . . 125

3.1 Transmitted-light photographs of Neogloboquadrina pachyderma . . . . . . . 136

3.2 Variation in growth of Neogloboquadrina pachyderma . . . . . . . . . . . 139

3.3 Growth of representative specimens of Neogloboquadrina pachyderma . . . . . . 140

3.4 Specimens with four chambers in the outer whorl . . . . . . . . . . . 141

3.5 Specimens with five chambers in the outer whorl . . . . . . . . . . . . . 142

3.6 Specimens with six chambers in the outer whorl . . . . . . . . . . 143

3.7 Rate of growth $v s$. proloculus size . . . . . . . . . . . . . . . . . 144 


\section{List of Tables}

1.1 Inventory of measured specimens $\ldots \ldots \ldots \ldots \ldots \ldots \ldots$

1.2 Inventory of measured specimens, continued $\ldots \ldots \ldots \ldots \ldots \ldots \ldots \ldots \ldots \ldots$

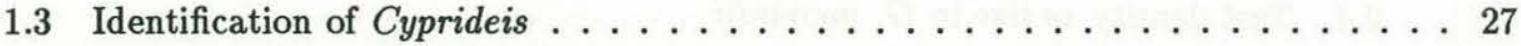

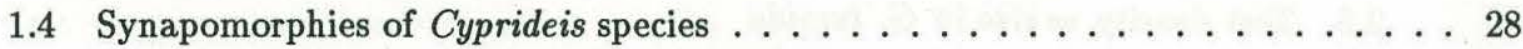

1.5 Specimens used to describe seasonal variation $\ldots \ldots \ldots \ldots \ldots \ldots$

1.6 Seasonal variation in size of $C$ margarita $\ldots \ldots \ldots \ldots \ldots \ldots$

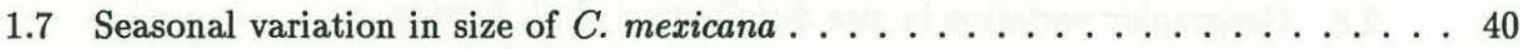

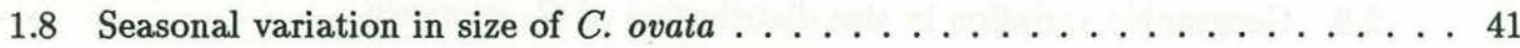

1.9 Seasonal variation in size of $C$. salebrosa var. A . . . . . . . . . . . 42

1.10 Geographic variation in size of $C$ margarita $\ldots \ldots \ldots \ldots \ldots \ldots$

1.11 Geographic variation in size of $C$ mexicana $\ldots \ldots \ldots \ldots \ldots$

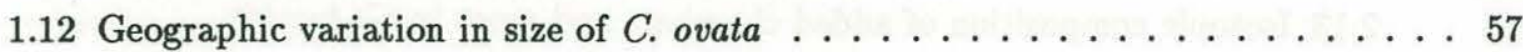

1.13 Geographic variation in size of $C$. salebrosa var. B . . . . . . . . . 58

1.14 Geographic variation in size of $C$. salebrosa var. A . . . . . . . . . 59

1.15 Rate of growth of Cyprideis species . . . . . . . . . . . . 73

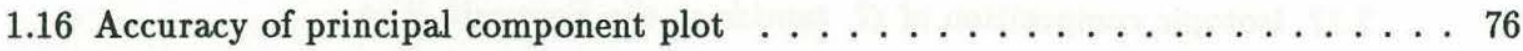

1.17 Accuracy of principal component plot, continued $\ldots \ldots \ldots \ldots$

2.1 Isotopic composition of G. menardii from the Ceara Rise . . . . . . . . . . . 112

2.2 Isotopic composition of $G$. tumida from the Ceara Rise . . . . . . . . . . 113

2.3 Isotopic composition of added shell material for G. menardii . . . . . . . . . 116

2.4 Isotopic composition of added shell material for G. tumida . . . . . . . . . . . 117

2.5 Isotopic composition of $G$. menardii from the Sierra Leone Rise . . . . . . . . 120

2.6 Isotopic composition of G. tumida from the Sierra Leone Rise . . . . . . . . 120 
2.7 Isotopic composition of $G$. menardii from the Bermuda Rise . . . . . . . . . 123

2.8 Isotopic composition of $G$. tumida from the Bermuda Rise . . . . . . . . . . 123 


\title{
Inference of ecology from the ontogeny of microfossils \\ by
}

\author{
Peter Neil Schweitzer
}

\author{
Submitted to the Massachusetts Institute of Technology- \\ Woods Hole Oceanographic Institution \\ Joint Program in Oceanography \\ on July 29,1989 , in partial fulfillment of the \\ requirements for the degree of \\ Doctor of Philosophy
}

\begin{abstract}
Studies of microfossils typically regard ontogeny as a confusing influence. Properly understood, it can instead be an enlightening factor, because it shows more aspects of the lives of individuals than do the form and distribution of adults alone. This work comprises three studies in which information about ontogeny is crucial for making inferences about the conditions under which fossil organisms lived.

The first part of this thesis examines the theory that heterochrony, change in the relative timing of somatic and reproductive development, is the morphological result of life-history evolution. A large body of paleontological literature concerns the importance of ontogeny as a source of morphological variation for evolution; morphologies that appear during one stage of an organism's development are made available for use in another simply by modifying the developmental program. Paleontologists need to know why this occurs, both so they can study the mechanism of evolution of extinct animals and so they can speak of the fossil record in terms that are applicable to modern forms. If life-history evolution causes heterochrony then the fossil record provides evidence of the nature of selection (in particular the age-specific mortality) that extinct animals experienced.

Four species of the ostracode genus Cyprideis were studied to determine whether differences in age at maturity are correlated with heterochrony in the expected manner. For each species the changes in size and shape through geological time were judged in the statistical context of modern geographic and seasonal variation. Living populations were sampled regularly to detect differences in seasonality and to estimate the duration of development.

Evolution of ontogeny occurs at the level of species in this group, but it is not simply related to differences in life-history. In comparisons among species, we find evidence of heterochrony where there is no difference in developmental timing, and a difference in developmental timing where there is no heterochrony. Size shows a similar pattern. Three of the four species show the expected positive correlation between size and age at maturity. The other species is relatively large yet matures rapidly. Cyprideis does not support the generalization that life-history evolution causes heterochrony, and casts doubt on the inference of life-history evolution from heterochrony where the data are drawn exclusively from extinct forms.

The second part of the thesis concerns the use of ontogenetic information to determine the habitat of deep-living planktonic foraminifera. Through careful morphological analysis the
\end{abstract}


populations of Globorotalia menardii and G. tumida were studied in detail at a single locality, the Ceara Rise. The foraminiferal test is dominated by two processes of growth, the accretion of chambers and the formation of an enveloping calcite crust. These can be recognized through measurements of shell size, shape, and density. The populations can be divided into groups according to their stage of chamber and crust development.

For both Globorotalia menardii and G. tumida, the measured isotopic composition of whole specimens indicates that the organisms live in the upper $50 \mathrm{~m}$ of the water, and that the crust is emplaced at depths below $50 \mathrm{~m}$, assuming that the shell is precipitated in equilibrium with seawater $\delta^{18} \mathrm{O}$. Measured values for G. tumida indicate crust formation at about $100 \mathrm{~m}$ at the Ceara Rise in the western equatorial Atlantic, slightly shallower at the Sierra Leone Rise in the eastern equatorial Atlantic.

Assuming that smaller and noncrusted forms represent the early stages of larger and crusted forms, respectively, one can calculate the oxygen- and carbon-isotopic composition of calcite added by the two processes. Crust composition in $G$. tumida appears to be in equilibrium with seawater, while in $G$. menardii the crust is lighter in $\delta^{13} \mathrm{C}$ than the equilibrium value.

Similar measures of isotopic composition from the Sierra Leone Rise and Bermuda Rise bear out these findings. At the Bermuda Rise, the isotopic data indicates growth in shallow water during the summer months, when a seasonal thermocline is well developed.

Apparently, both $G$. menardii and $G$. tumida require warm water or a shallow thermocline, with $G$. menardii occupying shallower water than $G$. tumida. These findings may be used to understand why these species disappear from the glacial Atlantic ocean, reappearing during interglacials, G. tumida preceding G. menardii.

The third part of the thesis shows a relatively simple relationship between characteristics of ontogeny such as proloculus size and rate of chamber expansion in 36 specimens of the planktonic foraminifer Neogloboquadrina pachyderma taken from sea ice in the Southern Ocean. The consequences for morphology of variations in ontogeny can be understood and used (a) to explain latitudinal variations in morphology, (b) to show why carbon isotopic composition is so variable and (c) to suggest ways of selecting specimens that minimize ontogenetic variations in shell chemistry.

Some variations in morphology may be caused by variations in ontogeny. The latitudinal gradient in the number of chambers showing in the outer whorl of Neogloboquadrina pachyderma described by Kennett (1968) may be explained by latitudinal gradient in the size of the proloculus.

Previously published variation in carbon isotopic composition of $N$. pachyderma with size is nearly as large as geographic gradients in the composition of specimens taken from a narrow size range. If the effect of ontogeny on $\delta^{13} \mathrm{C}$ is more highly correlated with chamber accretion than with test size, then geographic variations in the patterns of growth (specifically the rate of chamber size increase) may explain most of the geographic variation in $\delta^{13} \mathrm{C}$.

If the variation in growth patterns seen among these specimens is typical of most samples but the proportion of specimens having a given pattern of growth varies from place to place, specimens taken from a narrow size range having four chambers in the outer whorl may be expected to minimize ontogenetic variation consistently.

Thesis Supervisor: G.P. Lohmann

Title: Associate Scientist 


\section{Acknowledgements}

First and foremost, I would like to thank my parents, Margaret F. Schweitzer and the late Walter G. Schweitzer Jr., who instilled in me both the desire to learn and the discipline required to succeed.

Numerous people offered assistance and advice during the development of this work, chief among them my thesis supervisor G.P. Lohmann and the other members of my committee W.B. Curry, W.A. Berggren, and E.A. Boyle. In addition helpful comments and reviews of early drafts were given by N.C. Slowey, H.K. Dean, Les Kaufman, R.L. Kaesler and S.C. Stearns.

Samples were kindly supplied by T.M. Cronin, W.A. van den Bold, J.W. Teeter, E.A. Canuel, and G.A. Jones. D.R. Ostermann operated the mass spectrometer for isotopic analyses with consummate skill, instructing me on the methods of sample preparation and analysis.

Financial support came from WHOI education, NSF grants OCE82-14930, OCE84-10221, and OCE84-17040 to G.P. Lohmann.

Finally, I thank my wife Susan for her love, perseverance and patience throughout these long years. 


\section{Chapter 1}

\section{Life-history and the evolution of ontogeny in the ostracode genus Cyprideis}

\subsection{Introduction}

To infer the mechanisms of evolution from fossils, paleontologists must know how the conditions under which organisms lived affected the processes that generated and modified their morphology and distribution. In contrast, neontologists have focused their efforts on the evolution of life-history traits, characteristics of reproductive behavior considered by biologists to be the most important components of fitness (Stearns 1976). If paleontologists can translate the information contained in the form and distribution of fossils into information about life-history traits, they will be able to use the results of modern ecological theory to interpret evolutionary events and provide tests of life-history theory on geological timescales. To realize this potential, the crucial links between life-history and ontogeny must be tested.

The objective of this study is to test the relationships among age at maturity and the changes in size and shape that accompany growth. To test these relationships one must be able to measure all of the variables of interest, and so one must work with extant species. But since the results will be applied to paleontological problems, the subject taxa ought to have a fossil record. Comparisons among samples and among taxa require an understanding of the sources of variation within samples. Here seasonal variation in one locality is used to place confidence limits on geographic variation, which in turn provides confidence limits for assessing change through geological time.

Paleontologists have always been interested in the role of development in evolution (Gould 
1977), and have often paid special attention to the occurrence of heterochrony, change in the relative rates of somatic and reproductive development. Heterochrony encompasses four distinct processes; acceleration of maturity (progenesis), retardation of somatic development (neoteny), retardation of maturity (hypermorphosis) and acceleration of somatic development (usually abbreviated as acceleration). Both progenesis and neoteny produce paedomorphosis, meaning that descendant adults resemble the juvenile stage of their ancestors. In contrast, hypermorphosis and acceleration produce peramorphosis, in which descendant juveniles resemble the adult stages of ancestors. These relationships are shown schematically in figure 1.1. Many publications have detailed procedures for observing, classifying, and interpreting these various forms of heterochrony (Gould 1977; Alberch et al., 1979; McNamara 1986; Fink 1982).

Several authors have recently explored the idea that evolutionary changes in development represent organisms' adaptation to ecological hazards (Gould 1977; McKinney 1986). They reasoned that if changes in reproductive behavior can be understood as adaptation to particular ecological hazards, the fossil evidence of such changes gives paleontologists a valuable tool for understanding the ecology of extinct species. The crucial link between ecological theory and paleontological data is the use of heterochrony to infer life-history evolution. If reproduction and development are closely tied together, then changes in the reproductive behavior of individuals might affect the way they develop.

Gould (1977) supposed that morphology is indexed by chronological age in an evolutionary context: species that mature late look different from those that mature early. Specifically, the adults of species that mature early resemble juveniles of those that mature late. This theory is attractive because it links a life-history trait (age at maturity) with observable characteristics of fossil individuals (the shape of various developmental stages). Gould went a step farther, theorizing that new species arise by progenesis (acceleration of maturity) in unstable environments because the taxa there have $r$-selected reproductive behavior. Conversely, stable environments produce hypermorphosis (delayed maturity) because the taxa there are $K$-selected. This model predicts a significant difference in the character of evolutionary change. Progenesis makes descendant adults look like ancestral juveniles, while hypermorphosis makes descendant juveniles look like ancestral adults (Alberch et al., 1979). The model is attractive to paleontologists because geological observations are often sufficient to classify paleoenvironments as stable or 
unstable; McKinney (1986) provides an example.

Three aspects of Gould's theory must be reformulated if we are to apply it with confidence. The first is its concept of ecological adaptation. Gould's exposition was phrased in terms of $r$ - and $K$-selection, a theory of life-history tactics. Life-history tactics are sets of correlated life-history traits once thought to have evolved together to solve particular ecological problems. Life history traits include age and size at maturity, number and size of offspring, and the timing and costs of the reproductive efforts; see the review by Stearns (1976). The correlations among these traits are now believed to arise from processes other than coadaptation (Stearns 1980), and many ecologists have discarded the theory of $r$ - and $K$-selection because it does not accurately describe the processes that produce differences among taxa (Stearns 1983, 1984) and it does not accurately predict the response of populations to environmental stress (Stearns 1977). Since it concentrated on progenesis and hypermorphosis, Gould's theory should be specified as a relationship between environmental stress and age at maturity.

The second difficulty with Gould's theory is that the environmental stresses now thought to influence life-history traits include the probability and predictability of mortality as a function of an individual's age (Stearns 1977). These are not the sort of stresses that paleontologists can detect, and are much more specific than the vague concept of environmental stability employed, for example, by McKinney (1986). Paleoenvironmental analysis can suggest modern environments that are analogous to sedimentary facies, but within those modern environments a broad range of conditions may occur. Living organisms must be studied if characteristics of the environment are to be included in the theory. In the present study the reason for differences in age at maturity are not examined. The objective is instead to test the relationship between age at maturity and morphology.

The third problem that must be overcome in order to test Gould's theory is that one must make the assumption that shape changes with chronological age. If an individual's morphology is wholly determined by its stage of maturity, not how long it has lived, then changing the age at maturity does not alter the appearance of ontogeny in the fossil record. A test of this assumption requires measuring the chronological age of the specimens. Some animals have morphological features that actually record time (Jones 1986) but others do not. For those animals that do not show their chronological age, the dependence of shape on time might be 
inferred from field observation, culture experiments, or seasonal plasticity (many species grow more slowly in cold weather).

Gould (1977) and Alberch et al. (1979) provided formal methods for describing the evolution of ontogeny. In general, one must examine the relationships between size, shape, chronological age and developmental events. When we look at the fossils, however, one or more of the important elements is either lacking or cannot be properly interpreted. McKinney's (1986) analysis of echinoid evolution was conducted without direct observation of chronological age and with only one developmental event (presence of genital pores). McKinney equated size with chronological age, forgoing the possibility of distinguishing proportioned giantism from hypermorphosis and proportioned dwarfism from progenesis. Any change in size was interpreted as heterochrony. McNamara (1986) made the same assumption in his guide to the nomenclature of heterochrony. For example, neotenic species were assumed to have delayed maturity and thus larger size. But the correlation of neoteny and hypermorphosis that McNamara described is not part of the theory but is instead a finding that must be supported with evidence from living taxa, since the chronological age of fossils cannot be unequivocally measured in most cases. Neoteny is defined without reference to the age at maturity, but McNamara's key cannot find cases of pure neoteny.

Conversely, Schweitzer et al. (1986) equated developmental age with chronological age, making it impossible to distinguish progenesis from neoteny and hypermorphosis from acceleration. Selection on morphology was thus indistinguishable from selection on developmental timing. There is no way out of this dilemma, of course, unless more information is brought to bear, either in the form of observations on the living relatives of extinct animals or in the extrapolation into the fossil record of general rules known to constrain living animals. 


\section{Processes of heterochrony}
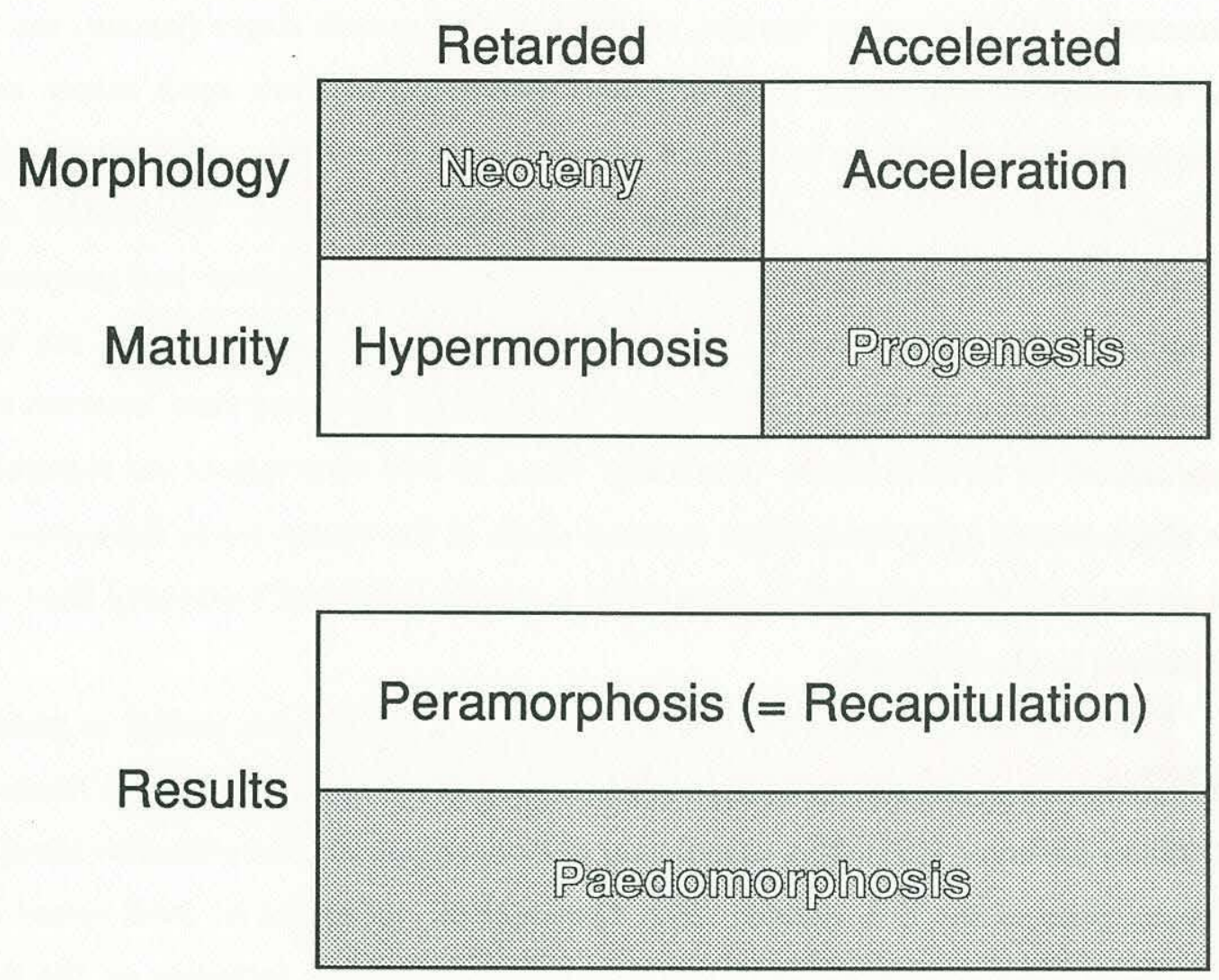

Figure 1.1: Processes of heterochrony. Where the chronological age and stage of maturity of specimens can be determined, the process of heterochrony can be identified. Where one or more of the critical variables cannot be measured, one can determine only the result, i.e. paedomorphosis or peramorphosis. 


\subsection{Materials and methods}

Several characteristics of ostracodes make them particularly useful for studies of the evolution of ontogeny. During the course of their development, these small crustaceans molt, shedding and completely replacing their calcareous carapaces (Kesling, 1951). The number of molts is consistent within ostracode families, so corresponding growth stages (instars) can be regarded as the same developmental event in closely related taxa. Their small calcite carapaces are frequently preserved whole in the rock record in great abundance, and because there are many extant ostracode species, their ecology can be studied in detail. The molted shells form a snapshot record of their development less disturbed by the resorption and accretion that occur continously in molluscs, so the shape and size of the developmental stages can be easily and accurately measured. Since the molting of the shell does not record time, however, chronological age cannot be measured from morphology alone, so field observations are required. Ontogeny is characterized using the average size and shape of the instars (as in Schweitzer et al.1986), since it is usually impossible to reconstruct a specific individual's ontogeny from molted shells scattered in the sediment.

The ostracode genus Cyprideis was chosen because it has been studied in great detail both morphologically (Sandberg 1964, 1974) and ecologically (Theissen 1966, Vesper 1972, Heip 1976a,b, Bodergat 1983). It is an indicator of Pleistocene shoreline sediments along the Atlantic coastal plain of the U.S. (Cronin 1979, Cronin et al. 1984) and its fossil record extends into the Pliocene (van den Bold 1976). It is today abundant and accessible on the tidal mudflats of many salt marshes and estuaries (Tressler and Smith 1948, Grossman and Benson 1967, Kontrovitz and Bitter 1976).

Ontogeny is documented by measuring the size, shape, and stage of maturity of specimens. To measure age at maturity one must observe closely the growth of representative individuals. Since size, shape, and stage of maturity are observed by inspection, it is feasible to assess the extent of variability these characteristics show. Four important sources of variability exist within the genus: seasonality, geography, anagenesis (variation within species through geologic time), and cladogenesis (variation among species). Within species, seasonality provides a context for evaluating geographic variation; geographic variations that are subsumed by seasonal variations are not regarded as significant. These two sources of variation in turn establish a context for 
assessing the statistical significance of variation within species through geologic time. Finally, all intraspecific variation helps us understand the significance of differences among species.

\subsubsection{Material used to characterize size and shape}

All of the samples taken to measure size and shape are listed in tables 1.1 and 1.2. Localities are listed in Appendix A. The modern samples listed were taken from the surface of tidal mudflats in or near salt marshes. The numbers of specimens measured are not necessarily representative of the relative abundance of the instars in the samples. However, where the number of specimens measured is few or none, the stage was either extremely rare or was absent; every effort was made to measure a representative growth series of each species in each sample. Since specimens were picked from the $150 \mu \mathrm{m}$ sieve, the A-5 and A-6 stages were often missed. All of the fossil samples were borrowed from other researchers. The procedures they used for washing and separating the specimens vary. In many cases the $250 \mu \mathrm{m}$ sieve seems to have been used, so specimens younger than A-3 were rarely measured in these samples.

Ideally we should examine stratigraphic sequences spaced regularly throughout a species' geographic range. In practice this is difficult to achieve for two reasons. First, the environment in which these ostracodes are found has a patchy stratigraphic distribution. Salt marshes are well known as resource-recycling ecosystems, and shells of Cyprideis often dissolve before the soft parts inside have decomposed, sometimes even before the individual has died. Preservation is a very unlikely event. Second, in order to accurately observe the living populations in any one location, one must sample throughout the year. It is impractical to carry out seasonal sampling programs in widely separated locations concurrently. Here seasonal variability was assessed using samples collected by the author at three-month intervals from Sippewissett Marsh, Massachusetts.

The best one can do is cover as much of the geographic range as possible with spot samples, mindful of the seasonal fluctuations in abundance. For C. ovata and C. salebrosa var. B this tactic worked well. Well-populated modern samples could be obtained from localities thousands of kilometers apart. For C. mexicana, C. margarita, and C. salebrosa var. A the stratigraphic and geographic distributions of the samples are not independent, so the geographic variation might be explained by the influence of geological time and vice versa. Our modern samples of 
the latter three taxa come from Massachusetts and Nova Scotia, but our fossil samples come from Virginia and the Carolinas (tables 1.1, 1.2, and appendix A).

\subsubsection{Regular sampling of living populations}

Ecological studies of ostracodes have only rarely concerned the estimation of life-history parameters. Most of those conducted by paleontologists dwell instead on associations of taxa with environmental data, other taxa, or both (e.g. Gutentag and Benson 1967, King and Kornicker 1970, Sandberg and Plusquellec 1974, Bodergat 1983). In his review of the literature on life-cycles of podocopid ostracodes, Horne (1980) found most studies were conducted by paleontologists using small monthly samples or culture experiments in the laboratory. The only species of Cyprideis subject to detailed study was C. torosa from northwestern Europe. Tressler and Smith (1948) made some observations on Cyprideis in the Chesapeake Bay, but it is not clear now what species they studied, since they referred to it as $C$. beaveni and the type material is now damaged (Sandberg 1964).

In the most detailed studies of ostracode ecology and life-history ever conducted, Heip (1976a,b), Herman and Heip (1982), and Herman et al. (1983) determined the character of the life cycle of Cyprideis torosa from a brackish-water pond in Belgium. Their eight year sampling program revealed that $C$. torosa matures in about 60 days during the summer months, with one generation per year. Both eggs and young were observed in the brood chambers of adult females. They measured the population density (number of specimens per unit area of the bottom) every two weeks, each time taking three samples $6 \mathrm{~cm}^{2}$ in area to a depth of $5 \mathrm{~cm}$. To reduce noise they smoothed the resulting time-series using a symmetrical three-point moving average. By fitting exponential curves to the density data for each instar and applying a simple model of production, they were able to estimate the rate of development overall and the duration of each of the six largest instars.

The present study included a significant ecological sampling program. During the spring and summer of 1988, samples were taken regularly from an exposed tidal mudflat in Sippewissett Marsh, a salt marsh on the southwestern coast of Cape Cod, Massachusetts. The median time between samples was 9.5 days. Twenty-five samples were processed, the first on March 3 , the last October 26. On each occasion, two samples were taken. Each consisted of four subsamples 
$3.5 \mathrm{~cm}^{2}$ in area taken to a depth of about $1.5 \mathrm{~cm}$. (Meiofauna are restricted to the upper $5 \mathrm{~mm}$, below which the sediment is black, indicating that very little oxygen is available.) The four subsamples were always taken from the same areas of the mudflat, approximately one meter apart, and were combined on the spot. The samples were washed through three sieves $(850 \mu \mathrm{m}$, $250 \mu \mathrm{m}$, and $75 \mu \mathrm{m})$. Ostracodes consistently passed through the $850 \mu \mathrm{m}$ sieve, and the larger material (mostly fragments of Spartina) was discarded. The fraction passing through the $75 \mu \mathrm{m}$ sieve was also discarded. Ostracodes were picked live from the material retained on the $250 \mu \mathrm{m}$ sieve. Material retained on the $75 \mu \mathrm{m}$ sieve was treated with bleach to remove the organic material; the ostracode shells were picked from the residue.

Fibrous plant material makes the picking difficult, so a modified version of Heip's (1976b) elutriation method was used. The material to be picked was placed in a beaker, and water was sprayed in so that the mixture swirled around. When the heavier material had settled to the bottom of the beaker, the suspended material was decanted and any ostracodes contained in it were picked from a petrie dish with the aid of a binocular microscope and a fine paint brush. Because ostracodes have calcium carbonate shells, they are heavier than most of the plant fragments, but lighter than sand grains. The first few decantings yield most of the plants and very few ostracodes. As this process is repeated, the ostracodes become concentrated with the sand. Eventually the ostracodes become the suspended material, and can be easily picked out. Then only sand remains. For the larger size fraction, it is important that this procedure be carried out within a few days of collection, because when ostracodes die, their shells open and their appendages protrude, becoming caught on plant fragments or in the surface layer of the water. Then it is much more difficult to pick them out. Also the clumsy movements of live ostracodes make them easier to find in the petrie dish.

The fine fraction (between $75 \mu \mathrm{m}$ and $250 \mu \mathrm{m}$ ) was first treated with excess chlorine bleach, allowed to stand overnight, and washed again through the $75 \mu \mathrm{m}$ sieve. This step removed most of the organic material and disarticulated the ostracodes' bivalved carapaces. Some plant material remained, however, and diatoms are also a problem, so the method of swirling and decanting was used on the fine fraction as well. It was also helpful to divide the fine fraction using a $150 \mu \mathrm{m}$ sieve. In general, the A-5 and A-6 stages were retained on the $75 \mu \mathrm{m}$ sieve, the A-3 and A-4 stages were retained on the $150 \mu$ m sieve, and adults, A-1, and A-2 stages were 
retained on the $250 \mu \mathrm{m}$ sieve.

From each sample the right valves of Cyprideis were identified and counted. Population density was calculated by dividing the number of individuals counted by the area from which they were taken. The sampled area did not change after the first month of the experiment.

\subsubsection{Quantitative description and analysis of shape variation}

Description of shape. The methods of shape measurement and description closely follow those described in Lohmann and Schweitzer (1988), Schweitzer et al. (1986), and Lohmann (1983). Right valves were measured in right lateral view (i.e. looking at the specimen from the outside, with the commissure flat on a glass slide). The posterior hinge tooth was made the starting point for the digitization. This assures that points on each shape function are close to homologous points on other outlines.

A modified form of the $\phi *$ function (Zahn and Roskies, 1972) was used to describe each shell's outline. Each specimen's outline is a smooth closed curve. When digitized, the curve is represented by a series of points. One hundred such points were chosen so that the distance between consecutive points on the shape was constant. The outline was thus represented by an equilateral polygon with 100 sides. Since shape is everything about this polygon except its position, orientation, and size, the shape description must not contain those three characteristics. Following Figure 3 of Zahn and Roskies (1972), we calculate the value of the function $\phi *$ only when it changes, at the vertices of the polygon. Letting $\theta_{k}$ denote the supplement of the $k$-th interior angle of the polygon, we can write the function $\phi *$ in this case as

$$
\phi *_{k}=\sum_{i=1}^{k} \theta_{i}-\frac{2 \pi k}{100}
$$

Position and orientation are eliminated by the use of angles; their values are not implicit in the $\phi *$ function. The length of the sides and the area of the polygon are measures of its size.

To incorporate some biological information in the description, which is otherwise purely geometrical, a biological landmark point (Bookstein et al., 1985) should be chosen as the point on the outline at which the $\phi *$ function begins. This consistency ensures that homologous features on different specimens will be described by nearly the same components of the function. Because homologous features on different-looking shapes will not always be described by the 
same components, every effort should be made to identify consistently locatable landmark points along the outlines. The $\phi *$ function can then be modified to describe only the curve segments between homologous landmarks, and the landmarks themselves can be analyzed separately using other methods, such as the tensor method of Bookstein (1978). The posterior hinge tooth is the only feature that can be consistently located on shells of every instar of these species of Cyprideis, so it was used as the starting point for each shape function.

Analysis of the relationships among shapes. Principal component analysis provides a basis for viewing multivariate data in which a few of the basis vectors can portray most of the relationships among the data points. The basis vectors are optimal in the sense that the first $k$ principal components (eigenvectors) explain more of the variation of the data than do the first $k$ of any other set of basis vectors (e.g. Fourier harmonics). We interpret the eigenvectors by looking at the spatial relationships among points about which we have additional information that was not explicitly included in the analysis, such as ontogenetic sequence, geographic provenance, or gender. This does not imply that the eigenvectors are optimal for characterizing ontogenetic sequence, geographic provenance, or sexual dimorphism - for these one would use discriminant functions - but rather that the variation among the shapes, which is caused by these and other factors, is being portrayed in the most efficient manner.

To summarize the variation in shape within instars, principal component analysis was used in the manner described by Schweitzer et al. (1986), and the average shape of each instar was used to represent the instar in an analysis of the variation among instars.

The principal components of variation among instars were calculated using the covariances among shapes rather than the correlations among shapes. This procedure differs from the methods used in Lohmann (1983) and Schweitzer et al. (1986). Beginning with a matrix $X$ each of whose columns contains the $\phi *$ function of one shape, the earlier studies cited above calculated principal components of the normalized matrix $Z$, whose columns have unit variance. $Z=A^{-1} X$ where $A$ is the diagonal matrix each of whose elements $a_{i}$ is the standard deviation of the shape function contained in the $i$ th column of $X$. (The columns of $X$ already have zero mean because the mean of $\phi *$ describes a shape's orientation, which we ignore.)

Here the principal components were calculated from the matrix $Y$, where $Y=(X-\bar{X})$ and $\bar{X}$ is the arithmetic mean of the columns of $X ; \bar{X}_{j}=\frac{1}{n} \sum_{k=1}^{n} X_{j k}$. The first principal 
component of $Y$ describes the variation of the shapes, whereas the first principal component of $Z$ describes the average shape.

The eigenfunctions of $Y$ are also used to "measure" shapes not contained in the matrix $X$. The small dots in some of the figures of this paper represent such shapes. They are computed as $(P-\bar{X})^{T} U$ where the columns of $P$ contain the $\phi *$ functions of the observed shapes and $U$ is the matrix of left singular vectors of $X$.

The dimensionality of the data space is reduced by projecting the observations onto their principal components, but that projection entails a loss of information. It is reasonable to ask how well the reduced space represents individual shapes. Since conclusions are drawn from the spatial relationships among points, the answer is to compare the distances among points in the reduced space to their distances in the full space. Each shape's Euclidean length in the full space is calculated from its loading on all eigenvectors. This length is compared with the length in the reduced space depicted. Shapes that are close to the mean are typically not well represented, since their lengths in the full space are small. We look instead for shapes whose lengths are large in the full space yet are not well represented in the reduced space.

\subsubsection{Detection of heterochrony}

Gould (1977) and Alberch et al. (1979) described ontogeny formally as a trajectory through the mathematical hyperspace defined by size and shape. Heterochrony is recognized by comparing the developmental trajectories of different taxa, and the six processes that produce heterochrony are identified by comparing the changes in ontogeny with the temporal sequence of developmental events. Fink (1982) showed how heterochrony could be inferred from phylogenetic analysis. Paedomorphosis, for example, is suggested by the occurrence of primitive characteristics in taxa whose other characteristics are largely derived.

Here the methods of Alberch et al. (1979) have been employed to find heterochrony. The molt stages of the ostracodes are treated as correlative developmental events, and maturity is marked by the last and largest instar. The developmental pathways of two or more species are plotted on the principal components of shape variation; the component that is most highly correlated with the ontogenetic sequence corresponds to the general shape factor $\sigma$ of Alberch et al. Paedomorphosis is inferred where the development of one species terminates at the juvenile 
stage of another, while peramorphosis is indicated by the reverse situation.

Note, however, that principal component analysis of shape development cannot separate purely heterochronic characteristics from those that are not heterochronic. Sexual dimorphism and non-ontogenetic variations among species may be correlated with ontogeny in a statistical sense. Alberch et al. described procedures for removing the nonlinear aspects of shape change from a heterochronic analysis (see their figure 10), but in practice these other characteristics cannot be completely eliminated.

On some of the plots that follow, ellipses are drawn to represent the $95 \%$ confidence interval for the sample mean. Such ellipses are computed by assuming the distribution of observations is bivariate normal, an assumption that may not be true. They are used to emphasize the location of points belonging to each instar rather than as a rigorous test of the differences between closely similar groups. (Note, however, that the largest ellipses represent the fewest observations.) 
Table 1.1: Inventory of specimens whose size and shape were measured.

\begin{tabular}{|c|c|c|c|c|c|c|c|c|c|c|}
\hline \multirow[t]{2}{*}{ Species } & \multicolumn{8}{|c|}{ instars represented } & \multirow[t]{2}{*}{ Age } & \multirow[t]{2}{*}{ Locality } \\
\hline & M & $\mathrm{F}$ & $A-1$ & $\mathrm{~A}-2$ & A-3 & A-4 & $A-5$ & $A-6$ & & \\
\hline \multicolumn{11}{|c|}{ margarita } \\
\hline & 13 & 11 & 3 & & & & & & Pleistocene & $78 \mathrm{TC} 42$ \\
\hline & 20 & 20 & 10 & & & & & & Pleistocene & $78 \mathrm{TC} 65 \mathrm{~A}$ \\
\hline & 20 & 20 & 19 & 20 & 6 & & & & May 87 & Sippewissett \\
\hline & 10 & 20 & 19 & 21 & 20 & & & & August 87 & Sippewissett \\
\hline & & & & & & 15 & 15 & 15 & July 88 & Sippewissett \\
\hline & 6 & 13 & 23 & 13 & 19 & 14 & 6 & & December 87 & Sippewissett \\
\hline & 2 & 6 & 2 & 6 & 2 & 1 & & & August 86 & Evangeline \\
\hline & & & 3 & 2 & & & & & September 87 & Beaufort \\
\hline & 4 & 1 & 2 & 2 & 1 & & & & Pleistocene & Waccamaw Fm. \\
\hline \multicolumn{11}{|c|}{ mexicana } \\
\hline & 20 & 20 & 20 & 20 & & & & & Pleistocene & Langley Bluffs \\
\hline & & 15 & 21 & 38 & 39 & 37 & 17 & 15 & August 85-6 & Evangeline \\
\hline & 12 & 20 & 10 & & & & & & Summer 84 & Barnstable \\
\hline & 20 & 14 & 20 & 20 & 16 & & & & May 87 & Sippewissett \\
\hline & & 21 & & & & 16 & & & August 87 & Sippewissett \\
\hline & & & & & & 15 & 15 & 19 & August 88 & Sippewissett \\
\hline & & & 5 & 20 & 20 & & & & December 87 & Sippewissett \\
\hline & & & & & 9 & 2 & & & September 87 & Beaufort \\
\hline & 11 & 15 & 10 & 9 & 2 & & & & Pleistocene & Waccamaw Fm. \\
\hline & 1 & 21 & 19 & 11 & 2 & & & & Pleistocene & $82 \mathrm{TC} 178$ \\
\hline & 9 & 20 & 17 & 8 & 3 & & & & Pleistocene & $82 \mathrm{TC} 179$ \\
\hline & & 3 & 4 & 7 & 1 & 2 & & & Pleistocene & $82 \mathrm{TC} 181$ \\
\hline \multicolumn{11}{|l|}{ ovata } \\
\hline & 5 & 9 & 19 & 13 & 7 & 1 & & & Summer 84 & Barnstable \\
\hline & 2 & 6 & 12 & 6 & 2 & & & & September 87 & Beaufort \\
\hline & & 4 & 24 & 30 & 29 & 10 & 1 & & July 86 & Assateague \\
\hline & 22 & 40 & 40 & 30 & 20 & 20 & 11 & & Living & San Salvador \\
\hline & & 18 & 18 & 21 & 11 & 1 & & & May 87 & Sippewissett \\
\hline & 9 & 16 & 19 & 15 & 17 & 15 & 2 & & August 87 & Sippewissett \\
\hline & & & & & & 13 & 15 & 6 & Summer 88 & Sippewissett \\
\hline & 5 & 13 & 22 & 20 & 17 & 5 & & & December 87 & Sippewissett \\
\hline
\end{tabular}


Table 1.2: Inventory of specimens whose size and shape were measured, continued.

\begin{tabular}{|c|c|c|c|c|c|c|c|c|c|c|}
\hline \multirow[t]{2}{*}{ Species } & \multicolumn{8}{|c|}{ instars represented } & \multirow[t]{2}{*}{ Age } & \multirow[t]{2}{*}{ Locality } \\
\hline & M & $\mathrm{F}$ & $A-1$ & $A-2$ & $\mathrm{~A}-3$ & $A-4$ & $A-5$ & $\mathrm{~A}-6$ & & \\
\hline \multicolumn{11}{|c|}{ floridana } \\
\hline & 10 & 9 & 9 & 1 & & & & & Pliocene & Duplin Fm. 47.5 \\
\hline & 10 & 9 & 10 & 4 & & & & & Pliocene & Duplin Fm. 48.5 \\
\hline & 2 & 7 & 5 & 2 & & & & & Pliocene & Duplin Fm. 52.5 \\
\hline \multicolumn{11}{|c|}{ salebrosa } \\
\hline & 3 & 34 & 25 & 16 & 9 & 4 & 5 & & August $85-6$ & Scott's Bay \\
\hline & 8 & 24 & 15 & 8 & & & & & Pleistocene & Norfolk Fm. \\
\hline & 1 & 6 & 7 & & & & & & Pleistocene & $81 \mathrm{TC} 77$ \\
\hline & 9 & 23 & 6 & 4 & & & & & Pleistocene & $81 \mathrm{TC} 78$ \\
\hline & 3 & 10 & 4 & 1 & & & & & Pleistocene & $81 \mathrm{TC} 79$ \\
\hline & 1 & 6 & 2 & 1 & & & & & Pleistocene & $81 \mathrm{TC} 80$ \\
\hline & 4 & 4 & 1 & 1 & & & & & Pleistocene & $82 \mathrm{TC} 174$ \\
\hline & 1 & 4 & 11 & 4 & 2 & 1 & & & Pleistocene & $82 \mathrm{TC} 176$ \\
\hline & 1 & 2 & 8 & 3 & & & & & Pliocene & Cul de Sac \\
\hline & 18 & 35 & 19 & 5 & & & & & Living & Lago de Valencia \\
\hline & 11 & 8 & 20 & 20 & 8 & & & & May 87 & Sippewissett \\
\hline & & 12 & 3 & 12 & 21 & 13 & & & August 87 & Sippewissett \\
\hline & & & & & & 14 & 14 & 17 & Summer 88 & Sippewissett \\
\hline & & & 6 & 13 & 9 & & & & December 87 & Sippewissett \\
\hline & & & 1 & 2 & 1 & 1 & & & September 87 & Beaufort \\
\hline & 20 & 20 & 20 & 20 & 16 & 18 & 20 & 6 & August 87 & Kouchibouguac \\
\hline & 6 & 14 & 20 & 22 & 12 & 3 & 1 & & Pleistocene & Caloosahatchee Fm. \\
\hline \multicolumn{11}{|l|}{ similis } \\
\hline & 28 & 31 & 42 & 20 & 14 & 15 & 8 & 12 & Living & Lago de Valencia \\
\hline
\end{tabular}




\subsection{Results and discussion}

\subsubsection{Taxonomy and phylogeny}

The foundation of any paleobiological research is the concept of taxonomy employed by the researcher. Because there is no universally applied procedure for classifying and identifying individuals, each researcher must describe his methods in detail if others are to fully appreciate his interpretations. The philosophy employed here is that of Wiley (1980); all members of a non-branching lineage belong to the same species. In practical terms, this means that if specimens from different places look different, they are not considered different species unless the two morphologies also are found together. This idea is based on two assumptions: (1) all of the specimens being classified are similar enough to consider the possibility of their being conspecific, and (2) individuals of the same species living in the same place will look alike. (Sexual and ontogenetic variants must be accounted for as well, but in ostracodes these forms are easy to identify.) The error in this procedure is that closely related species that do not occur together are combined under the same name; cladogenesis is inferred only when it is supported by biogeographic evidence. The danger in this procedure is that assumption (1) above requires experience on the part of the researcher and faith in that experience on the part of the reader.

Four species of Cyprideis recognizable under the conceptual framework described above live in tidal marshes and estuaries on the east coast of North America (table 1.3). Each has distinctive characteristics of shell texture and musculature by which it can be identified, even in juvenile stages. Each shows both sexual dimorphism and ontogenetic variation.

Anteromarginal denticles of the type that are characteristic of $C$. margarita are found on young instars (A-3 and A-4) of C. mexicana from Sippewissett Marsh. Neither species possesses these denticles in the A-5 and A-6 stages, and in C. mexicana the proportion of specimens with denticles decreases in the A-3 stage to become completely absent in the A-2 and later stages.

A complete phylogenetic analysis of the genus Cyprideis is beyond the scope of this study, since it would require detailed morphological and biogeographical analysis of species that live outside the study area and of the related genera Cytheridea and Haplocytheridea. Such an analysis may prove fruitful in the future, however, so a preliminary list of synapomorphies is presented here (table 1.4). At this writing there are too few synapomorphies to draw a clado- 
Table 1.3: Morphological characteristics used to identify species of Cyprideis. Surface textures of fossil specimens from the Duplin and Waccamaw Formations are uncertain because they may have been affected by taphonomic processes.

\begin{tabular}{l|ccccc}
\multicolumn{1}{c}{ taxon } & \multicolumn{5}{c}{ morphological characteristics } \\
& upper & postero & antero & normal \\
& surface & mandibular & ventral & marginal & pore \\
& texture & scar & flange & denticles & canals \\
\hline margarita & smooth & elongate & present & many & round \\
mexicana & pitted & rounded & absent & (see text) & round \\
ovata & reticulate & oval & present & few,weak & multiradiate \\
salebrosa & pitted & elongate & present & few,rare & round \\
\hline Duplin & smooth? & elongate & present & few & round \\
Waccamaw & pitted? & rounded & present & few & round
\end{tabular}

gram. Outgroup comparison was used to determine which characteristics of the morphology of Cyprideis can be used to make phylogenetic hypotheses. Characteristics common to both Cyprideis and the outgroup are regarded as primitive, while characteristics not possessed by the outgroup are derived. Common descent is inferred where two taxa share derived characteristics. From Sandberg's (1964) analysis of the relationships among genera of the family Cytherideidae (which includes Cyprideis), species of the genera Cytheridea and Haplocytheridea probably should be considered as outgroups for Cyprideis. Character polarity was assessed using published descriptions of these genera by van Morkhoven (1963) and Sandberg (1964) as well as living specimens of Haplocytheridea setipunctata, a species that is both morphologically and ecologically similar to Cyprideis. Material used for this purpose came from the San Salvador sample, in which H. setipunctata occurs with Cyprideis ovata (Sanger and Teeter 1982). 
Table 1.4: Synapomorphies (shared derived morphological characteristics) of the species of Cyprideis examined in this study. Species of Haplocytheridea and Cytheridea, in particular H. setipunctata, were used as outgroups, related taxa not belonging to the group of interest, whose morphological similarities with Cyprideis may indicate the polarity of shared characteristics.

\begin{tabular}{llcc} 
Key & Characteristic & Primitive state & Derived state \\
\hline 1 & Hinge structure & antimerodont & entomodont \\
2 & Concavity in ventral margin & anterior & posterior \\
3 & Anteromarginal denticles & large, numerous & few blunt or many small \\
4 & Male posteroventral margin & straight & convex \\
5 & Upper mandibular muscle scar & round to oval & elongate
\end{tabular}




\subsubsection{Ecology and life-history}

The four species Cyprideis margarita, C. mexicana, C. ovata, and C. salebrosa occur together on the surface of tidal mudflats in Sippewissett Marsh, Massachusetts. Regular measurements of population density show the seasonal changes in population structure that each species undergoes, and allow these changes to be compared with the results published by Heip (1976b) for $C$. torosa. Two samples were taken on each occasion; the average population density of each instar of each species is shown in figures $1.2,1.3,1.4$, and 1.5.

Similar changes of population structure occurred in all four species. Late juvenile instars present in March and April matured in May and June, producing a sharp increase of early juveniles that appeared later in successive instars. Males appeared first, but in all cases females were more numerous.

Clear differences among species are apparent as well. The new generation produced by Cyprideis margarita reached maturity in about two months, but $C$. mexicana that hatched during the summer probably matured the following spring. With minor exceptions, all growth stages of $C$. margarita are present in every sample. But most samples of $C$. mexicana contained only three or fewer instars. C. margarita appears to mature more rapidly than C. mexicana.

Cyprideis salebrosa and C. ovata occur in smaller numbers, but their patterns of population density are quite similar to those of the more abundant $C$. margarita and $C$. mexicana. In particular, C. salebrosa behaves like C. mexicana, and C. ovata like C. margarita. Three lines of evidence support this inference. First, the large peaks in abundance of juvenile specimens of C. ovata are nearly synchronous, like $C$. margarita, while those of $C$. salebrosa are progressively more offset in time, like $C$. mexicana. Second, the large increase in juveniles of $C$. ovata occurs at the beginning of June, like C. margarita, whereas $C$. salebrosa juveniles begin to increase in July, like C. mexicana. Third, the spot sample taken in December 1987 contained both adults and juveniles of $C$. ovata and $C$. margarita, but only juveniles (and only stages A-1, A-2, and A-3) of C. salebrosa and C. mexicana.

The most important environmental parameter for ostracode growth seems to be temperature (Heip, 1976b; Herman and Heip, 1982; Martens, 1985). Ostracodes grow more slowly in cold water and may reach a larger size than they do in warm water (Latifa, 1987). Variations of water temperature at Sippewissett Marsh (figure 1.6) support the observation by Heip (1976b) that 
growth and production in ostracodes is slowest when the water temperature goes below $15^{\circ} \mathrm{C}$, and fastest when it exceeds $20^{\circ} \mathrm{C}$. That development of Cyprideis mexicana and C. salebrosa slows dramatically through the winter months seems clear from the general aspect of figures 1.3 and 1.5. C. margarita also shows some evidence for retarded growth (figure 1.2). A secondary peak of juveniles appears in August, but progresses towards adulthood much more slowly than the cohort which hatched in early June. The slight bulges in A-2 and A-3 instars in late September and early October indicate that this second generation probably overwinters in juvenile form in much the same way as does the new generation of $C$. mexicana. The second generation is not obvious in C. ovata, due to its low population density and consequently higher noise.

The general patterns of abundance in other samples support these observations. Since the spot samples listed in tables 1.1 and 1.2 were not taken for the purpose of measuring population density, only general statements about relative abundance can be made. A sample taken from a salt marsh at Assateague Island National Seashore in Maryland, on July 5, 1986 contained all instars and both sexes of Cyprideis ovata, but only adult female C. mexicana, a population structure much like Sippewissett Marsh in late June. A salt marsh near Beaufort, North Carolina, sampled September 29, 1987 contained both sexes and all instars of $C$. ovata, juvenile stages A-1 through A-4 of C. salebrosa, stages A-1 and A-2 of C. margarita, and A-3 and A-4 of C. mexicana; approximately the same population structure as is found at Sippewissett Marsh in early October.

Some information about the ecology of Cyprideis salebrosa can be gained from the sample from the salt marsh at Kelly's beach in Kouchibouguac National Park, New Brunswick. There both sexes and all instars of C. salebrosa var. B occur in great abundance, quite unlike the distribution of $C$. salebrosa var. A from Sippewissett Marsh. The Kouchibouguac sample of C. salebrosa var. B was taken in August of 1987. The abundance of specimens and their population structure are much like that of $C$. margarita in Sippewissett Marsh; at no time during the summer of 1988 were all instars of $C$. salebrosa observed in a single sample, but this was the norm for $C$. margarita. These observations suggest that the life cycle of $C$. salebrosa var. B at Kouchibouguac is more like that of C. margarita than C. salebrosa var. A. 


\section{Cyprideis margarita on Sippewissett Marsh mudflat}

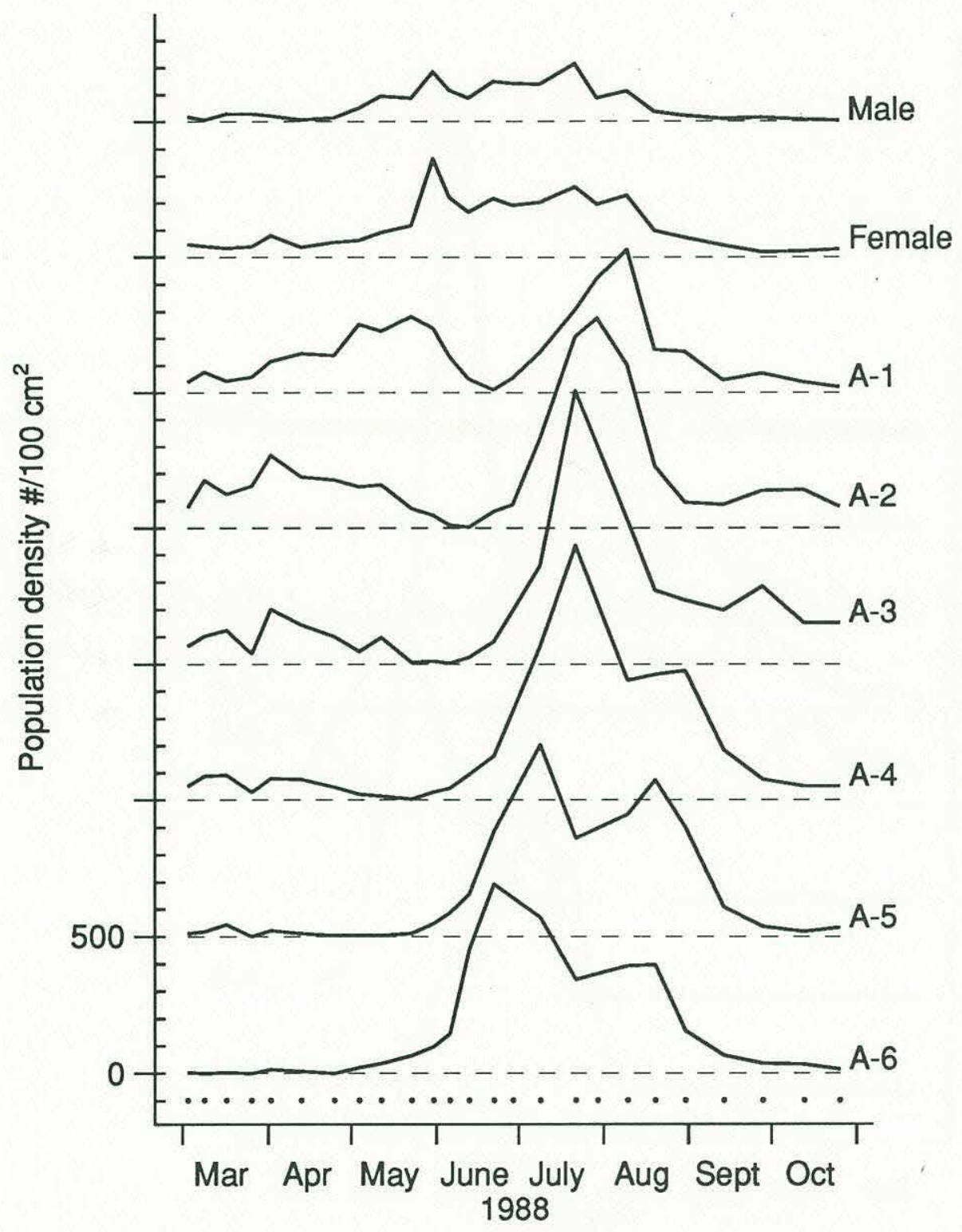

Figure 1.2: Population density of C. margarita from Sippewissett Marsh, Massachusetts during 1988. Each point is the average of two samples taken on the same date. Dots along the bottom axis mark the dates samples were collected. 


\section{Cyprideis mexicana on Sippewissett Marsh mudflat}

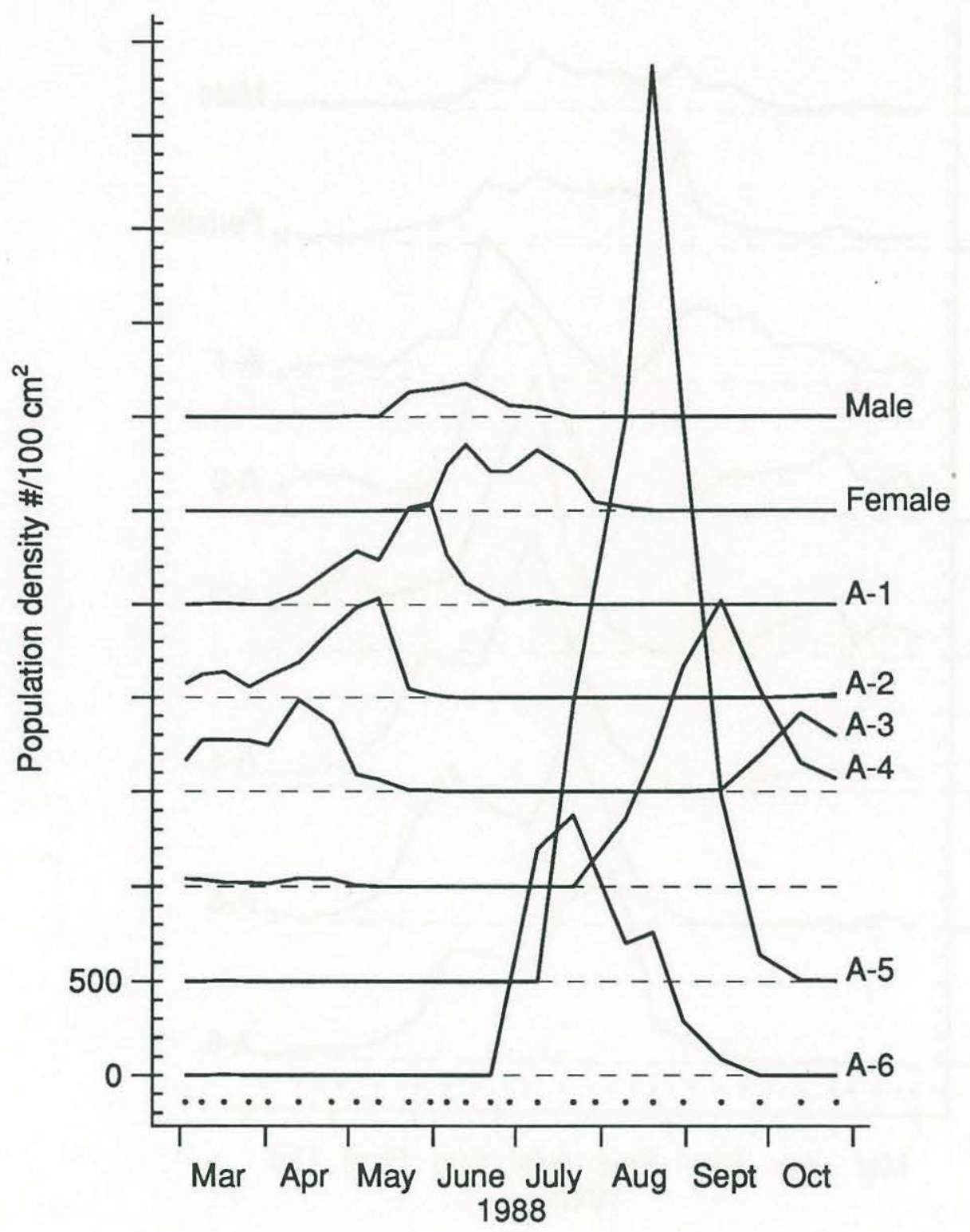

Figure 1.3: Population density of $C$. mexicana from Sippewissett Marsh, Massachusetts during 1988. Each point is the average of two samples taken on the same date. Dots along the bottom axis mark the dates samples were collected. 


\section{Cyprideis ovata in Sippewissett Marsh mudflat}

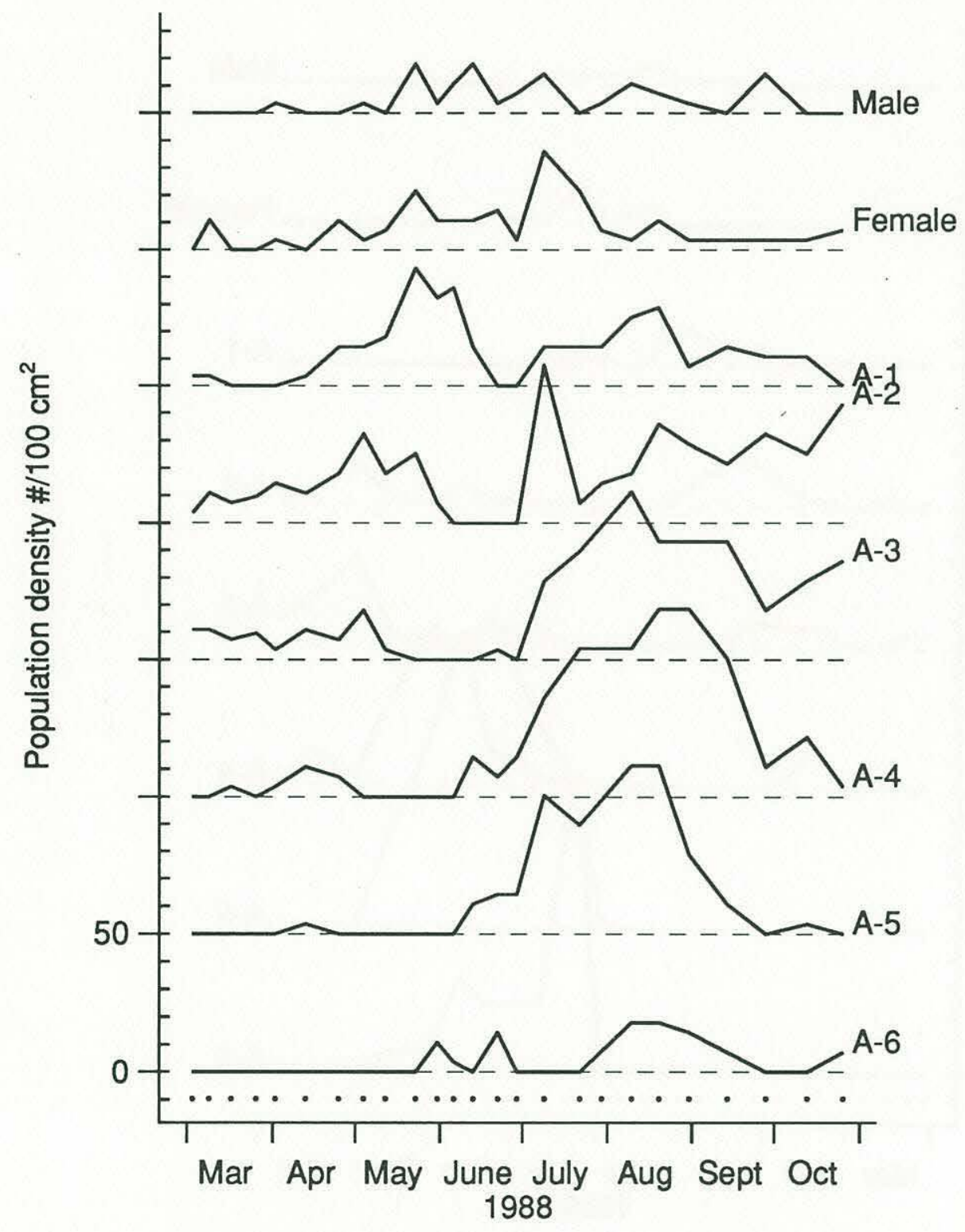

Figure 1.4: Population density of $C$. ovata from Sippewissett Marsh, Massachusetts during 1988. Each point is the average of two samples taken on the same date. Dots along the bottom axis mark the dates samples were collected. 


\section{Cyprideis salebrosa on Sippewissett Marsh mudflat}

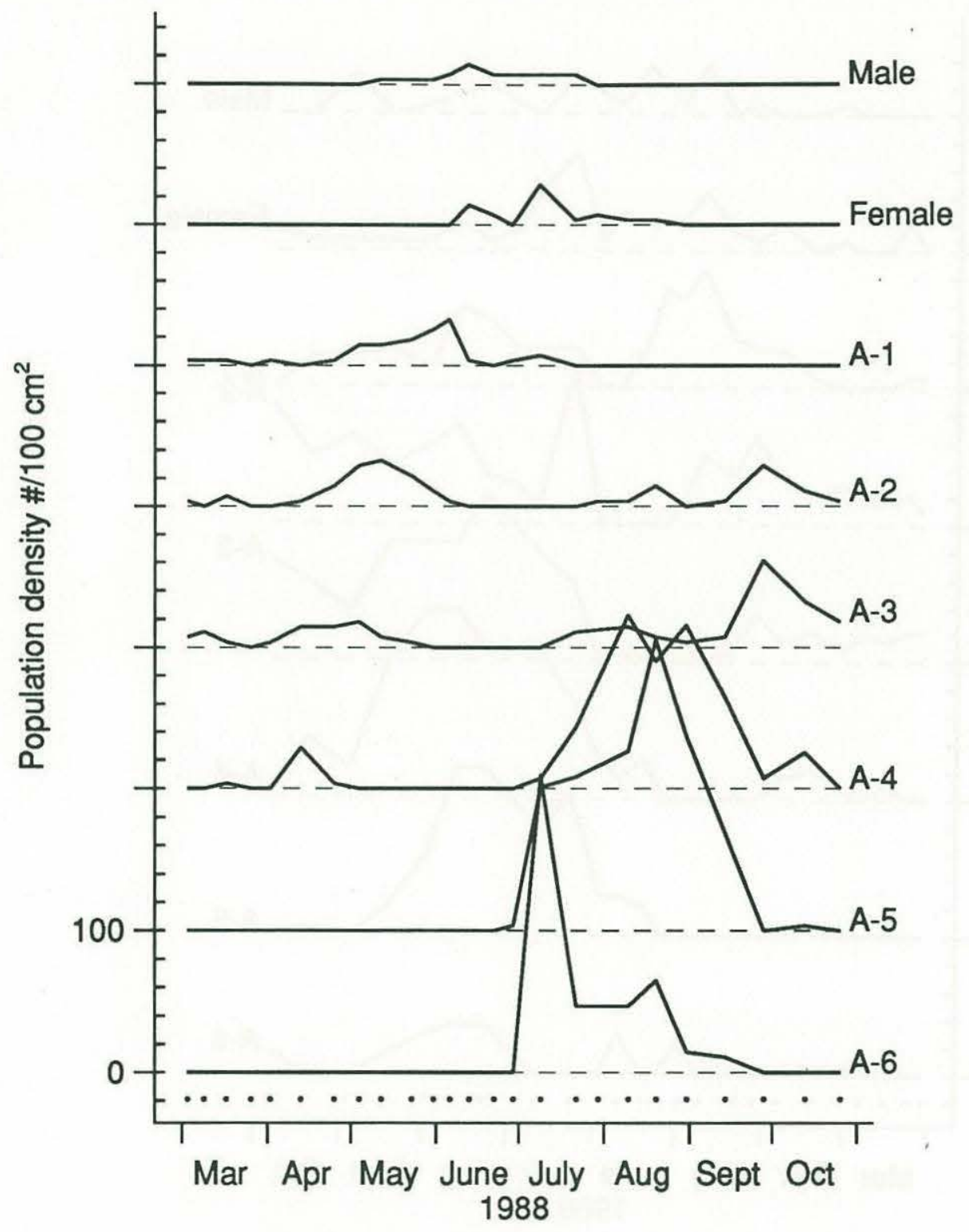

Figure 1.5: Population density of C. salebrosa var. A from Sippewissett Marsh, Massachusetts during 1988. Each point is the average of two samples taken on the same date. Dots along the bottom axis mark the dates samples were collected. 


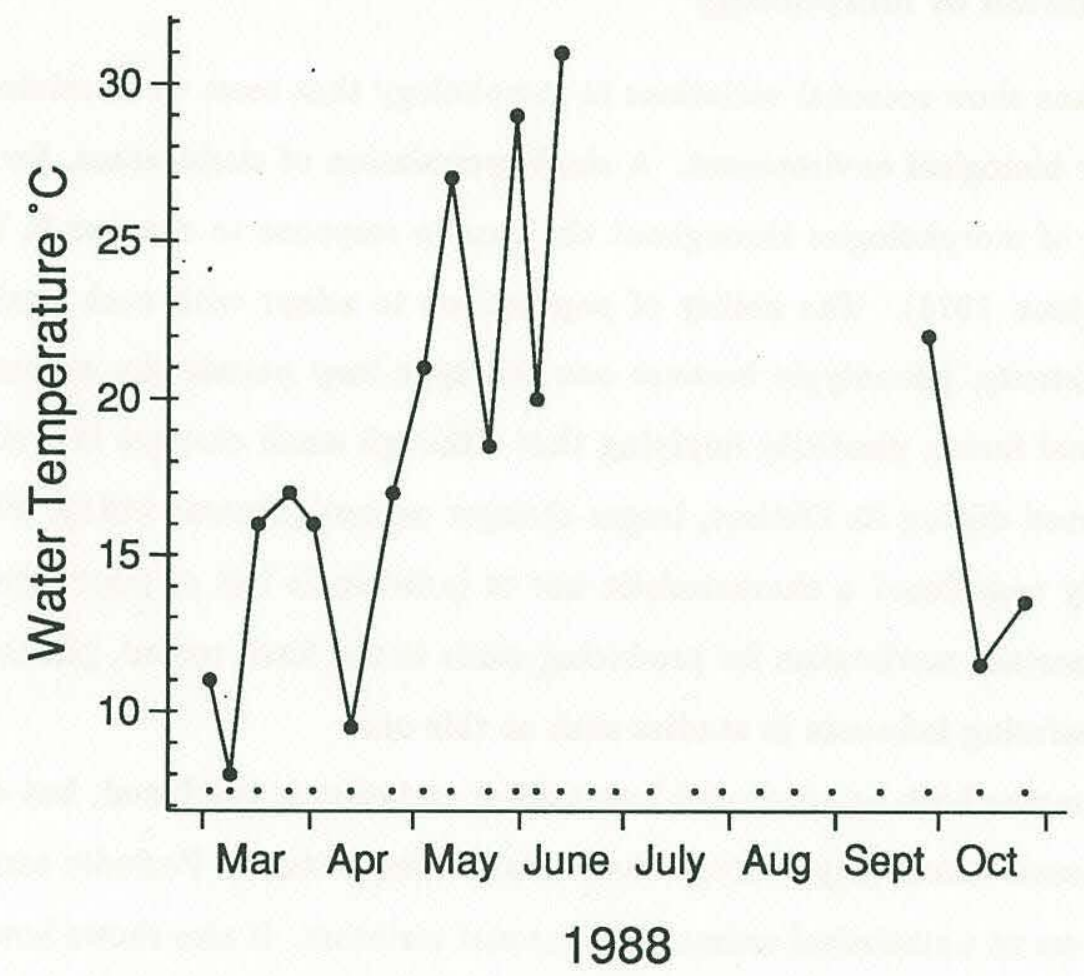

Figure 1.6: Temperature of the water at the sediment-water interface measured at the time of sampling. Dots along the bottom axis mark the dates samples were collected. 


\subsubsection{Sources of intraspecific variation}

Sources of morphological variation are hierarchical. With few exceptions, ontogenetic variation is present in every sample, seasonal variation is present at every location, and geographic variation is present in every species. In order to assess the statistical significance of differences among samples one must first understand these sources of within-sample variation. Below I present a series of intersample comparisons designed to estimate and compare these variations.

\section{Seasonal variation of morphology}

Some crustaceans show seasonal variations in morphology that seem to be related to aspects of the physical or biological environment. A single population of cladocerans, for example, may show a variety of morphologies throughout the year in response to changes in temperature or predation (Dodson 1974). The ability of populations to adapt with such flexibility is called phenotypic plasticity; phenotypic because one genotype may permit the expression of several different external forms, plasticity implying that although small changes in a single individual might be reversed during its lifetime, larger changes cannot (Stearns 1981). Plasticity of this sort is properly considered a characteristic not of individuals but of populations. Though it may be an important mechanism for producing stasis in the fossil record, phenotypic plasticity may have a confusing influence in studies such as this one.

In fossil samples both seasonal and interannual variation is combined, but differential production and preservation may obscure their relative importance. Periodic sampling of living populations gives us a statistical estimate of seasonal variation. It also shows how shape and size are affected by whatever environmental parameters can be measured, but in field studies many of the ecological variables that might be important can neither be controlled nor measured.

Samples used for this purpose were taken from Sippewissett Marsh on May 25, August 27, and December 2, 1987. Table 1.5 shows the number of specimens of each instar that were measured. Specimens were picked selectively to measure fifteen to twenty individuals of each instar of each species. Some instars were quite rare or simply could not be found, however. The strong differences in seasonality shown by this table prompted a more detailed investigation of these species' population dynamics.

Seasonal changes in size. Size was measured as the area of the outline of the right valve in 
Table 1.5: Inventory of specimens of Cyprideis whose size and shape were measured in order to describe seasonal variation. All specimens were taken from Sippewissett Marsh, Massachusetts in 1987.

\begin{tabular}{|c|c|c|c|c|c|c|c|c|}
\hline \multirow[b]{2}{*}{ species } & \multirow[b]{2}{*}{ date } & \multicolumn{7}{|c|}{ instars represented } \\
\hline & & M & $\mathrm{F}$ & A-1 & A-2 & $\mathrm{A}-3$ & $\mathrm{~A}-4$ & $A-5$ \\
\hline \multirow[t]{3}{*}{ margarita } & May 25 & 20 & 20 & 19 & 20 & 6 & & \\
\hline & August 27 & 10 & 20 & 19 & 21 & 20 & & \\
\hline & December 2 & 6 & 13 & 23 & 13 & 19 & 14 & 6 \\
\hline \multirow[t]{3}{*}{ mexicana } & May 25 & 20 & 14 & 20 & 20 & 16 & & \\
\hline & August 27 & & 21 & & & & 16 & \\
\hline & December 2 & & & 5 & 20 & 20 & & \\
\hline \multirow[t]{3}{*}{ ovata } & May 25 & & 18 & 18 & 21 & 11 & 1 & \\
\hline & August 27 & 9 & 16 & 19 & 15 & 17 & 15 & 2 \\
\hline & December 2 & 5 & 13 & 22 & 20 & 17 & 5 & \\
\hline \multirow[t]{3}{*}{ salebrosa var. $A$} & May 25 & 11 & 8 & 20 & 20 & 8 & & \\
\hline & August 27 & & 12 & 3 & 12 & 21 & 13 & \\
\hline & December 2 & & & 6 & 13 & 9 & & \\
\hline
\end{tabular}

right lateral view. Size differences were evaluated using univariate $t$ and $F$ statistics (tables 1.6, $1.7,1.8,1.9)$. Slight seasonal differences were found in all of the species, the magnitude of which ranged between one and two standard deviations of the data.

The three largest instars of Cyprideis margarita are largest in May and smallest in December. C. mexicana females are larger in May than in August, but are absent in December. C. ovata are generally largest in August and smallest in December, though results from the smaller instars are inconclusive. The two largest juvenile instars of C. salebrosa were smallest in May and largest in December and August.

Seasonal variation in shape. Shape was measured as the $\phi *$ function of Zahn and Roskies (1972). Shape variation was summarized using eigenfunction analysis (see above, Lohmann 1983, and Lohmann and Schweitzer in press). Each shape is plotted on the first three principal components of variation defined by the averages of all stages in all samples, thus avoiding a bias against rare stages. In all four species the first component of variation describes the ontogeny. The second and third components describe sexual dimorphism and non-ontogenetic seasonal 
variations. The results are used to assess the significance of geographic and stratigraphic variability and are shown below.

In one species the pattern of seasonal variation is interesting in its own right. In Cyprideis margarita, which shows significant variation of ontogeny (instars A-1, A-2, and A-3 in figures 1.7 and 1.8), December specimens are less advanced than their counterparts in May and August. The ecological data reported below provides evidence that the December specimens probably matured much more slowly than those collected in August and May. This suggests that when the intermolt period increases, the rate of development of shape decreases (meaning the shape changes that lead to adulthood occur in smaller steps). This plasticity seems to affect only the late preadult instars, since the adults are not affected in the same way. 
Table 1.6: Seasonal variation in size of $C$. margarita collected at Sippewissett Marsh, Massachusetts. Size is measured as $\log _{e}$ of the area of the shell's outline, measured in $\mathrm{mm}^{2}$. An approximate $t$-statistic is given as the ratio of the largest difference between sample means to the pooled within-sample standard deviation. The usual analysis of variance (Box 9.1 of Sokal and Rohlf 1969) produced the $F$-statistic. "ns" means the result is not statistically significant, implying the size of that instar does not vary seasonally.

\begin{tabular}{|c|c|c|c|c|c|c|c|c|c|}
\hline & & Male & Female & $A-1$ & A-2 & $A-3$ & $A-4$ & $A-5$ & $A-6$ \\
\hline \multirow{3}{*}{ May 25} & $n$ & 20 & 20 & 19 & 20 & 6 & 0 & 0 & 0 \\
\hline & $\bar{x}$ & -1.292 & -1.168 & -1.711 & -2.187 & -2.666 & & & \\
\hline & $s_{x}$ & 0.023 & 0.038 & 0.039 & 0.024 & 0.038 & & & \\
\hline \multirow{3}{*}{ August 27} & $n$ & 10 & 20 & 19 & 21 & 20 & 0 & 0 & 0 \\
\hline & $\bar{x}$ & -1.320 & -1.173 & -1.780 & -2.248 & -2.691 & & & \\
\hline & $s_{x}$ & 0.031 & 0.067 & 0.023 & 0.032 & 0.032 & & & \\
\hline \multirow{3}{*}{ December 2} & $n$ & 7 & 12 & 21 & 13 & 19 & 14 & 6 & 0 \\
\hline & $\bar{x}$ & -1.329 & -1.226 & -1.751 & -2.219 & -2.678 & -3.083 & -3.480 & \\
\hline & $s_{x}$ & 0.024 & 0.028 & 0.031 & 0.036 & 0.035 & 0.049 & 0.025 & \\
\hline \multirow{3}{*}{ July 1988} & $n$ & 0 & 0 & 0 & 0 & 0 & 15 & 15 & 15 \\
\hline & $\bar{x}$ & & & & & & -3.105 & -3.479 & -3.848 \\
\hline & $s_{x}$ & & & & & & 0.025 & 0.028 & 0.025 \\
\hline \multicolumn{2}{|l|}{ Range of $\bar{x}$} & 0.037 & 0.057 & 0.069 & 0.061 & 0.025 & 0.022 & 0.001 & \\
\hline \multirow{2}{*}{\multicolumn{2}{|c|}{$\begin{array}{l}\text { Pooled } s_{x} \\
\text { Approximate } t\end{array}$}} & 0.026 & 0.048 & 0.032 & 0.031 & 0.035 & 0.038 & 0.028 & \\
\hline & & 1.429 & 1.192 & 2.176 & 1.982 & 0.720 & 0.593 & 0.020 & \\
\hline \multirow{4}{*}{\multicolumn{2}{|c|}{$\begin{array}{l}F \text { statistic } \\
\text { numerator } d f \\
\text { denominator } d f \\
\text { significance }\end{array}$}} & 6.9 & 5.4 & 21.4 & 19.2 & 1.4 & 2.3 & 0.0 & \\
\hline & & 2 & 2 & 2 & 2 & 2 & 1 & 1 & \\
\hline & & 34 & 49 & 56 & 51 & 42 & 27 & 19 & \\
\hline & & 0.005 & 0.01 & 0.001 & 0.001 & ns & $\mathrm{ns}$ & $\mathrm{ns}$ & \\
\hline
\end{tabular}


Table 1.7: Seasonal variation in size of C. mexicana collected at Sippewissett Marsh, Massachusetts. See table 1.6 for details.

\begin{tabular}{|c|c|c|c|c|c|c|c|c|c|}
\hline & & Male & Female & A-1 & $A-2$ & $A-3$ & $A-4$ & $A-5$ & $A-6$ \\
\hline & $n$ & 20 & 14 & 20 & 20 & 16 & 0 & 0 & 0 \\
\hline May 25 & $\bar{x}$ & -0.833 & -0.777 & -1.473 & -2.126 & -2.683 & & & \\
\hline & $s_{x}$ & 0.032 & 0.058 & 0.050 & 0.042 & 0.039 & & & \\
\hline & $n$ & 0 & 21 & 0 & 0 & 0 & 16 & 0 & 0 \\
\hline August 27 & $\bar{x}$ & & -0.959 & & & & -3.090 & & \\
\hline & $s_{x}$ & & 0.043 & & & & 0.038 & & \\
\hline & $n$ & 0 & 0 & 5 & 20 & 20 & 0 & 0 & 0 \\
\hline December 2 & $\bar{x}$ & & & -1.428 & -2.088 & -2.686 & & & \\
\hline & $s_{x}$ & & & 0.028 & 0.035 & 0.042 & & & \\
\hline & $n$ & 0 & 0 & 0 & 0 & 0 & 15 & 15 & 19 \\
\hline August 1988 & $\bar{x}$ & & & & & & -3.113 & -3.506 & -3.845 \\
\hline & $s_{x}$ & & & & & & 0.034 & 0.023 & 0.027 \\
\hline Range of $\bar{x}$ & & & 0.182 & 0.045 & 0.038 & 0.002 & 0.023 & & \\
\hline Pooled $s_{x}$ & & & 0.051 & 0.048 & 0.039 & 0.042 & 0.037 & & \\
\hline Approximat & & & 3.597 & 0.947 & 0.978 & 0.050 & 0.613 & & \\
\hline$F$ statistic & & & 106.10 & 1.05 & 2.99 & 0.01 & 0.90 & & \\
\hline numerator $d$ & & & 1 & 1 & 1 & 1 & 1 & & \\
\hline denominator & & & 33 & 23 & 38 & 34 & 29 & & \\
\hline significance & & & 0.001 & ns & 0.1 & ns & ns & & \\
\hline
\end{tabular}


Table 1.8: Seasonal variation in size of $C$. ovata collected at Sippewissett Marsh, Massachusetts. See table 1.6 for details.

\begin{tabular}{|c|c|c|c|c|c|c|c|c|c|}
\hline & & Male & Female & $A-1$ & $A-2$ & $A-3$ & $A-4$ & $A-5$ & $A-6$ \\
\hline \multirow{3}{*}{ May 25} & $n$ & 0 & 18 & 18 & 21 & 11 & 1 & 0 & 0 \\
\hline & $\bar{x}$ & & -0.703 & -1.245 & -1.801 & -2.358 & -2.916 & & \\
\hline & $s_{x}$ & & 0.033 & 0.041 & 0.040 & 0.052 & & & \\
\hline \multirow{3}{*}{ August 27} & $n$ & 9 & 16 & 19 & 15 & 17 & 15 & 2 & 0 \\
\hline & $\bar{x}$ & -0.684 & -0.714 & -1.200 & -1.783 & -2.310 & -2.788 & -3.212 & \\
\hline & $s_{x}$ & 0.045 & 0.066 & 0.047 & 0.046 & 0.040 & 0.031 & 0.002 & \\
\hline \multirow{3}{*}{ December 2} & $n$ & 5 & 13 & 22 & 20 & 17 & 5 & 0 & 0 \\
\hline & $\bar{x}$ & -0.744 & -0.717 & -1.261 & -1.829 & -2.343 & -2.853 & & \\
\hline & $s_{x}$ & 0.024 & 0.040 & 0.053 & 0.046 & 0.031 & 0.015 & & \\
\hline \multirow{3}{*}{ Summer 1988} & $n$ & 0 & 0 & 0 & 0 & 0 & 13 & 15 & 6 \\
\hline & $\bar{x}$ & & & & & & -2.869 & -3.260 & -3.657 \\
\hline & $s_{x}$ & & & & & & 0.031 & 0.025 & 0.013 \\
\hline \multicolumn{2}{|l|}{ Range of $\bar{x}$} & 0.060 & 0.014 & 0.061 & 0.047 & 0.049 & 0.128 & 0.048 & \\
\hline \multirow{2}{*}{\multicolumn{2}{|c|}{$\begin{array}{l}\text { Pooled } s_{x} \\
\text { Approximate } t\end{array}$}} & 0.040 & 0.047 & 0.048 & 0.045 & 0.041 & 0.029 & 0.023 & \\
\hline & & 1.482 & 0.300 & 1.271 & 1.039 & 1.196 & 4.454 & 2.057 & \\
\hline \multirow{4}{*}{\multicolumn{2}{|c|}{$\begin{array}{l}F \text { statistic } \\
\text { numerator } d f \\
\text { denominator } d f \\
\text { significance }\end{array}$}} & 6.6 & 0.4 & 8.4 & 4.8 & 5.1 & 19.9 & 6.7 & \\
\hline & & 1 & 2 & 2 & 2 & 2 & 3 & 1 & \\
\hline & & 12 & 44 & 56 & 53 & 42 & 30 & 15 & \\
\hline & & 0.025 & ns & 0.001 & 0.025 & 0.01 & 0.001 & 0.025 & \\
\hline
\end{tabular}


Table 1.9: Seasonal variation in size of C. salebrosa var. A collected at Sippewissett Marsh, Massachusetts. See table 1.6 for details.

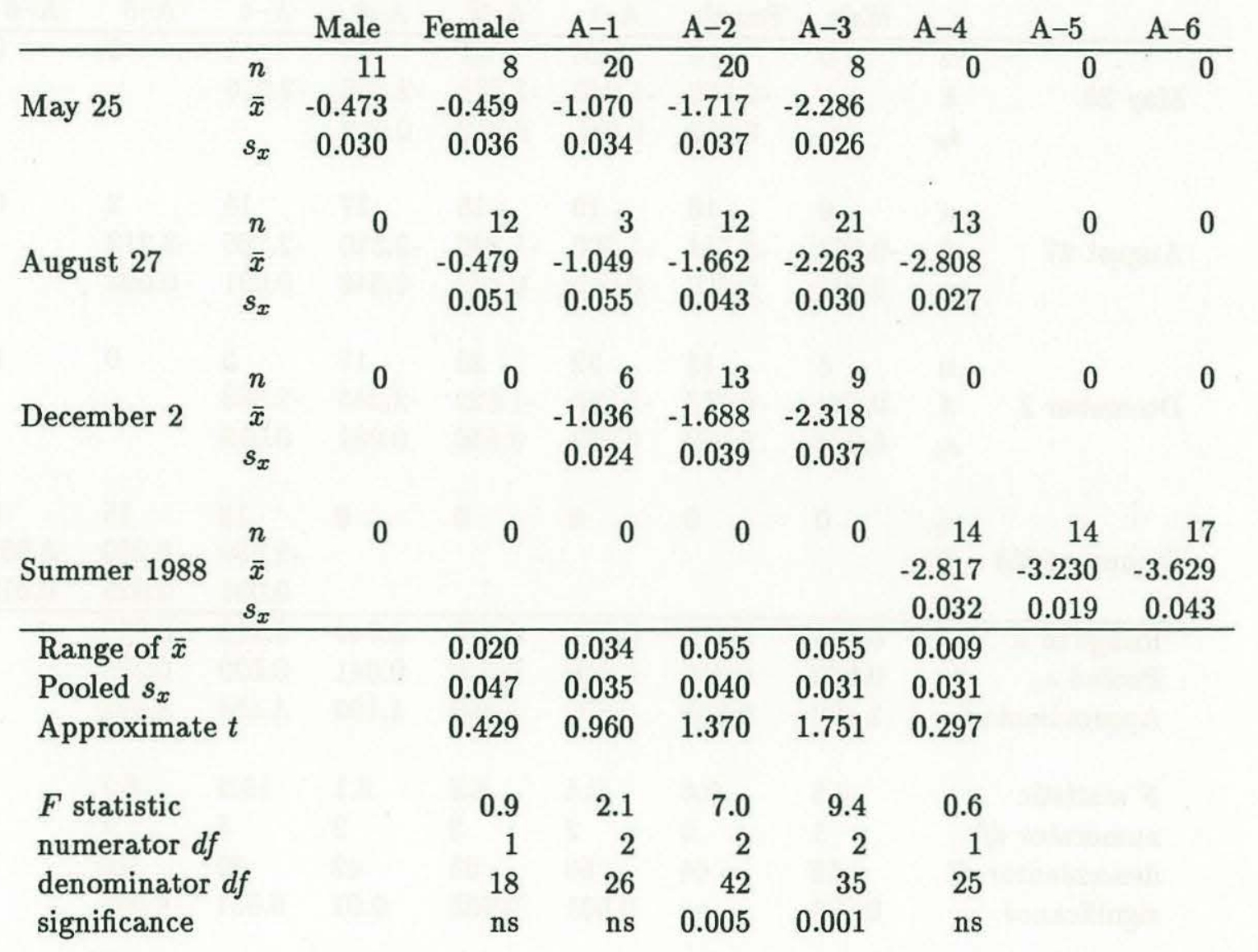




\section{Seasonal variation of Cyprideis margarita}

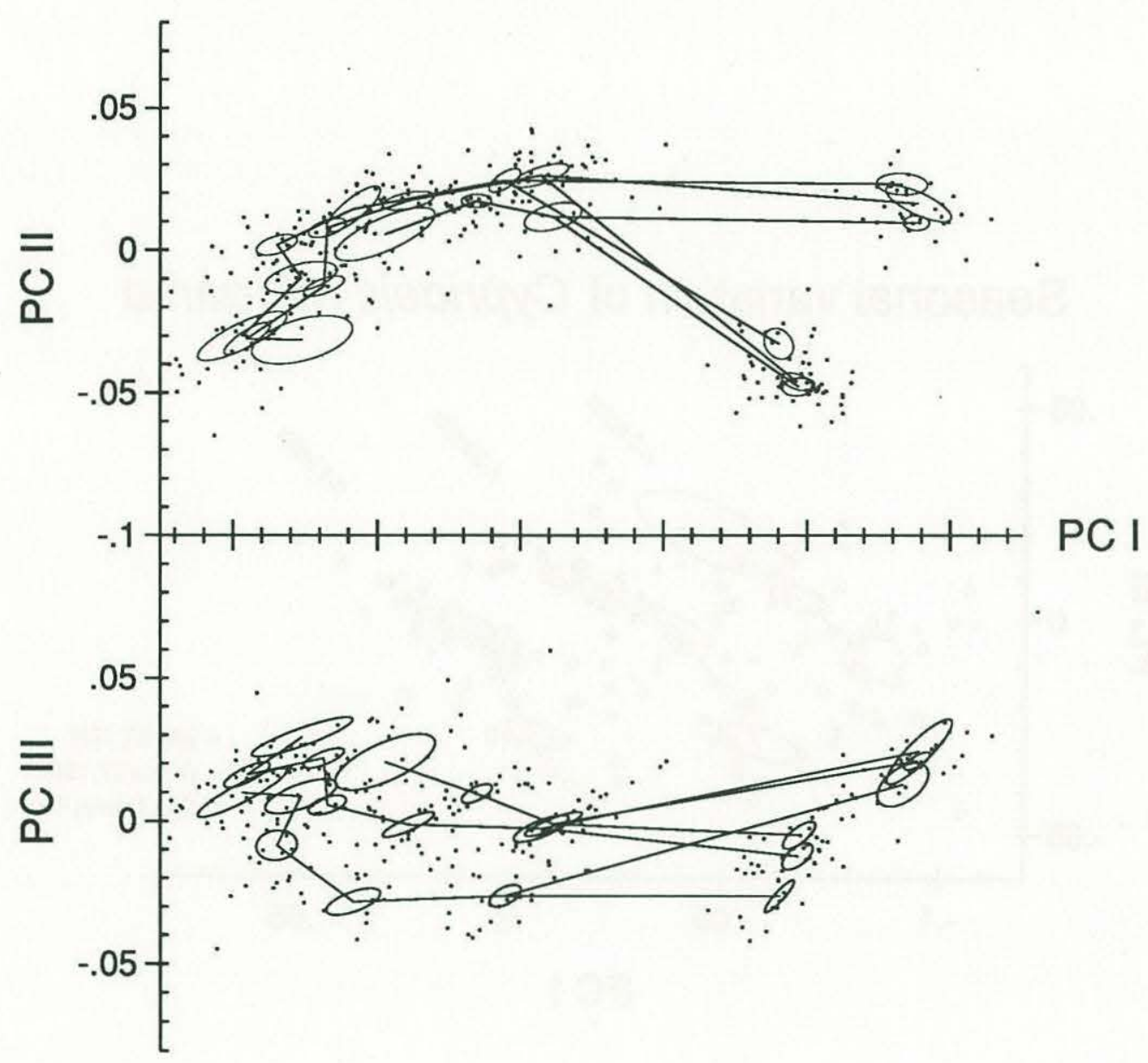

Figure 1.7: Seasonal variation in the shape of C. margarita from Sippewissett Marsh, Massachusetts. Lines connect the average shapes of instars in ontogenetic sequence. Sexual dimorphism is recognizable in the adults, so lines connect each adult dimorph with the corresponding A-1 instar. Ellipses represent $95 \%$ confidence intervals for the mean shape of each instar. The axes are the eigenfunctions of the instar averages of these samples. 


\section{Seasonal variation of Cyprideis margarita}

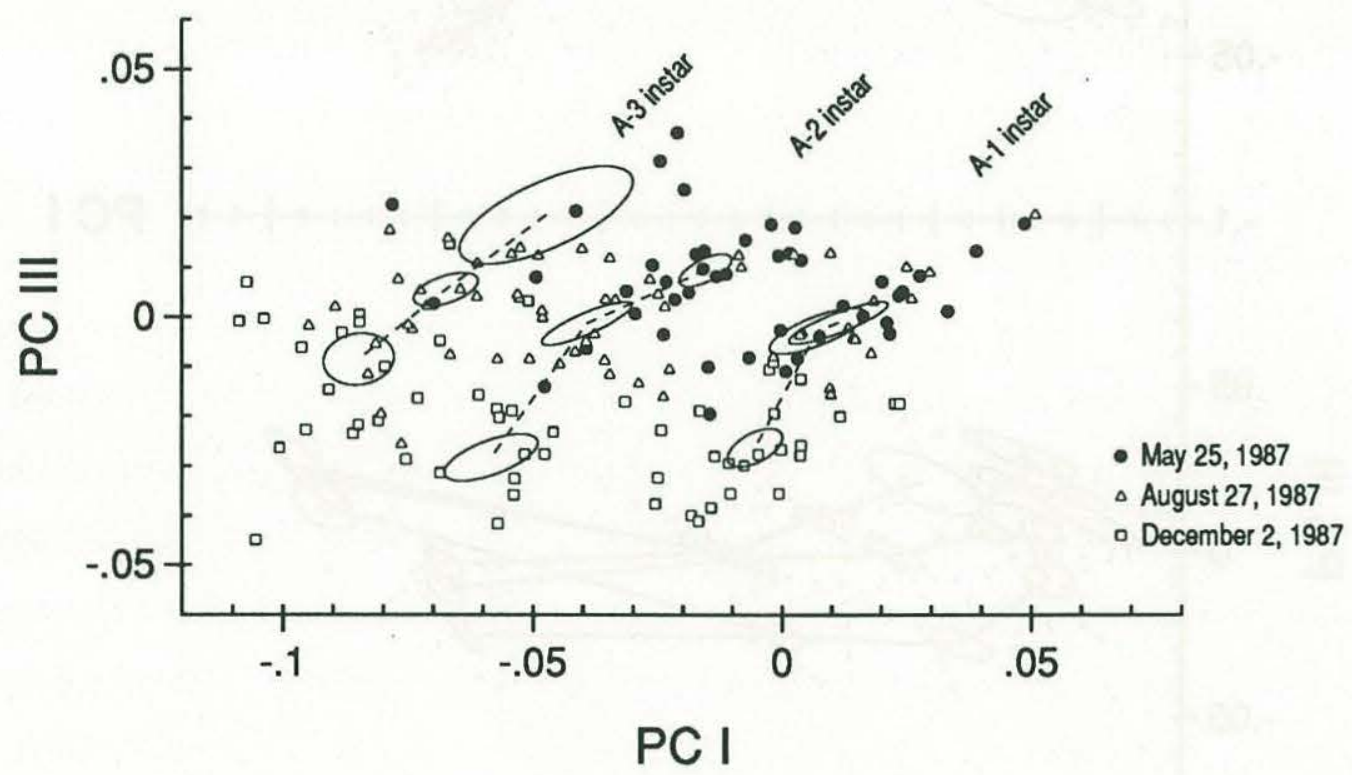

Figure 1.8: Seasonal variation in the shape of C. margarita from Sippewissett Marsh, Massachusetts. Details of the distribution of instars A-1, A-2 and A-3 shown in figure 1.7. The average shapes of corresponding instars are connected with dashed lines. Ellipses represent $95 \%$ confidence intervals for the mean shape of each instar. 


\section{Morphological variation in Cyprideis salebrosa}

Cluster analysis of the average shape of adult female shells of Cyprideis salebrosa suggests that two distinct morphologies exist (figure 1.9). Principal components analysis shows the same relationships among the averages (figure 1.10); the individual shapes can be plotted on these axes (figure 1.11) to show that the groups described by cluster analysis do not overlap. Note that the samples of living material show the dichotomy most clearly; fossil samples are intermediate in form.

Specimens from the Pleistocene of Virginia and the Carolinas and modern specimens from Sippewissett Marsh have a produced, slightly pointed anterior, while those from Nova Scotia, New Brunswick, Venezuela, and the Caloosahatchee Formation of the Florida Pleistocene have a stouter, more inflated anterior (figure 1.12). Specimens from the Pliocene of Haiti (Cul de Sac well) are intermediate in appearance, and appear to be the same form as the holotype, depicted by van den Bold (1963). Male specimens show the same pattern but are less sharply divided (figures 1.13, 1.14 and 1.15).

These two forms are regarded in this paper as subspecies. Their true relationship can be established only by more thorough sampling or by controlled experiment. Their geographic ranges appear to overlap, so more detailed sampling may reveal (a) living intermediate forms, implying that the shape variation is actually continuous; (b) living samples containing both forms, indicating reproductive isolation; or (c) clear differences in the character of the environments in which each form is found, indicating the two forms are environmentally-cued polymorphs (Reyment, 1983). With the present data one cannot choose among these interpretations. Because the relationship between them needs further clarification, this paper will refer to the type found at Sippewissett Marsh as "variety A" and the other (of which the Kouchibouguac specimens are typical) as "variety B". 
Female Cyprideis salebrosa instar averages Average linkage cluster analysis

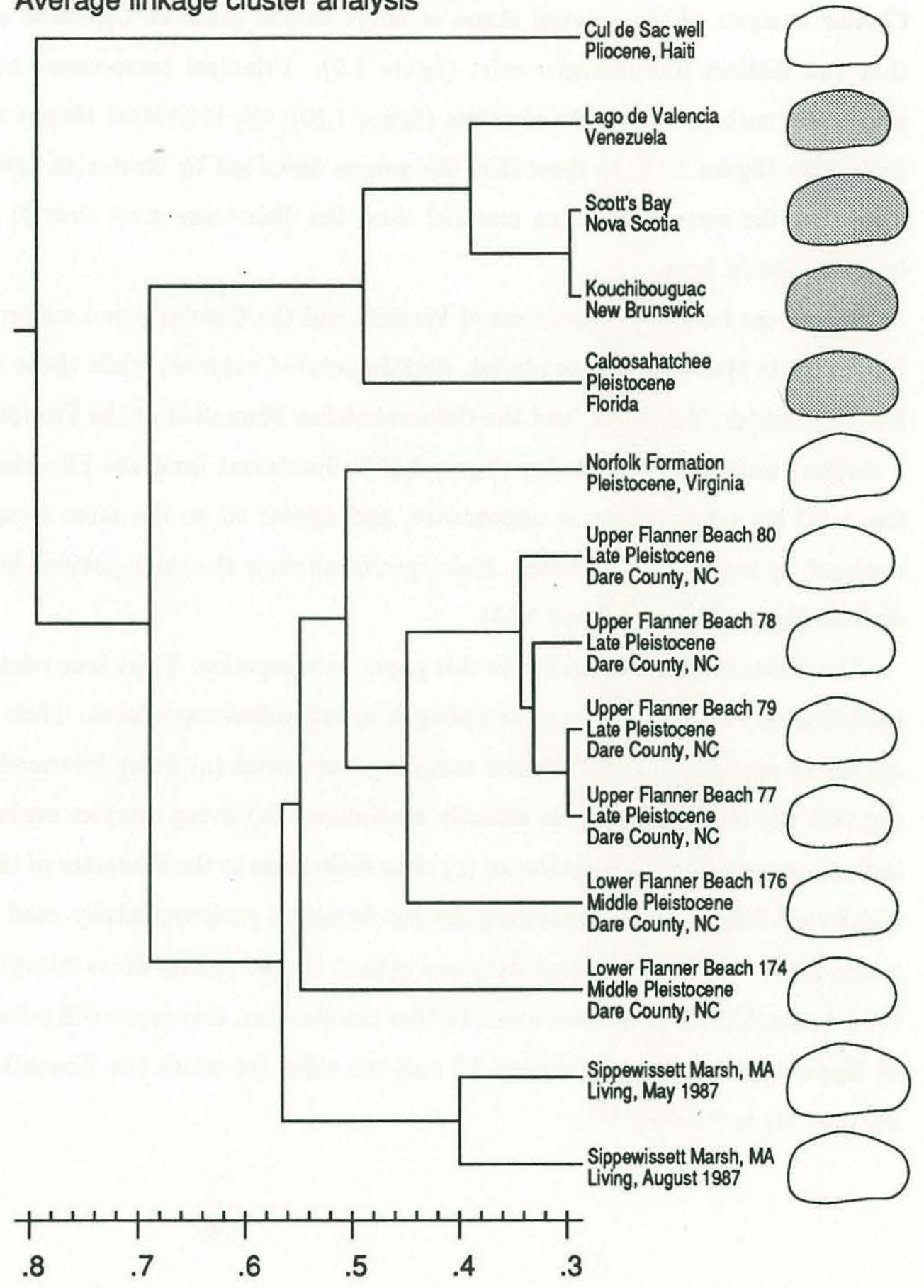

Figure 1.9: Cluster analysis of the average shapes of adult female Cyprideis salebrosa from all of the samples used in this study. The unweighted pair-group method with average linkage (UPGMA) was used with Euclidean distance, i.e. the distance between two groups was calculated as the average of the distances among their members. 


\section{Cyprideis salebrosa Adult Females}

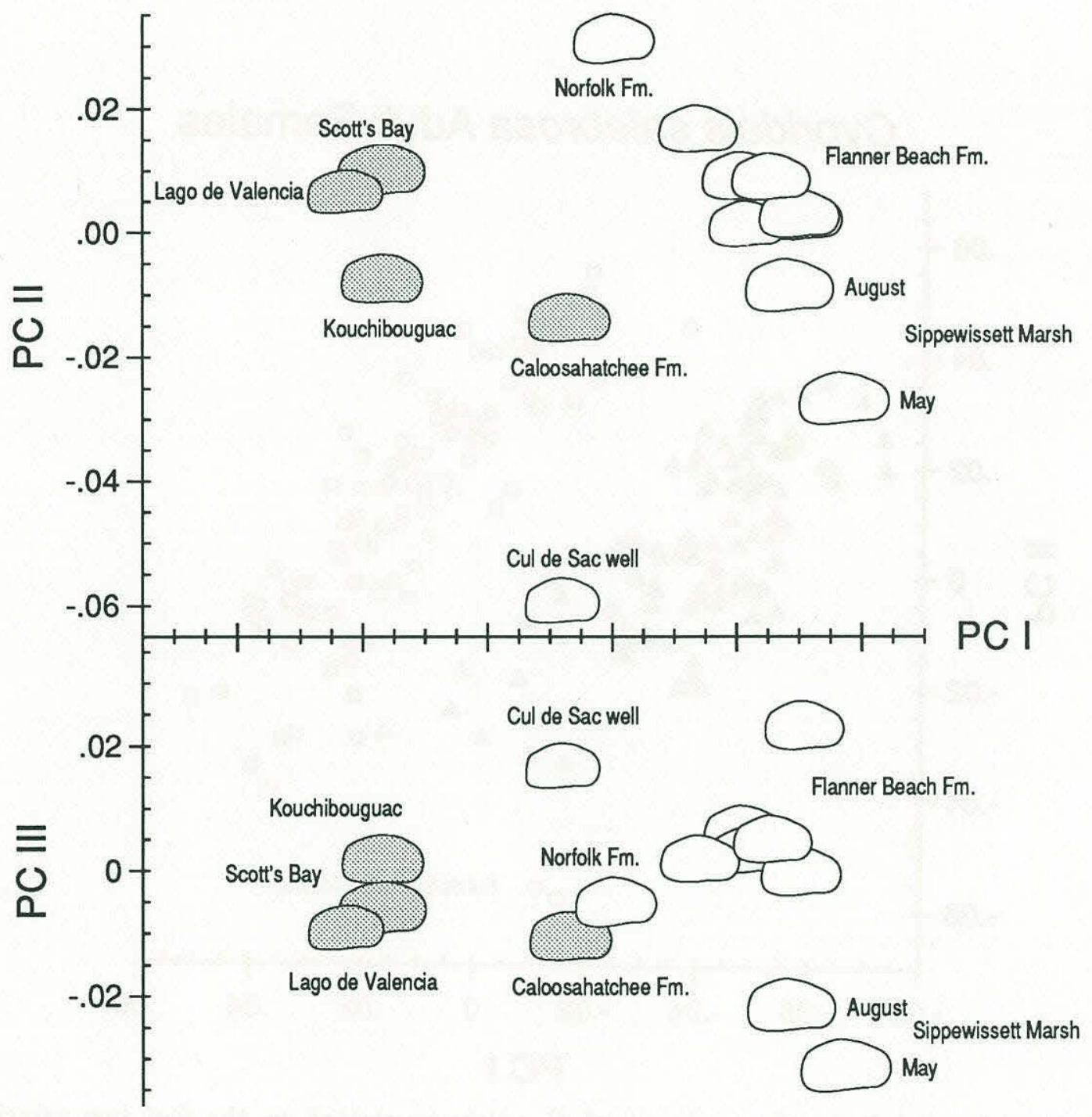

Figure 1.10: Adult female C. salebrosa plotted on the first three principal components of shape variation. Each shape plotted is the average of specimens found at the specified locality. Forms belonging to the smaller cluster shown in figure 1.9 are stippled and are called "variety B" in the text, open forms are called "variety A". 


\section{Cyprideis salebrosa Adult Females}

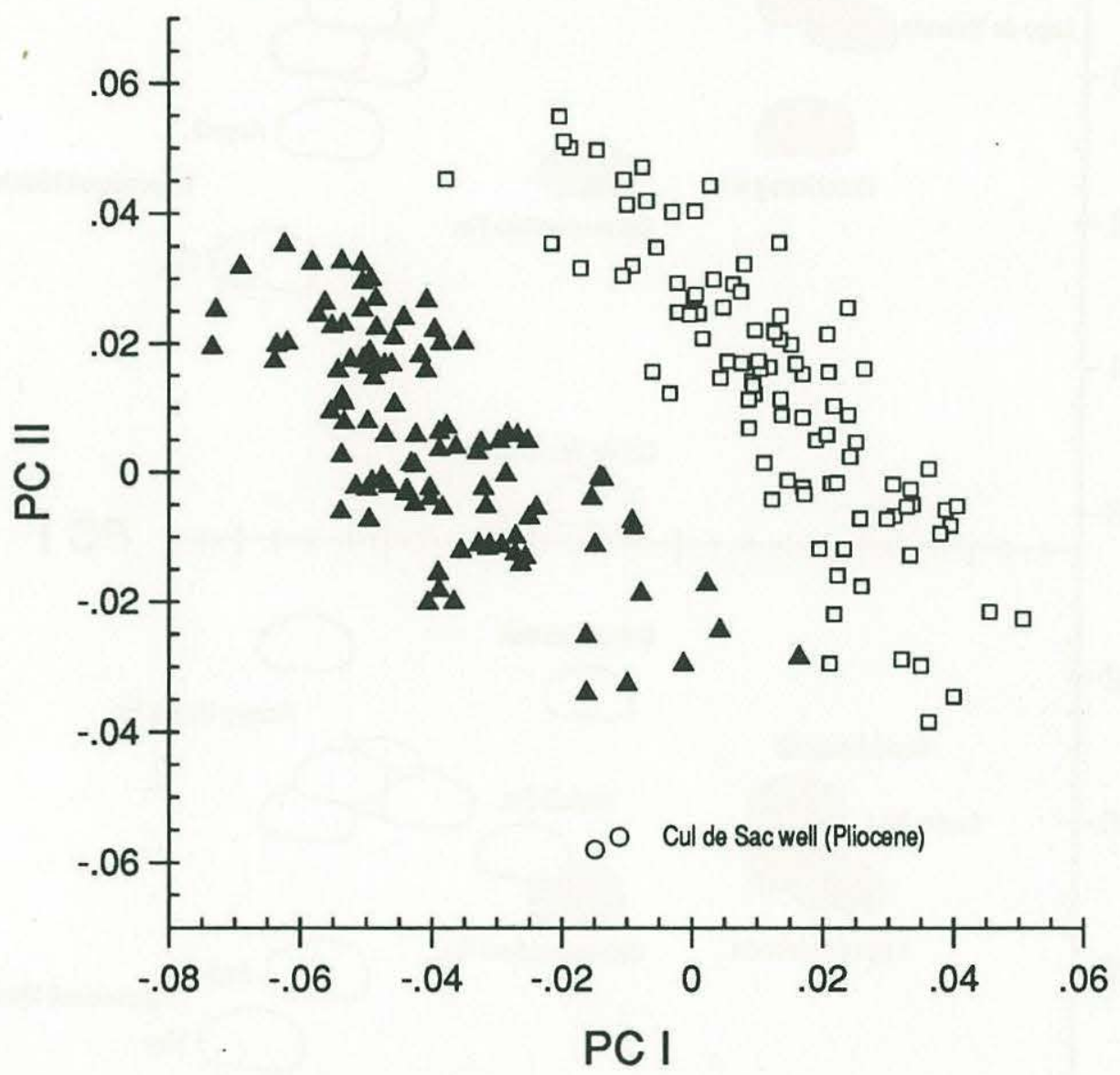

Figure 1.11: Adult female specimens of C. salebrosa plotted on the first two principal components of shape variation shown in figure 1.10. Open squares mark specimens from samples whose average shapes were judged to belong to variety A, filled triangles mark specimens from samples whose average shapes were judged to belong to variety $\mathrm{B}$. This plot shows that the groups described by the cluster analysis (figure 1.9) do not overlap. 


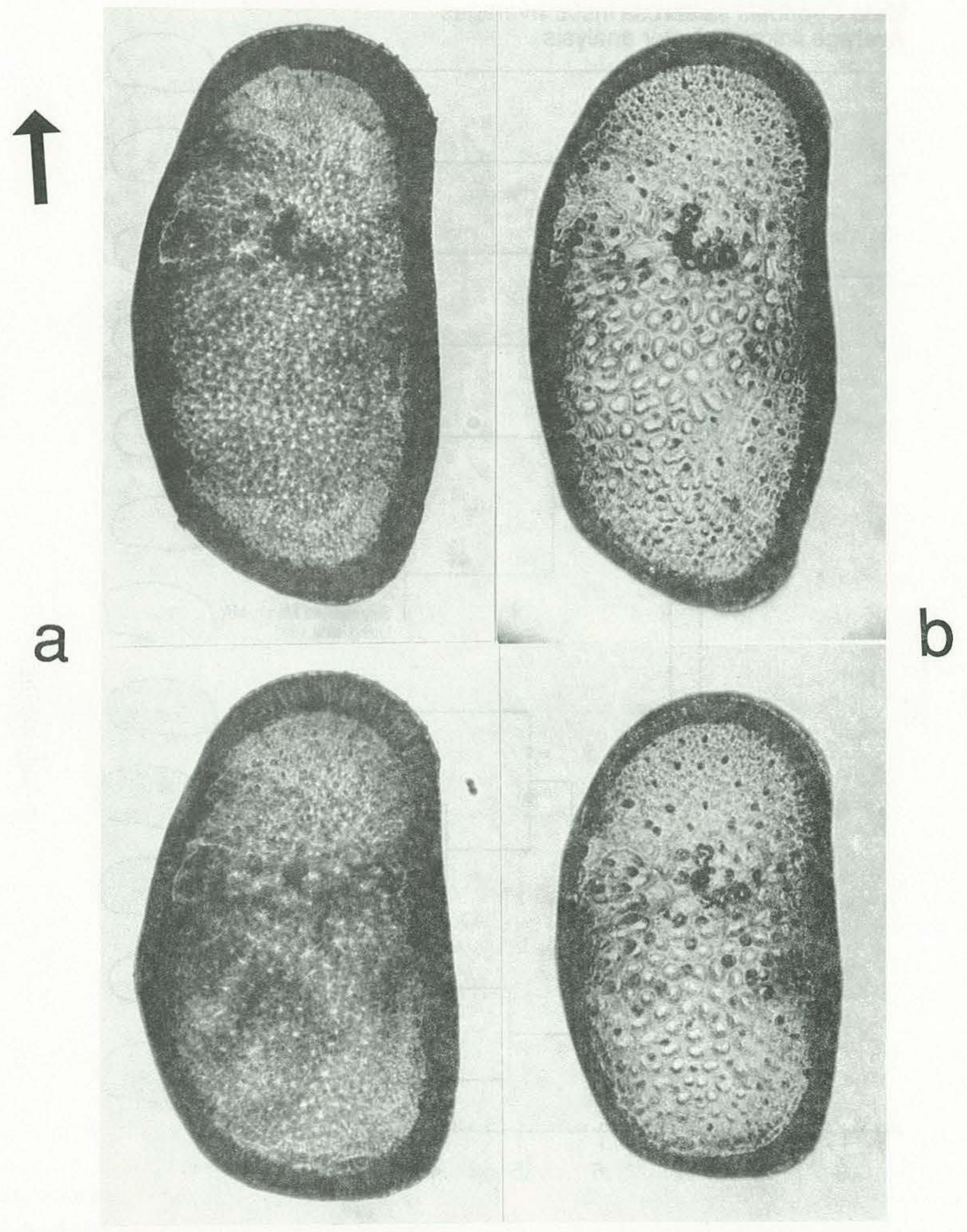

Figure 1.12: Cyprideis salebrosa varieties A and B. Adult male and female right valves in right lateral view. Arrow shows the anterior direction. 


\section{Male Cyprideis salebrosa instar averages \\ Average linkage cluster analysis}

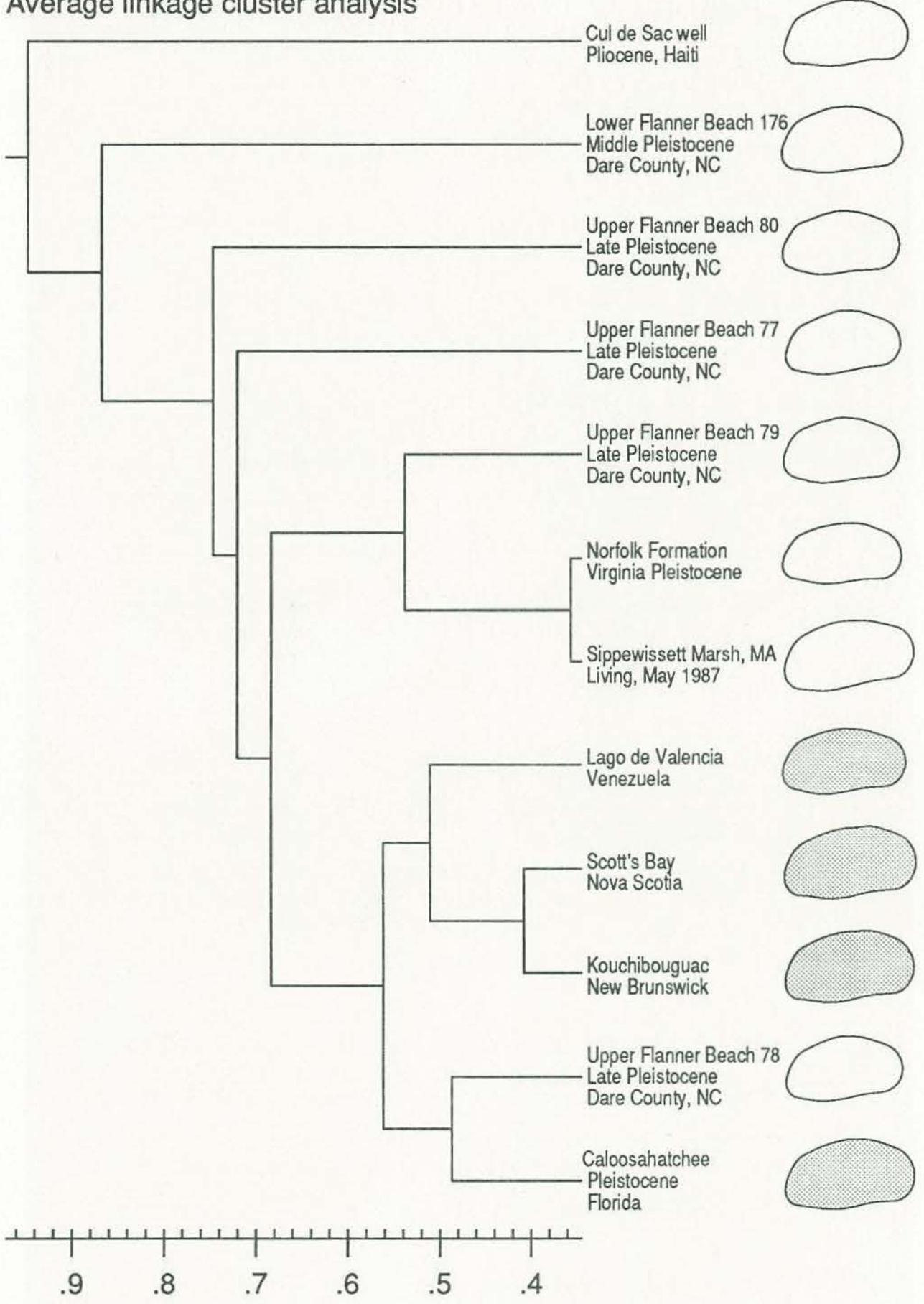

Figure 1.13: Cluster analysis of the average shapes of adult male $C$. salebrosa, calculated using Euclidean distance and the unweighted pair-group method with average linkage (UPGMA), i.e. the distance between two groups is calculated as the average distance among their members. Stippled shapes represent samples classified as variety B using the shape of their females (see figures 1.9, 1.10, and 1.11). 


\section{Cyprideis salebrosa Adult Males}

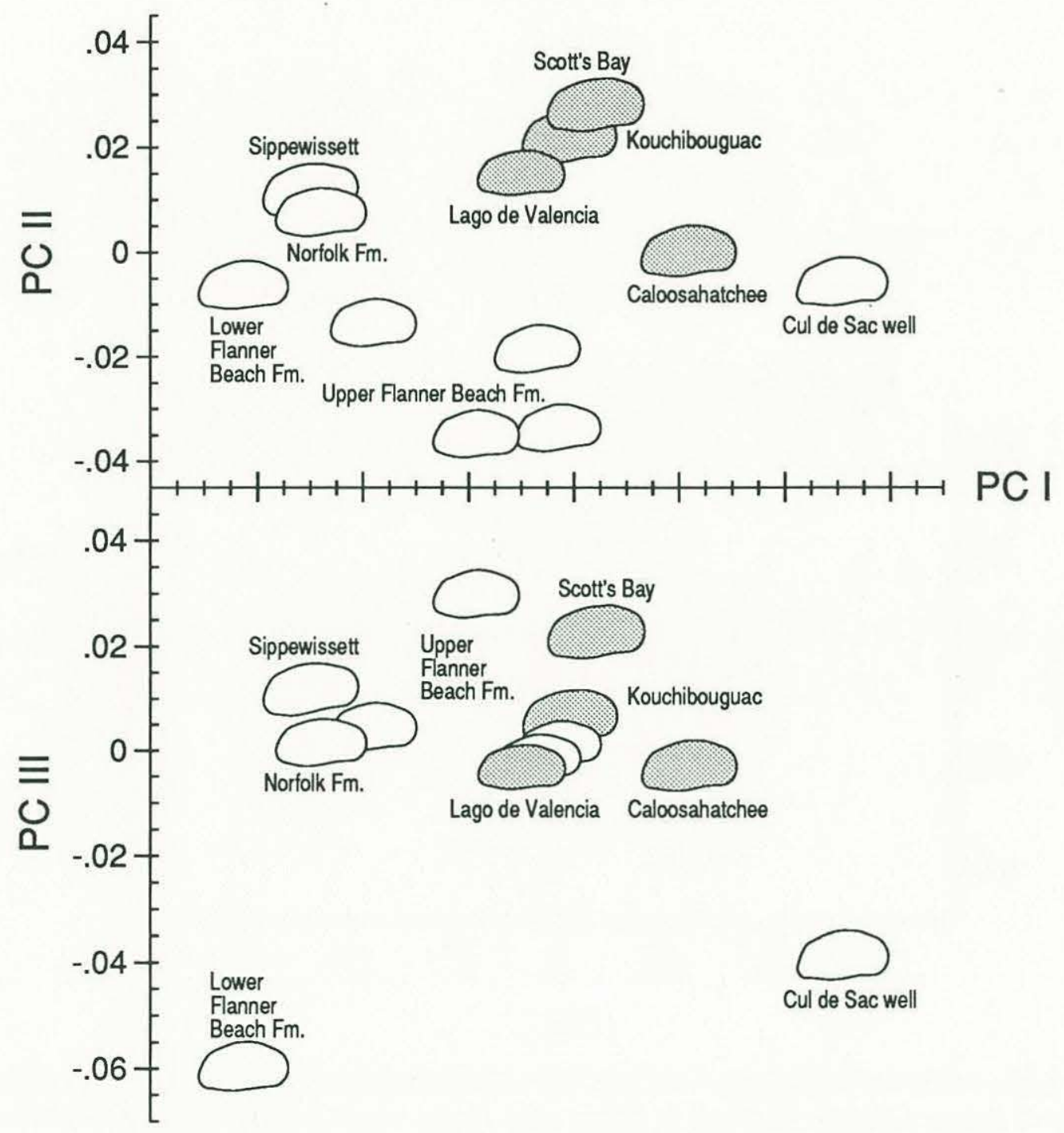

Figure 1.14: Adult male C. salebrosa plotted on the first three principal components of shape variation. Each shape plotted is the average of specimens found at the specified locality. 


\section{Cyprideis salebrosa Adult Males}

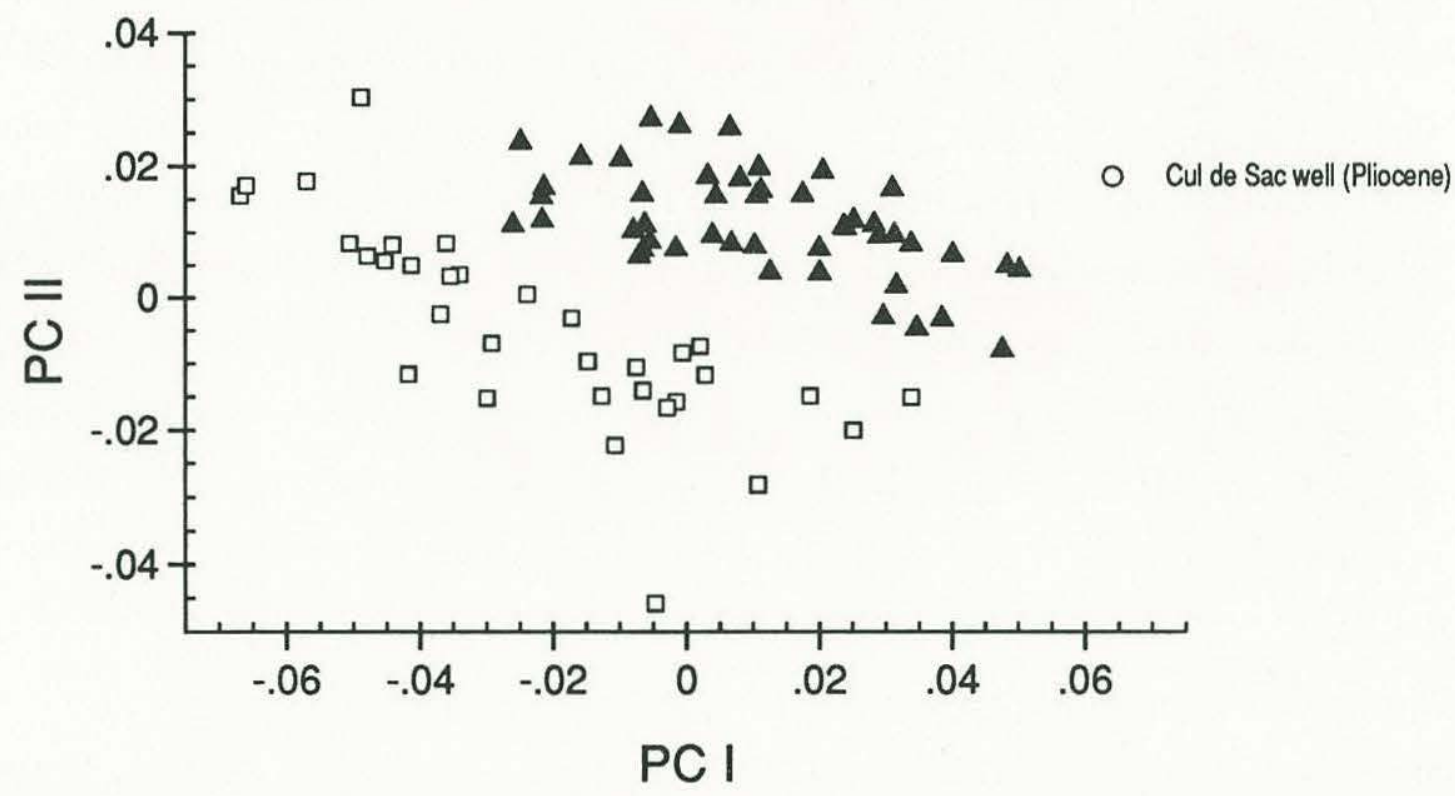

Figure 1.15: Adult male specimens of Cyprideis salebrosa plotted on the first two principal components of shape variation depicted in figure 1.14. Open squares mark specimens from samples whose average shapes were judged to belong to variety A, filled triangles mark specimens from samples whose average shapes were judged to belong to variety $B$. This plot shows that the groups described by the cluster analysis (figure 1.13) do not overlap. 


\section{Geographic and stratigraphic variation of morphology}

Size. Size varies significantly among samples from different localities (tables 1.10, 1.11, 1.12, 1.14, and 1.13). In general, the more southerly the locality, the smaller the specimens. The specimens of $C$. mexicana and C. margarita from the Waccamaw Formation are larger, however, than younger Pleistocene material from the same region. C. salebrosa var. B from the Pleistocene Caloosahatchee Formation of Florida are larger than living specimens from Lago de Valencia in Venezuela. These exceptions imply that geographic variation does not explain all of the size variation among samples from different places. Significant differences among modern samples (e.g. in C. ovata, of which no fossils were measured) suggest that geographic variation in size is slightly larger than seasonal variation.

In addition to the specimens that were measured, I have studied recent material from the Laguna de Tamiahua, in Veracruz, Mexico, collected by P.A. Sandberg as part of his 1964 monograph on Cyprideis and deposited in the U.S. National Museum. These specimens of C. salebrosa, C. ovata, and C. mexicana are uniformly smaller than those found on the Atlantic coast. The size of the adult Mexican C. salebrosa, for example, is about the same as the specimens from Lago de Valencia, Venezuela; the largest of these is smaller than the smallest of the Canadian adults. Every species of Cyprideis from the Caribbean and Gulf of Mexico is smaller there than to the north along the Atlantic coast.

Shape. The principal components of shape variability for each species are portrayed in figures $1.16,1.18,1.20,1.22$, and 1.24. Seasonal variability (figures 1.17, 1.19, 1.21, and 1.23) provides a context in which we can judge the significance of geographic variation; we need not try to explain differences smaller than the seasonal variation in Sippewissett Marsh. Seasonal variation in shape accounts for nearly all of the intraspecific variation shown in these plots. Exceptions are noted on each graph and labeled. Prominent exceptions are specimens of $C$. mexicana from the Waccamaw Formation and the Pliocene and Pleistocene specimens of C. salebrosa var. A.

A few other exceptions are less obvious. Pleistocene samples of adult $C$. margarita from the Princess Anne terrace formation and the Waccamaw Formation do not fall within the scatter defined by seasonal variation, yet material from the nearby Silver Bluff terrace formation does. Adult female $C$. ovata from San Salvador are more like male $C$. ovata than are specimens from 
other places, but the other instars from the same locality are not statistically different from specimens found in Massachusetts.

In addition to the shape of the outline, several other characteristics set the specimens of Cyprideis mexicana from the Waccamaw Formation apart from more modern specimens. Those from the Waccamaw Formation possess four to five blunt anteromarginal denticles like the denticles frequently observed in modern C. salebrosa and in C. floridana from the Duplin Formation. The Waccamaw specimens also possess a posteroventral flange, a feature typical of modern $C$. salebrosa and $C$. ovata but lacking in modern C. mexicana.

Cyprideis mexicana from the Waccamaw Formation appears to be a morphological intermediate; a population with the size, shape, and other characteristics of $C$. mexicana showing characteristics of C. floridana of the Duplin Formation and C. salebrosa of the Caloosahatchee Formation. Likewise the fossil specimens of C. salebrosa are morphologically intermediate with respect to the two living morphologies as shown above. These interpretations suggest that C. mexicana evolved from either C. floridana or C. salebrosa in the early Pleistocene, and that considerable anagenesis (morphological change through time without forming separate taxonomic entities) has occurred in the history of the species C. salebrosa. C. margarita first appears in the Waccamaw Formation, and though its shape is similar to C. mexicana, fossil specimens intermediate in other morphological characters have not been described. Evidence of the stratigraphic record of Cyprideis in the Caribbean region (van den Bold 1976) seems to indicate a Caribbean origin for C. salebrosa and C. ovata, but not for C. mexicana (van den Bold reports it is not found as a fossil) nor for C. margarita, which has never been reported in the Caribbean region. 
Table 1.10: Geographic variation in size of $C$. margarita. See table 1.6 for details.

\begin{tabular}{lrrrrrrrrr} 
& & Male & Female & A-1 & A-2 & A-3 & A-4 & A-5 & A-6 \\
\hline 78TC42 & $n$ & 20 & 20 & 10 & 0 & 0 & 0 & 0 & 0 \\
Pleistocene & $\bar{x}$ & -1.469 & -1.382 & -1.889 & & & & & \\
South Carolina & $s_{x}$ & 0.061 & 0.064 & 0.052 & & & & & \\
& & & & & & & & & \\
78TC65A & $n$ & 14 & 10 & 3 & 0 & 0 & 0 & 0 & 0 \\
Pleistocene & $\bar{x}$ & -1.374 & -1.309 & -1.661 & & & & & \\
South Carolina & $s_{x}$ & 0.030 & 0.039 & 0.026 & & & & & \\
& & & & & & & & & \\
Evangeline & $n$ & 2 & 6 & 2 & 6 & 2 & 1 & 0 & 0 \\
Beach & $\bar{x}$ & -1.318 & -1.185 & -1.672 & -2.171 & -2.640 & -3.043 & & \\
Nova Scotia & $s_{x}$ & 0.017 & 0.035 & 0.060 & 0.053 & 0.026 & 0.000 & & \\
& & & & & & & & & \\
Waccamaw Fm. & $n$ & 4 & 1 & 2 & 1 & 1 & 0 & 0 & 0 \\
Pleistocene & $\bar{x}$ & -1.307 & -1.235 & -1.740 & -2.204 & -2.687 & & & \\
North Carolina & $s_{x}$ & 0.070 & 0.000 & 0.045 & 0.000 & 0.000 & & & \\
\hline Range of $\bar{x}$ & & 0.162 & 0.197 & 0.228 & & & & & \\
Pooled $s_{x}$ & & 0.050 & 0.052 & 0.051 & & & & & \\
Approximate $t$ & & 3.250 & 3.771 & 4.489 & & & & &
\end{tabular}


Table 1.11: Geographic variation in size of $C$. mexicana. See table 1.6 for details.

\begin{tabular}{lrrrrrrrrr} 
& & Male & Female & A -1 & A-2 & A-3 & A-4 & A-5 & A-6 \\
\hline Barnstable & $n$ & 12 & 20 & 10 & 0 & 0 & 0 & 0 & 0 \\
Harbor MA & $\bar{x}$ & -0.868 & -0.945 & -1.529 & & & & & \\
Living & $s_{x}$ & 0.069 & 0.049 & 0.025 & & & & & \\
& & & & & & & & 0 & 0 \\
82TC178 & $n$ & 1 & 21 & 19 & 11 & 2 & 0 & 0 & \\
Pleistocene & $\bar{x}$ & -0.973 & -1.047 & -1.611 & -2.212 & -2.737 & & & \\
North Carolina & $s_{x}$ & & 0.043 & 0.048 & 0.035 & 0.065 & & & \\
& $n$ & & & & & & & & \\
82TC179 & $n$ & 9 & 20 & 17 & 8 & 3 & 0 & 0 & 0 \\
Pleistocene & $\bar{x}$ & -1.074 & -1.087 & -1.633 & -2.235 & -2.734 & & & \\
North Carolina & $s_{x}$ & 0.047 & 0.047 & 0.052 & 0.037 & 0.043 & & & \\
& & & & & & & & & \\
82TC181 & $n$ & 3 & 7 & 11 & 8 & 3 & 0 & 0 & 0 \\
Pleistocene & $\bar{x}$ & -0.933 & -1.285 & -1.947 & -2.239 & -2.999 & & & \\
North Carolina & $s_{x}$ & 0.058 & 0.308 & 0.306 & 0.182 & 0.219 & & & \\
& & & & & & & & & \\
Evangeline & $n$ & 0 & 13 & 20 & 20 & 20 & 20 & 0 & 0 \\
Beach NS & $\bar{x}$ & & -0.972 & -1.405 & -2.023 & -2.546 & -2.984 & & \\
1985 & $s_{x}$ & & 0.049 & 0.045 & 0.046 & 0.043 & 0.028 & & \\
& $n$ & & & & & & & & \\
Evangeline & $n$ & 0 & 2 & 1 & 18 & 19 & 17 & 17 & 15 \\
Beach NS & $\bar{x}$ & & -0.916 & -1.408 & -2.037 & -2.567 & -3.004 & -3.417 & -3.779 \\
1986 & $s_{x}$ & & 0.006 & & 0.047 & 0.033 & 0.041 & 0.031 & 0.046 \\
& & & & & & & & & \\
Langley Bluffs & $n$ & 20 & 20 & 20 & 20 & 0 & 0 & 0 & 0 \\
Pleistocene & $\bar{x}$ & -1.140 & -1.207 & -1.720 & -2.272 & & & & \\
Virginia & $s_{x}$ & 0.041 & 0.042 & 0.073 & 0.063 & & & & \\
& & & & & & & & \\
Waccamaw Fm. & $n$ & 11 & 15 & 10 & 8 & 2 & 0 & 0 & 0 \\
Pleistocene & $\bar{x}$ & -0.812 & -0.930 & -1.493 & -1.973 & -2.508 & & & \\
North Carolina & $s_{x}$ & 0.032 & 0.075 & 0.084 & 0.056 & 0.017 & & & \\
\hline Range of $\bar{x}$ & & 0.328 & 0.369 & 0.542 & 0.300 & 0.491 & 0.020 & & \\
Pooled $s_{x}$ & & 0.048 & 0.065 & 0.081 & 0.061 & 0.051 & 0.035 & & \\
Approximate $t$ & & 6.823 & 5.681 & 6.710 & 4.914 & 9.665 & 0.589 & & \\
& & & & & & & & &
\end{tabular}


Table 1.12: Geographic variation in size of $C$. ovata. See table 1.6 for details.

\begin{tabular}{lrrrrrrrrr} 
& & Male & Female & A-1 & A-2 & A-3 & A-4 & A-5 & A-6 \\
\hline San Salvador & $n$ & 22 & 40 & 54 & 30 & 20 & 20 & 11 & 0 \\
Bahamas & $\bar{x}$ & -0.760 & -0.860 & -1.300 & -1.793 & -2.294 & -2.753 & -3.132 & \\
Living & $s_{x}$ & 0.096 & 0.099 & 0.118 & 0.059 & 0.041 & 0.036 & 0.034 & \\
& & & & & & & & & \\
Assateague Is. & $n$ & 0 & 4 & 24 & 30 & 29 & 10 & 1 & 0 \\
Maryland & $\bar{x}$ & & -0.775 & -1.278 & -1.825 & -2.362 & -2.829 & -3.245 & \\
Living & $s_{x}$ & & 0.032 & 0.052 & 0.039 & 0.028 & 0.056 & & \\
& & & & & & & & & \\
Barnstable & $n$ & 5 & 9 & 19 & 13 & 7 & 1 & 0 & 0 \\
Harbor MA & $\bar{x}$ & -0.691 & -0.619 & -1.176 & -1.748 & -2.274 & -2.742 & & \\
Living & $s_{x}$ & 0.059 & 0.067 & 0.059 & 0.050 & 0.008 & & & \\
& & & & & & & & & \\
Beaufort & $n$ & 2 & 6 & 12 & 6 & 2 & 0 & 0 & 0 \\
North Carolina & $\bar{x}$ & -0.984 & -1.014 & -1.459 & -1.996 & -2.480 & & & \\
Living & $s_{x}$ & 0.004 & 0.036 & 0.050 & 0.033 & 0.014 & & & \\
\hline Range of $\bar{x}$ & & 0.294 & 0.396 & 0.284 & 0.247 & 0.206 & 0.076 & & \\
Pooled $s_{x}$ & & 0.086 & 0.085 & 0.086 & 0.049 & 0.030 & 0.044 & & \\
Approximate $t$ & & 3.417 & 4.656 & 3.281 & 5.081 & 6.808 & 1.724 & & \\
& & & & & & & & &
\end{tabular}


Table 1.13: Geographic variation in size of C. salebrosa var. B. See table 1.6 for details of the method. In all species of Cyprideis, specimens from the Caribbean and Gulf of Mexico are smaller than those found farther north. If those from Venezuela are not included in the analysis, the $t$-statistics are much closer to typical values for seasonal variation.

\begin{tabular}{lrrrrrrrrr} 
& & Male & Female & A-1 & A-2 & A-3 & A-4 & A-5 & A-6 \\
\hline Caloosahatchee Fm. & $n$ & 6 & 14 & 20 & 21 & 12 & 3 & 1 & 0 \\
Pleistocene & $\bar{x}$ & -0.489 & -0.627 & -1.170 & -1.757 & -2.343 & -2.800 & -3.190 & \\
Florida & $s_{x}$ & 0.071 & 0.099 & 0.118 & 0.059 & 0.049 & 0.044 & & \\
& & & & & & & & & \\
Kouchibouguac Park & $n$ & 20 & 20 & 20 & 20 & 16 & 18 & 20 & 6 \\
New Brunswick & $\bar{x}$ & -0.460 & -0.612 & -1.137 & -1.707 & -2.243 & -2.747 & -3.145 & -3.558 \\
Living & $s_{x}$ & 0.039 & 0.079 & 0.064 & 0.072 & 0.053 & 0.041 & 0.038 & 0.050 \\
& & & & & & & & & \\
Lago de Valencia & $n$ & 18 & 35 & 19 & 5 & 0 & 0 & 0 & 0 \\
Venezuela & $\bar{x}$ & -0.693 & -0.807 & -1.280 & -1.870 & & & & \\
Living & $s_{x}$ & 0.056 & 0.083 & 0.070 & 0.059 & & & & \\
& & & & & & & & & \\
Scott's Bay & $n$ & 3 & 34 & 25 & 16 & 9 & 5 & 5 & 0 \\
Nova Scotia & $\bar{x}$ & -0.437 & -0.473 & -0.982 & -1.561 & -2.167 & -2.111 & -3.076 & \\
Living & $s_{x}$ & 0.029 & 0.041 & 0.058 & 0.046 & 0.033 & 1.058 & 0.017 & \\
\hline Range of $\bar{x}$ & & 0.256 & 0.333 & 0.299 & 0.309 & 0.176 & 0.689 & 0.069 & \\
Pooled $s_{x}$ & & 0.050 & 0.071 & 0.077 & 0.061 & 0.048 & 0.247 & 0.036 & \\
Approximate $t$ & & 5.128 & 4.692 & 3.859 & 5.086 & 3.643 & 2.794 & 1.954 & \\
& & & & & & & & & \\
Excluding Lago de Valencia: & & & & & & & & & \\
Range of $\bar{x}$ & & 0.052 & 0.153 & 0.188 & 0.197 & & & & \\
Pooled $s_{x}$ & 0.046 & 0.065 & 0.080 & 0.061 & & & & \\
Approximate $t$ & & 1.129 & 2.364 & 2.365 & 3.224 & & & &
\end{tabular}


Table 1.14: Geographic variation in size of C. salebrosa var. A. See table 1.6 for details.

\begin{tabular}{|c|c|c|c|c|c|c|c|c|c|}
\hline & & Male & Female & $A-1$ & $A-2$ & $A-3$ & $A-4$ & $A-5$ & $A-6$ \\
\hline Cul de Sac well & $n$ & 1 & 2 & 8 & 3 & 0 & 0 & 0 & 0 \\
\hline Pliocene & $\bar{x}$ & -0.577 & -0.789 & -1.124 & -1.810 & & & & \\
\hline Haiti & $s_{x}$ & & 0.006 & 0.065 & 0.024 & & & & \\
\hline $82 \mathrm{TC} 174$ & $n$ & 0 & 4 & 4 & 1 & 1 & 0 & 0 & 0 \\
\hline Pleistocene & $\bar{x}$ & & -0.675 & -1.237 & -1.875 & -2.405 & & & \\
\hline North Carolina & $s_{x}$ & & 0.038 & 0.041 & & & & & \\
\hline $82 \mathrm{TC} 176$ & $n$ & 1 & 4 & 11 & 4 & 2 & 1 & 0 & 0 \\
\hline Pleistocene & $\bar{x}$ & -0.600 & -0.649 & -1.189 & -1.790 & -2.487 & -2.805 & & \\
\hline North Carolina & $s_{x}$ & & 0.054 & 0.070 & 0.046 & 0.005 & & & \\
\hline $81 \mathrm{TC} 77$ & $n$ & 1 & 6 & 7 & 0 & 0 & 0 & 0 & 0 \\
\hline Pleistocene & $\bar{x}$ & -0.711 & -0.765 & -1.286 & & & & & \\
\hline North Carolina & $s_{x}$ & & 0.042 & 0.050 & & & & & \\
\hline $81 \mathrm{TC} 78$ & $n$ & 9 & 23 & 6 & 4 & 0 & 0 & 0 & 0 \\
\hline Pleistocene & $\bar{x}$ & -0.676 & -0.705 & -1.259 & -1.818 & & & & \\
\hline North Carolina & $s_{x}$ & 0.031 & 0.055 & 0.038 & 0.046 & & & & \\
\hline $81 \mathrm{TC} 79$ & $n$ & 3 & 10 & 4 & 1 & 0 & 0 & 0 & 0 \\
\hline Pleistocene & $\bar{x}$ & -0.660 & -0.659 & -1.233 & -1.881 & & & & \\
\hline North Carolina & $s_{x}$ & 0.045 & 0.042 & 0.067 & & & & & \\
\hline $81 \mathrm{TC} 80$ & $n$ & 1 & 6 & 2 & 1 & 0 & 0 & 0 & 0 \\
\hline Pleistocene & $\bar{x}$ & -0.660 & -0.700 & -1.097 & -1.853 & & & & \\
\hline North Carolina & $s_{x}$ & & 0.038 & 0.010 & & & & & \\
\hline Norfolk Fm. & $n$ & 7 & 24 & 15 & 8 & 0 & 0 & 0 & 0 \\
\hline Pleistocene & $\bar{x}$ & -0.598 & -0.632 & -1.220 & -1.863 & & & & \\
\hline Virginia & $s_{x}$ & 0.071 & 0.069 & 0.056 & 0.048 & & & & \\
\hline Range of $\bar{x}$ & & 0.078 & 0.157 & 0.189 & 0.073 & & & & \\
\hline Pooled $s_{x}$ & & 0.051 & 0.054 & 0.061 & 0.046 & & & & \\
\hline Approximate $t$ & & 1.528 & 2.917 & 3.121 & 1.594 & & & & \\
\hline
\end{tabular}




\section{Shape variation of Cyprideis margarita}

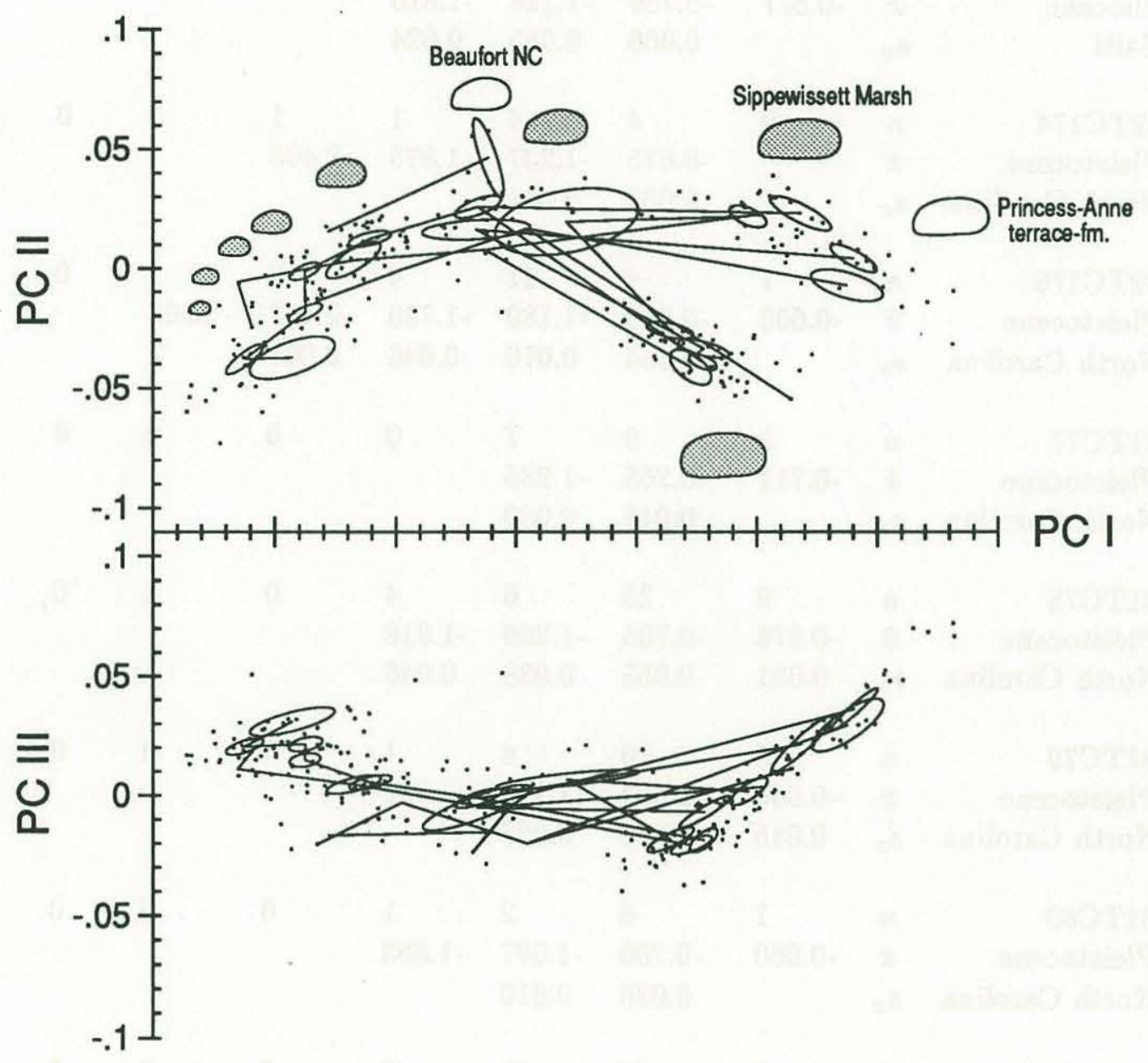

Figure 1.16: Geographic and stratigraphic variation in shape of $C$. margarita. Ellipses represent $95 \%$ confidence intervals for the means of samples represented by more than two specimens. Straight lines connect specimens from the same sample in ontogenetic sequence; lines connect both adult sexual dimorphs with the corresponding A-1 instar. 


\section{Seasonal variation of Cyprideis margarita}

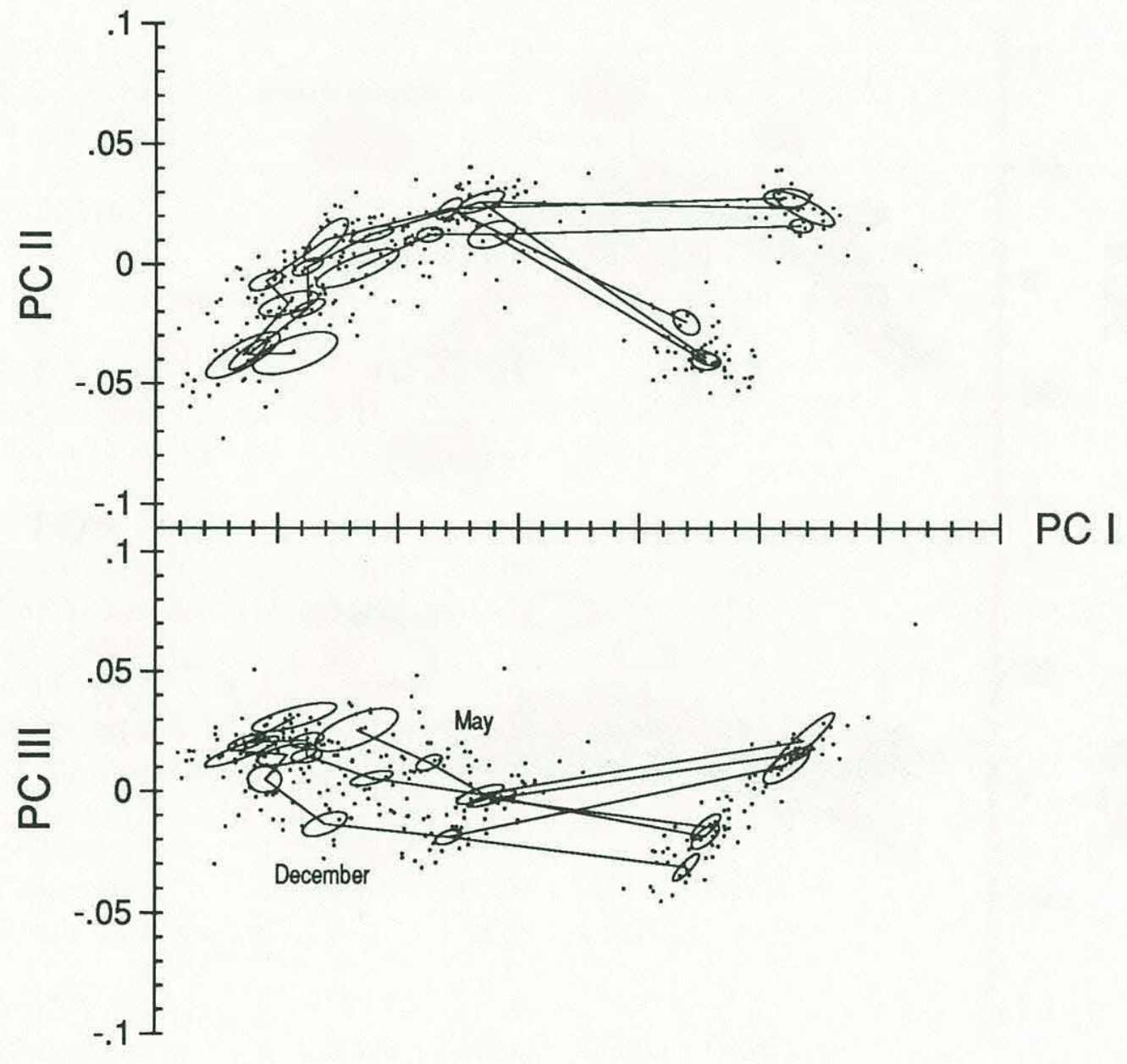

Figure 1.17: Seasonal variation in the shape of $C$. margarita, plotted on the axes of figure 1.16. 


\section{Shape variation of Cyprideis mexicana}

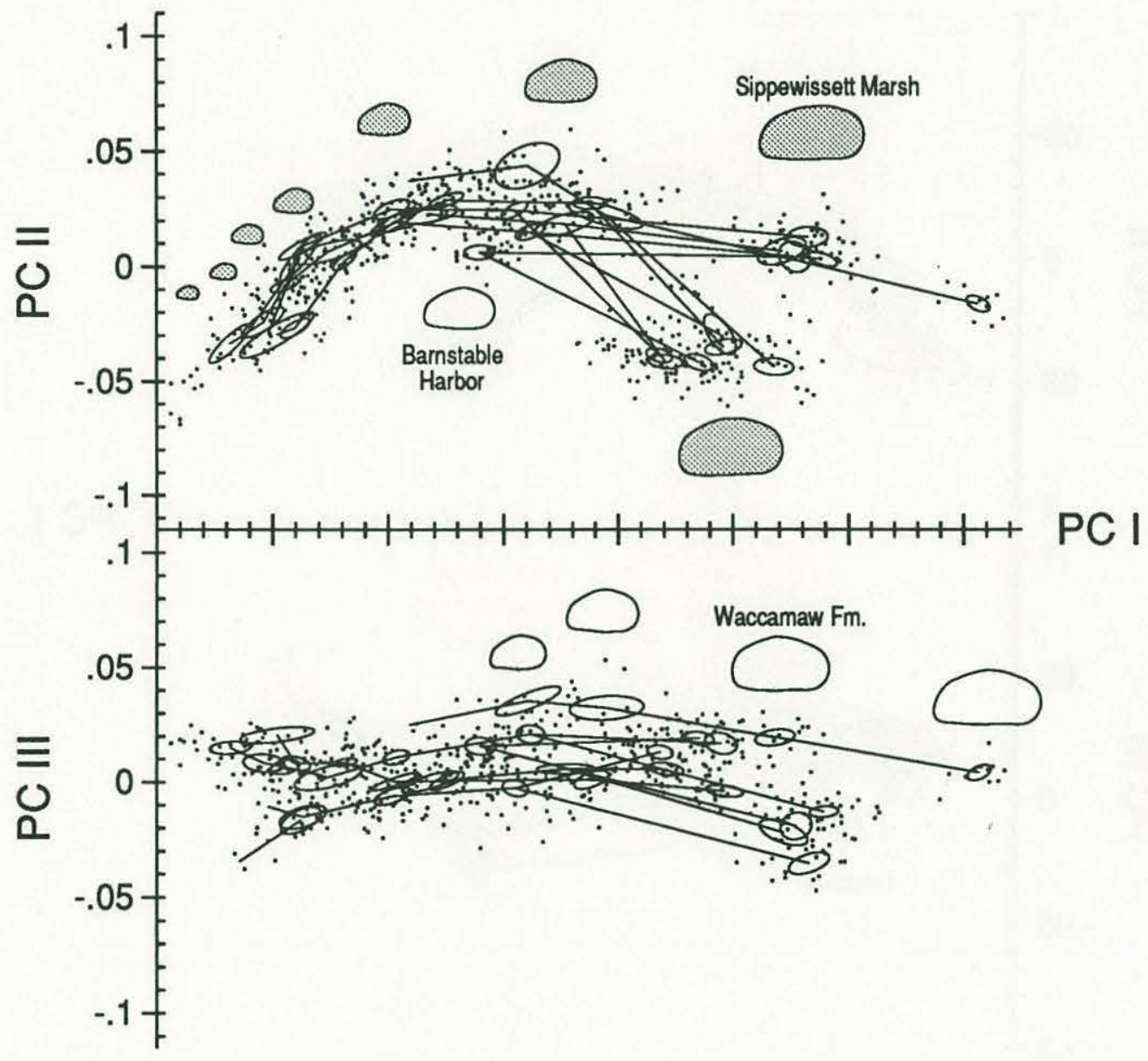

Figure 1.18: Geographic and stratigraphic variation in shape of $C$. mexicana. 


\section{Seasonal variation of Cyprideis mexicana}

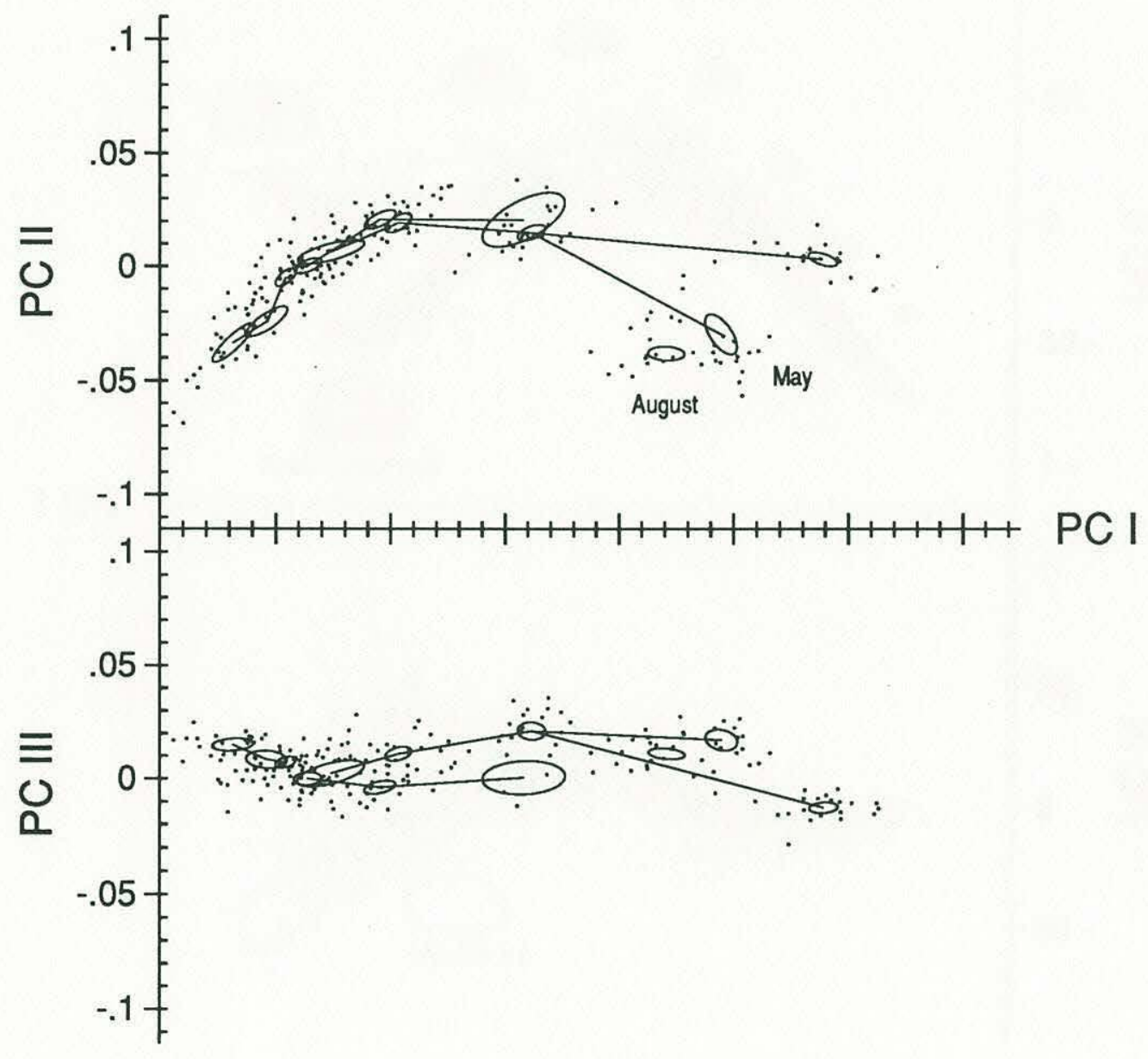

Figure 1.19: Seasonal variation in the shape of $C$. mexicana, plotted on the axes of figure 1.18. 


\section{Shape variation of Cyprideis ovata}

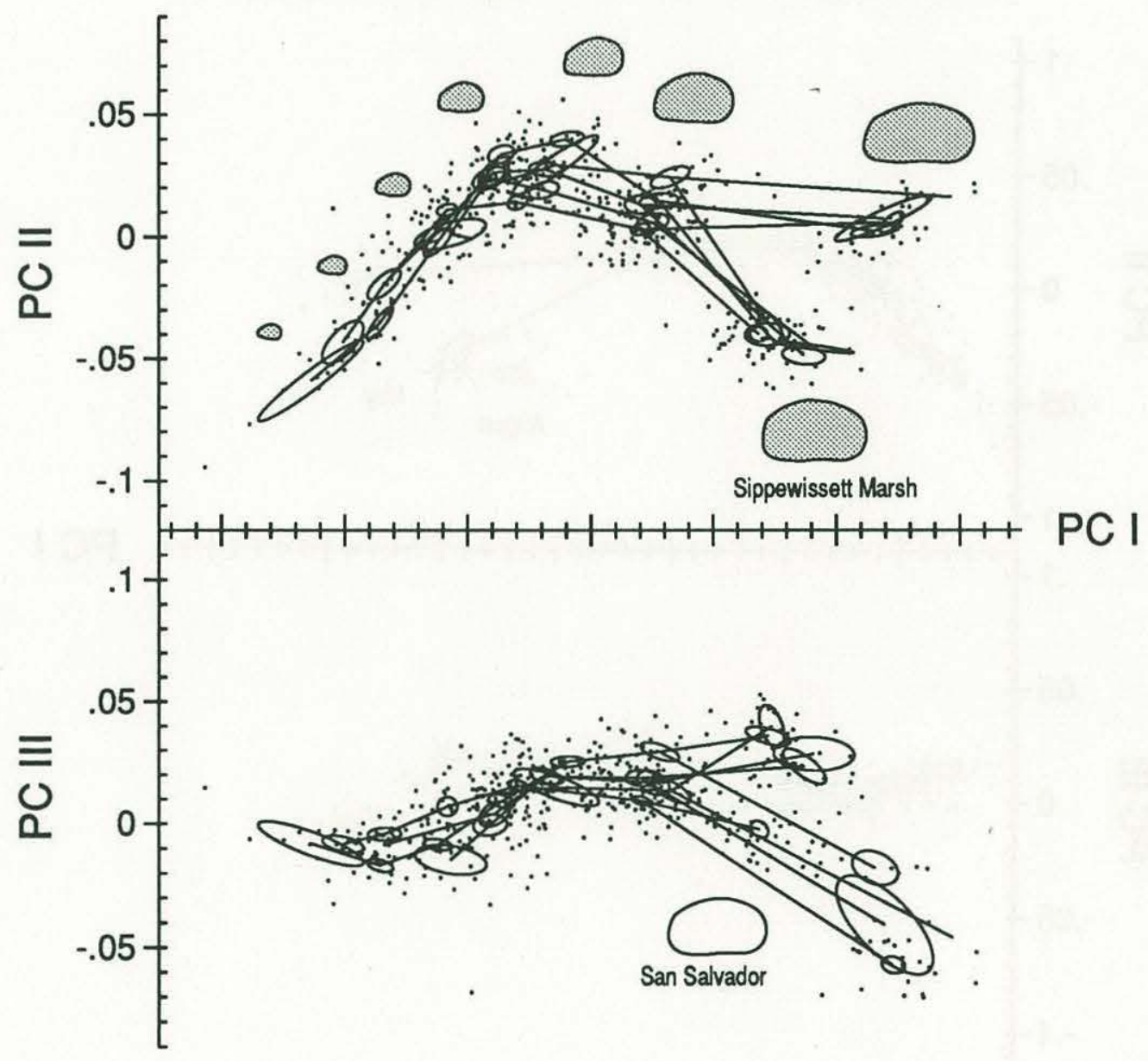

Figure 1.20: Geographic and stratigraphic variation in shape of $C$. ovata. Ellipses represent $95 \%$ confidence intervals for the means of samples represented by more than two specimens. Straight lines connect specimens from the same sample in ontogenetic sequence. 


\section{Seasonal variation of Cyprideis ovata}

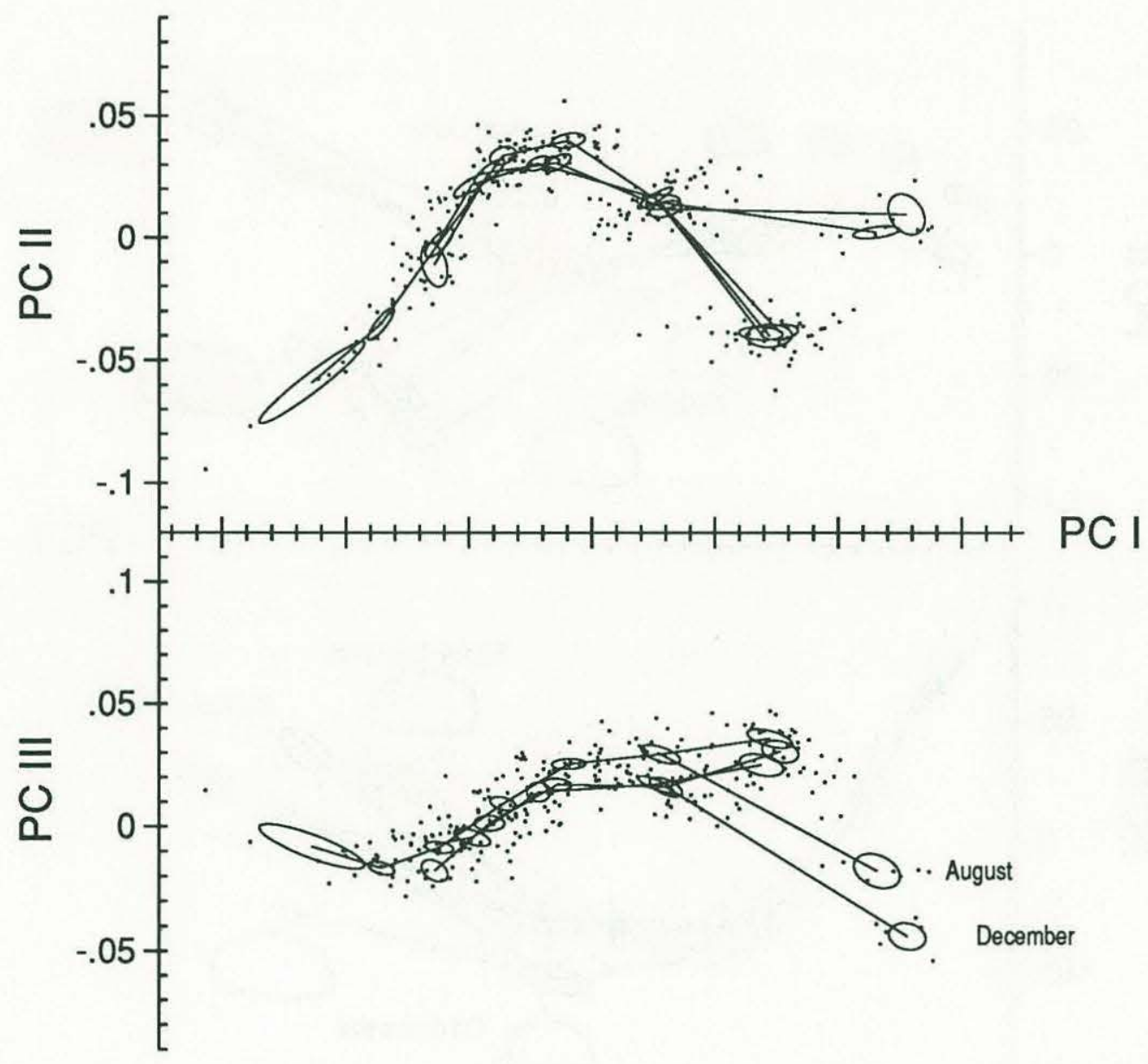

Figure 1.21: Seasonal variation in the shape of $C$. ovata, plotted on the axes of figure 1.20. 


\section{Shape variation of Cyprideis salebrosa variety $A$}

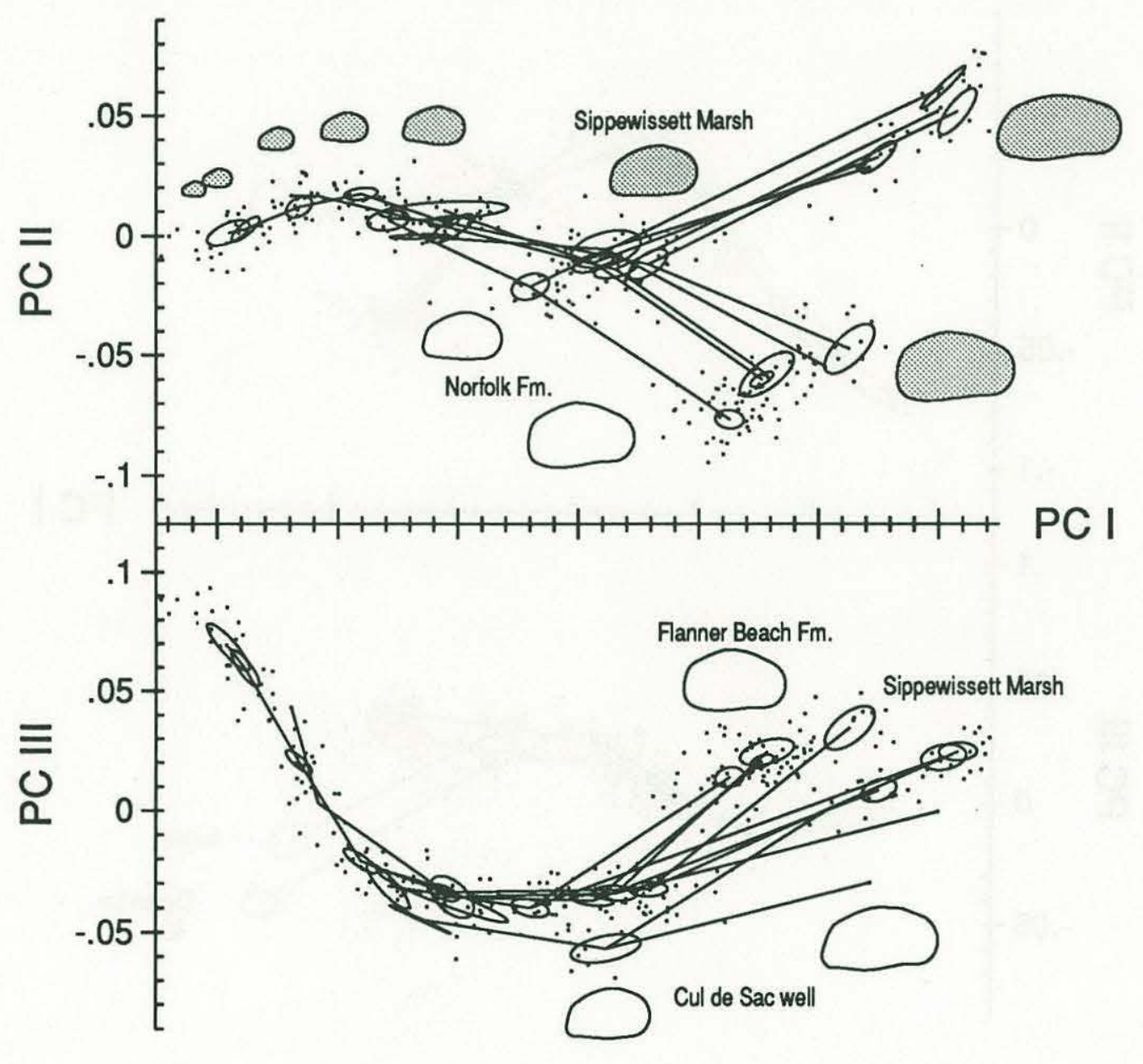

Figure 1.22: Geographic and stratigraphic variation in shape of C. salebrosa var. A. 


\section{Seasonal variation of Cyprideis salebrosa variety $\mathrm{A}$}

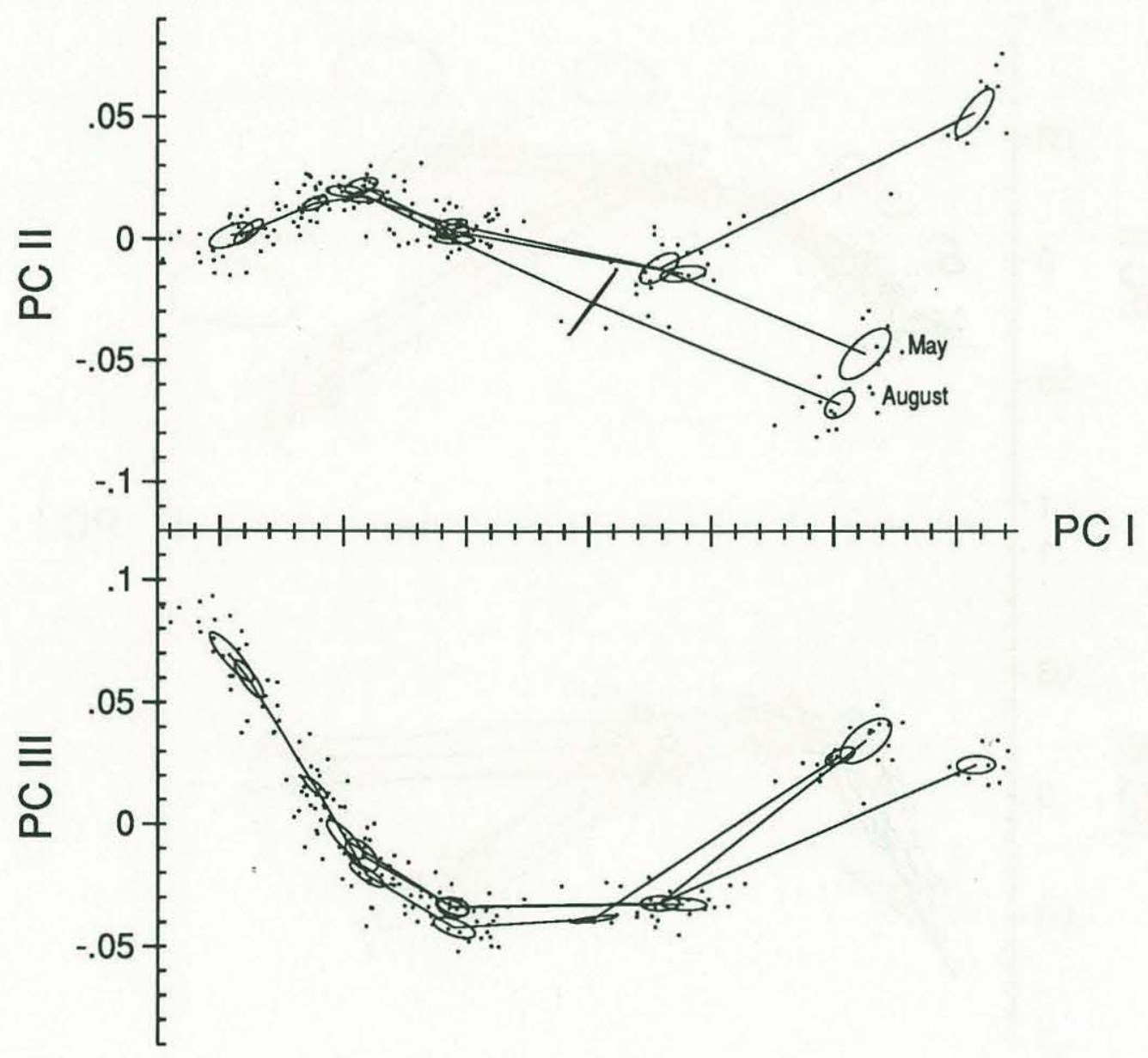

Figure 1.23: Seasonal variation in the shape of C. salebrosa var. A, plotted on the axes of figure 1.22 . 


\section{Shape variation of Cyprideis salebrosa variety B}

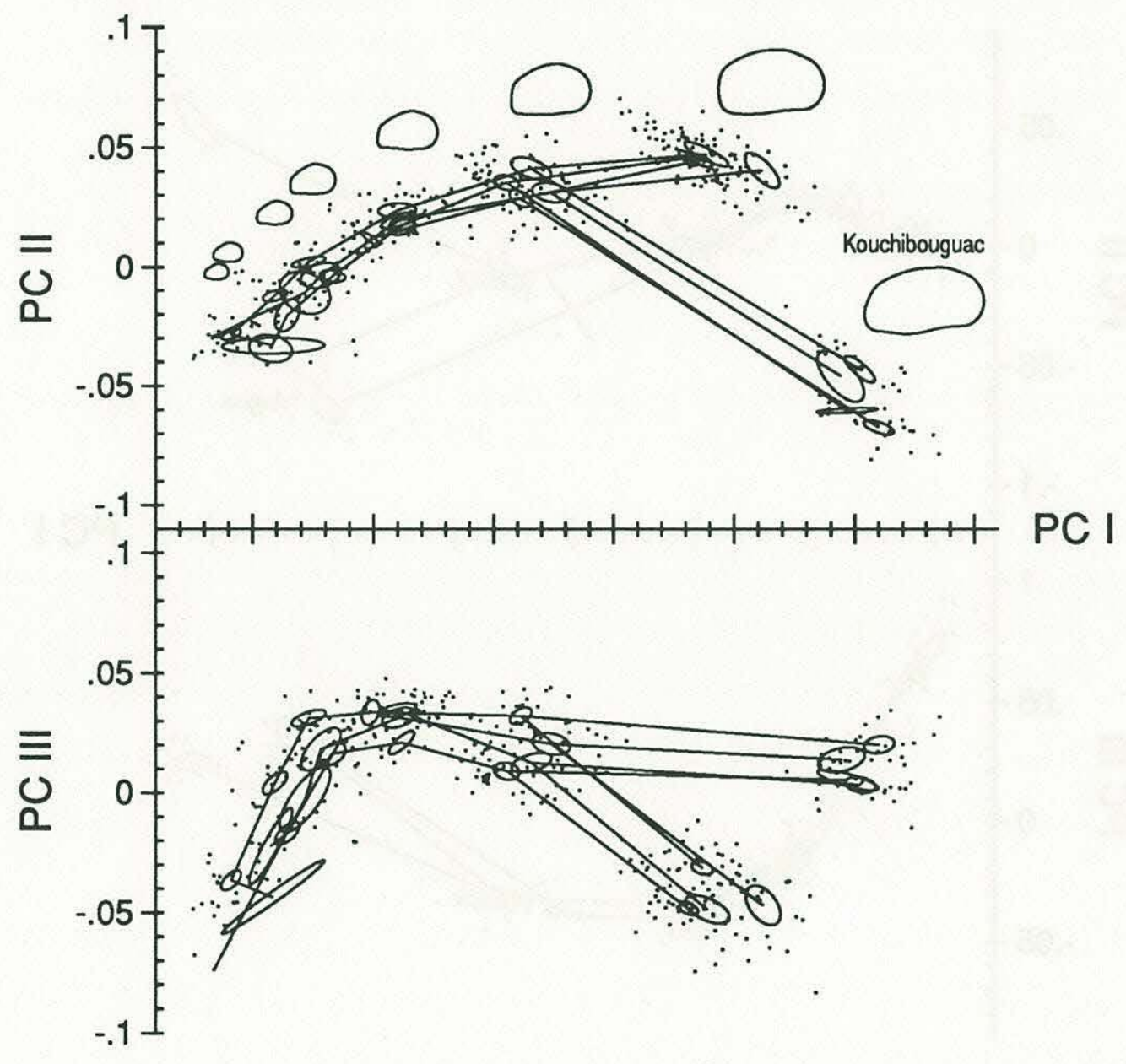

Figure 1.24: Geographic and stratigraphic variation in shape of $C$. salebrosa var. B. Since this variety of $C$. salebrosa does not live in Sippewissett Marsh, there is no corresponding plot of seasonal variation. 


\subsubsection{Morphological relationships among species}

Size. Changes in size that accompany age are usually plotted on logarithmic scales, because an individual's size at any particular stage of development is largely determined by its size at the preceding stage. Figure 1.25 shows the growth rates of each species in Sippewissett Marsh with those of C. salebrosa var. B and C. similis. Figure 1.26 shows all species together, and table 1.15 gives the parameters of the fitted curves and statistics indicating the quality of the fitted model (Draper and Smith 1982). The two smallest species have more nearly log-linear growth than do the larger taxa, but all are better fit by the more complicated log-quadratic model $\ln S_{i}=a+b i+c i^{2}$, where $S_{i}$ is the size of the $i$ th instar. C. mexicana grows by larger increments in the late preadult stages than during the early juvenile stages. In this species the A-2 and A-1 stages develop during the spring, after overwintering as juveniles. This suggests that overwintering affects the growth rate, but C. salebrosa var. A, the other species that overwinters only in juvenile form, does not show the same strong increase in size in the late preadult stages.

Shape. Figure 1.27 shows the covariation in shape shown by the four species living in Sippewissett Marsh and C. similis from Venezuela. Duplin specimens of C. floridana are plotted on the same axes. Ontogeny parallels the most important direction of shape change, the first principal component. Tables 1.16 and 1.17 show how well each instar is represented by the reduced space of principal components. Note that shapes close to the mean (e.g. the A-1 instar of C. mexicana) are not well represented because they have small lengths in the full space.

Heterochrony is a shift in the relative rates of somatic and reproductive development (Gould 1977). It can be seen only along directions of shape change that parallel ontogeny, by marking developmental events (here molt stages) along the trajectory. Schweitzer et al. (1986) provided a simple example in which adults of one species of the ostracode Cavellina resembled the last preadult stage (A-1 instar) of another. In that example the difference between species was as large as the change in shape each species showed during ontogeny. In Cyprideis the opposite is true; the differences among species are smaller than the ontogenetic variation of a single species.

Figure 1.27 shows the morphological evidence for heterochrony. It is an analysis of the changes in shape during ontogeny that are common to each of the four species. The meaning 
of the principal components of shape variation are interpreted by considering how the species, sexes, and instars are arranged on them. The earliest juvenile stages all plot together, and successive instars of each species are spread out along the first principal component. This component therefore describes ontogeny. The second component describes sexual dimorphism, while the third describes non-ontogenetic differences among species. Specimens that are farther to the right along the first principal component are regarded as having more specialized morphology; adults are more specialized than juveniles.

The A-1 instar of C. salebrosa is as specialized (i.e. as far along the first principal component) as are adults of $C$. mexicana and $C$. margarita. This relationship is apparent from cluster analysis as well (figure 1.28); A-1 C. salebrosa cluster with adults of the other species. Likewise the A-2 instar of $C$. salebrosa matches the A-1 instars of $C$. mexicana and $C$. margarita. C. ovata paces C. salebrosa up to the A-2 instar, then falls behind at the $\mathrm{A}-1$ and adult stages. Figure 1.27 was constructed using Cyprideis salebrosa var. A; C. salebrosa var. B shows the same heterochronic relationship to $C$. mexicana and $C$. margarita but to a lesser extent. C. floridana from the Duplin Formation closely parallels C. salebrosa var. A.

Cyprideis salebrosa is peramorphic relative to both C. mexicana and C. margarita, but the morphological relationship between the latter two species does not indicate heterochrony. These findings remain when the records of seasonal, geographic, and stratigraphic variability are taken into account. C. ovata is more complicated, showing early morphology as specialized as $C$. salebrosa but late morphology paralleling $C$. mexicana and C. margarita.

Were these solely extinct forms the analysis would stop here. The relationships among these species would simply be categorized with the appropriate words and speculation that C. salebrosa, whose stratigraphic record extends farthest into the past, spawned the two species C. mexicana and C. margarita by paedomorphosis. But since the life-history of each species has been examined, we know the parts of this story that pure paleontology does not provide. C. mexicana and $C$. salebrosa mature in approximately the same amount of time, but C. margarita matures much more quickly. The expected correlations, that delayed maturity yields specialized morphology and large size, and accelerated maturity leads to generalized morphology and small size, occur in only two of the four species studied here, C. salebrosa and C. margarita. C. ovata is nearly as large as C. salebrosa yet matures quickly, like C. margarita, 
while $C$. mexicana, which matures at the same rate as $C$. salebrosa, is nevertheless smaller. 

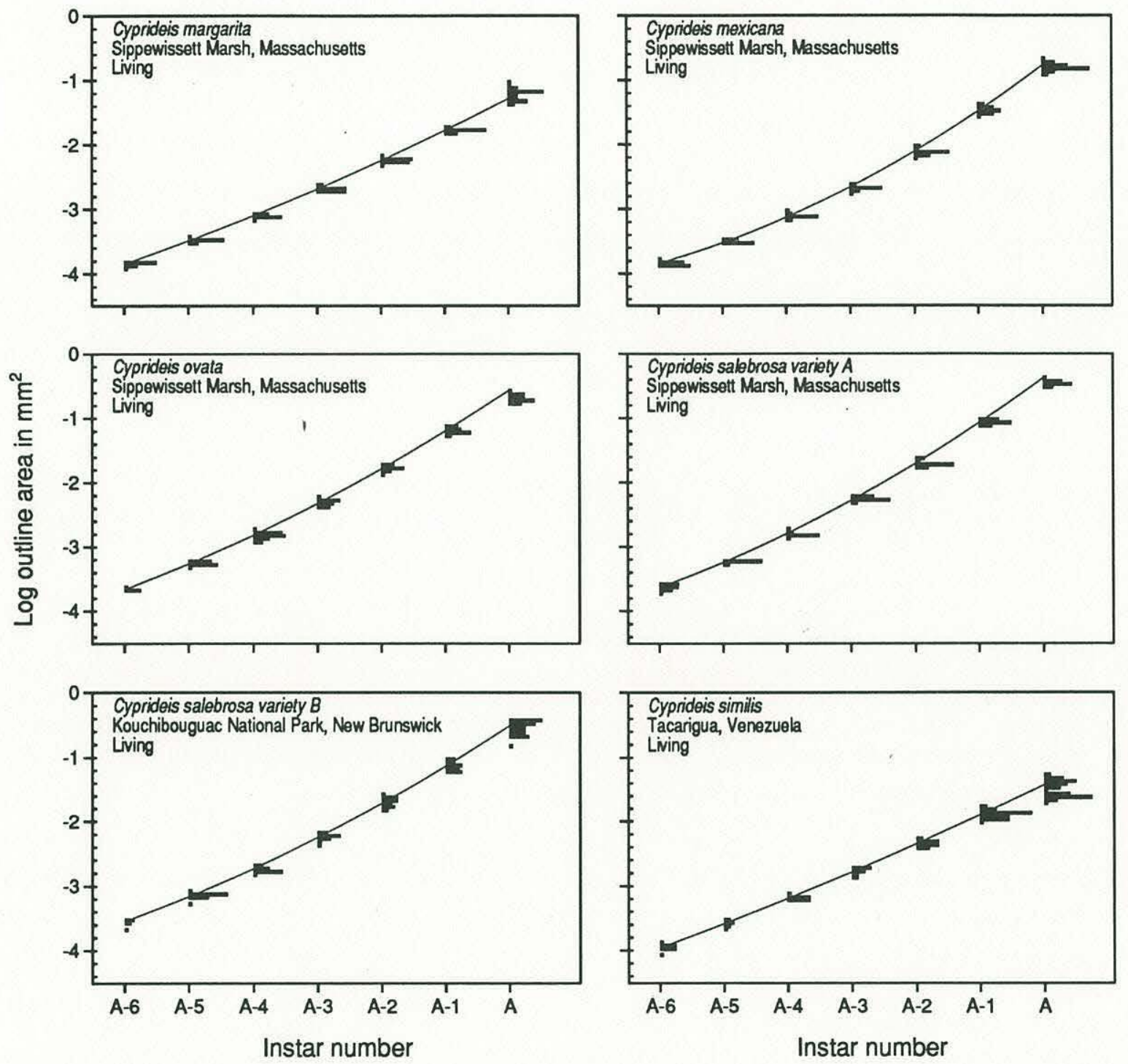

Figure 1.25: The growth of Cyprideis species. The logarithm of outline area is plotted as a function of instar number, ending at the terminal adult stage. Bimodality in the adult stage is due to sexual dimorphism, most pronounced in $C$. similis. The curved line shown is the quadratic regression of $\log$ size on instar number $S_{i}=e^{a+b i+c i^{2}}$, where $S_{i}$ is the size of the $i$ th instar. Regressions were calculated for the six preadult stages shown. Adults do not generally fit this simple model. 


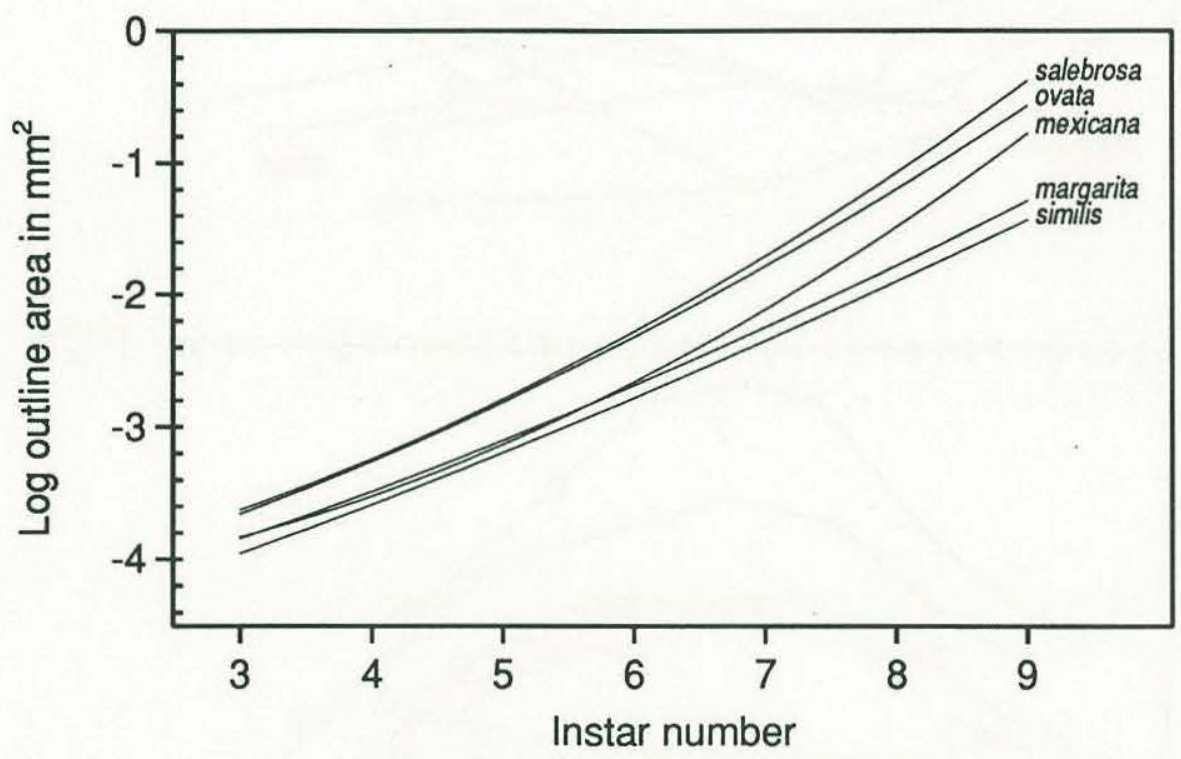

Figure 1.26: Curves from figure 1.25 superimposed. Those of $C$. salebrosa var. A and C. salebrosa var. B are essentially the same.

Table 1.15: Statistical characteristics of the curves shown in figure 1.25. The equation fitted is $\log S(i)=a+b i+c i^{2}$ where $i$ is the instar number and $S$ is the area of the shell's outline in $\mathrm{mm}^{2}$. "Linear $F$ " is the lack-of-fit statistic for a line $(c=0)$. "Quadratic $F$ " is the same statistic for the curve (see Draper and Smith 1982 §1.5). Adult specimens were not included in the regression statistics. In all cases the linear $F$-statistic for lack-of-fit is large, while the quadratic $F$-statistic is much smaller, indicating that the quadratic regression explains the data better than do the linear terms alone.

\begin{tabular}{lcccrc} 
taxon & $a$ & $b$ & $c$ & Linear $F$ & Quadratic $F$ \\
\hline C. margarita & -4.74993 & .26017 & .01388 & 37.225 & .554 \\
C. mexicana & -4.28589 & .03094 & .03991 & 180.415 & 5.629 \\
C. ovata & -4.57057 & .23362 & .02350 & 35.774 & 1.181 \\
C. salebrosa var. A & -4.41434 & .16896 & .03110 & 139.280 & 5.323 \\
C. salebrosa var. B & -4.39884 & .21103 & .02463 & 23.104 & 1.474 \\
C. similis & -4.95406 & .30196 & .00997 & 7.188 & .357
\end{tabular}




\section{Ontogeny of Cyprideis}

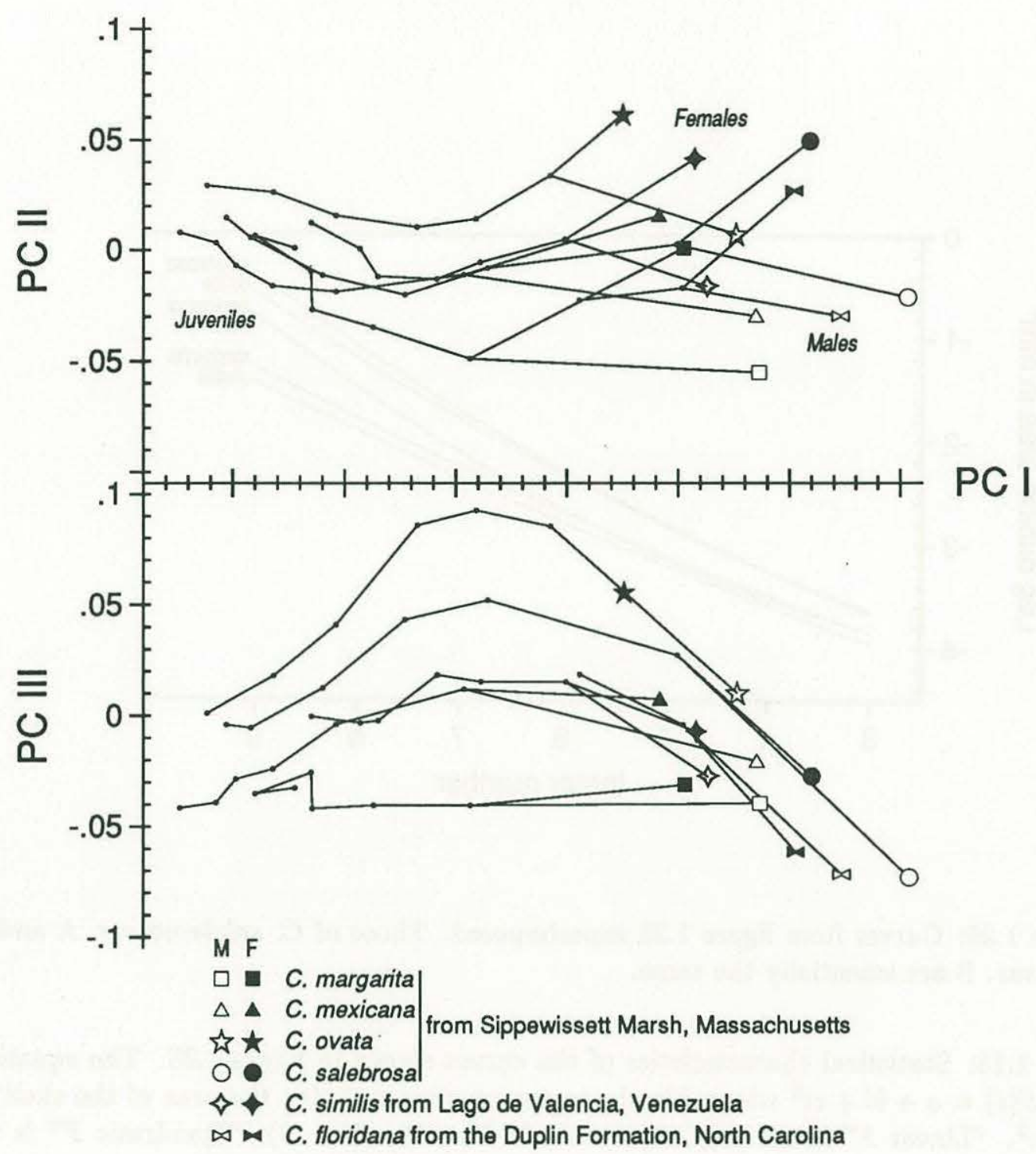

Figure 1.27: Shape variation among species of Cyprideis. Axes are the first three principal components of shape variation computed from the average shape of each instar of the species C. margarita, C. mexicana, C. ovata, C. salebrosa, and C. similis. C. floridana is shown as well, but was not used to compute the axes. Adult female specimens are marked with filled symbols, adult males are marked with open symbols. The meaning of such principal components is inferred from the distribution on the graph of characteristics that were not explicitly included in the analysis: species identification, gender, and ontogenetic stage of the specimens. The first principal component (PC I) is highly correlated with ontogeny, the second with gender. The third describes non-developmental differences among species. 


\section{Cyprideis from Sippewissett Marsh, Massachusetts \\ Average linkage cluster analysis}

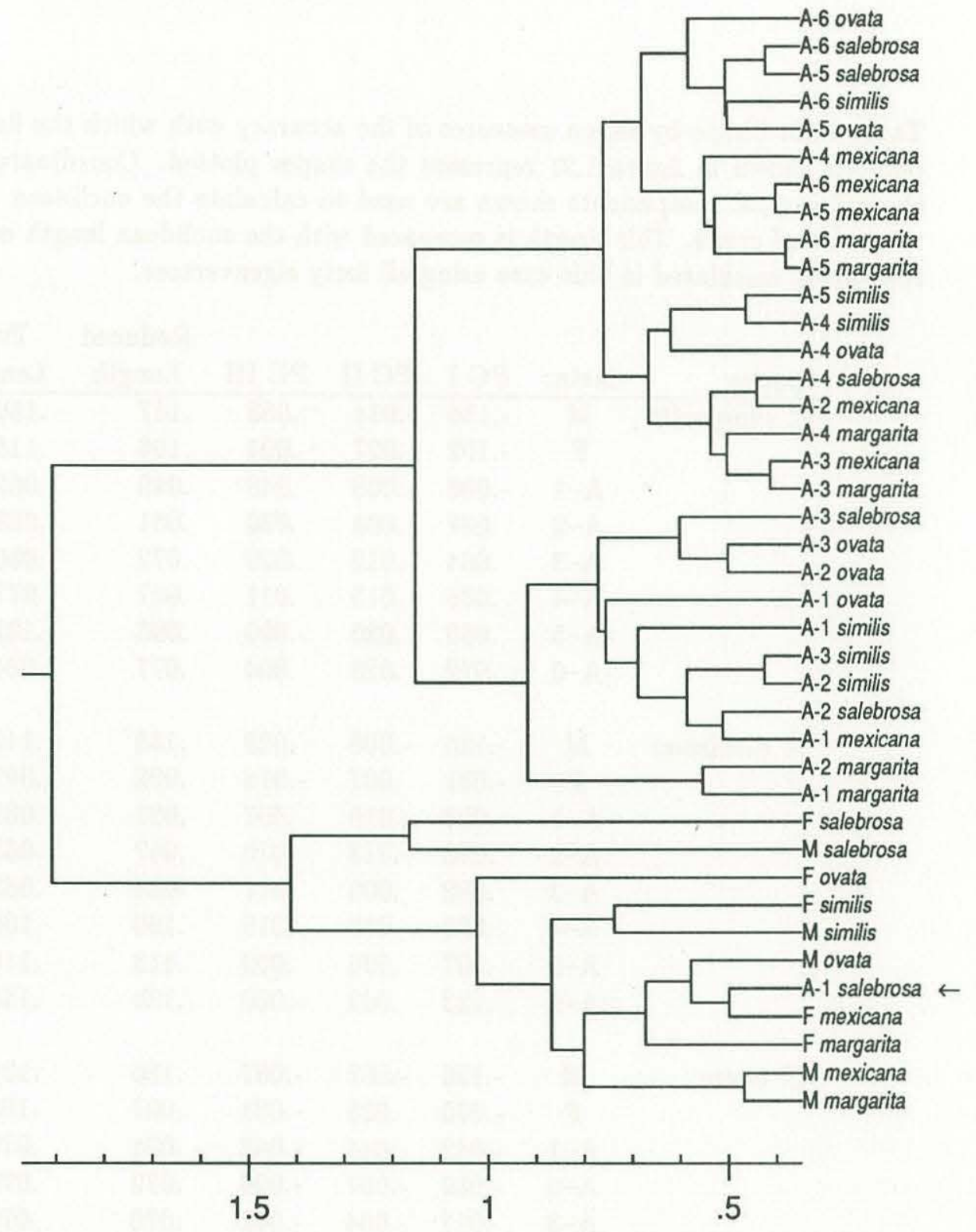

Figure 1.28: UPGMA cluster analysis of the instars of C. margarita, C. mexicana, C. ovata, C. salebrosa, and C. similis portrayed in figure 1.27. The distance measure is the Euclidean distance among shapes described by the $\phi *$ function. Note that the A-1 instar of C. salebrosa is clustered with adults of other species. 
Table 1.16: Shape-by-shape measures of the accuracy with which the first three principal components shown in figure 1.27 represent the shapes plotted. Coordinates of each shape on the three principal components shown are used to calculate the euclidean length of each point in the reduced space. This length is compared with the euclidean length of the same shape in the full space, calculated in this case using all forty eigenvectors.

\begin{tabular}{|c|c|c|c|c|c|c|c|}
\hline species & instar & PC I & PC II & PC III & $\begin{array}{l}\text { Reduced } \\
\text { Length }\end{array}$ & $\begin{array}{c}\text { Full } \\
\text { Length }\end{array}$ & $\begin{array}{c}\text { Accuracy } \\
(\%)\end{array}$ \\
\hline \multirow[t]{8}{*}{ C. margarita } & $\mathrm{M}$ & -.136 & -.014 & .053 & .147 & .150 & 97.7 \\
\hline & $\mathrm{F}$ & -.102 & .027 & .004 & .106 & .115 & 92.2 \\
\hline & $A-1$ & -.006 & -.008 & .048 & .049 & .062 & 79.3 \\
\hline & A-2 & .037 & .004 & .036 & .051 & .063 & 82.2 \\
\hline & $A-3$ & .064 & .012 & .029 & .072 & .080 & 89.5 \\
\hline & $A-4$ & .065 & .013 & .011 & .067 & .077 & 87.0 \\
\hline & $A-5$ & .089 & .035 & -.000 & .096 & .101 & 95.8 \\
\hline & $A-6$ & .072 & .028 & .004 & .077 & .084 & 92.5 \\
\hline \multirow[t]{8}{*}{ C. mexicana } & M & -.135 & -.008 & .028 & .138 & .142 & 97.3 \\
\hline & $\mathrm{F}$ & -.091 & .007 & -.014 & .092 & .097 & 95.1 \\
\hline & A-1 & -.003 & -.019 & .007 & .021 & .037 & 58.6 \\
\hline & $A-2$ & .053 & -.013 & .016 & .057 & .063 & 91.4 \\
\hline & $A-3$ & .082 & .006 & .017 & .084 & .088 & 94.7 \\
\hline & $A-4$ & .098 & .018 & .010 & .100 & .106 & 94.3 \\
\hline & $A-5$ & .107 & .036 & .003 & .113 & .116 & 97.8 \\
\hline & $A-6$ & .123 & .042 & -.000 & .130 & .135 & 96.9 \\
\hline \multirow[t]{8}{*}{ C. ovata } & M & -.126 & -.002 & -.007 & .126 & .131 & 96.5 \\
\hline & $\mathrm{F}$ & -.075 & .005 & -.061 & .097 & .108 & 89.6 \\
\hline & $A-1$ & -.042 & -.044 & -.042 & .074 & .079 & 93.9 \\
\hline & $A-2$ & -.009 & -.067 & -.026 & .072 & .079 & 92.2 \\
\hline & $A-3$ & .017 & -.064 & -.021 & .070 & .079 & 88.8 \\
\hline & $A-4$ & .053 & -.021 & -.019 & .061 & .071 & 85.4 \\
\hline & $A-5$ & .081 & .007 & -.025 & .085 & .095 & 89.9 \\
\hline & A-6 & .111 & .024 & -.025 & .117 & .123 & 94.7 \\
\hline
\end{tabular}


Table 1.17: Shape-by-shape measures of the accuracy with which the first three principal components shown in figure 1.27 represent the shapes plotted on them.

\begin{tabular}{|c|c|c|c|c|c|c|c|}
\hline species & instar & PC I & PC II & PC III & $\begin{array}{c}\text { Reduced } \\
\text { Length }\end{array}$ & $\begin{array}{c}\text { Full } \\
\text { Length }\end{array}$ & $\begin{array}{c}\text { Accuracy } \\
(\%)\end{array}$ \\
\hline \multirow[t]{8}{*}{ C. salebrosa } & M & -.203 & .044 & .029 & .210 & .229 & 91.7 \\
\hline & $\mathrm{F}$ & -.159 & .066 & -.038 & .177 & .184 & 96.2 \\
\hline & $A-1$ & -.099 & -.021 & -.006 & .101 & .108 & 93.9 \\
\hline & $A-2$ & -.014 & -.051 & -.000 & .053 & .061 & 87.3 \\
\hline & A-3 & .022 & -.054 & .010 & .060 & .069 & 87.5 \\
\hline & $A-4$ & .059 & -.020 & .007 & .063 & .071 & 89.6 \\
\hline & $A-5$ & .091 & .009 & -.004 & .092 & .100 & 92.3 \\
\hline & $A-6$ & .102 & .016 & -.012 & .104 & .111 & 94.2 \\
\hline \multirow[t]{8}{*}{ C. similis } & M & -.113 & .009 & .018 & .114 & .132 & 87.0 \\
\hline & $\mathrm{F}$ & -.107 & .042 & -.034 & .120 & .130 & 92.7 \\
\hline & $A-1$ & -.049 & -.008 & -.006 & .050 & .065 & 77.5 \\
\hline & $A-2$ & -.011 & -.017 & .002 & .021 & .042 & 49.8 \\
\hline & $A-3$ & .008 & -.027 & .008 & .029 & .046 & 63.2 \\
\hline & $A-4$ & .035 & -.008 & .010 & .037 & .052 & 71.9 \\
\hline & $A-5$ & .043 & .003 & -.000 & .043 & .058 & 73.4 \\
\hline & $A-6$ & .064 & .011 & -.010 & .066 & .076 & 86.8 \\
\hline \multirow[t]{4}{*}{ C. floridana } & M & .173 & -.029 & -.071 & .189 & .195 & 96.8 \\
\hline & $\mathrm{F}$ & .152 & .026 & -.061 & .166 & .187 & 89.1 \\
\hline & A-1 & .102 & -.017 & -.004 & .103 & .111 & 93.1 \\
\hline & $A-2$ & .055 & -.022 & .018 & .062 & .078 & 80.5 \\
\hline
\end{tabular}




\subsection{Conclusion}

Paleontologists have invested significant effort in detecting and classifying occurrences of heterochrony in the fossil record. These studies are of value only in the context of a theory that links the occurrence of heterochrony to elements of the organisms' ecology. Such a theory has been presented, i.e that heterochrony is caused by life-history evolution. If the fossil record contains identifiable examples of life-history evolution, paleontologists can use the results of modern population biology to understand the workings of anagenesis and cladogenesis over long periods of time.

A proper test of the theory linking age at maturity with morphological changes observable in fossils requires clarification of its underlying assumptions. In particular, shape is assumed to be dependent on chronological age, but size is not. If size is used as a proxy for chronological age, heterochrony cannot be cleanly distinguished from changes in size, and ambiguity results. Furthermore, maturity must be recognizable in the taxa that are studied, and sources of variation both within and among species must be understood.

Here four sympatric species of the ostracode genus Cyprideis were studied to determine the seasonal and geographic variation in size and shape, the record of change through geological time, and the dynamics of population growth. Figure 1.29 shows the expected correlations among the rates of growth, development, and maturation as well as the correlations observed in this study. In general, we expect accelerated maturity to yield generalized morphology and small size. Similarly, delayed maturity leads to specialized morphology and large size. Two of the four species studied here fit the expected pattern, Cyprideis margarita and C. salebrosa. The other two do not. Although it produces only one generation per year, C. mexicana has a pattern of morphological development like that of $C$. margarita. Similarly, C. ovata produces two generations per year like C. margarita but it is large, like C. salebrosa. The other two characteristics, morphological development in C. ovata and size of C. mexicana, change during ontogeny from one pattern to the other.

In higher taxa, heterochrony is understood by paleontologists as a mechanism that affects the degree of specialization, i.e. the precision with which morphology fits particular environmental circumstances. Paedomorphosis is, in effect, an escape from specialization, while peramorphosis is an increase in specialization. At the scale of populations and species, the significance of het- 
erochrony is still not well understood. Where it is caused by life-history evolution, occurrences of heterochrony can be interpreted using modern ecological theory. If time determines neither size nor shape and no independent estimate of age at maturity is available, heterochrony in fossils cannot be interpreted as life-history evolution. The findings of this research indicate at least that heterochrony is not always the result of life-history evolution.

Paleontologists may apply modern ecological theory to fossils, but only if they can obtain all of the necessary information about the timing of growth and maturation. For many taxa the necessary information can be obtained only by studying living representatives. 


\section{Summary of Results}
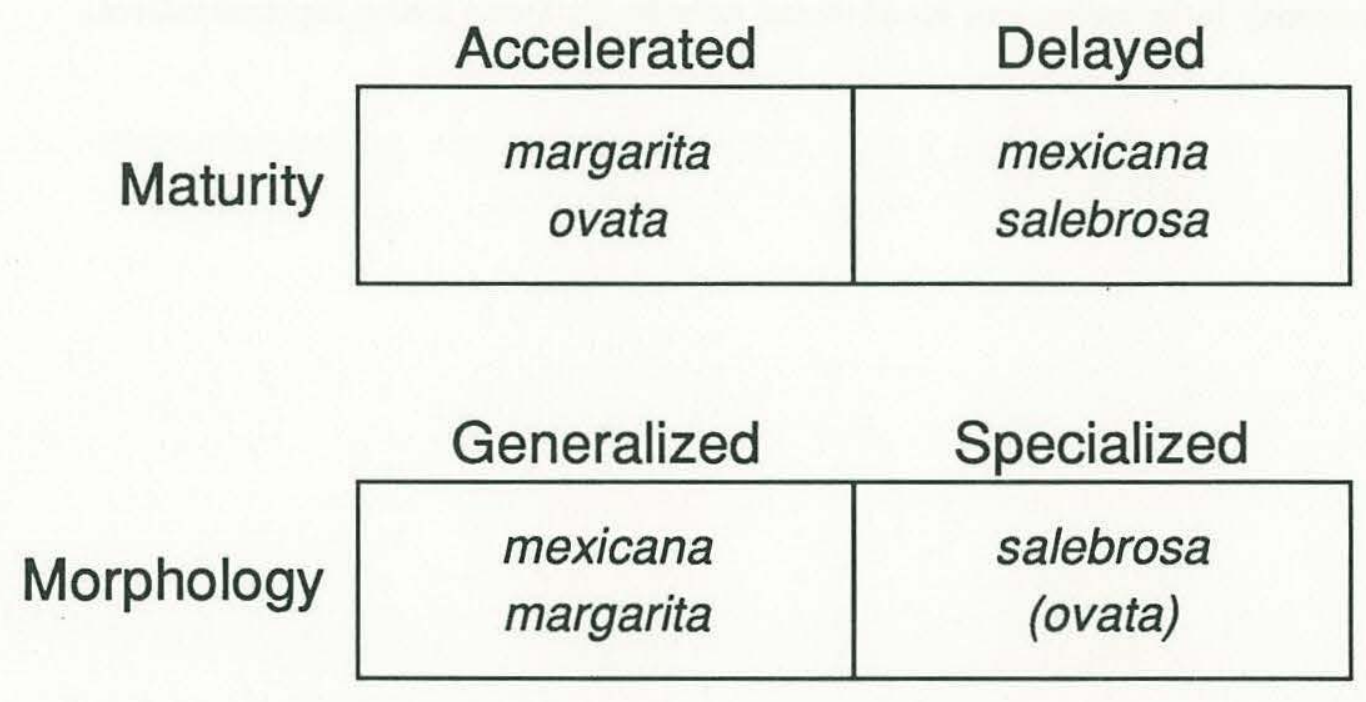

\begin{tabular}{|c|c|c|}
\hline & Small & Large \\
\hline Size & margarita & $\begin{array}{c}\text { salebrosa } \\
\text { ovata } \\
\text { (mexicana) }\end{array}$ \\
\hline
\end{tabular}

Figure 1.29: Summary of interspecific variation of morphology and ecology. Under assumptions commonly used by paleontologists, accelerated maturity leads to generalized morphology and small size, while delayed maturity leads to specialized morphology and large size. Two species studied here fit the expected pattern (Cyprideis margarita and C. salebrosa), while the other two do not. Parentheses indicate patterns that change from one category to the other during ontogeny. 


\subsection{Literature cited}

Alberch, P., S.J. Gould, G.F. Oster, and D.B. Wake. 1979. Size and shape in ontogeny and phylogeny. Paleobiology 5(3):296-317.

Bodergat, A.M. 1983. Les ostracodes, témoins de leur environment: Approche chimique et écologie en milieu lagunaire et océanique. Docum. Lab. Geol. Lyon, 88, 246p.

Bold, W.A. VAN DEN, 1963. Upper Miocene and Pliocene Ostracoda of Trinidad. Micropaleontology $9(4): 361-424$.

Bold, W.A. VAN DEN, 1976. Distribution of species of the tribe Cyprideidini (Ostracoda, Cytherideidae) in the Neogene of the Caribbean. Micropaleontology 22(1):1-43.

Bookstein, F.L., B. Chernoff, R.L. Elder, J.M. Humphries, G.R. Smith, And R.E. Strauss, 1985. Morphometrics in Evolutionary Biology. Special Publication 15, Academy of Natural Sciences of Philadelphia. 277p.

Cronin, T.M., L.M. Bybell, R.Z. Poore, B.W. Blackwelder, J.C. Liddicoat, and J.E. HAZEL. 1984. Age and correlation of emerged Pliocene and Pleistocene deposits, U.S. Atlantic coastal plain. Palaeogeography, Palaeoclimatology, Palaeoecology 47:21-51.

Dodson, S.I. 1974 Adaptive change in plankton morphology in response to size-selective predation: A new hypothesis of cyclomorphism. Limnology and Oceanography 19(5):721729 .

Draper, N.R., And H. Smith. 1981. Applied Regression Analysis, Second edition. Wiley \& Sons Inc., New York. 709p.

Edwards, R.A. 1944 Ostracoda from the Duplin Marl (Upper Miocene) of North Carolina. Journal of Paleontology 18(6):505-528.

Garbett, E.C., and R.F. Maddocks, 1979 Zoogeography of Holocene Cytheracean ostracodes in the bays of Texas. Journal of Paleontology 53(4):841-919.

Gould, S.J. 1977. Ontogeny and Phylogeny. Belknap Press, Cambridge, MA. 501p.

HeIP, C. 1976A. The spatial pattern of Cyprideis torosa (Jones, 1850) (Crustacea, Ostracoda). Journal of the Marine Biological Association of the United Kingdom 56:179-189.

HeIP, C. 1976в. The life-cycle of Cyprideis torosa (Crustacea, Ostracoda). Oecologia 24:229245.

Herman, P.M.J., And C. Heip. 1982. Growth and respiration of Cyprideis torosa Jones 1850 (Crustacea, Ostracoda). Oecologia 54:300-303.

Herman, P.M.J., C. Heip, and G. Vranken. 1983. The production of Cyprideis torosa Jones 1850 (Crustacea, Ostracoda). Oecologia 58:326-331. 
Horne, D.J. 1980. Life-cycles of podocopid Ostracoda - A review (with particular reference to marine and brackish-water species). pp. 581- 590. in R.F. Maddocks (ed.), Applications of Ostracoda. University of Houston Geosciences.

Jones, D.S. 1986. Sclerochronology and the size versus time problem in heterochronic anslysis. Geol. Soc. Amer. Abstracts with Programs 18(6):649

Kesling, R.V. 1951. The morphology of ostracod molt stages. Illinois Biological Monographs vol. 21 , nos. $1-3.324$ p.

Kontrovitz, M., And R. Bitter, 1976. Holocene ostracoda from the Shrewsbury River, New Jersey. Micropaleontology 22(1):72-82.

LAtifa, G.A. 1987. Effect of temperature on the development of embryonic and postembryonic stages of Heterocypris incongruens (Ramdohr, 1808) (Ostracoda). Crustaceana 52(1):95-100.

Lister, K.H. 1975. Quaternary freshwater ostracoda from the Great Salt Lake basin, Utah. University of Kansas Paleontological Contributions Paper 78. 34p.

Lohmann, G.P. 1983 Eigenshape analysis of microfossils: A general morphometric procedure for describing changes in shape. Mathematical Geology 15:659-672.

Lohmann, G.P. And P.N. Schweitzer, in press. On eigenshape analysis. Proceedings of the workshop on Morphometrics in Systematic Biology, University of Michigan, Ann Arbor.

MCKINNEY, M.L. 1986. Ecological causation of heterochrony: a test and implications for evolutionary theory. Paleobiology 12(3):282-289.

McNamara, K.J. 1986. A guide to the nomenclature of heterochrony. Journal of Paleontology $60(1): 4-13$.

Martens, K. 1985. Effects of temperature and salinity on postembryonic growth in Mytilocypris henricae (Chapman) (Crustacea, Ostracoda). Journal of Crustacean Biology 5(2):258272.

Reyment, R.A. 1983. Phenotypic evolution in microfossils. Pp. 209-254. In: Kecner, M.K., B. Wallace, and C.T. Prance, eds. Evolutionary Biology, vol. 16. Plenum; New York.

Sand berg, P.A., 1964. The ostracod genus Cyprideis in the Americas. Stockholm Contributions in Geology 12:1-176.

Sandberg, P.A., and P.L. Plusquellec, 1974. Notes on the anatomy and passive dispersal of Cyprideis (Cytheracea, Ostracoda). Geoscience and Man 6:1-26

Sanger, D.B., and J.W. Teeter, 1982. The distribution of living and fossil Ostracoda and their use in the interpretation of the post-Pleistocene history of Little Lake, San Salvador Island, Bahamas. CCFL Field Station Occasional Papers 1982 number 1. 
Schweitzer, P.N., R.L. Kaesler, and G.P. Lohmann. 1986. Ontogeny and heterochrony in the ostracode Cavellina Coryell from Lower Permian rocks in Kansas. Paleobiology 12(3):290-301.

Stearns, S.C. 1976. Life-history tactics: A review of the ideas. Quarterly Review of Biology $51(1): 3-47$.

Stearns, S.C. 1977. The evolution of life-history traits: A critique of the theory and a review of the data. Annual Reviews of Ecology and Systematics 8:145-171.

Stearns, S.C. 1981. The role of development in the evolution of life- histories. pp. 237-258. In: J.T. Bonner (ed.), Evolution and Development. Springer-Verlag; Berlin.

Stearns, S.C. 1982A. The emergence of evolutionary and community ecology as experimental sciences. Perspectives in Biology and Medicine 25(4):621-648.

Stearns, S.C. 1983. The impact of size and phylogeny on patterns of covariation in the life-history traits of mammals. Oikos 41(2):173-187.

Stearns, S.C. 1984. The effects of size and phylogeny on patterns of covariation in the life-history traits of lizards and snakes. American Naturalist 123:56-72.

Stout, L.N. 1981. An unusual occurrence of the brackish-water ostracode Cyprideis salebrosa in central Missouri. Journal of Paleontology 55(4):898-900.

Tressler, W.L., And E.M. Sмith. 1948. An ecological study of seasonal distribution of Ostracoda, Solomons Island, Maryland region. Publications, Chesapeake Biological Laboratory 71:1-61.

Theisen, B.F. 1966. The life history of seven species of ostracodes from a Danish brackish water locality. Medd. Danm. Fisk. og Havunders 4:215-270.

Vesper, B. 1972. Zur Morphologie und Okologie von Cyprideis torosa (Jones, 1850) (Crustacea, Ostracoda) unter besonderer Berucksichtigung seiner Biometrie. Mitt. Hamburg Zool. Mus. Inst. 68:21-77. 


\subsection{Appendix A. Sample localities}

Sources of measured specimens are given in tables 1.1 and 1.2. Sample localities in those tables are specified with a key word, referring to items in bold face in the list that follows.

Norfolk Formation, Late Pleistocene, Virginia. Sample 156, locality 16 of Cronin (1979). Material loaned by T.M. Cronin.

78TC65A Princess-Anne terrace-formation, Late Pleistocene, South Carolina. Locality 11 of Cronin (1979). Material loaned by T.M. Cronin.

78TC42 Silver Bluff terrace-formation, Late Pleistocene, South Carolina. Locality 2 of Cronin (1979). Material loaned by T.M. Cronin.

Waccamaw Formation, Early Pleistocene, North Carolina. Locality 40 in figure 2 of Cronin et al. (1984). Material loaned by T.M. Cronin.

Duplin Formation, Late Pliocene, North Carolina. Locality 65 in figure 3 of Cronin et al. (1984), sample LB-173 of Cronin (1981). Three subsamples (47.5, 48.5, and 49.5) represent different samples from the same outcrop. Material loaned by T.M. Cronin.

Caloosahatchee Formation, Early Pleistocene, Florida. The slide was marked "Below Bee Branch Member". Material loaned by T.M. Cronin.

81TC77,78,79,80 Upper part of Flanner Beach Formation, Late Middle Pleistocene, Dare County, North Carolina. Material loaned by T.M. Cronin.

82TC174,176,178,179,181 Lower part of Flanner Beach Formation, Middle Pleistocene, Dare County, North Carolina. Material loaned by T.M. Cronin.

Langley Bluffs, Late Pleistocene, Virginia. Material loaned by T.M. Cronin.

Cul de Sac 51, 772' borehole in Haiti (van den Bold 1976).

Lago de Valencia (Isla Tacarigua), Venezuela (van den Bold 1976)

Beaufort, North Carolina. salt marsh near roadway sampled September 29, 1987 by E.A. Canuel.

Evangeline Beach, Nova Scotia, sampled by the author near the low tide line August 14, 1985 and August 22, 1986.

Scott's Bay, Nova Scotia. Picnic grounds off Wharf Road. Sampled by the author from a small tidal creek bounded by cobble beaches August 16, 1985 and August 21, 1986.

Assateague Island, Maryland. Sampled by the author from a pond in the Old Ferry Landing area July 5, 1986.

San Salvador, Bahamas. Sample taken from Reckley Hill Pond by J.W. Teeter. 
Barnstable Harbor, Massachusetts. Sampled biweekly during summer 1984 by N.P. Gurwick and the author.

Kouchibouguac National Park, New Brunswick. Pond in salt marsh on mainland shore behind barrier island at Kelly's Beach sampled by the author August 1987.

Sippewissett Marsh, Massachusetts. Sampled by the author on numerous occasions (see text). 


\subsection{Appendix B. Counts of specimens sampled from Sippewissett Marsh}

Details of the methods of sampling living populations are given in the text. This section lists raw data obtained. For each species a sample list is given with the following elements:

1. The number of specimens counted in the specified instar or sex, designated by the letters $\mathrm{M}, \mathrm{F}, \mathrm{A}-1, \mathrm{~A}-2, \mathrm{~A}-3, \mathrm{~A}-4, \mathrm{~A}-5, \mathrm{~A}-6$.

2. Total number of specimens counted from the given sample.

3. Date the sample was taken. All were taken during 1988.

4. Day number in the year.

5. Surface area sampled in $\mathrm{mm}^{2}$.

6. Description of the sample. Specimen cups are $6 \mathrm{~cm}$ in diameter, syringes are $2 \mathrm{~cm}$ in diameter. Missing fine fractions are noted also. 
Ostracode population counts on Sippewissett Marsh Mudflat, 1988

\begin{tabular}{|c|c|c|c|c|c|c|c|c|c|c|c|c|c|}
\hline \multicolumn{2}{|c|}{ Cyprideis } & \multicolumn{2}{|c|}{ margarita } & \multirow[b]{2}{*}{$A-3$} & \multirow[b]{2}{*}{$A-4$} & \multirow[b]{2}{*}{$A-5$} & \multirow[b]{2}{*}{$A-6$} & \multirow[b]{2}{*}{ total } & Sample & \multirow{2}{*}{$\stackrel{\#}{\# \text { Day }}$} & \multirow{2}{*}{$\begin{array}{c}\text { Surface } \\
\text { Area }\end{array}$} & \multirow[b]{2}{*}{ Description } & \\
\hline M & $\mathrm{F}$ & $A-1$ & $A-2$ & & & & & & Date & & & & \\
\hline 5 & 13 & 11 & 21 & 18 & 14 & 3 & 1 & 86 & $03 / 03$ & 63 & 27.33971 & One sp. cup & \\
\hline 2 & 11 & 21 & 48 & 28 & 24 & 5 & 0 & 139 & $03 / 09$ & 69 & 27.33971 & One sp. cup & \\
\hline 8 & 9 & 12 & 34 & 34 & 25 & 12 & 1 & 135 & $03 / 17$ & 77 & 27.33971 & One sp. cup & \\
\hline 3 & 4 & 6 & 16 & 4 & 3 & 0 & 0 & 36 & $03 / 26$ & 86 & 10.39082 & Three syr. (1) & \\
\hline 0 & 2 & 3 & 3 & 4 & 1 & 0 & 0 & 13 & $03 / 26$ & 86 & 27.33971 & One sp. cup (2) & \\
\hline 3 & 11 & 16 & 37 & 28 & 11 & 3 & 2 & 111 & $04 / 02$ & 93 & 13.85443 & Four syr. & \\
\hline 2 & 6 & 16 & 25 & 21 & 14 & 2 & 1 & 87 & $04 / 12$ & 103 & 13.85443 & Four syr. (1) & \\
\hline 0 & 4 & 24 & 27 & 19 & 7 & 1 & 1 & 83 & $04 / 12$ & 103 & 13.85443 & Four syr. (2) & \\
\hline 2 & 9 & 19 & 20 & 13 & 4 & 0 & 0 & 67 & $04 / 25$ & 116 & 13.85443 & Four syr. (1) & \\
\hline 2 & 6 & 19 & 29 & 15 & 9 & 1 & 0 & 81 & $04 / 25$ & 116 & 13.85443 & Four syr. (2) & \\
\hline 4 & 13 & 43 & 13 & 9 & 4 & 0 & 3 & 89 & $05 / 04$ & 125 & 13.85443 & Four syr. (1) & \\
\hline 10 & 4 & 27 & 29 & 4 & 2 & 1 & 3 & 80 & $05 / 04$ & 125 & 13.85443 & Four syr. (2) & \\
\hline 13 & 16 & 36 & 18 & 14 & 3 & 0 & 6 & 106 & $05 / 12$ & 133 & 13.85443 & Four syr. (1) & \\
\hline 13 & 9 & 27 & 26 & 13 & 1 & 1 & 4 & 94 & $05 / 12$ & 133 & 13.85443 & Four syr. (2) & \\
\hline 13 & 21 & 48 & 8 & 1 & 1 & 2 & 14 & 108 & $05 / 23$ & 144 & 13.85443 & Four syr. (1) & \\
\hline 11 & 11 & 30 & 12 & 1 & 0 & 1 & 4 & 70 & $05 / 23$ & 144 & 13.85443 & Four syr. (2) & \\
\hline 33 & 52 & 27 & 6 & 1 & 3 & 3 & 14 & 139 & $05 / 31$ & 152 & 13.85443 & Four syr. (1) & \\
\hline 18 & 49 & 39 & 7 & 2 & 5 & 10 & 13 & 143 & $05 / 31$ & 152 & 13.85443 & Four syr. (2) & \\
\hline 19 & 36 & 19 & 1 & 0 & 4 & 13 & 21 & 113 & $06 / 06$ & 158 & 13.85443 & Four syr. (1) & \\
\hline 13 & 25 & 18 & 2 & 1 & 8 & 11 & 19 & 97 & $06 / 06$ & 158 & 13.85443 & Four syr. (2) & \\
\hline 11 & 23 & 7 & 1 & 6 & 8 & 17 & 56 & 129 & $06 / 13$ & 165 & 13.85443 & Four syr. (1) & \\
\hline 13 & 23 & 7 & 0 & 1 & 18 & 26 & 69 & 157 & $06 / 13$ & 165 & 13.85443 & Four syr. (2) & \\
\hline 18 & 29 & 2 & 5 & 8 & 27 & 54 & 107 & 250 & $06 / 22$ & 174 & 13.85443 & Four syr. (1) & \\
\hline 23 & 31 & 1 & 12 & 15 & 18 & 53 & 85 & 238 & $06 / 22$ & 174 & 13.85443 & Four syr. (2) & \\
\hline 13 & 22 & 10 & 13 & - & - & - & - & 58 & $06 / 29$ & 181 & 13.85443 & Four syr. >250um & (1) \\
\hline 26 & 31 & 5 & 11 & - & - & - & - & 73 & $06 / 29$ & 181 & 13.85443 & Four syr. $>250 u m$ & (2) \\
\hline 16 & 27 & 19 & 37 & 5 & 3 & 0 & 4 & 111 & $07 / 09$ & 191 & 13.85443 & Four syr. (1) & \\
\hline 22 & 29 & 22 & 54 & 95 & 154 & 195 & 154 & 725 & $07 / 09$ & 191 & 13.85443 & Four syr. (2) & \\
\hline 30 & 45 & 50 & 109 & 166 & 135 & 41 & 41 & 617 & $07 / 22$ & 204 & 13.85443 & Four syr. (1) & \\
\hline 29 & 27 & 35 & 87 & 113 & 124 & 59 & 54 & 528 & $07 / 22$ & 204 & 13.85443 & Four syr. (2) & \\
\hline 7 & 7 & 5 & 23 & - & - & - & - & 42 & $07 / 22$ & 204 & 6.92722 & Two syr. >250um & (3) \\
\hline 14 & 23 & 54 & 115 & - & - & - & - & 206 & $07 / 30$ & 212 & 13.85443 & Four syr. $>250 u m$ & (1) \\
\hline 10 & 31 & 63 & 100 & - & - & - & - & 204 & $07 / 30$ & 212 & 13.85443 & Four syr. $>250 u m$ & (2) \\
\hline 22 & 34 & 74 & 84 & 68 & 44 & 69 & 59 & 454 & $08 / 10$ & 223 & 13.85443 & Four syr. (1) & \\
\hline 9 & 29 & 72 & 83 & 79 & 78 & 55 & 50 & 455 & $08 / 10$ & 223 & 13.85443 & Four syr. (2) & \\
\hline 5 & 16 & 27 & 35 & 50 & 88 & 88 & 75 & 384 & $08 / 20$ & 233 & 13.85443 & Four syr. (1) & \\
\hline 5 & 11 & 17 & 28 & 25 & 40 & 71 & 35 & 232 & $08 / 20$ & 233 & 13.85443 & Four syr. (2) & \\
\hline 2 & 3 & 20 & 17 & 35 & 64 & 59 & 17 & 217 & $08 / 31$ & 244 & 13.85443 & Four syr. (1) & \\
\hline 4 & 17 & 22 & 9 & 30 & 68 & 52 & 26 & 228 & $08 / 31$ & 244 & 13.85443 & Four syr. (2) & \\
\hline 0 & 4 & 7 & 7 & 32 & 27 & 19 & 13 & 109 & $09 / 14$ & 258 & 13.85443 & Four syr. (1) & \\
\hline 3 & 8 & 6 & 17 & 23 & 24 & 11 & 5 & 97 & $09 / 14$ & 258 & 13.85443 & Four syr. (2) & \\
\hline 4 & 4 & 12 & 19 & 41 & 10 & 6 & 9 & 105 & $09 / 28$ & 272 & 13.85443 & Four syr. (1) & \\
\hline 0 & 1 & 8 & 19 & 38 & 11 & 4 & 1 & 82 & $09 / 28$ & 272 & 13.85443 & Four syr. (2) & \\
\hline 1 & 4 & 3 & 22 & 23 & 8 & 3 & 3 & 67 & $10 / 13$ & 287 & 13.85443 & Eour syr. (1) & \\
\hline 1 & 2 & 8 & 17 & 19 & 6 & 2 & 6 & 61 & $10 / 13$ & 287 & 13.85443 & Four syr. (2) & \\
\hline 0 & 2 & 1 & 8 & 18 & 9 & 4 & 1 & 43 & $10 / 26$ & 300 & 13.85443 & Four syr. (1) & \\
\hline 1 & 6 & 5 & 14 & 24 & 5 & 5 & 3 & 63 & $10 / 26$ & 300 & 13.85443 & Four syr. (2) & \\
\hline 463 & 800 & 1023 & 1328 & 1144 & 1112 & 962 & 980 & 7812 & & & & & \\
\hline
\end{tabular}




\begin{tabular}{|c|c|c|c|c|c|c|c|c|c|c|c|c|c|}
\hline \multicolumn{2}{|c|}{ Cyprideis } & \multicolumn{7}{|c|}{ mexicana } & \multirow{2}{*}{$\begin{array}{c}\text { Sample } \\
\text { Date }\end{array}$} & \multirow{2}{*}{$\begin{array}{c}\text { \# } \\
\text { Day }\end{array}$} & \multirow{2}{*}{$\begin{array}{c}\text { Surface } \\
\text { Area }\end{array}$} & \\
\hline M & $F$ & $A-1$ & $A-2$ & $A-3$ & $A-4$ & $A-5$ & $A-6$ & Total & & & & Description & \\
\hline 0 & 0 & 0 & 21 & 45 & 11 & 0 & 0 & 77 & $03 / 03$ & 63 & 27.33971 & One sp. cup & \\
\hline 0 & 0 & 1 & 34 & 75 & 10 & 0 & 0 & 120 & $03 / 09$ & 69 & 27.33971 & One sp. cup & \\
\hline 0 & 0 & 2 & 38 & 75 & 6 & 1 & 1 & 123 & $03 / 17$ & 77 & 27.33971 & One sp. cup & \\
\hline 0 & 0 & 0 & 6 & 28 & 2 & 0 & 0 & 36 & $03 / 26$ & 86 & 10.39082 & Three syr. (1) & \\
\hline 0 & 0 & 0 & 4 & 9 & 1 & 0 & 0 & 14 & $03 / 26$ & 86 & 27.33971 & One sp. cup (2) & \\
\hline 0 & 0 & 0 & 16 & 34 & 2 & 0 & 0 & 52 & $04 / 02$ & 93 & 13.85443 & Four syr. & \\
\hline 0 & 0 & 3 & 17 & 38 & 5 & 0 & 0 & 63 & $04 / 12$ & 103 & 13.85443 & Four syr. (1) & \\
\hline 0 & 0 & 15 & 36 & 87 & 7 & 0 & 0 & 145 & $04 / 12$ & 103 & 13.85443 & Four syr. (2) & \\
\hline 0 & 0 & 27 & 53 & 39 & 5 & 0 & 0 & 124 & $04 / 25$ & 116 & 13.85443 & Four syr. (1) & \\
\hline 0 & 0 & 27 & 49 & 62 & 6 & 0 & 0 & 144 & $04 / 25$ & 116 & 13.85443 & Four syr. (2) & \\
\hline 1 & 0 & 42 & 56 & 10 & 1 & 0 & 0 & 110 & $05 / 04$ & 125 & 13.85443 & Four syr. (1) & \\
\hline 1 & 0 & 37 & 79 & 15 & 1 & 0 & 0 & 133 & $05 / 04$ & 125 & 13.85443 & Four syr. (2) & \\
\hline 1 & 0 & 30 & 65 & 9 & 0 & 0 & 0 & 105 & $05 / 12$ & 133 & 13.85443 & Four syr. (1) & \\
\hline 0 & 0 & 36 & 83 & 9 & 0 & 0 & 0 & 128 & $05 / 12$ & 133 & 13.85443 & Four syr. (2) & \\
\hline 26 & 1 & 85 & 6 & 1 & 0 & 0 & 0 & 119 & $05 / 23$ & 144 & 13.85443 & Four syr. (1) & \\
\hline 11 & 0 & 58 & 7 & 1 & 0 & 0 & 0 & 77 & $05 / 23$ & 144 & 13.85443 & Four syr. (2) & \\
\hline 22 & 5 & 64 & 4 & 2 & 0 & 0 & 0 & 97 & $05 / 31$ & 152 & 13.85443 & Four syr. (1) & \\
\hline 19 & 4 & 86 & 1 & 0 & 0 & 0 & 0 & 110 & $05 / 31$ & 152 & 13.85443 & Four syr. (2) & \\
\hline 22 & 33 & 38 & 0 & 0 & 0 & 0 & 0 & 93 & $06 / 06$ & 158 & 13.85443 & Four syr. (1) & \\
\hline 22 & 34 & 35 & 1 & 0 & 0 & 0 & 0 & 92 & $06 / 06$ & 158 & 13.85443 & Four syr. (2) & \\
\hline 24 & 43 & 11 & 0 & 0 & 0 & 0 & 0 & 78 & $06 / 13$ & 165 & 13.85443 & Four syr. (1) & \\
\hline 25 & 55 & 21 & 0 & 0 & 0 & 0 & 0 & 101 & $06 / 13$ & 165 & 13.85443 & Four syr. (2) & \\
\hline 18 & 38 & 3 & 0 & 0 & 0 & 0 & 0 & 59 & $06 / 22$ & 174 & 13.85443 & Four syr. (1) & \\
\hline 14 & 21 & 8 & 0 & 0 & 0 & 0 & 0 & 43 & $06 / 22$ & 174 & 13.85443 & Four syr. (2) & \\
\hline 6 & 29 & 1 & 0 & - & - & - & - & 36 & $06 / 29$ & 181 & 13.85443 & Four syr. >250um & (1) \\
\hline 11 & 30 & 0 & 0 & - & - & - & - & 41 & $06 / 29$ & 181 & 13.85443 & Four syr. $>250 u m$ & (2) \\
\hline 8 & 37 & 3 & 0 & 0 & 0 & 0 & 0 & 48 & $07 / 09$ & 191 & 13.85443 & Four syr. (1) & \\
\hline 6 & 53 & 3 & 0 & 0 & 0 & 0 & 331 & 393 & $07 / 09$ & 191 & 13.85443 & Four syr. (2) & \\
\hline 0 & 24 & 0 & 0 & 0 & 0 & 199 & 174 & 397 & $07 / 22$ & 204 & 13.85443 & Four syr. (1) & \\
\hline 0 & 33 & 0 & 0 & 0 & 0 & 206 & 207 & 446 & $07 / 22$ & 204 & 13.85443 & Four syr. (2) & \\
\hline 0 & 8 & 0 & 0 & - & - & - & - & 8 & $07 / 22$ & 204 & 6.92722 & Two syr. >250um & (3) \\
\hline 0 & 8 & 0 & 0 & - & - & - & - & 8 & $07 / 30$ & 212 & 13.85443 & Four syr. $>250 u m$ & (1) \\
\hline 0 & 5 & 0 & 0 & - & - & - & - & 5 & $07 / 30$ & 212 & 13.85443 & Four syr. >250um & (2) \\
\hline 0 & 3 & 0 & 0 & 0 & 60 & 394 & 102 & 559 & $08 / 10$ & 223 & 13.85443 & Four syr. (1) & \\
\hline 0 & 2 & 0 & 0 & 0 & 39 & 428 & 92 & 561 & $08 / 10$ & 223 & 13.85443 & Four syr. (2) & \\
\hline 0 & 0 & 0 & 0 & 0 & 108 & 816 & 119 & 1043 & $08 / 20$ & 233 & 13.85443 & Four syr. (1) & \\
\hline 0 & 0 & 0 & 0 & 0 & 84 & 534 & 91 & 709 & $08 / 20$ & 233 & 13.85443 & Four syr. (2) & \\
\hline 0 & 0 & 0 & 0 & 0 & 163 & 420 & 48 & 631 & $08 / 31$ & 244 & 13.85443 & Four syr. (1) & \\
\hline 0 & 0 & 0 & 0 & 0 & 160 & 412 & 32 & 604 & $08 / 31$ & 244 & 13.85443 & Four syr. (2) & \\
\hline 0 & 0 & 0 & 0 & 0 & 228 & 125 & 19 & 372 & $09 / 14$ & 258 & 13.85443 & Four syr. (1) & \\
\hline 0 & 0 & 0 & 0 & 3 & 193 & 146 & 5 & 347 & $09 / 14$ & 258 & 13.85443 & Four syr. (2) & \\
\hline 0 & 0 & 0 & 0 & 31 & 173 & 26 & 0 & 230 & $09 / 28$ & 272 & 13.85443 & Four syr. (1) & \\
\hline 0 & 0 & 0 & 0 & 22 & 117 & 13 & 0 & 152 & $09 / 28$ & 272 & 13.85443 & Four syr. (2) & \\
\hline 0 & 0 & 0 & 1 & 49 & 71 & 0 & 0 & 121 & $10 / 13$ & 287 & 13.85443 & Four syr. (1) & \\
\hline 0 & 0 & 0 & 1 & 66 & 110 & 2 & 0 & 179 & $10 / 13$ & 287 & 13.85443 & Four syr. (2) & \\
\hline 0 & 0 & 0 & 1 & 48 & 82 & 1 & 0 & 132 & $10 / 26$ & 300 & 13.85443 & Four syr. (1) & \\
\hline 0 & 0 & 0 & 5 & 34 & 76 & 0 & 0 & 115 & $10 / 26$ & 300 & 13.85443 & Four syr. (2) & \\
\hline 237 & 466 & 636 & 584 & 792 & 1721 & 3723 & 1221 & 9380 & & & & & \\
\hline
\end{tabular}


Ostracode population counts on Sippewissett Marsh Mudflat, 1988

\begin{tabular}{|c|c|c|c|c|c|c|c|c|c|c|c|c|c|}
\hline Cypri & & ovata & & & & & & & Sample & $\#$ & Surface & & \\
\hline M & F & $A-1$ & $A-2$ & $A-3$ & A-4 & $A-5$ & $A-6$ & Total & Date & Day & Area & Description & \\
\hline 0 & 0 & 1 & 1 & 3 & 0 & 0 & 0 & 5 & $03 / 03$ & 63 & 27.33971 & One sp. cup & \\
\hline 0 & 3 & 1 & 3 & 3 & 0 & 0 & 0 & 10 & $03 / 09$ & 69 & 27.33971 & One sp. cup & \\
\hline 0 & 0 & 0 & 2 & 2 & 1 & 0 & 0 & 5 & $03 / 17$ & 77 & 27.33971 & One sp. cup & \\
\hline 0 & 0 & 0 & 1 & 1 & 0 & 0 & 0 & 2 & $03 / 26$ & 86 & 10.39082 & Three syr. (1) & \\
\hline 0 & 1 & 0 & 0 & 0 & 0 & 0 & 0 & 1 & $03 / 26$ & 86 & 27.33971 & One sp. cup (2) & \\
\hline 1 & 1 & 0 & 4 & 1 & 1 & 0 & 0 & 8 & $04 / 02$ & 93 & 13.85443 & Four syr. & \\
\hline 0 & 0 & 0 & 0 & 1 & 0 & 1 & 0 & 2 & $04 / 12$ & 103 & 13.85443 & Four syr. (1) & \\
\hline 0 & 0 & 1 & 3 & 2 & 3 & 0 & 0 & 9 & $04 / 12$ & 103 & 13.85443 & Four syr. (2) & \\
\hline 0 & 2 & 1 & 3 & 0 & 0 & 0 & 0 & 6 & $04 / 25$ & 116 & 13.85443 & Four syr. (1) & \\
\hline 0 & 1 & 3 & 2 & 2 & 2 & 0 & 0 & 10 & $04 / 25$ & 116 & 13.85443 & Four syr. (2) & \\
\hline 0 & 0 & 1 & 5 & 2 & 0 & 0 & 0 & 8 & $05 / 04$ & 125 & 13.85443 & Four syr. (1) & \\
\hline 1 & 1 & 3 & 4 & 3 & 0 & 0 & 0 & 12 & $05 / 04$ & 125 & 13.85443 & Four syr. (2) & \\
\hline 0 & 1 & 1 & 3 & 1 & 0 & 0 & 0 & 6 & $05 / 12$ & 133 & 13.85443 & Four syr. (1) & \\
\hline 0 & 1 & 4 & 2 & 0 & 0 & 0 & 0 & 7 & $05 / 12$ & 133 & 13.85443 & Four syr. (2) & \\
\hline 3 & 4 & 4 & 4 & 0 & 0 & 0 & 0 & 15 & $05 / 23$ & 144 & 13.85443 & Four syr. (1) & \\
\hline 2 & 2 & 8 & 3 & 0 & 0 & 0 & 0 & 15 & $05 / 23$ & 144 & 13.85443 & Four syr. (2) & \\
\hline 1 & 1 & 5 & 1 & 0 & 0 & 0 & 3 & 11 & $05 / 31$ & 152 & 13.85443 & Four syr. (1) & \\
\hline 0 & 2 & 4 & 1 & 0 & 0 & 0 & 0 & 7 & $05 / 31$ & 152 & 13.85443 & Four syr. (2) & \\
\hline 2 & 1 & 3 & 0 & 0 & 0 & 0 & 1 & 7 & $06 / 06$ & 158 & 13.85443 & Four syr. (1) & \\
\hline 1 & 2 & 7 & 0 & 0 & 0 & 0 & 0 & 10 & $06 / 06$ & 158 & 13.85443 & Four syr. (2) & \\
\hline 2 & 2 & 4 & 0 & 0 & 1 & 0 & 0 & 9 & $06 / 13$ & 165 & 13.85443 & Four syr. (1) & \\
\hline 3 & 1 & 0 & 0 & 0 & 3 & 3 & 0 & 10 & $06 / 13$ & 165 & 13.85443 & Four syr. (2) & \\
\hline 1 & 1 & 0 & 0 & 1 & 1 & 2 & 3 & 9 & $06 / 22$ & 174 & 13.85443 & Four syr. (1) & \\
\hline 0 & 3 & 0 & 0 & 0 & 1 & 2 & 1 & 7 & $06 / 22$ & 174 & 13.85443 & Four syr. (2) & \\
\hline 0 & 1 & 0 & 0 & - & - & - & - & 1 & $06 / 29$ & 181 & 13.85443 & Four syr. $>250$ um & (1) \\
\hline 2 & 0 & 0 & 0 & - & - & - & - & 2 & $06 / 29$ & 181 & 13.85443 & Four syr. $>250$ um & (2) \\
\hline 1 & 2 & 0 & 2 & 1 & 0 & 0 & 0 & 6 & $07 / 09$ & 191 & 13.85443 & Four syr. (1) & \\
\hline 1 & 3 & 2 & 6 & 3 & 5 & 7 & 0 & 27 & $07 / 09$ & 191 & 13.85443 & Four syr. (2) & \\
\hline 0 & 3 & 2 & 1 & 5 & 10 & 6 & 0 & 27 & $07 / 22$ & 204 & 13.85443 & Four syr. (1) & \\
\hline 0 & 3 & 2 & 1 & 6 & 5 & 5 & 0 & 22 & $07 / 22$ & 204 & 13.85443 & Four syr. (2) & \\
\hline 0 & 2 & 2 & 1 & - & - & - & - & 5 & $07 / 22$ & 204 & 6.92722 & Two syr. >250um & (3) \\
\hline 1 & 1 & 2 & 2 & - & - & - & - & 6 & $07 / 30$ & 212 & 13.85443 & Four syr. $>250$ um & (1) \\
\hline 0 & 1 & 2 & 2 & - & - & - & - & 5 & $07 / 30$ & 212 & 13.85443 & Four syr. $>250 u m$ & (2) \\
\hline 3 & 0 & 4 & 3 & 5 & 7 & 9 & 2 & 33 & $08 / 10$ & 223 & 13.85443 & Four syr. (1) & \\
\hline 0 & 1 & 3 & 2 & 12 & 8 & 8 & 3 & 37 & $08 / 10$ & 223 & 13.85443 & Four syr. (2) & \\
\hline 2 & 1 & 6 & 7 & 9 & 8 & 10 & 4 & 47 & $08 / 20$ & 233 & 13.85443 & Four syr. (1) & \\
\hline 0 & 2 & 2 & 3 & 3 & 11 & 7 & 1 & 29 & $08 / 20$ & 233 & 13.85443 & Four syr. (2) & \\
\hline 1 & 1 & 1 & 4 & 7 & 7 & 5 & 3 & 29 & $08 / 31$ & 244 & 13.85443 & Four syr. (1) & \\
\hline 0 & 0 & 1 & 4 & 5 & 12 & 3 & 1 & 26 & $08 / 31$ & 244 & 13.85443 & Four syr. (2) & \\
\hline 0 & 1 & 1 & 2 & 4 & 12 & 1 & 1 & 22 & $09 / 14$ & 258 & 13.85443 & Four syr. (1) & \\
\hline 0 & 0 & 3 & 4 & 8 & 2 & 2 & 1 & 20 & $09 / 14$ & 258 & 13.85443 & Four syr. (2) & \\
\hline 3 & 1 & 1 & 5 & 3 & 3 & 0 & 0 & 16 & $09 / 28$ & 272 & 13.85443 & Four syr. (1) & \\
\hline 1 & 0 & 2 & 4 & 2 & 0 & 0 & 0 & 9 & $09 / 28$ & 272 & 13.85443 & Four syr. (2) & \\
\hline 0 & 1 & 0 & 2 & 6 & 2 & 0 & 0 & 11 & $10 / 13$ & 287 & 13.85443 & Four syr. (1) & \\
\hline 0 & 0 & 3 & 5 & 2 & 4 & 1 & 0 & 15 & $10 / 13$ & 287 & 13.85443 & Four syr. (2) & \\
\hline 0 & 0 & 0 & 7 & 8 & 0 & 0 & 1 & 16 & $10 / 26$ & 300 & 13.85443 & Four syr. (1) & \\
\hline 0 & 2 & 0 & 5 & 2 & 1 & 0 & 1 & 11 & $10 / 26$ & 300 & 13.85443 & Four syr. (2) & \\
\hline 32 & 56 & 90 & 114 & 113 & 110 & 72 & 26 & 613 & & & & & \\
\hline
\end{tabular}


Ostracode population counts on Sippewissett Marsh Mudflat, 1988

\begin{tabular}{|c|c|c|c|c|c|c|c|c|c|c|c|c|c|c|}
\hline Cypri & & salek & rosa & & & & & & Sample & $\#$ & Surface & & & \\
\hline M & $\mathrm{F}$ & $A-1$ & $A-2$ & $A-3$ & $A-4$ & $A-5$ & $A-6$ & Total & Date & Day & Area & Descriptio & & \\
\hline 0 & 0 & 1 & 1 & 2 & 0 & 0 & 0 & 4 & $03 / 03$ & 63 & 27.33971 & One sp. cu & & \\
\hline 0 & 0 & 1 & 0 & 3 & 0 & 0 & 0 & 4 & $03 / 09$ & 69 & 27.33971 & One sp. cu & & \\
\hline 0 & 0 & 1 & 2 & 1 & 1 & 0 & 0 & 5 & $03 / 17$ & 77 & 27.33971 & One sp. cu & & \\
\hline 0 & 0 & 0 & 0 & 0 & 0 & 0 & 0 & 0 & $03 / 26$ & 86 & 10.39082 & Three syr. & (1) & \\
\hline 0 & 0 & 0 & 2 & 1 & 0 & 0 & 0 & 3 & $03 / 26$ & 86 & 27.33971 & One sp. cu & ap (2) & \\
\hline 0 & 0 & 1 & 0 & 1 & 0 & 0 & 0 & 2 & $04 / 02$ & 93 & 13.85443 & Four syr. & & \\
\hline 0 & 0 & 0 & 1 & 3 & 0 & 0 & 0 & 4 & $04 / 12$ & 103 & 13.85443 & Four syr. & (1) & \\
\hline 0 & 0 & 0 & 0 & 1 & 8 & 0 & 0 & 9 & $04 / 12$ & 103 & 13.85443 & Four syr. & (2) & \\
\hline 0 & 0 & 1 & 2 & 2 & 1 & 0 & 0 & 6 & $04 / 25$ & 116 & 13.85443 & Four syr. & (1) & \\
\hline 0 & 0 & 0 & 2 & 2 & 0 & 0 & 0 & 4 & $04 / 25$ & 116 & 13.85443 & Four syr. & (2) & \\
\hline 0 & 0 & 4 & 7 & 3 & 0 & 0 & 0 & 14 & $05 / 04$ & 125 & 13.85443 & Four syr. & (1) & \\
\hline 0 & 0 & 0 & 1 & 2 & 0 & 0 & 0 & 3 & $05 / 04$ & 125 & 13.85443 & Four syr. & (2) & \\
\hline 0 & 0 & 0 & 3 & 0 & 0 & 0 & 0 & 3 & $05 / 12$ & 133 & 13.85443 & Four syr. & (1) & \\
\hline 1 & 0 & 4 & 6 & 2 & 0 & 0 & 0 & 13 & $05 / 12$ & 133 & 13.85443 & Four syr. & (2) & \\
\hline 0 & 0 & 3 & 4 & 0 & 0 & 0 & 0 & 7 & $05 / 23$ & 144 & 13.85443 & Four syr. & (1) & \\
\hline 1 & 0 & 2 & 2 & 1 & 0 & 0 & 0 & 6 & $05 / 23$ & 144 & 13.85443 & Four syr. & (2) & \\
\hline 0 & 0 & 5 & 2 & 0 & 0 & 0 & 0 & 7 & $05 / 31$ & 152 & 13.85443 & Four syr. & (1) & \\
\hline 1 & 0 & 2 & 1 & 0 & 0 & 0 & 0 & 4 & $05 / 31$ & 152 & 13.85443 & Four syr. & (2) & \\
\hline 1 & 0 & 6 & 0 & 0 & 0 & 0 & 0 & 7 & $06 / 06$ & 158 & 13.85443 & Four syr. & (1) & \\
\hline 1 & 0 & 3 & 1 & 0 & 0 & 0 & 0 & 5 & $06 / 06$ & 158 & 13.85443 & Four syr. & (2) & \\
\hline 2 & 0 & 1 & 0 & 0 & 0 & 0 & 0 & 3 & $06 / 13$ & 165 & 13.85443 & Four syr. & (1) & \\
\hline 2 & 4 & 0 & 0 & 0 & 0 & 0 & 0 & 6 & $06 / 13$ & 165 & 13.85443 & Four syr. & (2) & \\
\hline 2 & 2 & 0 & 0 & 0 & 0 & 0 & 0 & 4 & $06 / 22$ & 174 & 13.85443 & Four syr. & (1) & \\
\hline 0 & 0 & 0 & 0 & 0 & 0 & 0 & 0 & 0 & $06 / 22$ & 174 & 13.85443 & Four syr. & (2) & \\
\hline 0 & 0 & 1 & 0 & - & - & - & - & 1 & $06 / 29$ & 181 & 13.85443 & Four syr. & $>250 u m$ & (1) \\
\hline 2 & 0 & 0 & 0 & - & - & - & - & 2 & $06 / 29$ & 181 & 13.85443 & Four syr. & $>250 u m$ & (2) \\
\hline 0 & 2 & 0 & 0 & 0 & 0 & 0 & 0 & 2 & $07 / 09$ & 191 & 13.85443 & Four syr. & (1) & \\
\hline 1 & 2 & 1 & 0 & 0 & 1 & 14 & 29 & 48 & $07 / 09$ & 191 & 13.85443 & Four syr. & (2) & \\
\hline 1 & 1 & 0 & 0 & 1 & 6 & 11 & 0 & 20 & $07 / 22$ & 204 & 13.85443 & Four syr. & (1) & \\
\hline 1 & 0 & 0 & 0 & 2 & 6 & 19 & 13 & 41 & $07 / 22$ & 204 & 13.85443 & Four syr. & (2) & \\
\hline 0 & 0 & 0 & 0 & - & - & - & - & 0 & $07 / 22$ & 204 & 6.92722 & Two syr. & $>250 u m$ & (3) \\
\hline 0 & 1 & 0 & 1 & - & - & - & - & 2 & $07 / 30$ & 212 & 13.85443 & Four syr. & $>250 u m$ & (1) \\
\hline 0 & 1 & 0 & 0 & - & - & - & - & 1 & $07 / 30$ & 212 & 13.85443 & Four syr. & $>250 u m$ & (2) \\
\hline 0 & 0 & 0 & 1 & 2 & 16 & 17 & 10 & 46 & $08 / 10$ & 223 & 13.85443 & Four syr. & (1) & \\
\hline 0 & 1 & 0 & 0 & 2 & 18 & 18 & 3 & 42 & $08 / 10$ & 223 & 13.85443 & Four syr. & (2) & \\
\hline 0 & 0 & 0 & 0 & 1 & 15 & 28 & 8 & 52 & $08 / 20$ & 233 & 13.85443 & Four syr. & (1) & \\
\hline 0 & 1 & 0 & 4 & 1 & 10 & 29 & 10 & 55 & $08 / 20$ & 233 & 13.85443 & Four syr. & (2) & \\
\hline 0 & 0 & 0 & 0 & 0 & 14 & 22 & 3 & 39 & $08 / 31$ & 244 & 13.85443 & Four syr. & (1) & \\
\hline 0 & 0 & 0 & 0 & 1 & 18 & 16 & 1 & 36 & $08 / 31$ & 244 & 13.85443 & Four syr. & (2) & \\
\hline 0 & 0 & 0 & 1 & 1 & 7 & 11 & 3 & 23 & $09 / 14$ & 258 & 13.85443 & Four syr. & (1) & \\
\hline 0 & 0 & 0 & 0 & 1 & 11 & 8 & 0 & 20 & $09 / 14$ & 258 & 13.85443 & Four syr. & (2) & \\
\hline 0 & 0 & 0 & 5 & 9 & 1 & 0 & 0 & 15 & $09 / 28$ & 272 & 13.85443 & Four syr. & (1) & \\
\hline 0 & 0 & 0 & 3 & 8 & 1 & 0 & 0 & 12 & $09 / 28$ & 272 & 13.85443 & Four syr. & (2) & \\
\hline 0 & 0 & 0 & 2 & 2 & 0 & 1 & 0 & 5 & $10 / 13$ & 287 & 13.85443 & Four syr. & (1) & \\
\hline 0 & 0 & 0 & 1 & 7 & 7 & 0 & 0 & 15 & $10 / 13$ & 287 & 13.85443 & Four syr. & (2) & \\
\hline 0 & 0 & 0 & 0 & 2 & 0 & 0 & 0 & 2 & $10 / 26$ & 300 & 13.85443 & Four syr. & (1) & \\
\hline 0 & 0 & 0 & 1 & 3 & 0 & 0 & 0 & 4 & $10 / 26$ & 300 & 13.85443 & Four syr. & (2) & \\
\hline 16 & 15 & 37 & 56 & 67 & 141 & 194 & 80 & 06 & & & & & & \\
\hline
\end{tabular}




\section{Chapter 2}

\section{Ontogeny and habitat of modern menardiiform planktonic foraminifera}

\subsection{Introduction}

Paleoceanographers seek to infer the history of ocean chemistry and circulation, especially the relationships between climatic changes and the character of the ocean. Foraminifera form the focus of much paleoceanographic research because these unicellular organisms draw from the ocean the materials needed to build their shells, leaving in the sea-floor sediments a cryptic record of ocean physics and chemistry. Understanding this record in terms compatible with modern oceanography has been difficult because the measurable characteristics of foraminiferal shell chemistry are dependent not only on the water but also on aspects of the organisms themselves.

Chief among the biological factors that affect foraminiferal shell chemistry is ontogeny, the course of development of individual specimens. Several studies have shown that smaller specimens have different proportions of the isotopes of carbon and oxygen than do larger specimens taken from the same samples. Typically, the measured $\delta^{18} \mathrm{O}$ of small specimens is less than that of larger specimens, and the measured $\delta^{13} \mathrm{C}$ of small specimens is lower than that of larger specimens (Berger et al. 1978, Keigwin and Boyle in press, Hemleben et al. 1985). These size-related variations in isotopic chemistry reflect metabolic and ecological changes that occur during the development of individual organisms. The change in the rate of metabolism that accompanies age is thought to bring $\delta^{13} \mathrm{C}$ closer to equilibrium with water (Berger 1978), while vertical migration to deeper waters is thought to increase $\delta^{18} \mathrm{O}$ (Hemleben et al. 1985). The 
metabolic effect on $\delta^{13} \mathrm{C}$ is strongest in shallow-dwelling spinose species such as Globigerinoides ruber and G. sacculifer, while the effect of vertical migration on $\delta^{18} \mathrm{O}$ is strongest in nonspinose species such as Globorotalia truncatulinoides, G. hirsuta, G. menardii, G. tumida (Hemleben et al. 1987).

Fairbanks et al. (1982) collected living planktonic foraminifera from MOCNESS tows in the Panama Basin. Based on the isotopic composition of the shells, they concluded that shell growth was restricted to the upper $100 \mathrm{~m}$ of the water column, even though individuals were found to contain protoplasm throughout the upper 2000m. Durazzi (1981) measured isotopic composition of large $(>600 \mu \mathrm{m})$ specimens of Globorotalia menardii from core tops at various locations in the equatorial Atlantic and Caribbean regions, concluding that this species lives between $50 \mathrm{~m}$ and $200 \mathrm{~m}$ water depth.

Berger et al. (1978) looked for the dependence of size on isotopic composition in Globorotalia cultrata (=G. menardii) and G. tumida. For G. cultrata, the differences in $\delta^{18} \mathrm{O}$ among size fractions were as large as the differences between glacial and modern samples of most other species. Size was monotonic with $\delta^{18} \mathrm{O}$ in G. cultrata, but not in G. tumida. Berger et al. interpreted this variation as indicating that $G$. cultrata grows both in the mixed layer and in the upper part of the thermocline.

These species present an unusual opportunity for paleoceanography, because chemical variations associated with the large hydrographic gradients of the upper thermocline must be integrated into their shells. If the history of those hydrographic gradients could be described, their responses to glacial-interglacial climatic changes could be understood.

The purpose of this study is to discover the relationship between ontogeny and depth habitat in two species of planktonic foraminifera, Globorotalia menardii and G. tumida. Supposing ontogeny to consist of a sequence of discrete developmental stages, the objective is to determine the nature and sequence of the developmental stages and the depth habitat of each stage. The results of this study provide two important benefits, a refinement in the interpretation of stable-isotope measurements and key ecological data to help explain why both $G$. menardii and G. tumida disappeared from the Atlantic ocean during glacial time, reappearing again during interglacials (Ericson and Wollin, 1956). 


\subsection{Materials and methods}

Each species was studied in detail at a single locality, and a few attributes were studied at geographically separated sites. The detailed study included analysis of size distribution, the change of shape with size, the distribution of shell weight and density, and stable-isotopic compositions of each ontogenetic stage that could be identified.

\subsubsection{Sources of studied material}

All specimens were taken from Holocene samples in the tops of cores with well-documented stratigraphies.

KNR110-43PC 1-3cm This piston core was taken from 3436m water depth on the northeast slope of the Ceara Rise, a bathymetric high off the northeast coast of Brazil, in the equatorial Atlantic Ocean (Curry and Lohmann in manuscript, Curry and Crowley 1987).

EN066-44GGC 0-2cm This giant gravity core was taken from 3421m water depth on the slopes of the Sierra Leone Rise, a bathymetric high off the west coast of Africa near Sierra Leone (Curry and Lohmann 1985, Curry and Lohmann in manuscript).

BX "G" 0-2cm This box core was taken from $4469 \mathrm{~m}$ water depth on the Bermuda Rise southeast of Bermuda (Buesseler and Sholkovitz 1987).

\subsubsection{Sampling procedures}

Because they grow by the accretion of chambers, individual foraminifera increase in size throughout ontogeny. Different specimens may grow at different rates, and may have different-sized proloculi (initial chambers). A sample drawn from sediment may have a strong modal size distribution, however. In order to get an accurate picture of the ontogenetic sequence one must sample evenly across size, i.e. in a stratified design. Samples were first sieved at $\frac{1}{4} \phi$ intervals from $\phi=2.5(177 \mu \mathrm{m})$ to $\phi=.5(710 \mu \mathrm{m})$. Here $\phi=-\log _{2} d$ where $d$ is the diameter measured in millimeters. In some cases it was impractical to pick all of the specimens retained on each sieve, and so the size-fraction was split using a standard micropaleontological sample splitter. 


\subsubsection{Measurement of foraminiferal morphology}

\section{Size and shape}

The volume of the test was estimated by measuring the areas of the outlines, or silhouettes, in edge and apical views. If the test were perfectly conical, the volume could be estimated as follows. The apical view of a globorotaliid test corresponds to the base of the cone used to model its size. Cones have circular bases, so the area of the apical view can be rewritten $A_{\text {apical }}=\pi r^{2}$. Similarly, the edge view of the test corresponds to an axial section of the cone, which is an isosceles triangle with base $2 r$ and height $h$. Its area can be written $A_{\text {edge }}=r h$. The volume of a cone is $V=\frac{1}{3} \pi r^{2} h$. Solving for $r$ yields $V=\frac{1}{3} A_{\text {edge }} \sqrt{A_{\text {apical }} \pi}$. Shape is measured as the relative sizes of the two projections used to characterize the specimens. The ratio of the test outline area in edge view to its area in apical view reflects the sphericity of the test, an important character in the taxonomy of menardiiform globorotaliids.

\section{Weight and density}

Specimens were weighed individually using a Cahn 25 ultramicrobalance with a nominal precision of $0.1 \mu \mathrm{g}$. Density was calculated by dividing the measured weight by the volume calculated using the method described above.

Using a few simple assumptions, we may construct a theoretical model of density changes during foraminiferal ontogeny. If the thickness of the walls of newly-formed chambers do not increase in direct proportion to the chambers' volumes, the overall density of the foraminiferal test should decrease when chambers are added. The calcite crust noted by many authors (e.g. Orr 1967) greatly increases the density of the test, since it is accreted over the entire outer surface of the test and does little to increase test volume.

\subsubsection{Measurement of stable-isotopic composition}

A mass spectrometer was used to measure the relative proportion of stable isotopes of carbon and oxygen. These are compared to a standard reference material and expressed as $\delta^{18} \mathrm{O}$ and $\delta^{13} \mathrm{C}$ (Emiliani 1954). In this study isotopic measurements are reported in parts per thousand $(\%)$ relative to the PDB standard using standard preparation and calibration techniques de- 
scribed in Curry et al. (1988). Specimens were first cleaned in an ultrasonic bath, dried and weighed to determine whether sufficient material was available for a measurement. The instrument used here (a VG Micromass 602E) required samples to be at least .12mg in mass. Samples therefore consisted of groups of specimens from the same $\frac{1}{4} \phi$ size fraction having approximately equal densities. The samples were crushed and roasted at $400^{\circ} \mathrm{C}$ under vacuum for one hour.

\section{Fractional shell chemistry}

Since the foraminiferal shell grows by accretion, its chemistry reflects that of all of the waters in which it was formed; the variations in water properties that the individual experiences are mathematically integrated to produce the isotopic composition that can be measured. To understand the changes in composition that occur during ontogeny, the isotopic record must be mathematically differentiated. This can be accomplished by assuming that the distribution of morphology and isotopic composition in sediment samples reflects that of the living populations that produced the sediment.

The composition of the calcite crust can be estimated by assuming that noncrusted specimens represent the state of crusted specimens prior to the formation of the crust (Lohmann and Curry, in review). The crust composition can be calculated as

$$
M_{\text {crust }} \delta_{\text {crust }}=M_{c} \delta_{c}-M_{n} \delta_{n}
$$

where $M_{c}$ is the mass of crusted specimens, $M_{u}$ is the mass of noncrusted specimens, and $\delta_{c}$ and $\delta_{n}$ are the isotopic compositions of crusted and noncrusted specimens. $M_{\text {crust }}$ is estimated as the difference in mass, $M_{c}-M_{n}$. The equation is solved to find $\delta_{\text {crust }}$, the composition of the crust material.

Chamber compositions may be estimated using a similar strategy. Restricting attention to noncrusted specimens and assuming that small specimens accurately represent the early ontogenetic stages of large specimens, a mass balance equation can be used to determine the composition of the added chambers as follows:

$$
M_{k} \delta_{k}=M_{j+k} \delta_{j+k}-M_{j} \delta_{j}
$$

where $M_{j}$ is the mass of the $j$ th stage, and the quantity to be estimated is the composition of the added portion $k$. 
Because these calculations involve quantities that are measured with error, the statistical dispersion of the results is more complicated than that of the original measurements. Errors in the results are strongest in the case of added chamber compositions because the change in mass due to adding a chamber is small compared with the change in mass due to forming the crust. Since the change in mass appears in the denominator of both measures of fractional shell composition, it is imperative that the masses be accurately estimated. As the change in mass decreases, errors in the compositional measurements are magnified.

Chamber addition, measured here as the difference in mass between successive size-fractions of noncrusted specimens, typically increases the mass of Globorotalia menardii by $50 \%$, and of G. tumida by $79 \%$. By contrast, crust growth (i.e. the difference between crusted and noncrusted specimens in the same size-fraction) changes mass by $125 \%$ in $G$. menardii and $154 \%$ in G. tumida.

A conservative estimate of the uncertainty in measurements of fractional shell composition can be derived by calculating the fractional shell composition using all possible combinations of whole-shell compositions. In particular, we may expect that the true value of $\delta_{f}$ obeys the relation

$$
\frac{M_{2} \min \left(\delta_{2}\right)-M_{1} \max \left(\delta_{1}\right)}{M_{2}-M_{1}}<\delta_{f}<\frac{M_{2} \max \left(\delta_{2}\right)-M_{1} \min \left(\delta_{1}\right)}{M_{2}-M_{1}}
$$

where $\min \left(\delta_{1}\right)$ is the smallest of the measured values of whole shells lacking the skeletal element whose composition we are trying to estimate, and $\max \left(\delta_{1}\right)$ is the largest such value. Because weight is easier to measure than isotopic composition, the mean values of $M_{1}$ and $M_{2}$ are used. In most cases, weights could be obtained for twenty or thirty specimens, while isotopic compositions could be obtained only for two or three small groups of specimens. 


\subsection{Results}

\subsubsection{Taxonomy}

The taxonomy of menardiiform globorotaliids is difficult to use for biological identification. As for most groups of foraminifera, classifications have been erected by paleontologists with the goal of using the fossils for biostratigraphy. In that pursuit, one must only determine whether specimens of a particular morphology are present in each sample, not identify every specimen. Different names may not correspond to different species; they often represent only the extremes of a continuum of variation. To study the distribution of a species that is morphologically variable we need to be able to identify individuals, not samples, and decide which individuals to include or exclude from study. We also need to be able to associate juvenile specimens with the corresponding adults.

Large specimens of Globorotalia menardii and G. tumida can usually be identified unequivocally, but among juvenile specimens the characteristics that distinguish them are either not present (e.g. the thick crust of G. tumida) or are intermediate in form (e.g. the extent of apical and umbilical expansion). A major goal of this study was to document the variation of morphology throughout the whole range of size, relating the morphologies that have names (e.g. G. cultrata, G. menardii, and G. tumida, and G. ungulata) to each other in ontogenetic sequence if appropriate. This task is accomplished by comparing the size- and shape-distributions of populations with qualitative observations of the structure of individual shells and measures of the encrustation of the test.

Globorotalia tumida is traditionally separated from $G$. menardii by the presence in the former of a thicker test, less circular chambers in apical view, thicker crust, and the tendency of chambers to form a sharp point on the umbilical side of the test (i.e. a closed umbilicus) (Parker 1962). Figures 2.6 and 2.7 show a clear dichotomy in test thickness. The correlation of group membership and test thickness indicates that this characteristic was regarded as crucial for identification. 


\subsubsection{Morphological changes of ontogeny}

Three characteristics of the foraminiferal test were used to describe ontogeny, its size, shape, and weight. Obviously, weight increases with size, but the size-distribution of weights shows two distinct populations. Weight follows a $\log$-log relationship with size, i.e. $\log W=a+$ $b \log V$. Figures 2.1 and 2.2 indicate that smaller individuals follow a different size-weight relationship than do larger specimens. The slope $b$ appears to be the same for both small and large specimens, but the intercept differs. This dichotomy is best explained with reference to a simple model of foraminiferal growth.

Ontogeny in menardiiform globorotaliids is dominated by two processes, chamber accretion and crust formation. Chamber accretion tends to lower the bulk density of the test, while encrustation produces a sharp increase in test bulk density (figures $2.4,2.5$, and 2.3). In both species the presence of the crust is easily seen by examining the surface texture of the test; it can be confirmed by measuring the density of the test.

In Globorotalia menardii, the test becomes axially compressed during ontogeny, meaning that the area of the edge view decreases in proportion to that of the apical view as the test gets larger (figure 2.6). This tendency is especially strong among crusted specimens, though it is also apparent in specimens lacking the crust. Crusted specimens of G. tumida show a slight trend towards compressed form, but noncrusted G. tumida do not (figure 2.7). An important consequence of these trends in shape change is that noncrusted individuals of both species smaller than about $177 \mu \mathrm{m}$ have nearly the same degree of axial compression. This is the main reason why the smallest specimens are so difficult to identify.

\section{Geographic variation in ontogeny}

Emplacement of the crust may occur over a range of sizes, though large specimens are mostly crusted and small specimens mostly noncrusted. A survey of samples from several separate locations shows variation in the size at which the crust is emplaced. Figure 2.8 shows the relative abundance of crusted and noncrusted specimens of $G$. tumida in each size fraction at the Ceara and Sierra Leone Rises in the equatorial Atlantic and the Bermuda Rise in the North Atlantic. Samples from the two equatorial sites are nearly alike, but at the Bermuda Rise sample, crusting appears to occur at a smaller size. The size fraction containing approximately equal numbers 
of crusted and noncrusted specimens provides a convenient measure of this difference. At the Ceara Rise and Sierra Leone Rise, noncrusted specimens and crusted specimens are equally abundant in the size fraction retained on the $250 \mu \mathrm{m}$ sieve, while at the Bermuda Rise the same condition applies to the $212 \mu \mathrm{m}$ size-fraction. Similar data for $G$. menardii are shown in figure 2.9. In the $300 \mu \mathrm{m}$ size fraction at the Bermuda Rise, however, noncrusted specimens account for $28 \%$ of the G. menardii compared to $7.5 \%$ for G. tumida. 


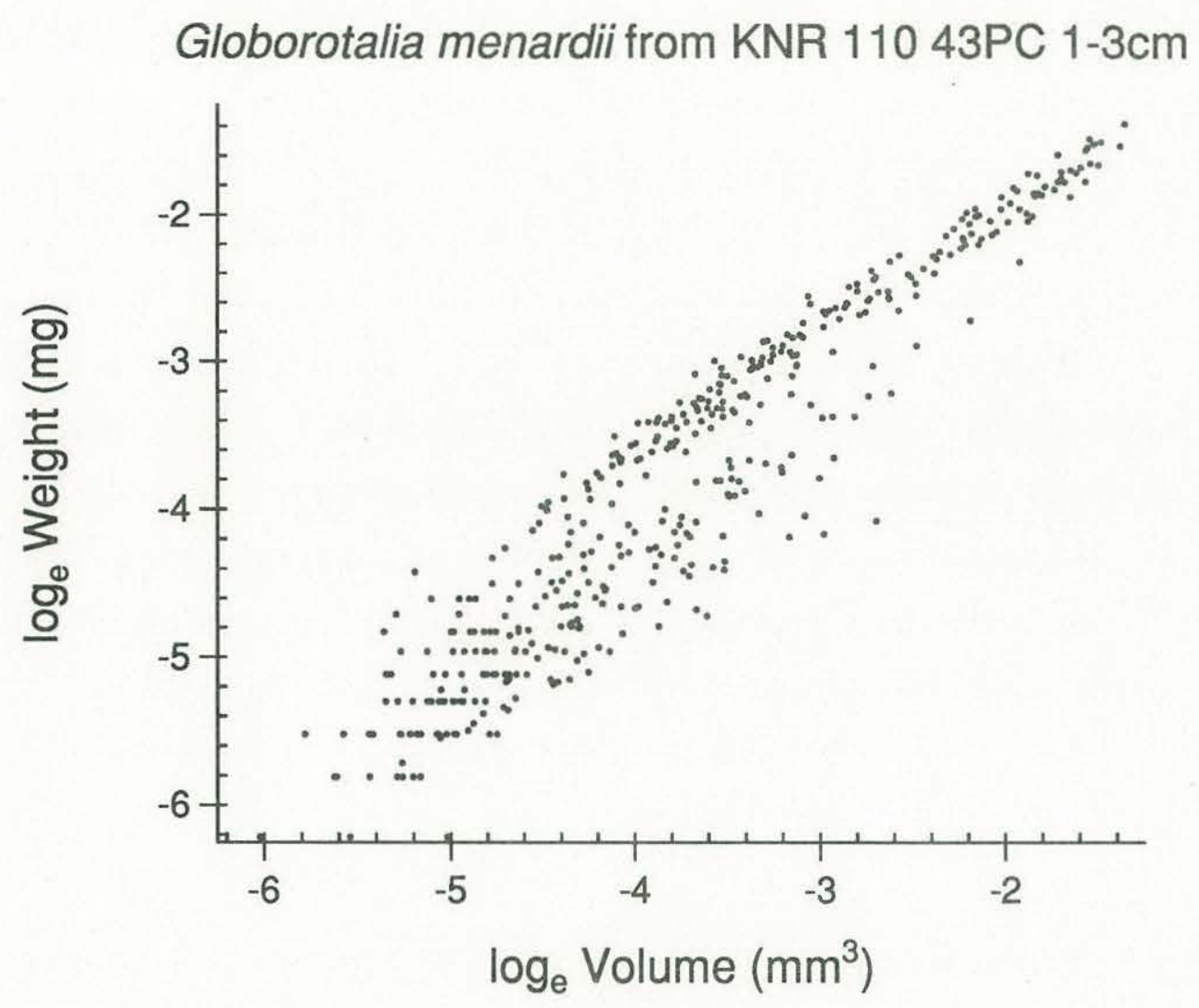

Figure 2.1: Variation in the weight of the test of Globorotalia menardii with size. The smallest specimens were retained on the $177 \mu \mathrm{m}$ sieve, the largest were retained on the $710 \mu \mathrm{m}$ sieve. Specimens smaller than $177 \mu \mathrm{m}$ are difficult to identify. Volume was calculated using the areas of the edge and spiral views; for the purposes of calculating volume the shape is modeled as a cone. 


\section{Globorotalia tumida from KNR 110 43PC 1-3cm}

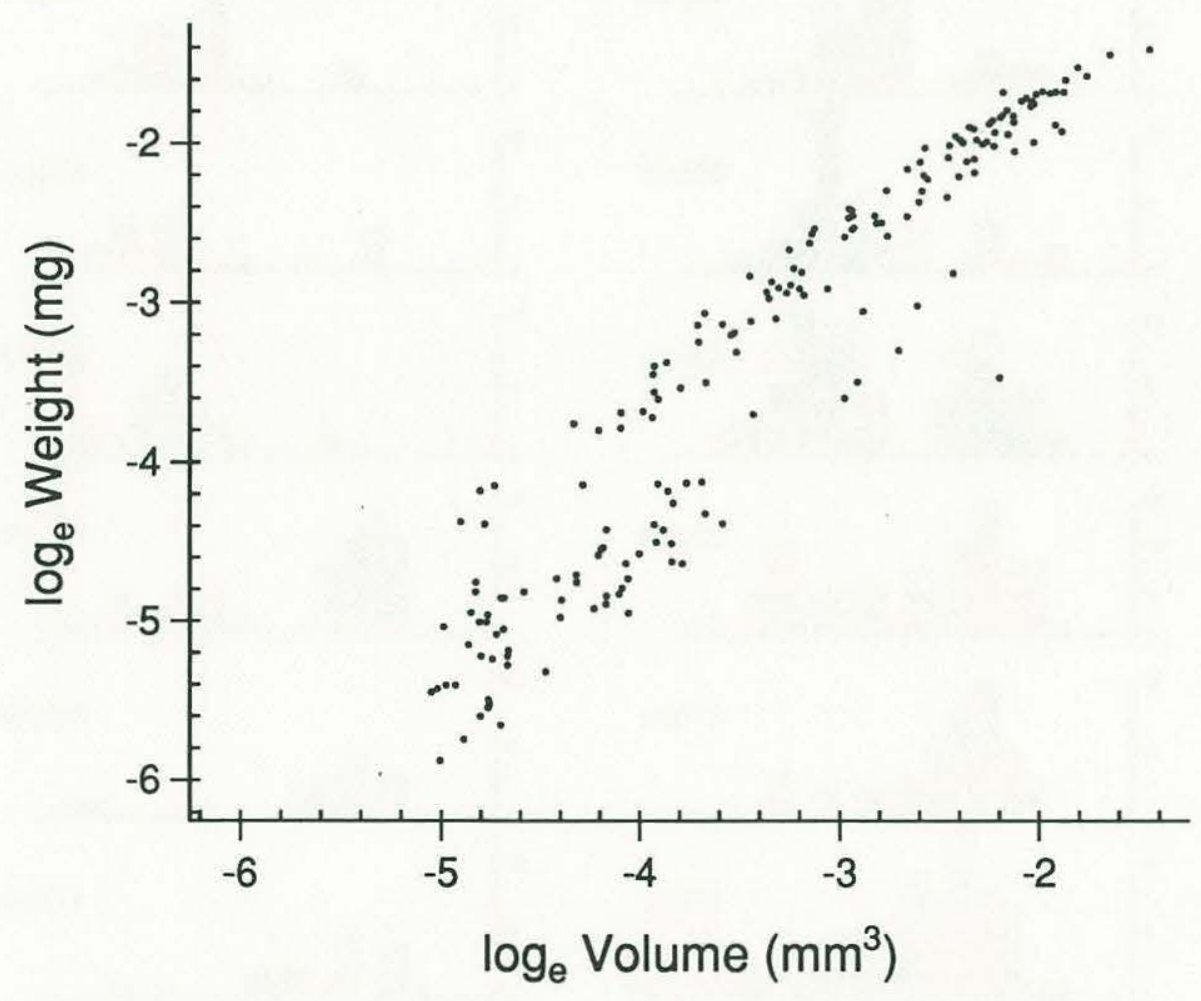

Figure 2.2: Variation in the weight of the test of Globorotalia tumida with size. The smallest specimens were retained on the $177 \mu \mathrm{m}$ sieve, the largest were retained on the $600 \mu \mathrm{m}$ sieve. Volume was calculated using the areas of the edge and spiral views; for the purposes of calculating volume the shape is modeled as a cone. 
G. menardii
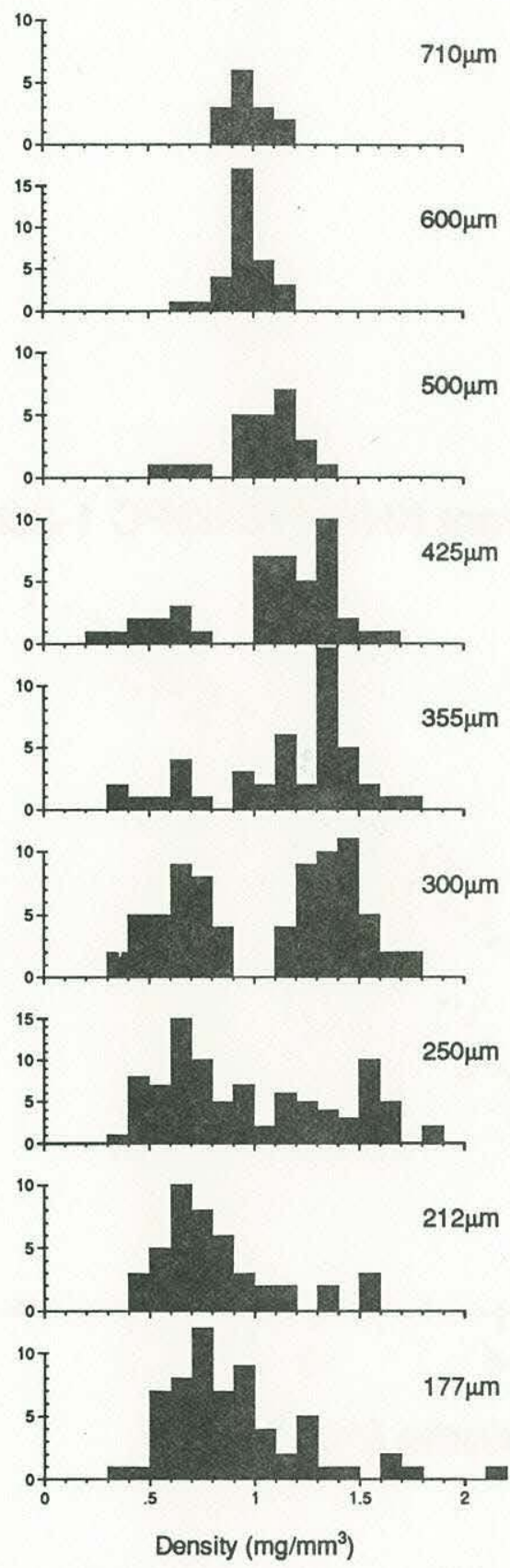

G. tumida
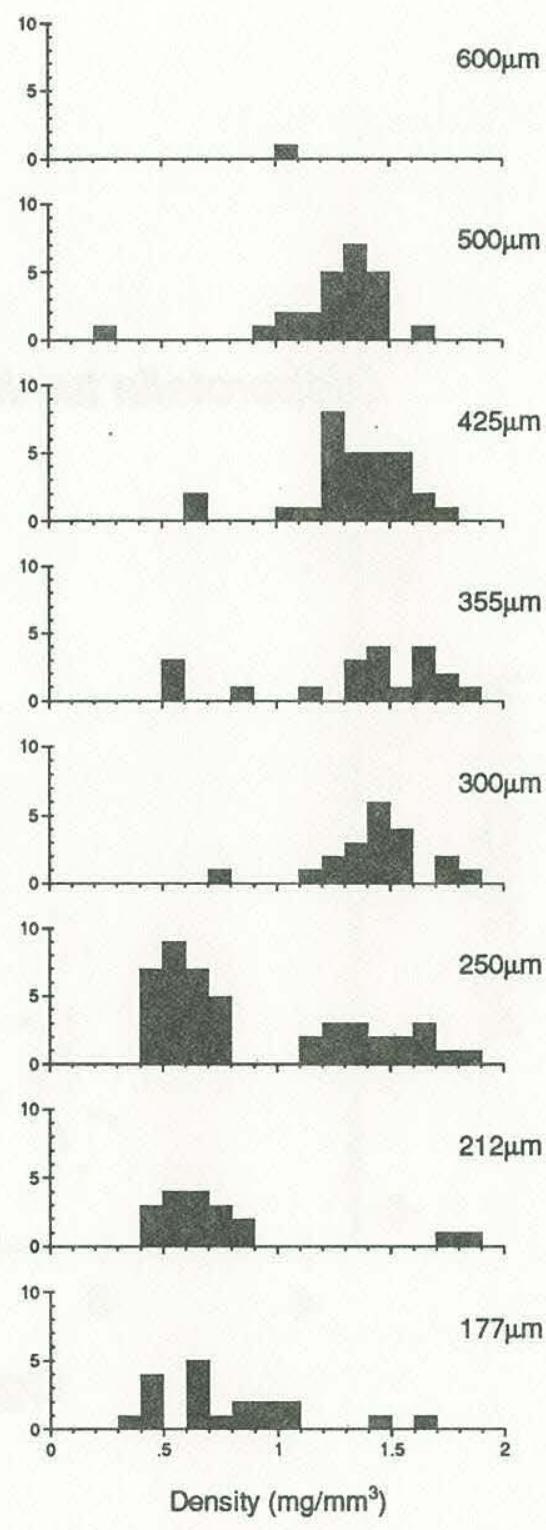

Figure 2.3: Histograms of test density in specimens from various sieve-size fractions. Two populations are apparent over much of the range of size. Denser specimens invariably show coarse crystalline texture in the outer wall of the test, particularly the earliest portions of the final whorl. 


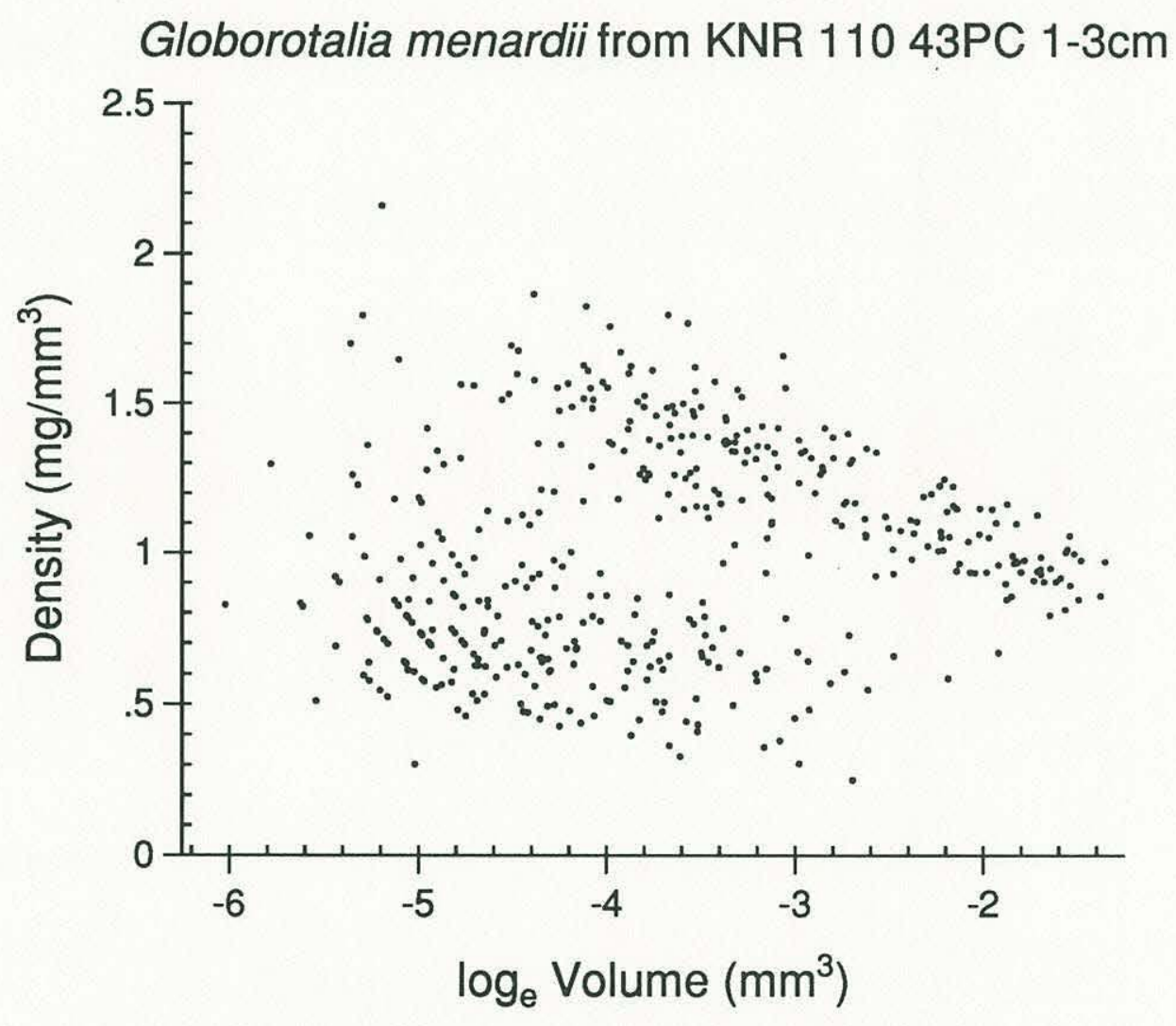

Figure 2.4: Variation in the density of the test of Globorotalia menardii with size. Two populations are apparent, having significantly different densities. Within these populations density decreases as size increases. The character of these two populations reflect the two processes of growth, chamber accretion and secondary encrustation. 


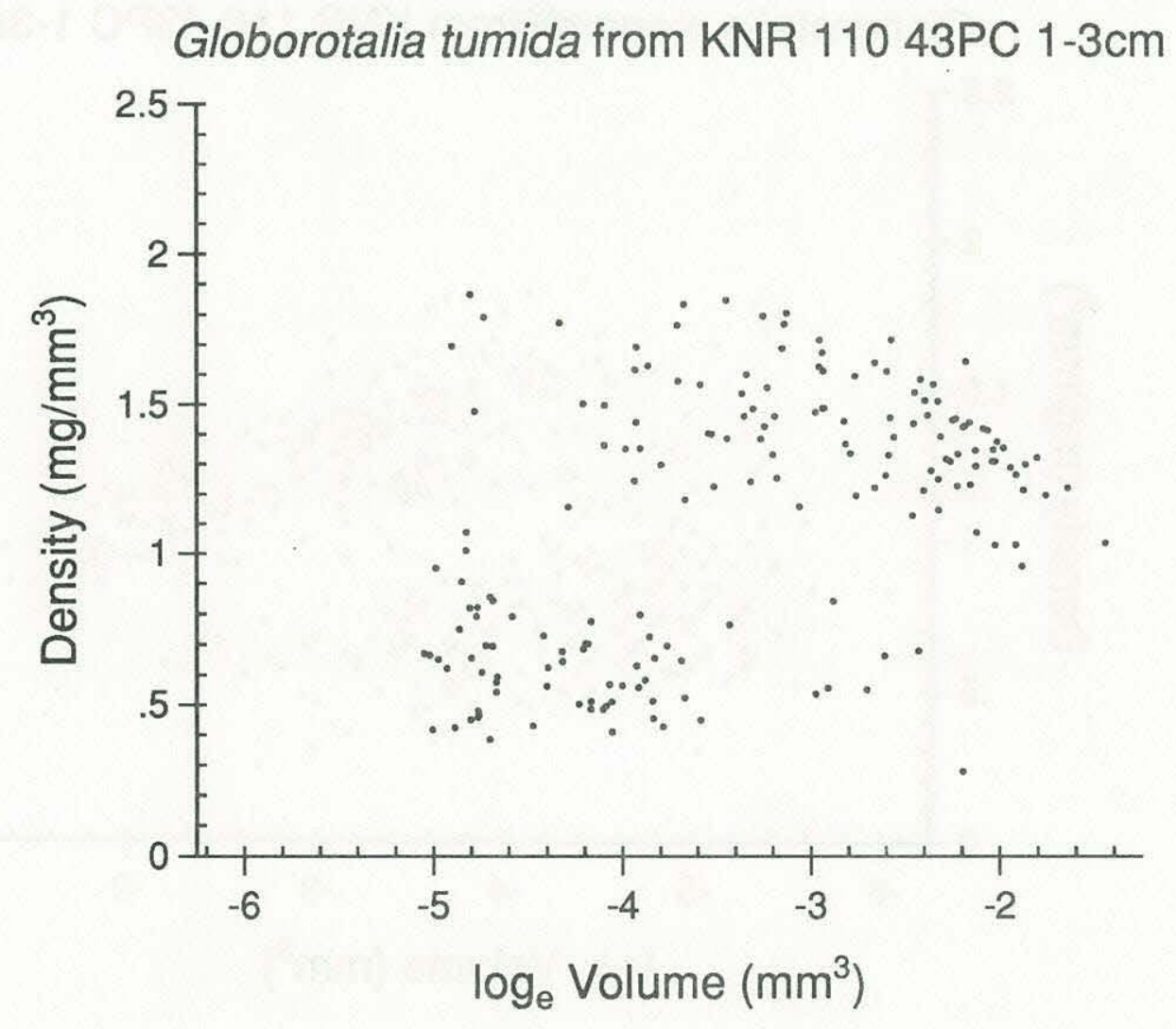

Figure 2.5: Variation in the density of the test of Globorotalia tumida with size. Volume was calculated as in figure 2.4. Shells of $G$. tumida are typically larger than those of $G$. menardii from the same sieve, reflecting the umbilical expansion characteristic of $G$. tumida. No G. tumida were found on the $710 \mu \mathrm{m}$ sieve. 


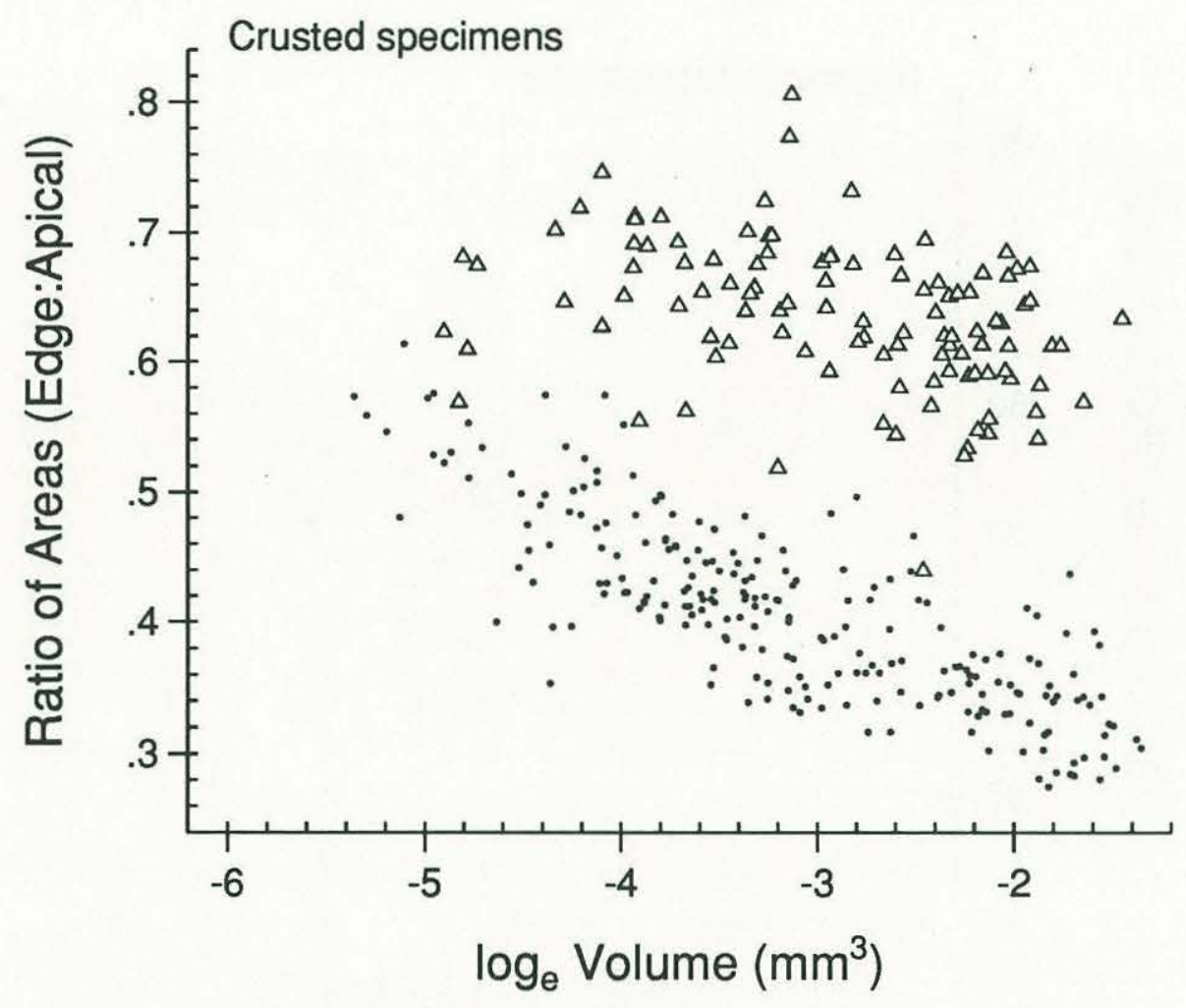

Figure 2.6: Axial compression of the test in crusted specimens of Globorotalia menardii and $G$. tumida. Dots represent specimens of $G$. menardii, triangles represent $G$. tumida. The ordinate is the ratio of the area of the specimen in edge view to its area in apical view. Notice that the ordinate represents the principal characteristic that distinguishes G. menardii from $G$. cultrata, the latter form being the most compressed variety of the former. 


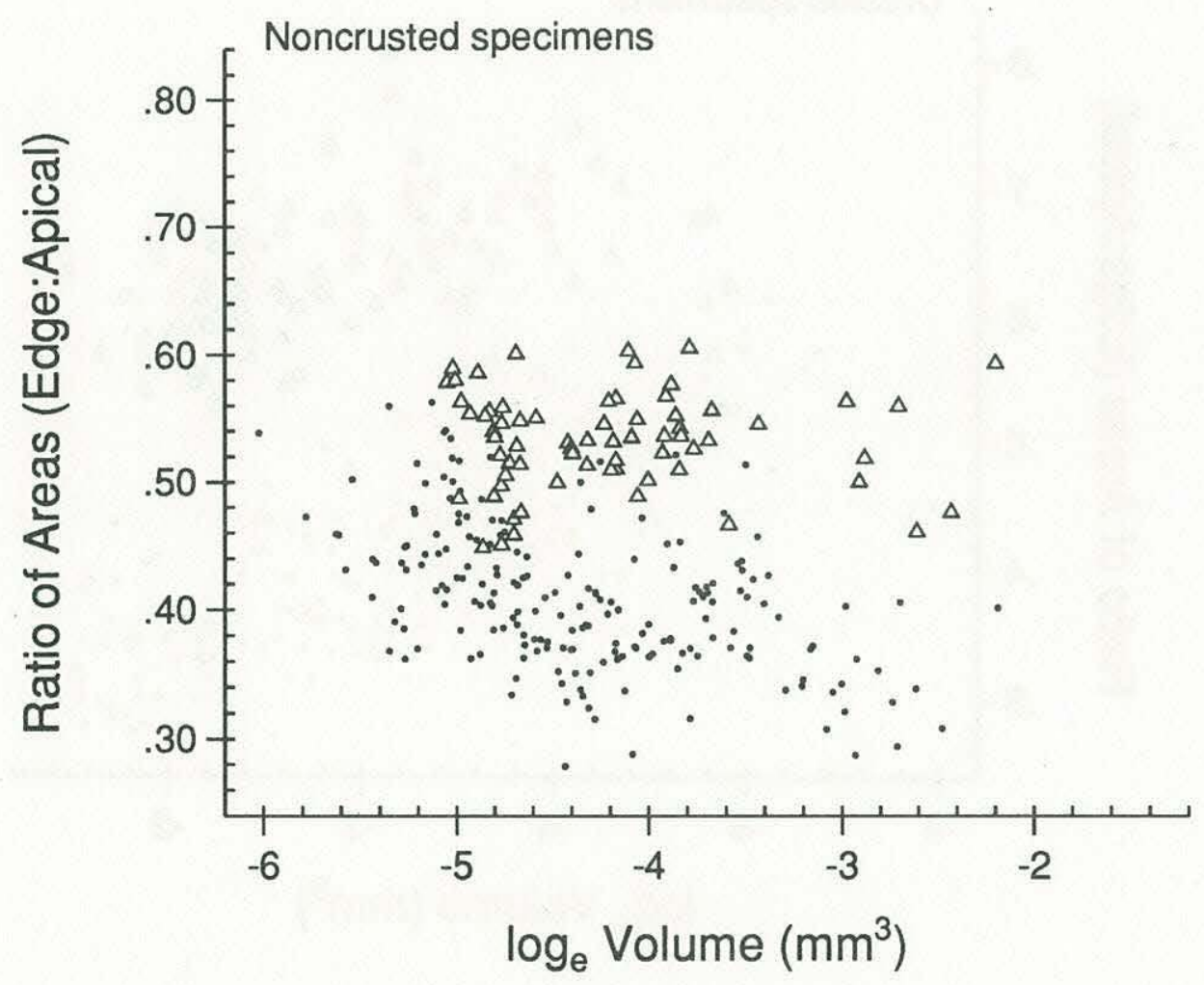

Figure 2.7: Axial compression of the test in noncrusted specimens of Globorotalia menardii and $G$. tumida. Dots represent specimens of $G$. menardii, triangles represent $G$. tumida. Axes are as in figure 2.6. Notice that noncrusted G. tumida do not become compressed as they get larger, while $G$. menardii do. 

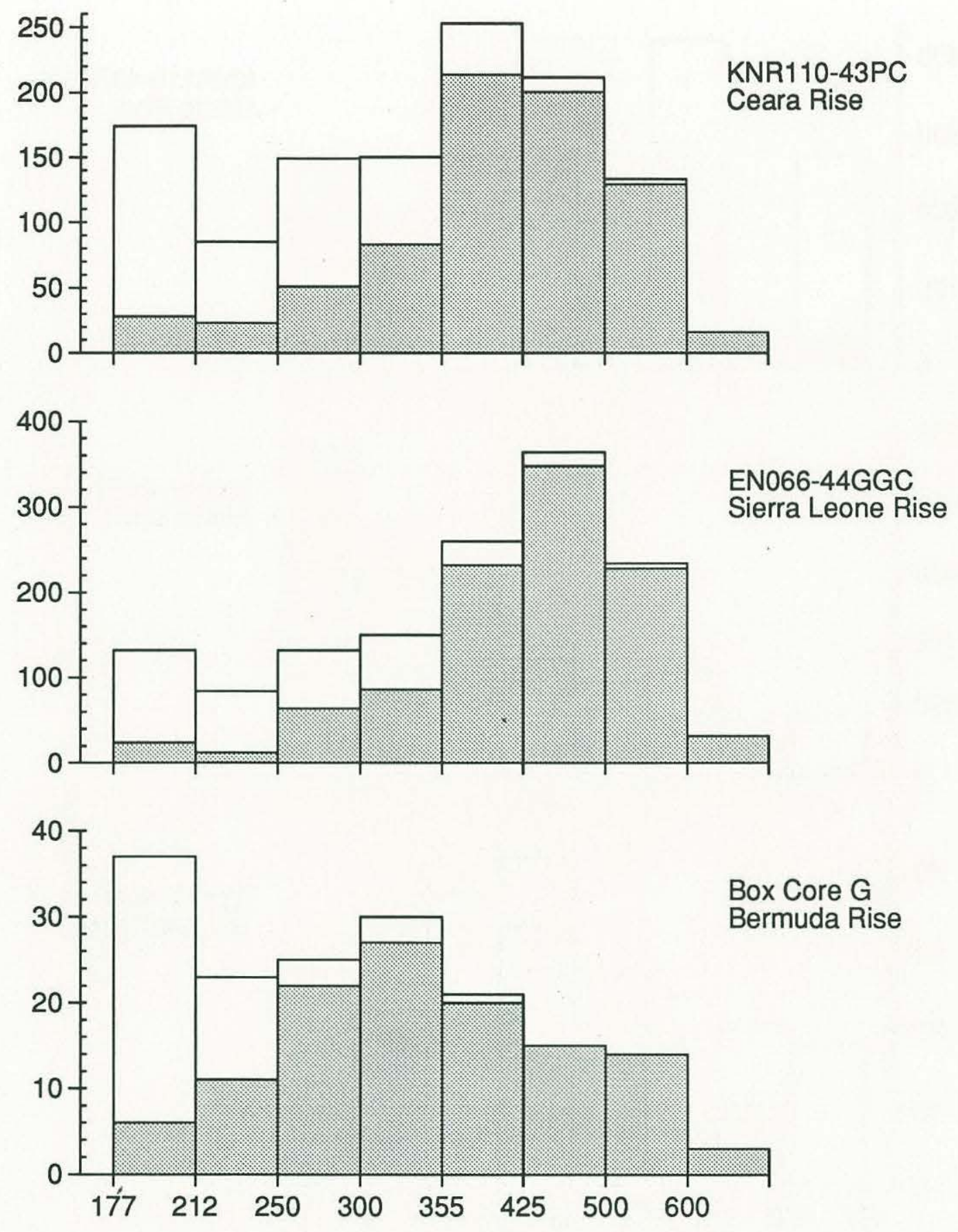

Figure 2.8: Geographic variation in size distribution of Globorotalia tumida. The shaded regions represent the abundance of crusted specimens in the given size-fractions. Unfilled regions stacked above the shaded areas represent the abundance of noncrusted specimens. 

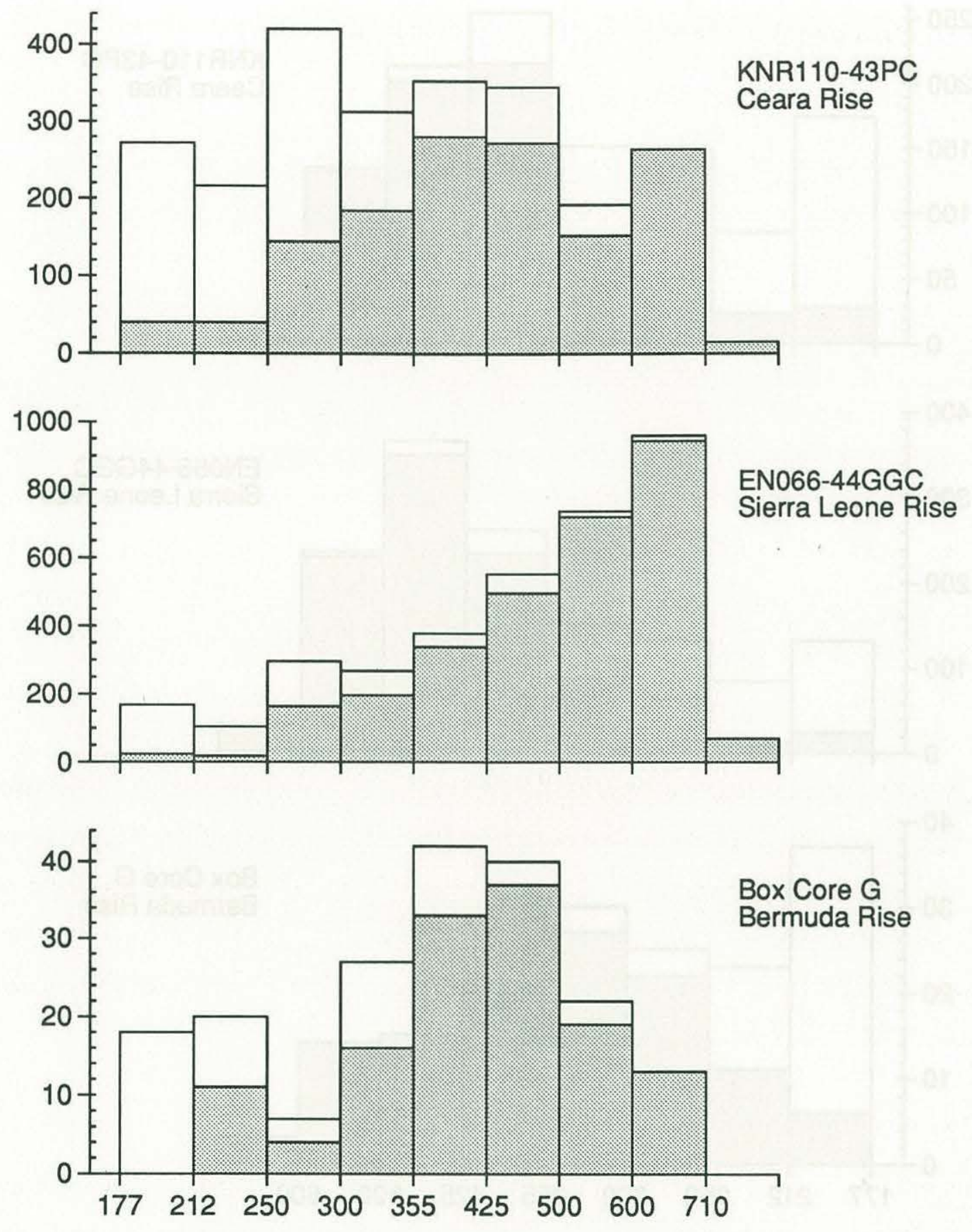

Figure 2.9: Geographic variation in size distribution of Globorotalia menardii. The shaded regions represent the abundance of crusted specimens in the given size-fractions. Unfilled regions stacked above the shaded areas represent the abundance of noncrusted specimens. 


\subsubsection{Ontogenetic changes in isotopic composition}

\section{Isotopic composition of whole shells}

Isotopic composition of whole shells yields broad patterns that can be used to make general statements about the depth habitat of these organisms. Calculations yielding the average shell compositions in each size fraction for both crusted and noncrusted specimens are shown in tables 2.1 and 2.2. These data are plotted with the expected composition of calcite precipitated in equilibrium with seawater at various depths (figures 2.10 and 2.11).

Equilibrium compositions were calculated from hydrographic data for GEOSECS station 39 of Bainbridge (1981), using methods described in detail by Lohmann and Curry (in review). Briefly, seawater $\delta^{18} \mathrm{O}$ relative to SMOW (Standard Mean Ocean Water) is calculated from salinity using a relationship shown in Broecker (1986) corrected to the PDB standard by subtracting 0.22 (Friedman and O'Neil 1977). For $\delta^{18} \mathrm{O}$ of calcite precipitated in equilibrium with seawater, the paleotemperature equation is used (Epstein et al. 1953, Craig, 1965). Seawater $\delta^{13} \mathrm{C}$ is calculated from its relationship to $\left[\mathrm{PO}_{4}\right]$ (Broecker 1982) using a surface-water $\delta^{13} \mathrm{C}$ value of 2.3. It too is corrected for temperature following Grossman (1984).

Generally, $\delta^{18} \mathrm{O}$ increases with increasing size in $G$. menardii, with a total size-related range of about $2 \%$, greater than the change in $\delta^{18} \mathrm{O}$ of Globigerinoides sacculifer at this site since the last glacial maximum (Curry and Crowley 1987). Noncrusted G. tumida show a slight trend in $\delta^{18} \mathrm{O}$ with size, spanning half the range of $\delta^{18} \mathrm{O}$ shown by $G$. menardii. For both species the mean $\delta^{18} \mathrm{O}$ of noncrusted specimens is about the same. Crusted specimens of both species have about $1 \%$ higher $\delta^{18} \mathrm{O}$ than do noncrusted specimens.

\section{Isotopic composition of added chambers and crust}

Changes in isotopic chemistry that occur during ontogeny can be interpreted more precisely with reference to biological models of growth. Here two key assumptions are used: (1) small specimens represent the early stages of large specimens, and (2) noncrusted specimens represent the pre-crusting status of crusted specimens. The first assumption allows us to compare the chemistry of successive size fractions of noncrusted specimens, so deriving the composition of the added noncrust (i.e. chamber) material. The second assumption allows us to calculate the 
composition of the calcite crust. Because the crust is distributed widely over the surface of the test, it does not increase the specimen's size. To calculate the composition of the crust, crusted specimens are compared with noncrusted specimens from the same size-fraction.

Results are listed in tables 2.3 and 2.4 ; the data are shown in figures 2.12 and 2.13 . In both species the calculated compositions of the crusts of various size-fractions all fall near each other, with a scatter of about $0.6 \%$ in both $\delta^{18} \mathrm{O}$ and $\delta^{13} \mathrm{C}$. The crusts of G. tumida fall close to the equilibrium values, while those for $G$. menardii fall away from equilibrium values, by about $1 \%_{0}$ in $\delta^{13} \mathrm{C}$ and about $2 \%_{0}$ in $\delta^{18} \mathrm{O}$. Calculated compositions of added chamber material approximately follow the equilibrium values in $G$. menardii but not in G. tumida.

\subsubsection{Geographic variations in isotopic composition}

To make a thorough study of geographic variation in isotopic composition, one should conduct analyses of widely separate localities in the same manner as those described above for the Ceara Rise. In an exploratory study such as this one, however, a few carefully selected analyses may yield enough information to indicate the character of geographic variability. In an analysis of a single size-fraction, the composition of the crust can be calculated if there are enough specimens of both noncrusted and crusted form. The size-distributions of both Globorotalia menardii and G. tumida indicate that most specimens grow the crust over a range of sizes; there are few crusted specimens smaller than $212 \mu \mathrm{m}$, and few noncrusted specimens greater than $500 \mu \mathrm{m}$.

Suppose that individuals in any given population generally grow the crust when they have reached a particular size which depends on local hydrography. Assuming the life-cycle to be purely deterministic and the local hydrography to be invariant, there would be a sharp division in size between crusted and noncrusted specimens. The sieve-size interval containing the size of crust formation would contain both crusted and noncrusted specimens, since sieve sizes would not generally coincide with the size of crust formation.

In practice, the life-cycle of individuals may be subject to random influences (e.g. individuals may be vertically advected by eddys) and the hydrography varies on a seasonal basis. The formation of the crust is spread out over a range of sizes. If only one size-fraction is to be analyzed, the best one to use in any location should be the one in which most of the specimens form their crusts, i.e. the size in which the numbers of crusted and noncrusted specimens is 
most nearly the same.

Figures 2.9 and 2.8 show that noncrusted and crusted specimens are nearly equal in abundance in the $250-300 \mu \mathrm{m}$ size-fraction at the Sierra Leone Rise. Specimens from this size-fraction show the same patterns in isotopic composition as the samples from the Ceara Rise (tables 2.5 and 2.6, figures 2.14 and 2.15). Noncrusted specimens are lighter in $\delta^{18} \mathrm{O}$ than crusted specimens by about 1qz, and the composition of the crust itself falls near the equilibrium values for G. tumida and slightly off the equilibrium values for $G$. menardii.

At the Bermuda Rise, the abundance of noncrusted and crusted G. tumida are closest in the $212-250 \mu \mathrm{m}$ size-fraction. Weaker patterns of abundance are seen in G. menardii. Two size-fractions of G. tumida and one of G. menardii were subjected to isotopic analysis. Results are shown in tables 2.7 and 2.8 and figures 2.16 and 2.17. In both species the composition of the crusted specimens is much closer to that of noncrusted specimens than at either of the two equatorial sites. In both species the shell compositions fall away from those that would be expected if the calcite were precipitated in equilibrium with seawater. This can be explained partially by noticing that the Bermuda Rise is a region where the surface ocean hydrography undergoes large changes seasonally. The equilibrium values plotted in the figures were calculated from GEOSECS station 121, which was occupied at the end of March, 1973. Water temperature at the nearby Panulirus II station reaches a minimum at this time, and the seasonal thermocline, whose effects extend to nearly $200 \mathrm{~m}$ in summer, is almost completely suppressed in March (E. Schroeder, pers. comm. reported in Deuser et al. 1981). Equilibrium values of surface-water $\delta^{18} \mathrm{O}$ increase $2 \%$ from April to August (Deuser et al. 1981). If G. menardii and G. tumida grow in equilibrium with seawater $\delta^{18} \mathrm{O}$, they must be growing during the summer at the Bermuda Rise. Evidence that $G$. menardii precipitates in equilibrium with seawater $\delta^{18} \mathrm{O}$ was presented by Curry et al. (1983) and Fairbanks et al. (1982) for the Panama Basin. 
Table 2.1: Measured isotopic composition of Globorotalia menardii from the Ceara Rise (core KNR110-43PC). Average compositions of individuals from each size-fraction are shown, and in size-fractions containing both crusted and noncrusted specimens these two morphologies were analyzed separately.

\begin{tabular}{cccccc} 
& & & & \multicolumn{2}{c}{ Average } \\
Sieve & $\mathrm{c} / \mathrm{n}$ & $\delta^{18} \mathrm{O}$ & $\delta^{13} \mathrm{C}$ & $\delta^{18} \mathrm{O}$ & $\delta^{13} \mathrm{C}$ \\
177 & $\mathrm{n}$ & -1.81 & 2.26 & & \\
& $\mathrm{n}$ & -1.63 & 1.56 & -1.72 & 1.56 \\
212 & $\mathrm{n}$ & -1.78 & 1.90 & & \\
& $\mathrm{n}$ & -2.43 & 1.74 & -2.10 & 1.82 \\
250 & $\mathrm{n}$ & -1.83 & 1.89 & & \\
& $\mathrm{n}$ & -1.54 & 2.40 & & \\
& $\mathrm{n}$ & -1.57 & 2.13 & -1.65 & 2.14 \\
& $\mathrm{c}$ & -1.23 & 1.63 & & \\
& $\mathrm{c}$ & -1.14 & 1.67 & & \\
& $\mathrm{c}$ & -1.36 & 1.86 & -1.24 & 1.72 \\
300 & $\mathrm{n}$ & -1.44 & 2.08 & & \\
& $\mathrm{n}$ & -1.17 & 2.26 & & \\
& $\mathrm{n}$ & -2.05 & 2.29 & -1.55 & 2.21 \\
& $\mathrm{c}$ & -1.31 & 1.75 & & \\
& $\mathrm{c}$ & -0.95 & 1.88 & & \\
& $\mathrm{c}$ & -0.61 & 2.19 & -0.96 & 1.94 \\
355 & $\mathrm{n}$ & -1.43 & 2.22 & & \\
& $\mathrm{n}$ & -1.07 & 2.48 & -1.25 & 2.35 \\
& $\mathrm{c}$ & -1.16 & 1.96 & & \\
& $\mathrm{c}$ & -0.95 & 2.16 & -1.05 & 2.06 \\
525 & $\mathrm{n}$ & -1.34 & 1.75 & & \\
& $\mathrm{n}$ & -0.86 & 2.44 & -1.10 & 2.09 \\
& $\mathrm{c}$ & -0.85 & 2.20 & & \\
& $\mathrm{c}$ & -0.63 & 2.08 & -0.74 & 2.14 \\
& $\mathrm{n}$ & -0.32 & 1.87 & & \\
& $\mathrm{n}$ & -1.23 & 2.43 & -0.78 & 2.15 \\
& $\mathrm{c}$ & -0.72 & 2.31 & & \\
& $\mathrm{c}$ & -1.14 & 1.88 & -0.93 & 2.09 \\
& $\mathrm{c}$ & -0.32 & 2.03 & & \\
& $\mathrm{c}$ & -1.01 & 2.25 & -0.67 & 2.14 \\
& $\mathrm{c}$ & -0.57 & 2.19 & & \\
& $\mathrm{c}$ & -0.31 & 1.84 & -0.44 & 2.02
\end{tabular}


Table 2.2: Measured isotopic composition of Globorotalia tumida from the Ceara Rise (core KNR110-43PC). Average compositions of individuals from each size-fraction are shown, and in size-fractions containing both crusted and noncrusted specimens these two morphologies were analyzed separately.

\begin{tabular}{|c|c|c|c|c|c|}
\hline \multirow[b]{2}{*}{ Sieve } & \multirow[b]{2}{*}{$\mathrm{c} / \mathrm{n}$} & \multirow[b]{2}{*}{$\delta^{18} \mathrm{O}$} & \multirow[b]{2}{*}{$\delta^{13} \mathrm{C}$} & \multicolumn{2}{|c|}{ Average } \\
\hline & & & & $\delta^{18} \mathrm{O}$ & $\delta^{13} \mathrm{C}$ \\
\hline \multirow[t]{2}{*}{177} & $\mathrm{n}$ & -1.71 & 1.87 & & \\
\hline & $\mathrm{n}$ & -1.82 & 1.74 & -1.77 & 1.81 \\
\hline \multirow[t]{2}{*}{212} & $\mathrm{n}$ & -1.27 & 1.72 & & \\
\hline & $\mathrm{n}$ & -1.54 & 1.76 & -1.41 & 1.74 \\
\hline \multirow[t]{9}{*}{250} & c & -0.23 & 2.06 & & \\
\hline & c & -0.81 & 1.97 & & \\
\hline & c & -1.32 & 1.34 & & \\
\hline & c & -0.31 & 1.57 & & \\
\hline & c & -0.78 & 1.48 & -0.69 & 1.68 \\
\hline & $\mathrm{n}$ & -1.24 & 2.33 & & \\
\hline & $\mathrm{n}$ & -1.61 & 2.07 & & \\
\hline & $\mathrm{n}$ & -1.88 & 1.93 & & \\
\hline & $\mathrm{n}$ & -1.42 & 2.23 & -1.54 & 2.14 \\
\hline \multirow[t]{5}{*}{300} & c & -0.32 & 1.80 & & \\
\hline & c & -0.36 & 2.00 & & \\
\hline & c & -0.16 & 1.91 & & \\
\hline & c & -0.07 & 1.98 & -0.23 & 1.92 \\
\hline & $\mathrm{n}$ & -1.35 & 2.44 & -1.35 & 2.44 \\
\hline \multirow[t]{4}{*}{355} & c & -0.13 & 1.98 & & \\
\hline & c & -0.50 & 2.15 & -0.32 & 2.06 \\
\hline & $\mathrm{n}$ & -1.61 & 1.52 & & \\
\hline & $\mathrm{n}$ & -1.00 & 1.88 & -1.31 & 1.70 \\
\hline \multirow[t]{5}{*}{425} & c & -0.32 & 2.14 & & \\
\hline & c & 0.59 & 2.08 & & \\
\hline & c & -0.89 & 1.94 & -0.21 & 2.05 \\
\hline & $\mathrm{n}$ & -1.39 & 2.13 & & \\
\hline & $\mathrm{n}$ & -1.44 & 1.57 & -1.42 & 1.85 \\
\hline \multirow[t]{4}{*}{500} & c & 0.26 & 1.53 & & \\
\hline & c & 0.05 & 2.09 & & \\
\hline & c & -0.09 & 2.22 & 0.07 & 1.95 \\
\hline & $\mathrm{n}$ & -1.08 & 1.44 & -1.08 & 1.44 \\
\hline \multirow[t]{3}{*}{600} & c & -0.88 & 1.47 & & \\
\hline & c & -0.15 & 2.08 & & \\
\hline & c & 1.26 & 1.74 & -0.52 & 1.77 \\
\hline
\end{tabular}




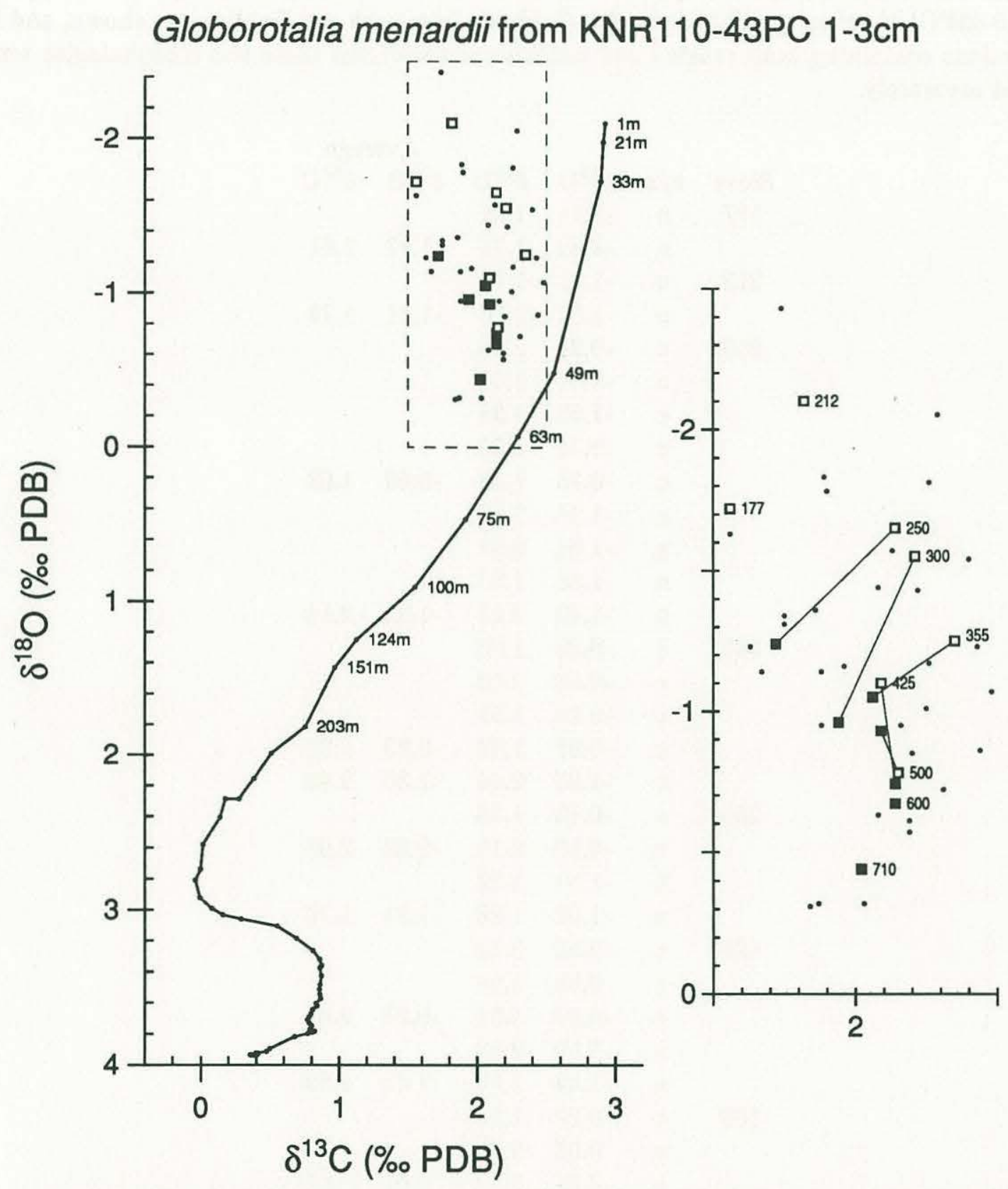

Figure 2.10: Variation in isotopic composition of Globorotalia menardii at the Ceara Rise in the Western Equatorial Atlantic. Observed values are marked as small dots. The average composition of each size fraction is shown as a square symbol. Noncrusted shells are marked with open squares, crusted shells are marked with filled squares. The solid line represents equilibrium calcite compositions calculated from hydrographic data (GEOSECS cast 39). The dashed line marks the area shown in the inset. In the inset, lines connect values for the same size-fraction. 


\section{Globorotalia tumida from KNR110-43PC 1-3cm}

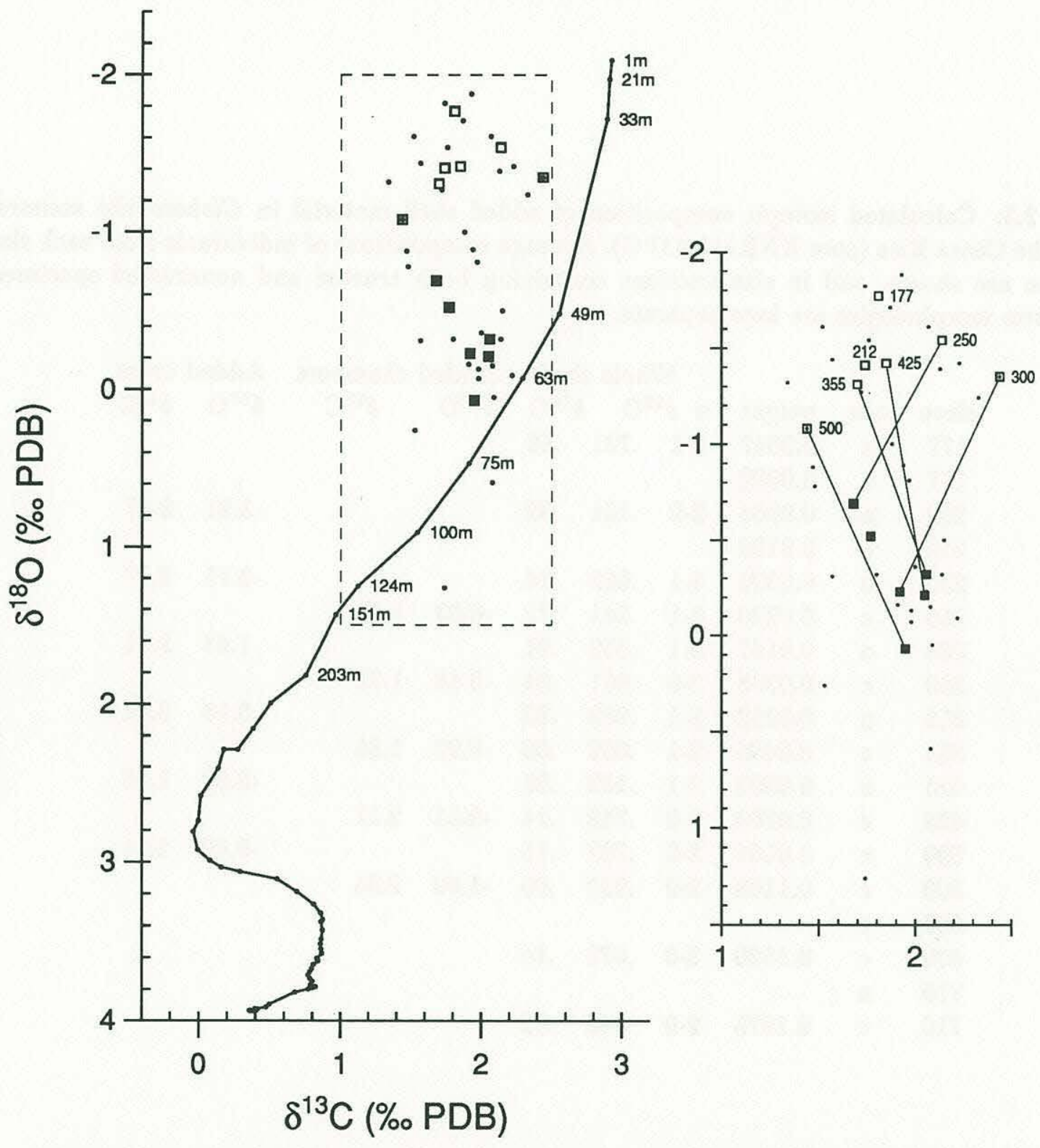

Figure 2.11: Variation in isotopic composition of Globorotalia tumida at the Ceara Rise in the Western Equatorial Atlantic. Observed values are marked as small dots. The average composition of each size fraction is shown as a square symbol. Noncrusted shells are marked with open squares, crusted shells are marked with filled squares. The solid line represents equilibrium calcite compositions calculated from hydrographic data (GEOSECS cast 39). The dashed line marks the area shown in the inset. In the inset, lines connect values for the same size-fraction. 
Table 2.3: Calculated isotopic composition of added shell material in Globorotalia menardii from the Ceara Rise (core KNR110-43PC). Average compositions of individuals from each sizefraction are shown, and in size-fractions containing both crusted and noncrusted specimens these two morphologies are kept separate.

\begin{tabular}{cccccccccccc} 
& & \multicolumn{1}{c}{ Whole shells } & \multicolumn{3}{c}{ Added chambers } & \multicolumn{2}{c}{ Added crust } \\
sieve & c/n & weight & $n$ & $\delta^{18} \mathrm{O}$ & $\delta^{13} \mathrm{C}$ & $\delta^{18} \mathrm{O}$ & $\delta^{13} \mathrm{C}$ & $\delta^{18} \mathrm{O}$ & $\delta^{13} \mathrm{C}$ \\
177 & $\mathrm{n}$ & 0.0047 & $2-1$ & .721 & .56 & & & & & \\
177 & $\mathrm{c}$ & 0.0092 & & & & & & & \\
212 & $\mathrm{n}$ & 0.0064 & $2-2$ & .101 & .82 & & & -3.21 & 2.57 \\
212 & $\mathrm{c}$ & 0.0129 & & & & & & & \\
250 & $\mathrm{n}$ & 0.0096 & $3-1$ & .652 & .14 & & & -0.75 & 2.77 \\
250 & $\mathrm{c}$ & 0.0220 & $3-1$ & .241 & .72 & -0.93 & 1.39 & & \\
300 & $\mathrm{n}$ & 0.0167 & $3-1$ & .552 & .21 & & & -1.43 & 2.31 \\
300 & $\mathrm{c}$ & 0.0368 & $3-0$ & .961 & .94 & -0.46 & 1.72 & & \\
355 & $\mathrm{n}$ & 0.0202 & $2-1$ & .252 & .35 & & & 0.18 & 3.01 \\
355 & $\mathrm{c}$ & 0.0495 & $2-1$ & .052 & .06 & -0.92 & 1.86 & & \\
425 & $\mathrm{n}$ & 0.0302 & $2-1$ & .102 & .09 & & & -0.80 & 1.58 \\
425 & $\mathrm{c}$ & 0.0769 & $2-0$ & .742 & .14 & -0.51 & 2.17 & & \\
500 & $\mathrm{n}$ & 0.0564 & $2-0$ & .782 & .15 & & & -0.40 & 2.21 \\
500 & $\mathrm{c}$ & 0.1108 & $2-0$ & .932 & .09 & -1.09 & 2.04 & & \\
600 & $\mathrm{n}$ & & & & & & & & \\
600 & $\mathrm{c}$ & 0.1520 & $2-0$ & .672 & .14 & & & & \\
710 & $\mathrm{n}$ & & & & & & & & \\
710 & $\mathrm{c}$ & 0.1975 & $2-0$ & .442 & .02 & & & &
\end{tabular}


Table 2.4: Calculated isotopic composition of added shell material in Globorotalia tumida from the Ceara Rise (core KNR110-43PC). Average compositions of individuals from each sizefraction are shown, and in size-fractions containing both crusted and noncrusted specimens these two morphologies were analyzed separately.

\begin{tabular}{|c|c|c|c|c|c|c|c|c|c|}
\hline \multirow[b]{2}{*}{ sieve } & \multirow[b]{2}{*}{$\mathrm{c} / \mathrm{n}$} & \multirow[b]{2}{*}{ weight } & \multicolumn{3}{|c|}{ Whole shells } & \multicolumn{2}{|c|}{ Added chambers } & \multicolumn{2}{|c|}{ Added crust } \\
\hline & & & $\delta^{18} \mathrm{O}$ & $\delta^{13} \mathrm{C}$ & $n$ & $\delta^{18} \mathrm{O}$ & $\delta^{13} \mathrm{C}$ & $\delta^{18} \mathrm{O}$ & $\delta^{13} \mathrm{C}$ \\
\hline \multirow[t]{2}{*}{177} & $\mathrm{n}$ & 0.0053 & -1.77 & 1.81 & 2 & & & & \\
\hline & c & 0.0112 & & & & & & & \\
\hline \multirow[t]{2}{*}{212} & $\mathrm{n}$ & 0.0061 & -1.41 & 1.74 & 2 & 0.86 & 1.33 & & \\
\hline & c & 0.0156 & & & & & & & \\
\hline \multirow[t]{2}{*}{250} & $\mathrm{n}$ & 0.0109 & -1.54 & 2.14 & 4 & -1.71 & 2.65 & & \\
\hline & c & 0.0294 & -0.69 & 1.68 & 5 & & & -0.19 & 1.41 \\
\hline \multirow[t]{2}{*}{300} & $\mathrm{n}$ & 0.0226 & -1.35 & 2.44 & 1 & -1.17 & 2.72 & & \\
\hline & c & 0.0521 & -0.23 & 1.92 & 4 & & & 0.63 & 1.53 \\
\hline \multirow[t]{2}{*}{355} & $\mathrm{n}$ & 0.0404 & -1.31 & 1.70 & 2 & -1.25 & 0.76 & & \\
\hline & c & 0.0841 & -0.32 & 2.06 & 2 & & & 0.60 & 2.40 \\
\hline \multirow[t]{2}{*}{425} & $\mathrm{n}$ & 0.0586 & -1.42 & 1.85 & 2 & -1.66 & 2.18 & & \\
\hline & c & 0.1315 & -0.21 & 2.05 & 3 & & & 0.76 & 2.22 \\
\hline \multirow[t]{2}{*}{500} & $\mathrm{n}$ & 0.0608 & -1.08 & 1.44 & 1 & 7.91 & -9.56 & & \\
\hline & c & 0.1726 & 0.07 & 1.95 & 3 & & & 0.70 & 2.22 \\
\hline \multirow[t]{2}{*}{600} & $\mathrm{n}$ & & & & & & & & \\
\hline & c & 0.2187 & -0.52 & 1.77 & 3 & & & & \\
\hline
\end{tabular}




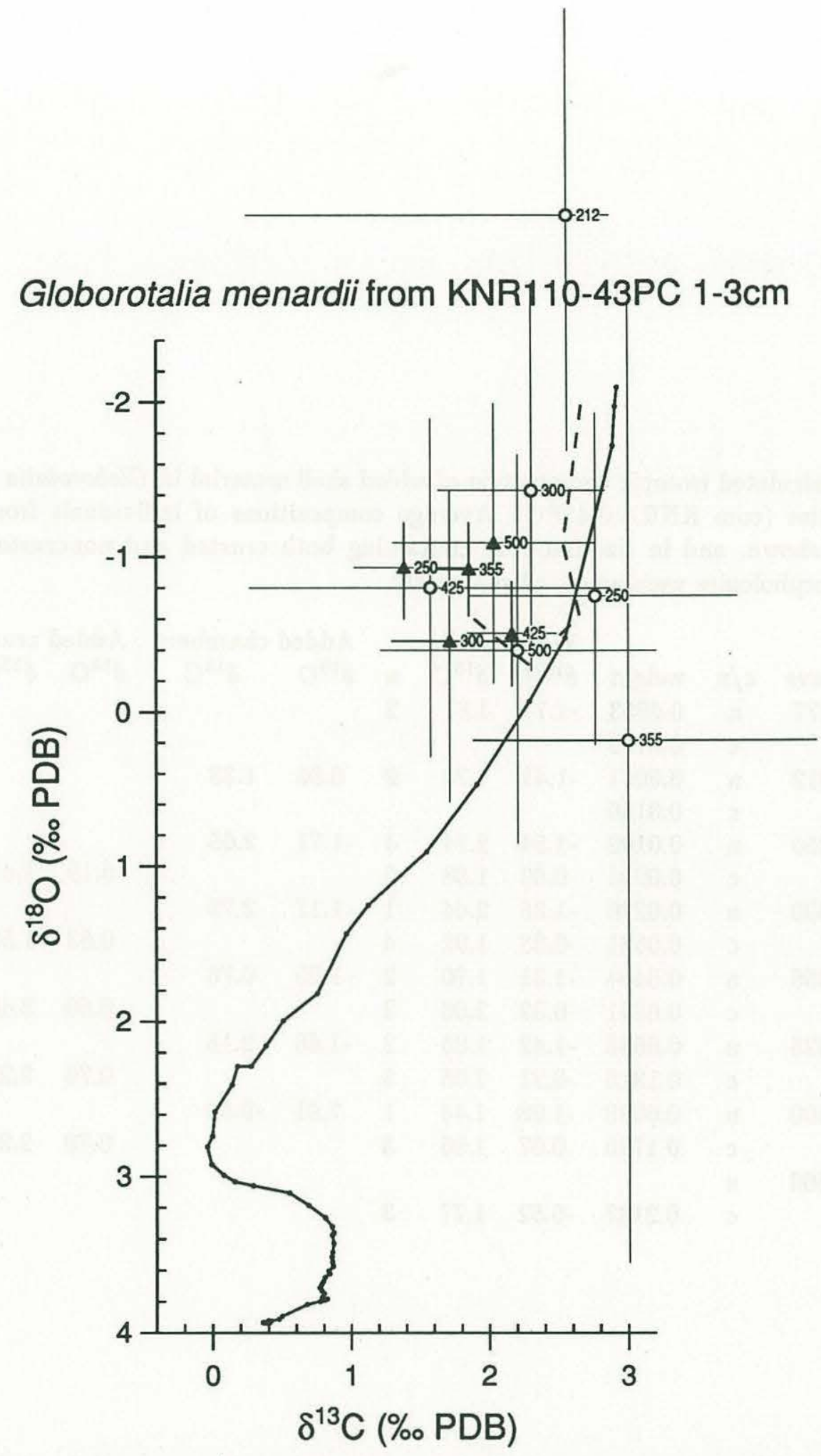

Figure 2.12: Variation in isotopic composition of chambers (circles) and crust (triangles) added to tests of Globorotalia menardii during ontogeny. The dashed line connects points calculated as the running mean of the chamber compositions (i.e. a moving average of the circles). 


\section{Globorotalia tumida from KNR110-43PC 1-3cm}

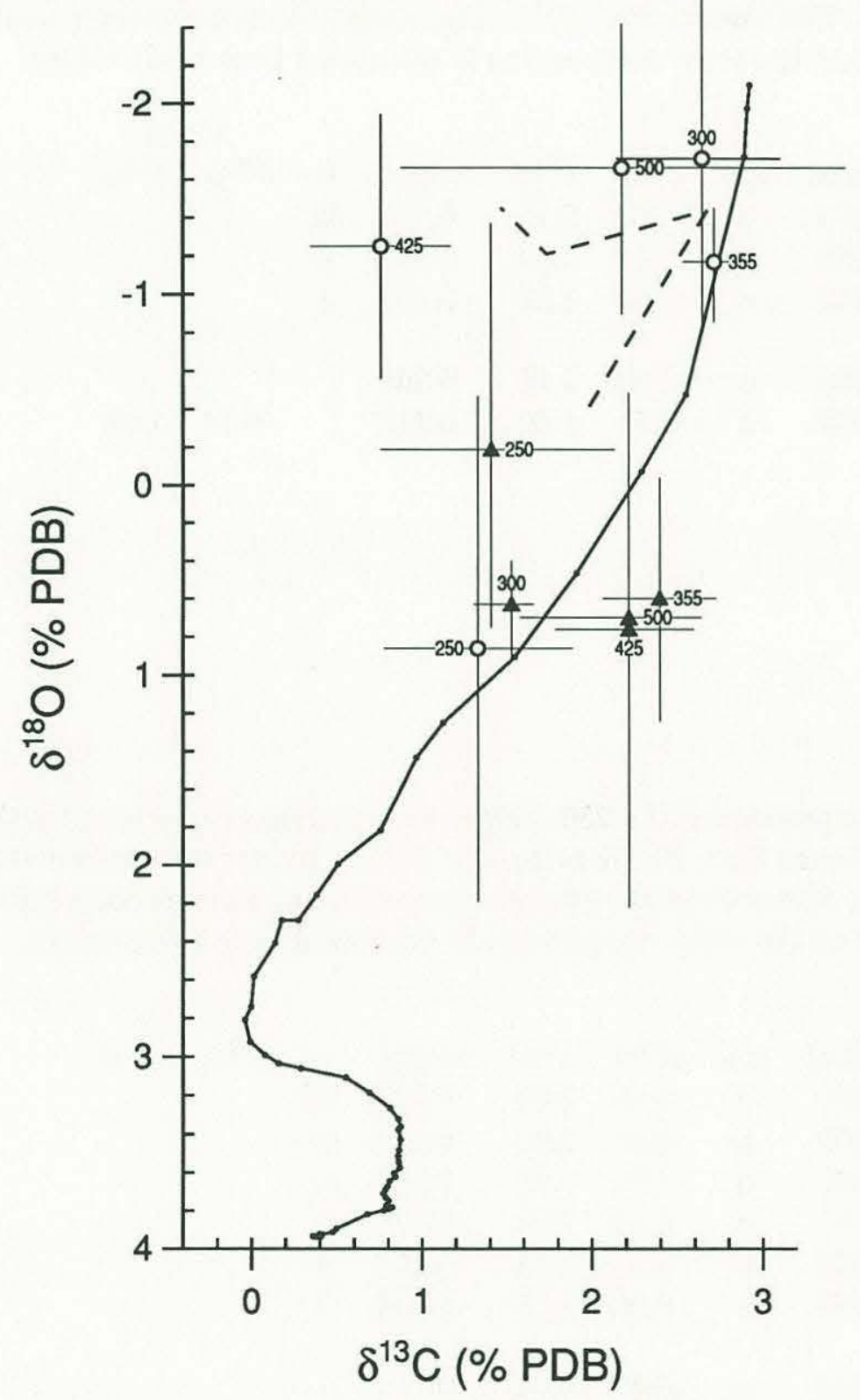

Figure 2.13: Variation in isotopic composition of chambers (circles) and crust (triangles) added to tests of Globorotalia tumida during ontogeny. The dashed line connects points calculated as the running mean of the chamber compositions (i.e. a moving average of the circles). 
Table 2.5: Isotopic composition of the 250-300 $\mu \mathrm{m}$ size-fraction of $G$. menardii from core EN066$44 \mathrm{GGC}$ at the Sierra Leone Rise. In the table, $\mathrm{c} / \mathrm{n}$ shows whether the specimens analyzed were crusted or noncrusted. The rows at the bottom summarize the average composition and weight of each size-fraction, and the crust composition is calculated from these values.

\begin{tabular}{ccccrccc} 
& & & & & \multicolumn{4}{c}{ Crust } \\
sieve & $\mathrm{c} / \mathrm{n}$ & $\delta^{18} \mathrm{O}$ & $\delta^{13} \mathrm{C}$ & weight & $n$ & $\delta^{18} \mathrm{O}$ & $\delta^{13} \mathrm{C}$ \\
250 & $\mathrm{n}$ & -1.60 & 2.15 & 0.267 & 32 & & \\
250 & $\mathrm{c}$ & -0.07 & 1.60 & 0.183 & 8 & & \\
250 & $\mathrm{c}$ & -1.35 & 1.37 & 0.159 & 8 & & \\
& & & & & & & \\
250 & $\mathrm{n}$ & -1.60 & 2.15 & 0.008 & & & \\
250 & $\mathrm{c}$ & -0.71 & 1.49 & 0.021 & & -0.14 & 1.06
\end{tabular}

Table 2.6: Isotopic composition of the $250-300 \mu \mathrm{m}$ size-fraction of $G$. tumida from core EN06644GGC at the Sierra Leone Rise. In the table, $c / n$ shows whether the specimens analyzed were crusted or noncrusted. The rows at the bottom summarize the average composition and weight of each size-fraction, and the crust composition is calculated from these values.

\begin{tabular}{ccrrrrrr} 
& \multicolumn{1}{c}{} & \multicolumn{1}{c}{ crust } \\
250 & $\mathrm{n}$ & -0.98 & 2.05 & 0.127 & 10 & & \\
250 & $\mathrm{n}$ & -0.72 & 2.09 & 0.118 & 12 & & \\
250 & $\mathrm{n}$ & -1.04 & 1.96 & 0.129 & 14 & & \\
250 & $\mathrm{c}$ & 0.11 & 1.53 & 0.198 & 5 & & \\
250 & $\mathrm{c}$ & 0.36 & 1.58 & 0.164 & 6 & & \\
250 & $\mathrm{c}$ & 0.00 & 1.45 & 0.194 & 7 & & \\
& & & & & & & \\
250 & $\mathrm{n}$ & -0.91 & 2.03 & 0.010 & & & \\
250 & $\mathrm{c}$ & 0.16 & 1.52 & 0.031 & & 0.70 & 1.26
\end{tabular}




\section{Globorotalia menardii from EN066-44GGC 0-2cm}

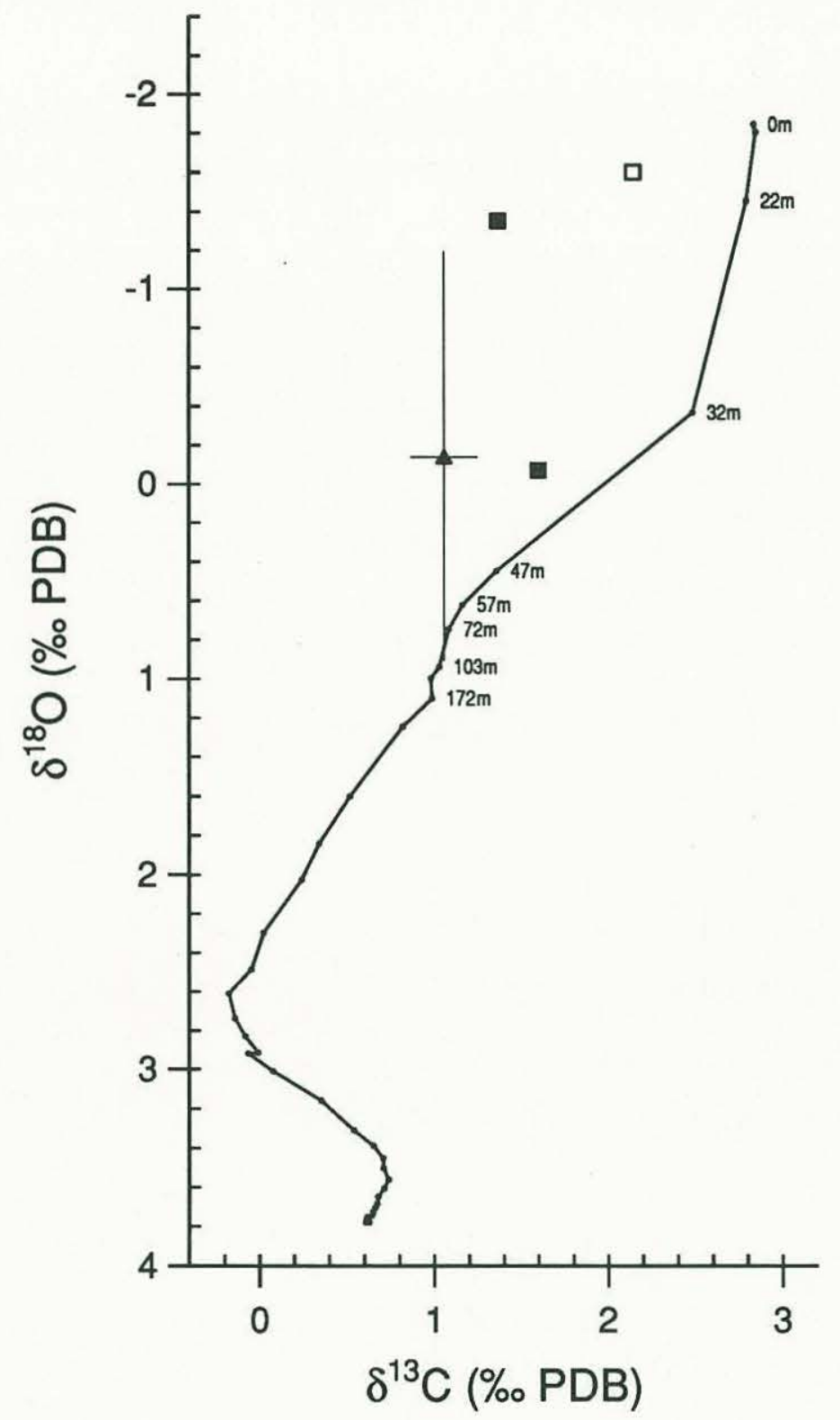

Figure 2.14: Variation in isotopic composition of Globorotalia menardii at the Sierra Leone Rise. Specimens were taken from the size fraction between $250 \mu \mathrm{m}$ and $300 \mu \mathrm{m}$. The line shows the composition of calcite precipitated in equilibrium with seawater at various depths, calculated from the hydrographic data of GEOSECS station 112. 


\section{Globorotalia tumida from EN066-44GGC 0-2cm}

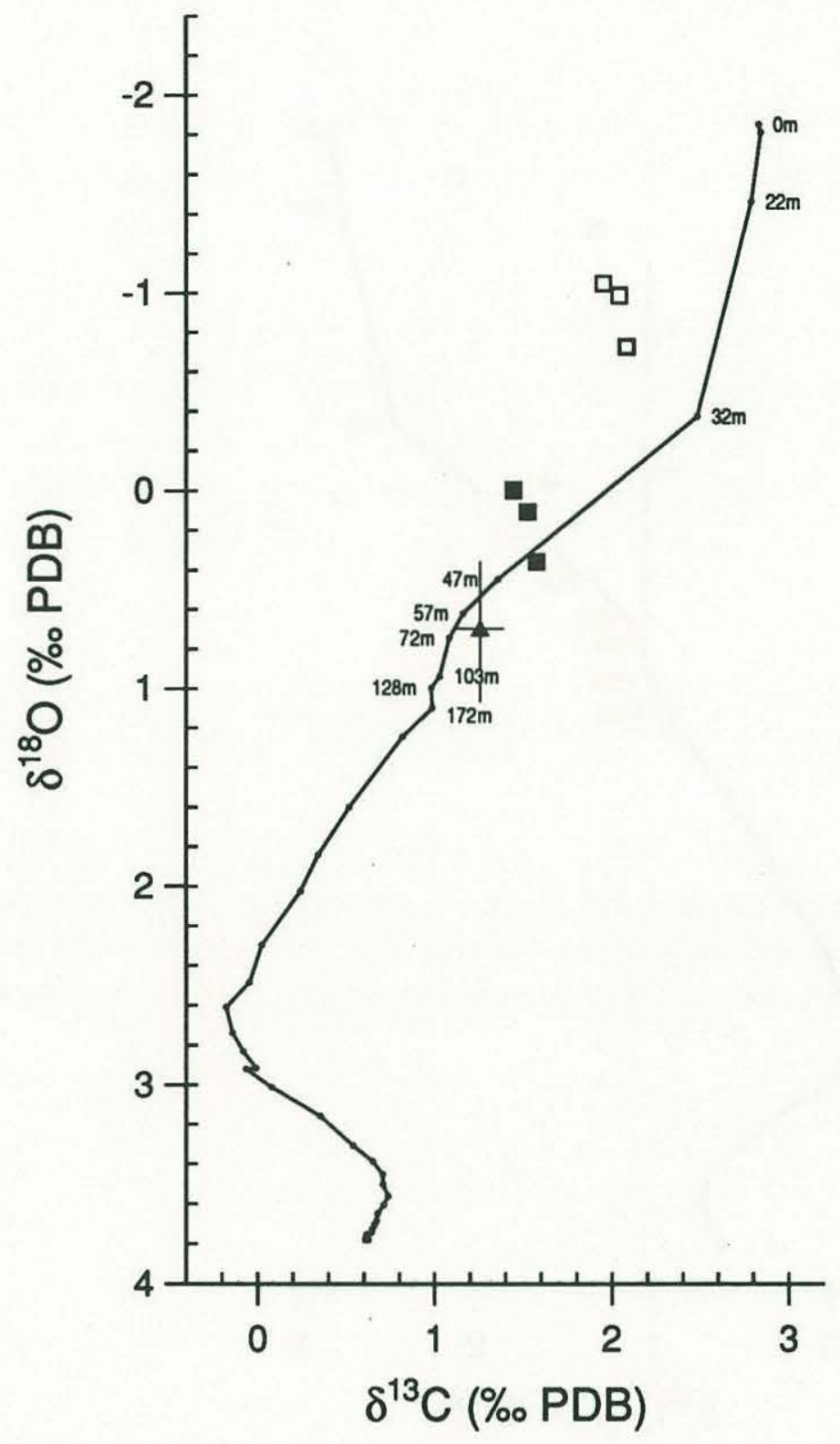

Figure 2.15: Variation in isotopic composition of Globorotalia tumida at the Sierra Leone Rise. Specimens were taken from the $250-300 \mu \mathrm{m}$ size fraction. The line shows the composition of calcite precipitated in equilibrium with seawater at various depths, calculated from the hydrographic data of GEOSECS station 112. 
Table 2.7: Isotopic composition of the $300-355 \mu \mathrm{m}$ size-fraction of $G$. menardii from box core "G" at the Bermuda Rise. In the table, c/n shows whether the specimens analyzed were crusted or noncrusted. The rows at the bottom summarize the average composition and weight of each size-fraction, and the crust composition is calculated from these values.

\begin{tabular}{cccccccc} 
& & & & & \multicolumn{4}{c}{ Crust } \\
sieve & $\mathrm{c} / \mathrm{n}$ & $\delta^{18} \mathrm{O}$ & $\delta^{13} \mathrm{C}$ & weight & $n$ & $\delta^{18} \mathrm{O}$ & $\delta^{13} \mathrm{C}$ \\
300 & $\mathrm{n}$ & -0.71 & 1.42 & 0.184 & 10 & & \\
300 & $\mathrm{n}$ & -1.10 & 1.31 & 0.140 & 10 & & \\
300 & $\mathrm{n}$ & -1.28 & 1.39 & 0.130 & 10 & & \\
300 & $\mathrm{c}$ & -0.41 & 1.62 & 0.266 & 6 & & \\
300 & $\mathrm{c}$ & -1.07 & 1.31 & 0.247 & 6 & & \\
300 & $\mathrm{c}$ & -0.65 & 1.55 & 0.218 & 6 & & \\
& & & & & & & \\
300 & $\mathrm{n}$ & -1.03 & 1.37 & 0.015 & & & \\
300 & $\mathrm{c}$ & -0.71 & 1.49 & 0.041 & & -0.52 & 1.56
\end{tabular}

Table 2.8: Isotopic composition of the $212-250 \mu \mathrm{m}$ and $300-355 \mu \mathrm{m}$ size-fractions of G. tumida from box core " $G$ " at the Bermuda Rise. In the table, $c / n$ shows whether the specimens analyzed were crusted or noncrusted. The rows at the bottom summarize the average composition and weight of each size-fraction, and the crust composition is calculated from these values.

\begin{tabular}{ccrrrrrr} 
& & & & & \multicolumn{3}{c}{ Crust } \\
sieve & $\mathrm{c} / \mathrm{n}$ & $\delta^{18} \mathrm{O}$ & $\delta^{13} \mathrm{C}$ & weight & $n$ & $\delta^{18} \mathrm{O}$ & $\delta^{13} \mathrm{C}$ \\
212 & $\mathrm{n}$ & 0.00 & 0.83 & 0.117 & 13 & & \\
212 & $\mathrm{n}$ & -0.68 & 0.93 & 0.122 & 18 & & \\
212 & $\mathrm{c}$ & -0.35 & 0.95 & 0.136 & 8 & & \\
212 & $\mathrm{c}$ & -0.06 & 0.67 & 0.153 & 8 & & \\
212 & $\mathrm{c}$ & -0.32 & 0.79 & 0.130 & 8 & & \\
300 & $\mathrm{n}$ & -0.96 & 1.35 & 0.140 & 8 & & \\
300 & $\mathrm{n}$ & -0.45 & 1.35 & 0.181 & 6 & & \\
300 & $\mathrm{c}$ & -0.11 & 1.62 & 0.335 & 6 & & \\
300 & $\mathrm{c}$ & -0.44 & 1.95 & 0.357 & 6 & & \\
& & & & & & & \\
212 & $\mathrm{n}$ & -0.34 & 0.88 & 0.008 & & & \\
212 & $\mathrm{c}$ & -0.24 & 0.80 & 0.017 & & -0.17 & 0.74 \\
300 & $\mathrm{n}$ & -0.70 & 1.35 & 0.023 & & & \\
300 & $\mathrm{c}$ & -0.28 & 1.79 & 0.058 & & 0.01 & 2.07
\end{tabular}




\section{Globorotalia menardii from Box Core "G"}

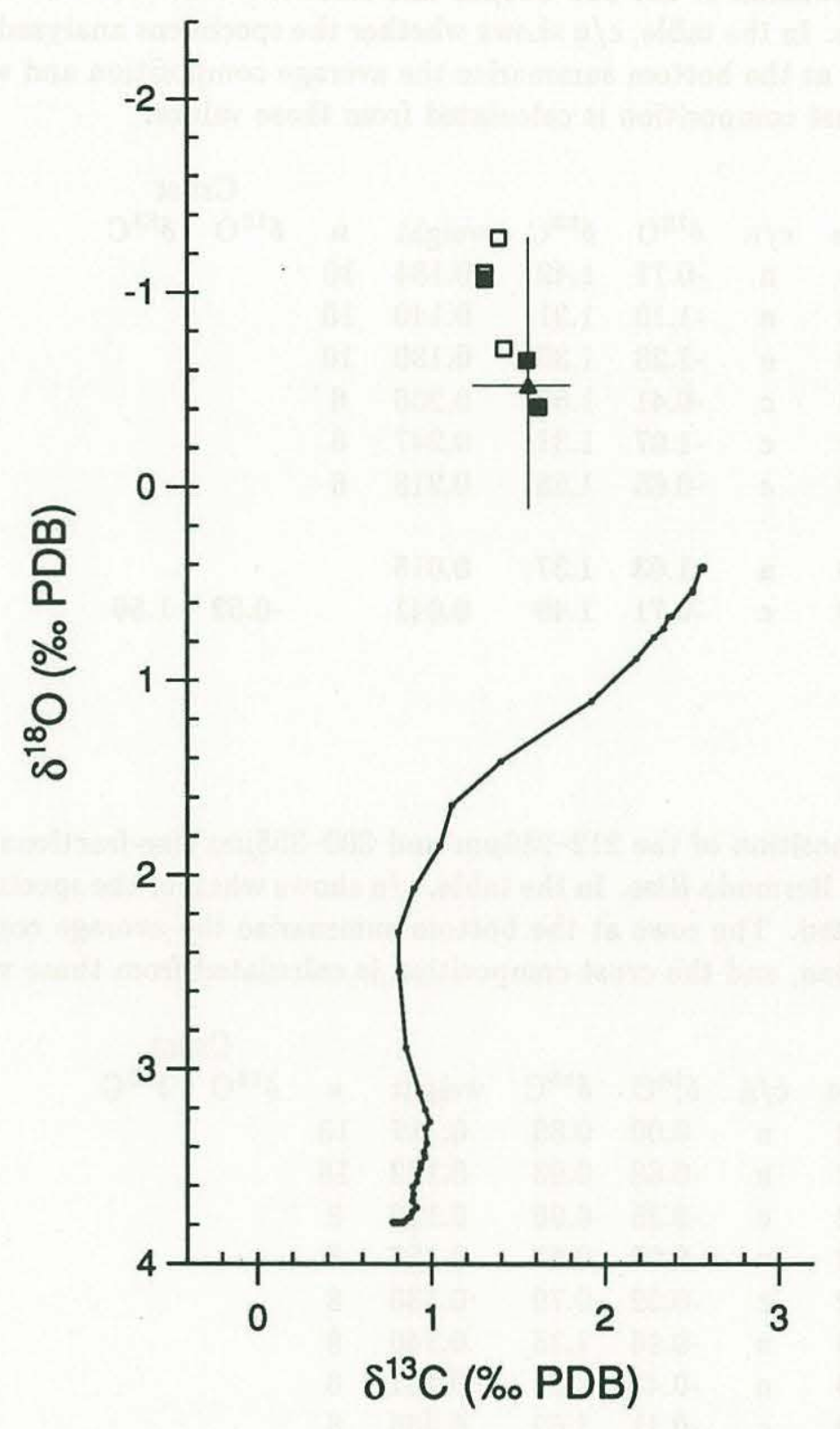

Figure 2.16: Variation in isotopic composition of Globorotalia menardii at the Bermuda Rise. Specimens were taken from the $300-355 \mu \mathrm{m}$ size fraction. The line shows the composition of calcite precipitated in equilibrium with seawater at various depths, calculated from the hydrographic data of GEOSECS station 121. 


\section{Globorotalia tumida from Box Core "G"}

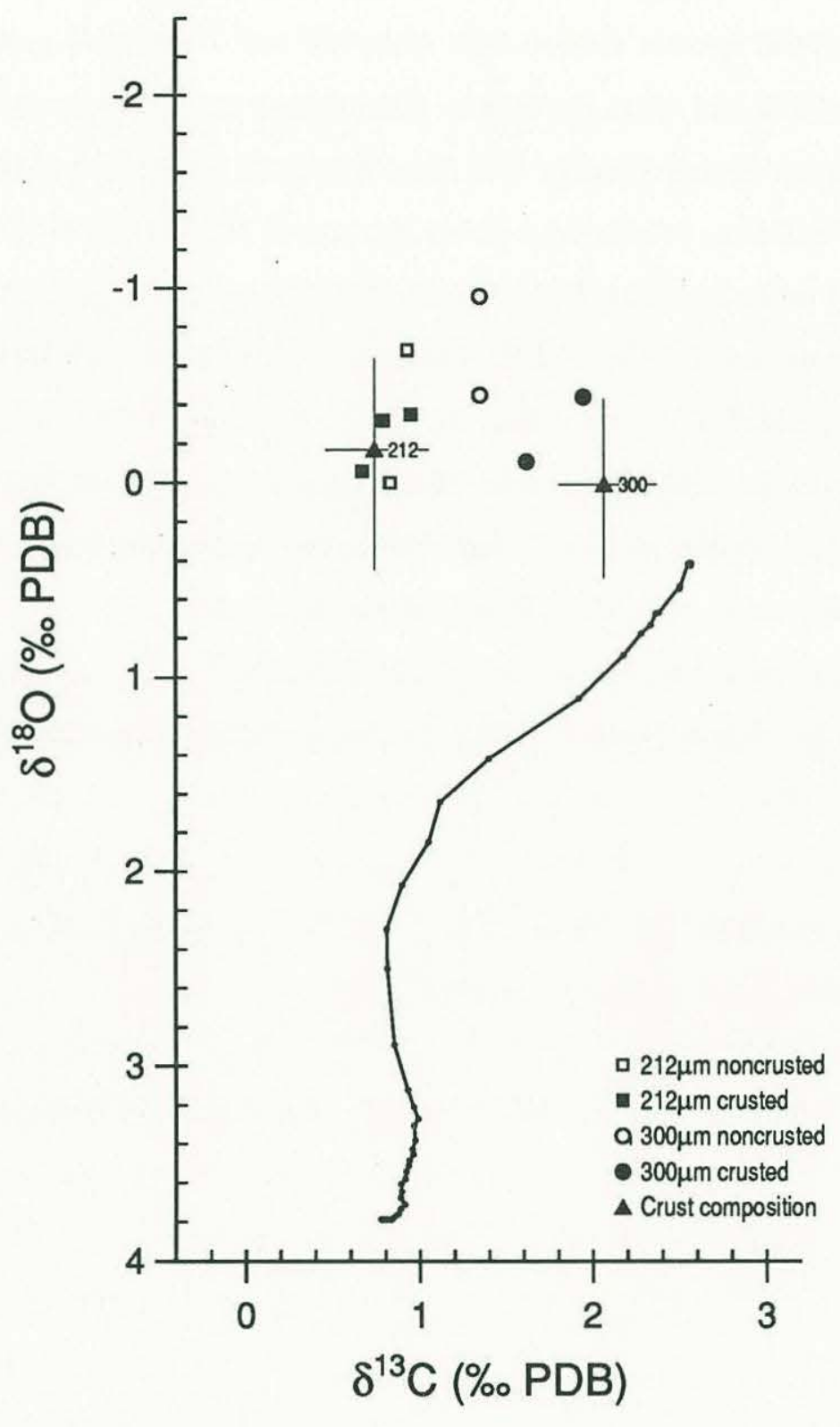

Figure 2.17: Variation in isotopic composition of Globorotalia tumida at the Bermuda Rise. Two size-fractions are shown, $212-250 \mu \mathrm{m}$ and $300-355 \mu \mathrm{m}$. The line shows the composition of calcite precipitated in equilibrium with seawater at various depths, calculated from the hydrographic data of GEOSECS station 121. 


\subsection{Discussion}

The planktonic foraminiferal species Globorotalia menardii and G. tumida grow through two processes, chamber accretion and crust formation. Chamber accretion increases the volume of the test, leading to lower measured density. The crust increases the weight of the test without strongly affecting its overall size, producing a sharp increase in the density of the test. Crusted specimens look different from noncrusted specimens, of course-the assignment of the specific name $G$. ungulata to the noncrusted form of $G$. tumida is proof of that. This analysis reinforces the view that morphological differences among specimens must be interpreted in light of the processes of growth. The aid of ontogeny in identifying specimens breaks down, however, when the smallest noncrusted specimens are examined. There the best characteristic for separating the species, relative thickness in edge view, fails to show dichotomy.

The size at which most of the tests become crusted (measured as the size-fraction in which crusted and noncrusted specimens occur in equal numbers) varies geographically. If the size of crust formation is regarded as a developmental event, this aspect of development is accelerated (with respect to size) at the Bermuda Rise. This acceleration and the comparative rarity of G. menardii and G. tumida at the Bermuda Rise suggest that the development of these species is affected by differences in hydrography occurring there.

By assuming that the test is precipitated in equilibrium with seawater $\delta^{18} \mathrm{O}$ the depth habitat of each developmental stage can be estimated. For both Globorotalia menardii and G. tumida, the measured isotopic composition of whole specimens indicates that the organisms live in the upper $50 \mathrm{~m}$ of the water, and that the crust is emplaced at depths below $50 \mathrm{~m}$. Measured values for G. tumida indicate crust formation at about $100 \mathrm{~m}$ at the Ceara Rise in the western equatorial Atlantic, slightly shallower at the Sierra Leone Rise in the eastern equatorial Atlantic. Thunell et al. (1983) show evidence that the yearly peak in production of G. menardii in the Panama Basin occurs in winter; the present study shows isotopic evidence from the Bermuda Rise indicating production during summer, when the seasonal thermocline is strongest.

The isotopic evidence presented here indicates that growth and crust formation are strongly influenced by the waters of the shallow mixed layer above the thermocline. Crust composition indicates formation between $75 \mathrm{~m}$ and $100 \mathrm{~m}$ in G. tumida and about $50 \mathrm{~m}$ in G. menardii. 
We find variation in the size-fraction in which crusted and noncrusted specimens are equally abundant. Specimens of G. tumida from the Bermuda Rise appear to produce the crust at a smaller size than those from the equatorial Atlantic. This difference may be related to the thickness of the mixed layer, but to resolve that relationship will require much more precise sampling of the Bermuda Rise population, both in time and space.

The isotopic composition of added calcite suggests that crust material is near equilibrium with seawater, while chamber material is out of equilibrium in $\delta^{13} \mathrm{C}$ if we assume that $\delta^{18} \mathrm{O}$ is close to equilibrium throughout most of the size range.

Both Globorotalia menardii and G. tumida are absent from Atlantic sediments of glacial age; their absence is consistent enough to be a valuable tool in late Pleistocene stratigraphy (Ericson and Wollin 1956). In the transition from glacial to interglacial sediments, G. tumida usually appears earlier than G. menardii (Jones 1988). Ecological changes in the glacial ocean must surely be the cause of their disappearance and subsequent reappearance, and these may have expression in hydrography. The present study shows that $G$. menardii and $G$. tumida live and grow in the mixed layer above the thermocline. Changes to the upper $50 \mathrm{~m}$ would be expected to affect $G$. menardii, while $G$. tumida would be affected by changes to deeper water $(100 \mathrm{~m})$. The difference in depth habitat reported here may help explain why the appearance of the two species in sediment cores is not synchronous. 


\subsection{Conclusions}

Ontogeny should be a crucial part of the study of planktonic foraminifera-it is, after all, the process that generates both the form of the test and its chemical composition. Consistent techniques whose aim is to "rule out" ontogenetic variation may in fact emphasize it if ontogeny varies from place to place. Here the size at which the crust is formed varies geographically. Specimens taken from a narrow size range at the Bermuda Rise should not be compared with Ceara Rise specimens from the same size range; the two groups represent different developmental stages.

Isotopic composition of both Globorotalia menardii and G. tumida appears to be controlled by the character of the upper $50-100 \mathrm{~m}$ of the ocean, and production may be maximized in different seasons at different localites, presumably in response to changes in the distribution of nutrients and other water properties. These observations contrast with similar data for G. truncatulinoides (Hemleben et al. 1985, Lohmann and Curry in review) indicating a much deeper habitat for that species. G. truncatulinoides is quite abundant at the Bermuda Rise, where $G$. menardii and G. tumida are rare; it is nearly absent at the Ceara Rise, where the latter two species are abundant.

Both Globorotalia menardii and G. tumida live and grow in the upper $100 \mathrm{~m}$ of the ocean, flourishing where the thermocline is fairly close to the surface, but restricted to warm water. Of the two species, $G$. menardii is the shallower species; isotopic measurements of G. tumida consistently indicate a deeper habitat than the corresponding sizes of the population of G. menardii. The addition of chambers in G. menardii corresponds with an increase in depth as measured by the isotopic composition of added chamber material, but this trend is not apparent in $G$. tu-

mida. Crust composition in G. tumida is near equilibrium with seawater at about $100 \mathrm{~m}$ depth, but in $G$. menardii the crust is consistently off equilibrium by about $1 \%$ in $\delta^{13} \mathrm{C}$, assuming shell material is precipitated in equilibrium with seawater $\delta^{18} \mathrm{O}$. 


\subsection{Literature cited}

Bainbridge, A.E. 1981. GEOSECS Atlantic Expedition Volume 1. U.S. Government Printing Office, Washington, D.C.

Berger, W.H., J.S. Killingley, and E. Vincent. 1978. Stable isotopes in deep-sea carbonates: box core ERDC-92, west equatorial Pacific. Oceanological Acta 1(2):203-216.

Broecker, W.S. 1982. Glacial to interglacial changes in ocean chemistry. Progress in Oceanography 11:151-197.

Broecker, W.S. 1986. Oxygen isotope constraints on surface ocean temperatures. Quaternary Research

Buesseler, K.O. and E.R. Sholkovitz. 1987. The geochemistry of fallout plutonium in the North Atlantic: I. A pore water study in shelf, slope and deep-sea sediments. Geochimica et Cosmochimica Acta 51:2605-2622.

Craig, H. 1965. The measurement of oxygen isotope paleotemperatures. pp 161-182 in Tongiorgi, E. (ed.). Stable Isotopes in Oceanographic Studies and Paleotemperatures. Consiglio Nazionale delle Ricerche Laboratorio di Geologia Nucleare (Pisa).

Curry, W.B. and T.J. Crowley. 1987. The $\delta^{13} \mathrm{C}$ of equatorial Atlantic surface waters: Implications for ice age $\mathrm{pCO}_{2}$ levels. Paleoceanography 2(5):489-517.

Curry, W.B., J.-C. Duplessy, L.M. Labeyrie, and N.J. Shackleton. 1988. Changes in the distribution of $\delta^{13} \mathrm{C}$ of deep water $\Sigma \mathrm{CO}_{2}$ between the last glaciation and the Holocene. Paleoceanography $3(3): 317-341$.

Curry, W.B. and G.P. Lohmann. in manuscript. Reconstructing past particle fluxes in the tropical Atlantic ocean.

Curry, W.B. and G.P. Lohmann. 1985. Carbon deposition rates and deep water residence time in the equatorial Atlantic Ocean throughout the last 160,000 years. pp285-301 in Sundquist, E.T. and W.S. Broecker (eds), The Carbon Cycle and Atmospheric $\mathrm{CO}_{2}$ : Natural Variations Archean to Present. Geophysical Monograph 32. American Geophysical Union, Washington D.C.

Curry, W.B., R.C. Thunell, and S. Honjo. 1983. Seasonal changes in the isotopic composition of planktonic foraminifera collected in Panama Basin sediment traps. Earth and Planetary Science Letters 64:33-43.

Deuser, W.G., E.H. Ross, C. Hemleben, and M. Spindler. 1981. Seasonal changes in species composition, numbers, mass, size, and isotopic composition of planktonic foraminifera settling into the deep Sargasso Sea. Palaeogeography, Palaeoclimatology, Palaeoecology 33:103-127.

Durazzi, J.T. 1981. Stable-isotope studies of planktonic foraminifera in North Atlantic core tops. Palaeogeography, Palaeoclimatology, Palaeoecology 33:157-172. 
Emiliani, C. 1971. Depth habitats of growth stages of pelagic foraminifera. Science 173:11221124.

Epstein, S., R. Buchsbaum, H.A. Lowenstam, H.C. Urey. 1953. Revised carbonate-water isotopic temperature scale. Bulletin of the Geological Society of America 64:1315-1326.

Ericson, D.B., and G. Wollin. 1956. Correlation of six cores from the equatorial Atlantic and the Caribbean. Deep-Sea Research 3:104-125.

Fairbanks, R.G., M. Sverdlove, R. Free, P.H. Wiebe, and A.W.H. Be. 1982. Vertical distribution and isotopic fractionation of living planktonic foraminifera from the Panama Basin. Nature 298:841-844.

Friedman, I. and J.R. O'Neil. 1977. Compilation of stable isotope fractionation factors of geochemical interest. U.S. Geological Survey Professional Paper 440-KK, 70p.

Grossman, E.L. 1984. Carbon isotope fractionation in live benthic foraminifera-comparison with inorganic precipitate studies. Geochimica et Cosmochimica Acta 48:1505-1512.

Hemleben, C., A.W.H. Be, O.R. Anderson, and S. Tuntivate. 1977. Test morphology, organic layers and chamber formation of the planktonic foraminifer Globorotalia menardii (d'Orbigny). Journal of Foraminiferal Research 7:1-25.

Hemleben, C. and M. Spindler. 1983. Recent advances in research on living planktonic foraminifera. Utrecht Micropaleontological Bulletin 30:141- 170.

Hemleben, C., M. Spindler, and O.R. Anderson. 1987. Modern Planktonic Foraminifera. Springer-Verlag, New York. 363p.

Hemleben, C., M. Spindler, I. Breitinger, and W.G. Deuser. 1985. Field and laboratory studies on the ontogeny and ecology of some globorotaliid species from the Sargasso Sea off Bermuda. Journal of Foraminiferal Research 15(4):254-272.

Jones, G.A. 1988. Using accelerator ${ }^{14} \mathrm{C}$ dating to determine the mechanism and timing of Holocene repopulation of the Atlantic ocean by Globorotalia menardii and G. tumida. (abstract) Thirteenth International Radiocarbon Conference, Dubrovnik, Yugoslavia. p103.

Lohmann, G.P., and W.B. Curry. in review. Shell growth and chemistry of the planktonic foraminifera Globorotalia truncatulinoides, Part III: Shell Chemistry. submitted to Paleoceanography.

Orr, W.N. 1967. Secondary calcification in the foraminiferal genus Globorotalia. Science 157(3796):1554-1555.

Parker, F.L. 1962. Planktonic foraminiferal species in Pacific sediments. Micropaleontology $8(2): 219-254$. 


\section{Chapter 3}

\section{Size and shape in isotopic analysis of the planktonic foraminifer Neogloboquadrina pachyderma: Ontogenetic considerations}

\subsection{Introduction}

Planktonic foraminifera are important indicators of the chemical character of ancient oceans because they draw from the ocean water the materials needed to build their shells. Inferences about the chemical history of the ocean are complicated, however, because the shell composition is affected both by the environment in which the organisms grow and the processes of growth themselves. To make use of foraminiferal chemistry as a paleoceanographic tool we must know how to separate the effects on chemistry that are specific to individual taxa or growth stages from the chemical signal impressed on the specimens by their environment.

Ontogeny affects the isotopic composition of foraminifera in important ways. Stable-isotopic measurements of planktonic foraminifera often show systematic variation with size (Berger et al. 1978, Curry and Matthews 1981, Keigwin and Boyle in press); smaller specimens are generally farther from equilibrium with seawater $\delta^{13} \mathrm{C}$ than are larger specimens. Because the component of variation of $\delta^{13} \mathrm{C}$ directly attributable to size is of the same order of magnitude as the glacialinterglacial variations in seawater composition, a clear understanding of the size effect will refine our power to measure the nature and timing of climatic change.

The process that generates the covariance of size and isotopic composition is not well understood. One explanation is that the fractionation of carbon isotopes is a function of the rate 
of metabolism, which decreases throughout the life of the individual (Berger et al. 1978). But this explanation relates isotopic fractionation not to size itself, but to maturity. It works if larger individuals are more mature than smaller individuals, a condition that is true of individuals, but not necessarily true of populations. Size varies systematically with geography in numerous species (Kennett 1976); should we assume that populations with smaller maximum sizes fractionate carbon more than those with larger maximum sizes?

The usual tactic for measuring isotopic composition is to measure a narrow range of test sizes. This tactic has two important drawbacks. First, variation in the growth of the specimens among samples may cause measurements of the same size fraction to be just like measuring different size fractions of a single sample. Second, the variability of growth within samples decreases the precision with which isotopic composition is estimated. Both of these drawbacks probably affect most experiments, with the effect of diminishing our power to resolve true variations in the isotopic composition of ocean waters.

The problem of separating ontogenetic from environmental effects on measured stable isotopic compositions must be solved by careful study of ontogenetic effects in single samples, where the environmental variability is at a minimum. This is because ontogenetic variability is present in every sample, and the "mean ontogeny" may itself vary among samples. This paper shows a relatively simple relationship between characteristics of ontogeny such as proloculus size and rate of chamber expansion. The consequences for morphology of variations in ontogeny can be understood and used (a) to explain latitudinal variations in morphology, (b) to show why carbon isotopic composition is so variable and (c) to suggest ways of selecting specimens that minimize ontogenetic variations in shell chemistry.

These objectives are achieved by describing the growth of individual foraminifera in terms compatible with the biological process itself - the successive addition of chambers-and by assuming that the effect of metabolism on isotopic fractionation follows the addition of chambers rather than the size of the specimen per se. If the effect of ontogeny on $\delta^{13} \mathrm{C}$ is more highly correlated with chamber accretion than with test size, specimens taken from a narrow size range may be expected to show higher variability in $\delta^{13} \mathrm{C}$ than specimens that have built the same number of chambers.

One objective of this study is to point out that some variations in morphology may be caused 
by variations in ontogeny. The latitudinal gradient in the number of chambers showing in the outer whorl of Neogloboquadrina pachyderma described by Kennett (1968) may be explained by latitudinal gradient in the size of the proloculus. Proloculus size is an important life-history trait (Stearns 1976), and the indication that it varies with environment or geography suggests that life-history theory may be invoked to help explain the observed morphological variability. Further, the history of changes in proloculus size can be related to climatic changes, indicating the ecological response of the organism. 


\subsection{Materials and methods}

Neogloboquadrina pachyderma is a species of planktonic foraminifera found exclusively in highlatitude regions of the world ocean. Because it is one of the few species found living in these areas that is preserved in cored sediment, it provides useful information about the chemical history of polar surface waters.

Specimens of Neogloboquadrina pachyderma were taken from sea ice in the Southern ocean by M. Spindler and brought to the laboratory for observation. They were photographed using transmitted light. Figure 3.1 shows two such photographs. The data presented in this paper was taken from measurements of 36 photographs.

The specimens used in this paper are not a strictly random sample. Instead, they were selected to represent the full range of variation in proloculus size present in the population. The relative abundance of specimens with large or small proloculi is not represented in these data.

\subsubsection{Measurement of foraminiferal ontogeny}

Measures of foraminiferal morphology are meaningful only to the extent that they reflect the processes by which the test is generated and modified. Methods of outline analysis such as Fourier shape analysis and eigenshape analysis cannot usually provide insight into the process of growth because the measurements they generate are complex functions of the size, position, and sequence of chambers. Ideally the description of ontogeny should reflect the process of growth, the successive addition of chambers.

Growth has been modeled by Berger (1969) and Arnold (1982). Although the parameters needed to model foraminiferal growth (rate of expansion of chambers, degree of overlap and angle between the centers of adjacent chambers) tend to vary during the late stages of ontogeny,/ the models faithfully predict the appearance of juvenile forms.

Given a natural population, the problem is to make measurements that can be used to estimate the parameters of growth and, if necessary, describe what causes a shape to deviate from a simple growth model. Measurements of chamber size and sequence form the basis of our analysis.

Like many planktonic foraminifera, Neogloboquadrina pachyderma forms spherical chambers 
that are circular in projection. Each chamber can be measured by calculating the circle that best fits its two-dimensional projection. This is done by digitizing as many points along the outer edge of the chamber as can be confidently located, and using the digitized points $(x, y)$ to calculate the regression of $z=x^{2}+y^{2}$ on $[x, y, 1]$ (Bookstein 1978). The resulting coefficients $(2 a, 2 b, c)$ describe the circle $(x-a)^{2}+(y-b)^{2}=c^{2}$ that fits the observed points in a least squares sense. Note that the center of the circle need not be estimated beforehand, and there need only be three points along the chamber wall. Of course, the more points one can digitize, the more closely will the estimated circle fit them, especially where the length of arc over which the points extend is small in relation to the radius of the fitted circle.

To characterize the growth of the test, its size is calculated as each chamber is plotted in sequence. In the present study this was accomplished using a raster-graphics video image of the reconstructed specimen, to which chambers were added incrementally. As each chamber was added, the outline of the specimen's image was captured as a polygon, whose area could be calculated.

Outlines captured from the reconstructed specimens were also used to calculate the number of chambers showing in the outer whorl of each growth stage. The sutures (outline points where chambers abut) were noted, and the outline segments between them were fitted with circles in the manner described earlier. These segments of circles were measured as angles of arc, since the traditional description of chambers that are partially hidden seems to rely on the extent to which the chamber protrudes from the test, not on the size of the chamber. A chamber was considered fractional if its exposed arc was less than three fourths of the median for all chambers in the outer whorl. Details of this and the other procedures used are presented in an appendix listing computer program source code. 


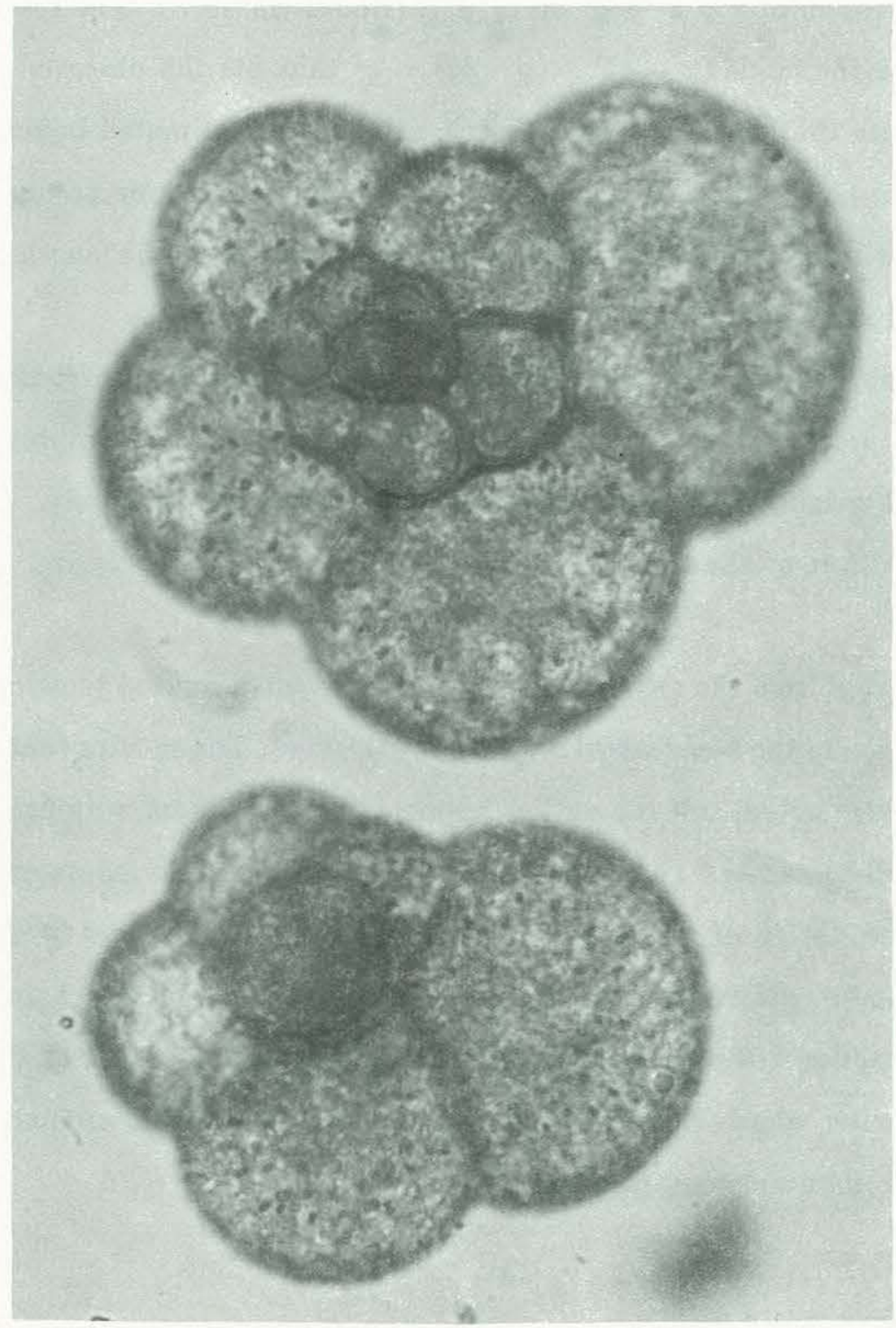

Figure 3.1: Photographs of Neogloboquadrina pachyderma in transmitted light. Note the different growth patterns of these two specimens; the proloculus is much larger in one than in the other, and there is a corresponding difference in the number of chambers. Photograph courtesy of Michael Spindler. 


\subsection{Results}

For each specimen a growth series was constructed by successively adding chambers to the proloculus. The size of each stage thus constructed could be measured as the area of its outline. Results are shown in figure 3.2. Each specimen is represented by a series of points, since its size increases as chambers are added. Representative specimens are plotted in figure 3.3.

These data show that specimens having the same number of chambers need not be the same size. Likewise specimens of the same size need not be composed of the same number of chambers. If one were to choose from this sample only individuals of uniform size, a wide variation in chamber number would be found.

The large conditional variance of chamber number with size indicates that some specimens seem to grow in smaller increments than others. Using a linear model of growth, with test size denoted $S$ and chamber number by $i, S=a+b i$. Log-transforming the test size (figure $3.2 \mathrm{~b}$ ) shows that the specimens with high rates of growth $b$ are those that have large proloculi.

Growth curves such as these are better fit by an exponential model, however. Rather than describing the growth as $S=a+b i$, we should use $S=C e^{r i}$ or $\ln S=\ln C+r i$. Because the growth is explained well by exponential curves, a modified sampling strategy might be suggested. The slope of the curve relates the size of the test to the size of chambers added to it. Where the curve slopes gently, added chambers are small in relation to the whole test. Where the slope is steep, added chambers are large in relation to the test on which they are built. If the added chambers are relatively small, many are required to complete a whorl, while fewer chambers are required if they are relatively larger. The slope of the curve thus dictates the number of chambers in the test's outer whorl.

The number of chambers in the outer whorl generally follows the slope of the growth curves (figures 3.4, 3.5 and 3.6). Forms with five and six chambers in the outer whorl are concentrated in regions where the growth curves slope gently, while those with four chambers in the outer whorl occur where the growth curves slope steeply. Exceptions to the pattern can be explained in three ways. First, there will not be more chambers in the outer whorl than there are in the specimen, so specimens with few chambers generally have all chambers in the outer whorl. Second, although the growth of an individual follows an exponential curve in a statistical sense, chance variations affect the number of chambers in the outer whorl. Third, some specimens 
simply do not fit this simple model of variation. Among specimens with proloculi larger than about $20 \mu \mathrm{m}$ the correlation between growth rate and proloculus size is .79, but some specimens with smaller proloculi also have high growth rates (figure 3.7 ). These specimens tend to have fewer chambers in the outer whorl than are expected using the model.

Selecting specimens with four chambers in the outer whorl generally concentrates those with large proloculi (figure 3.4), and among specimens of equal size separates those composed of different numbers of chambers. Those with five or six chambers in the outer whorl occur over a wider range of chamber numbers (figures 3.5 and 3.6 ). 

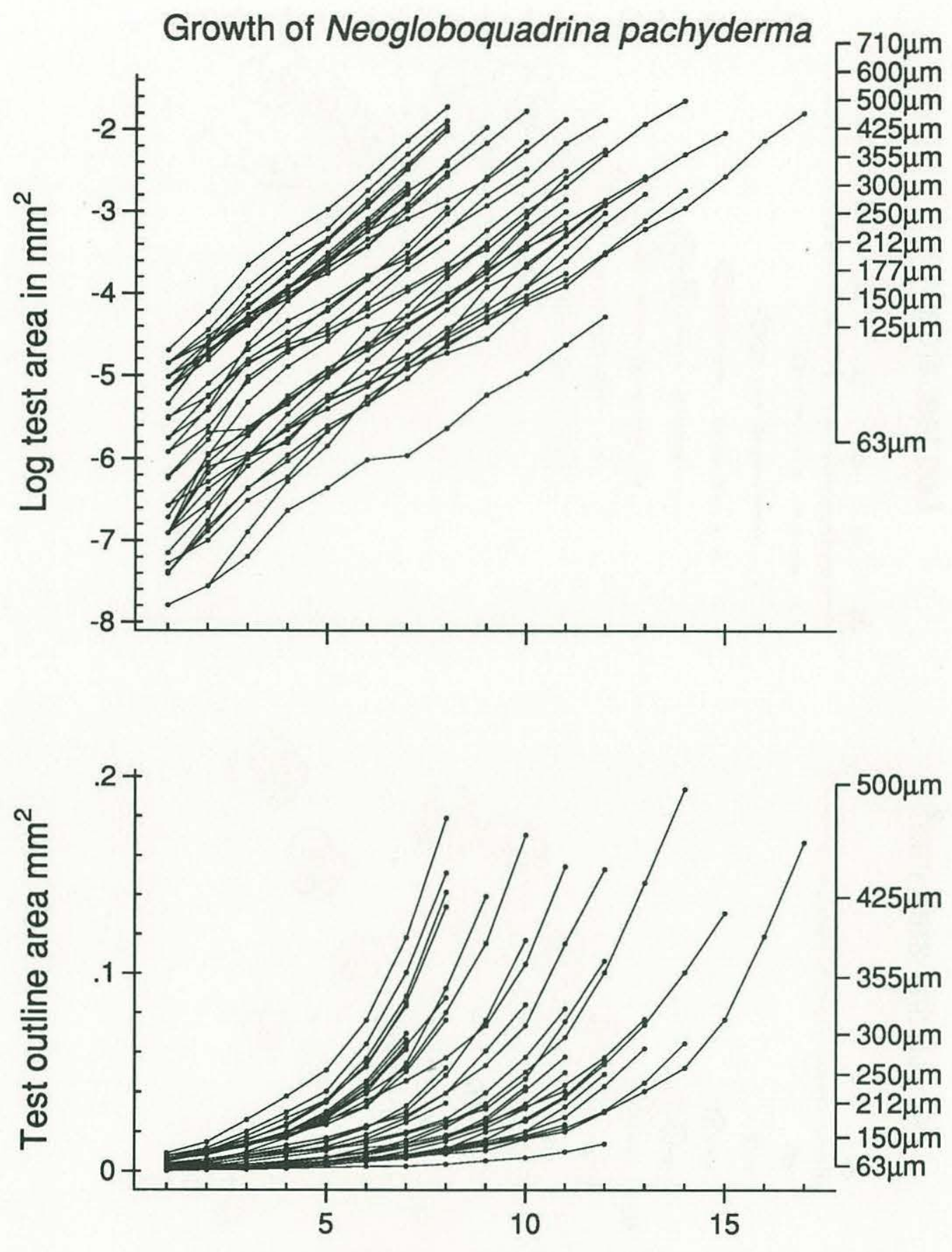

Number of chambers

Figure 3.2: Variation in growth of Neogloboquadrina pachyderma. Each line describes the change in test size of one specimen that results from the addition of chambers. 

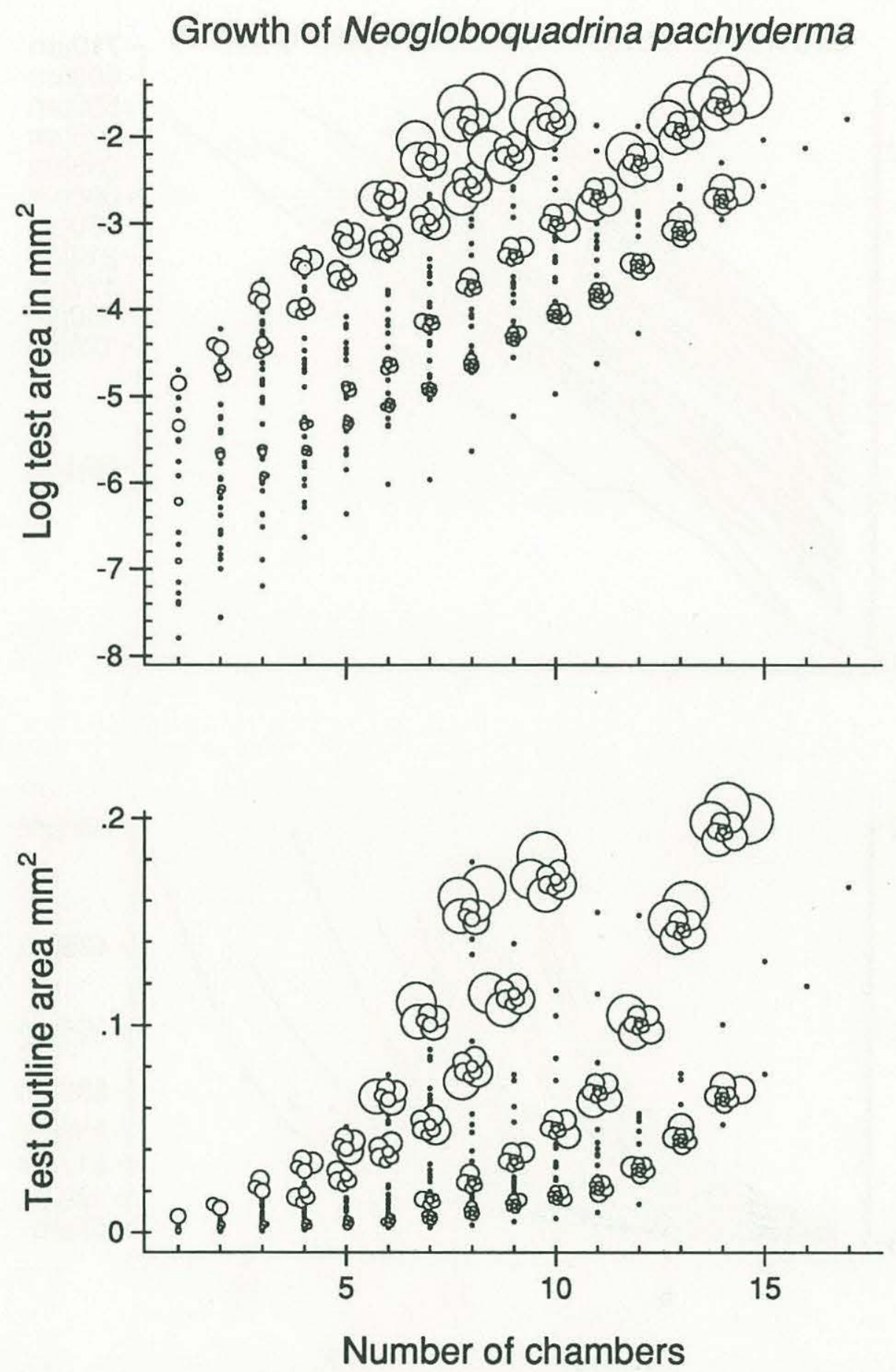

Figure 3.3: The growth of representative specimens of Neogloboquadrina pachyderma. Specimens composed of the same number of chambers may not be the same size, and those of the same size may not have the same number of chambers. 

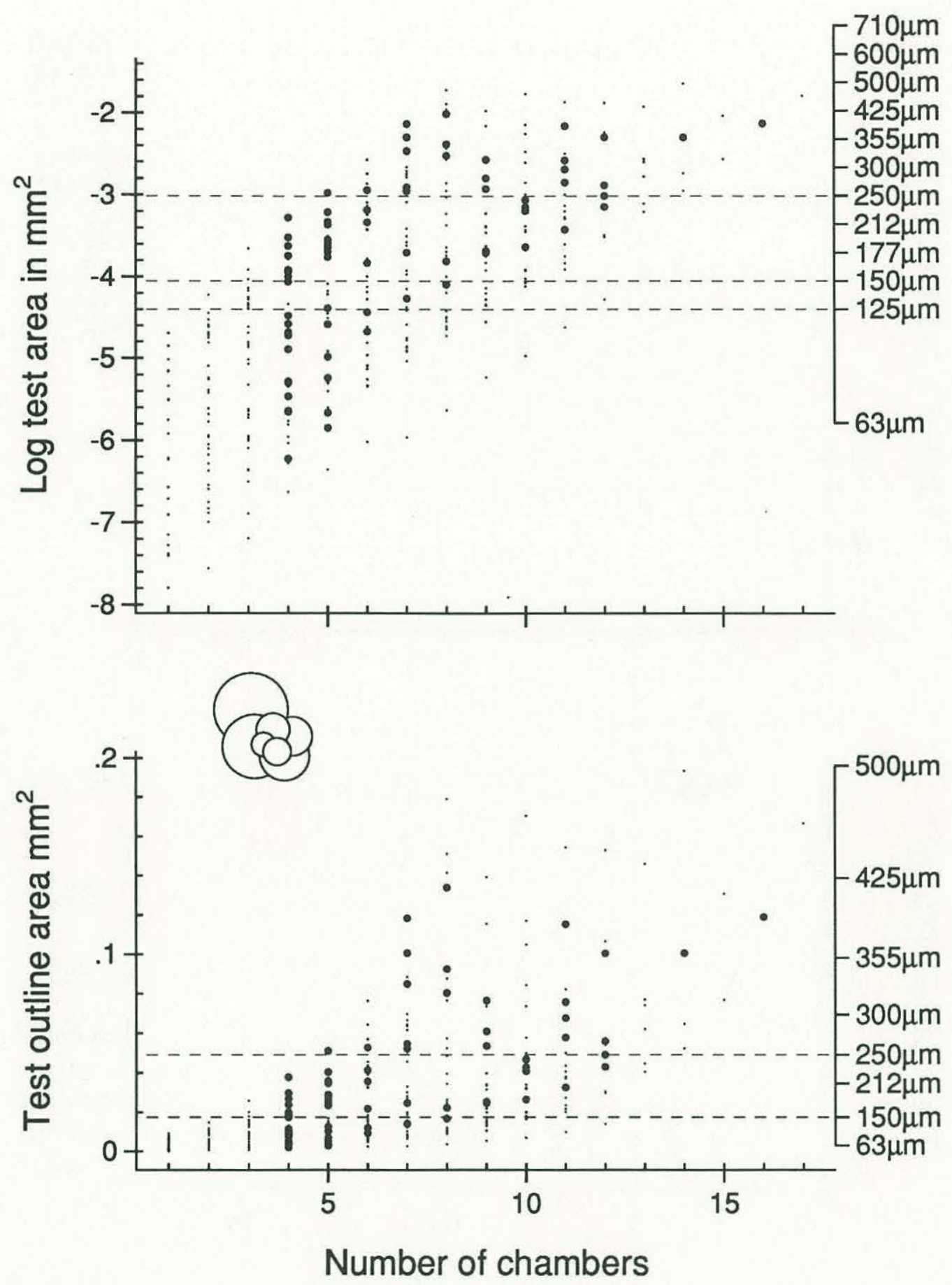

Figure 3.4: Specimens with four chambers in the outer whorl. The scale on the right side shows the sieve size at $\frac{1}{4} \phi$ intervals, calculated from the test outline area $A$ using the formula for a circle, $d=2 \sqrt{\frac{A}{\pi}}$ and $\phi=-\log _{2} d$ 

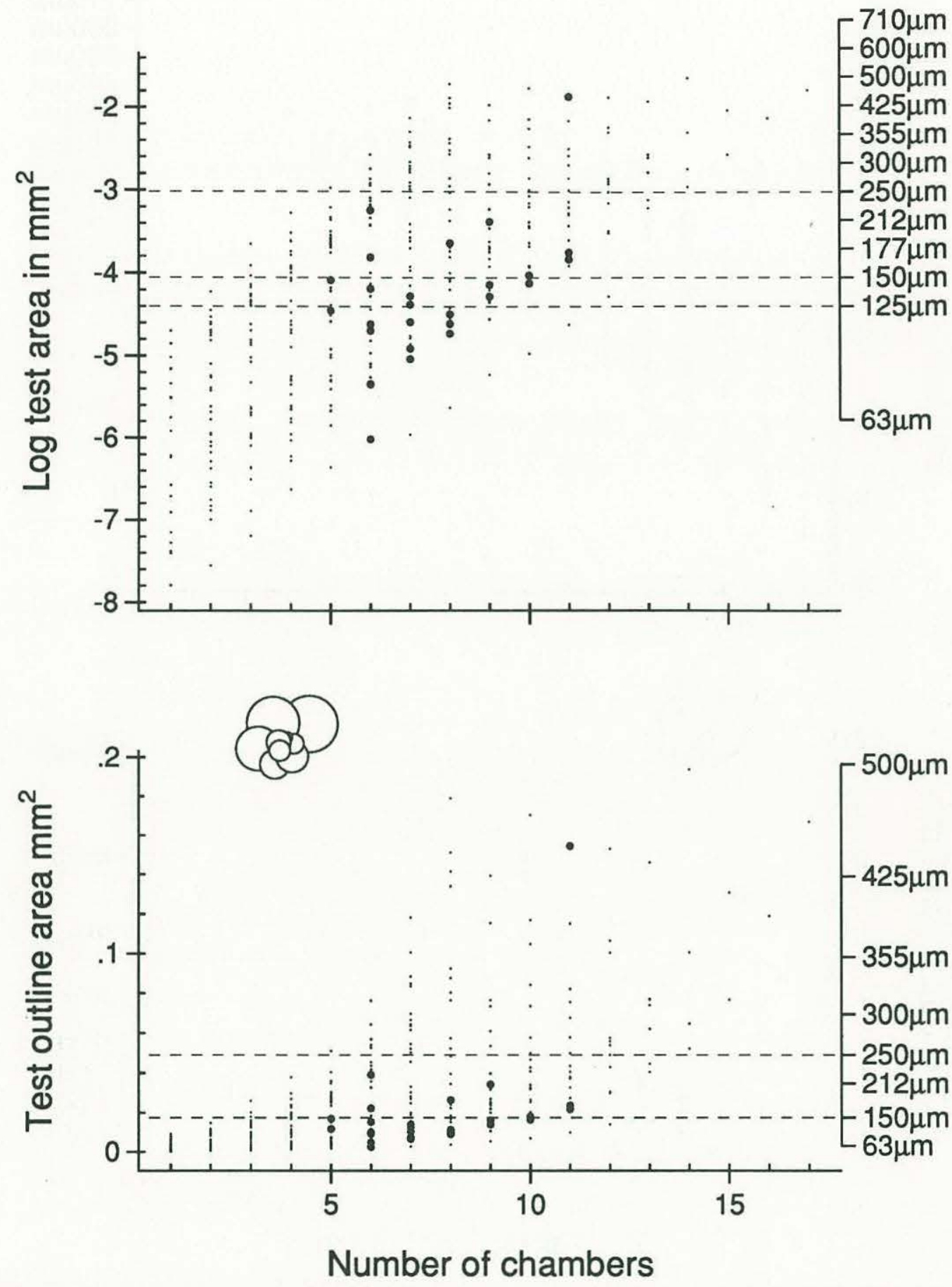

Figure 3.5: Specimens with five chambers in the outer whorl. The scale on the right side shows the sieve size at $\frac{1}{4} \phi$ intervals, calculated from the test outline area $A$ using the formula for a circle, $d=2 \sqrt{\frac{A}{\pi}}$ and $\phi=-\log _{2} d$ 

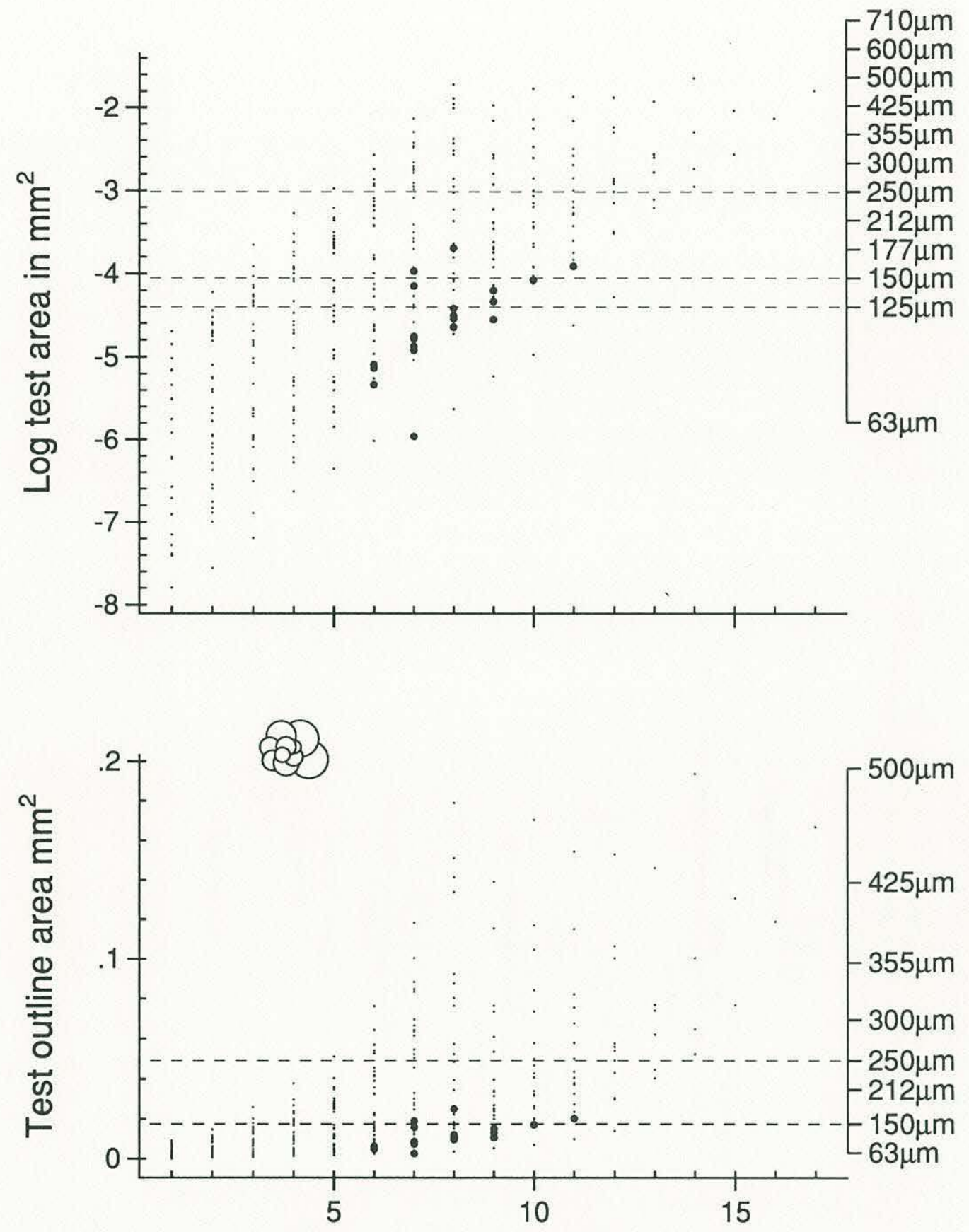

Number of chambers

Figure 3.6: Specimens with six chambers in the outer whorl. The scale on the right side shows the sieve size at $\frac{1}{4} \phi$ intervals, calculated from the test outline area $A$ using the formula for a circle, $d=2 \sqrt{\frac{A}{\pi}}$ and $\phi=-\log _{2} d$ 


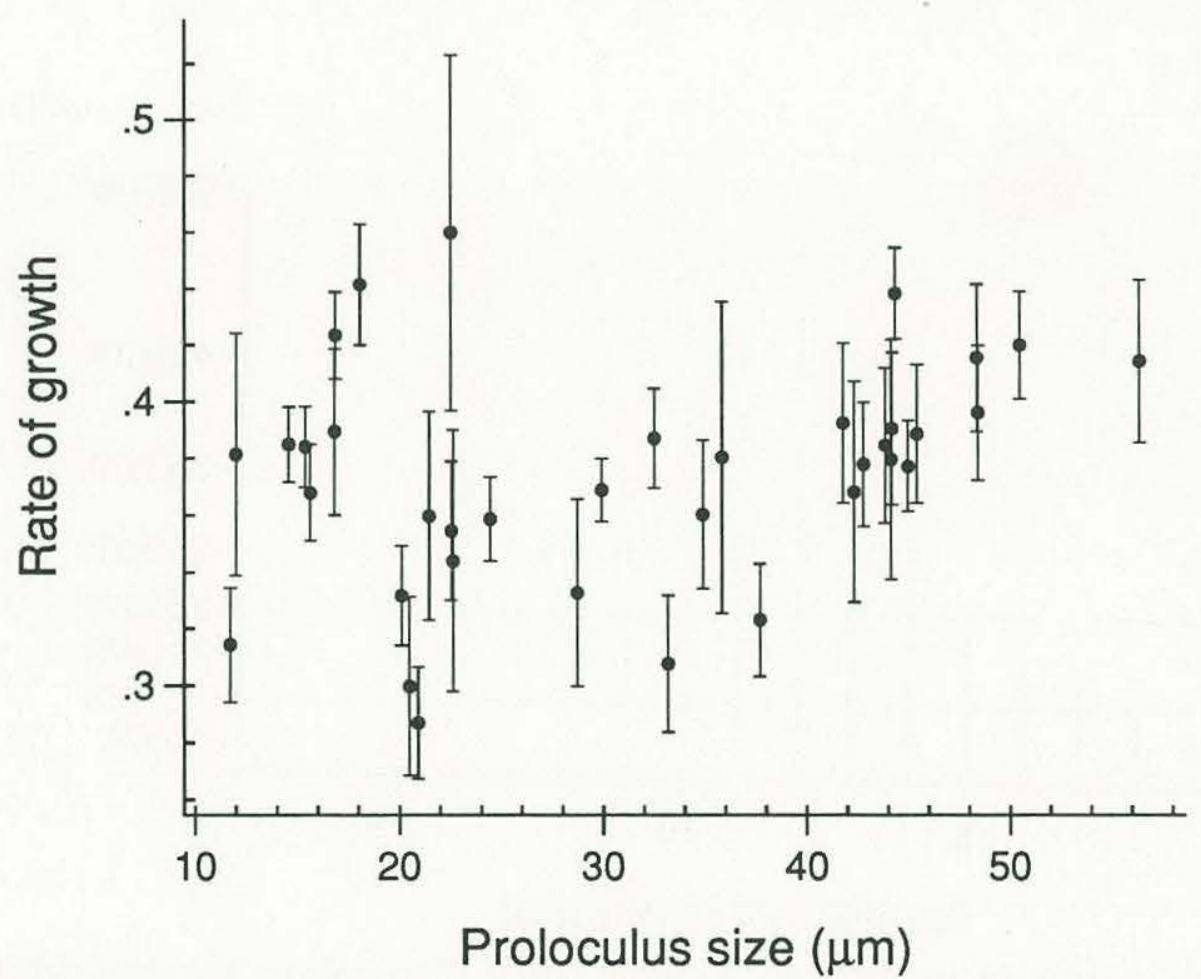

Figure 3.7: Rate of exponential increase in size plotted against the size of the proloculus. The ordinate is the value $r$ taken from the regression of log size on number of chambers $i$; $\ln S=\ln C+r i$. Error bars indicate $95 \%$ confidence limits on the regression coefficients $r$. 


\subsection{Discussion}

Understanding morphological variation of planktonic foraminifera requires an understanding of ontogeny. To see the nature of morphological variability in a useful way, one must measure the morphology in terms compatible with the process that generates it, the successive addition of chambers. Variations in the growth of Neogloboquadrina pachyderma indicate (1) that a wide range of chamber numbers can be found even in samples from a narrow range of sizes, (2) the size of the proloculus determines the character of subsequent growth, and (3) because growth is exponential, the number of chambers in the outer whorl of the test is largely determined by the size of the proloculus and the number of chambers of which the test is made.

These observations are consistent with those of Aksu and Vilks (1988) who noted that forms having five to seven chambers were most abundant in the size fraction between $63 \mu \mathrm{m}$ and $125 \mu \mathrm{m}$ in sediment samples. Aksu and Vilks regarded these forms (previously described as a separate species) as environmental variants - the present study shows evidence that the forms are ontogenetic stages, not environmental variants.

Similarly, Vilks (1975) found kummerform tests always larger than quadrate and normalform tests of $N$. pachyderma from the Canadian arctic. This observation is consistent with our data but represents deviation from the simple model of exponential growth. The model predicts that the number of chambers in the outer whorl should steadily decrease, but many of these specimens increase from 4 to $4 \frac{1}{2}$ as they reach large size.

As noted above, this sample is not strictly random, but is instead stratified to show the range of variation in proloculus size and the morphology that results. The statistical distribution of proloculus size in natural populations will probably be different than the distribution in this sample. Paleoceanographers studying Neogloboquadrina pachyderma need to know how that distribution varies from place to place and through time. If the disequilibrium of $\delta^{13} \mathrm{C}$ follows the number of chambers rather than a specimen's size, two samples in which the distribution of proloculus size differed would also have different measured $\delta^{13} \mathrm{C}$ if specimens were selected solely on the basis of size.

The selection procedure suggested here is to choose from a narrow range of size only those specimens with four chambers in the outer whorl. This method will isolate specimens composed of nearly the same number of chambers provided that the growth rate is correlated with 
proloculus size. Among the specimens analyzed here, most do fit this model, but several of those with proloculi smaller than about $20 \mu \mathrm{m}$ do not. These growth patterns may be rare, however. Further study must determine whether such specimens form a significant part of natural populations. 


\subsection{Conclusions}

Growth in Neogloboquadrina pachyderma is highly variable. In the size interval over which specimens are sampled for isotopic analysis, specimens of the same size may be composed of many different numbers of chambers. The pattern of growth of an individual is largely determined by the size of its proloculus.

Variation among specimens generally follows a simple model in which the rate of increase in size (on a log scale) is proportional to the size of the proloculus. Under this model, the number of chambers in the outer whorl is correlated with the total number of chambers in specimens taken from a narrow size range. In specimens taken from the size interval between $150 \mu \mathrm{m}$ and $250 \mu \mathrm{m}$, a sampling strategy that includes only specimens with four chambers in the outer whorl tends to minimize the variability in total chamber number. It is desirable to minimize this variability if the disequilibrium $\delta^{13} \mathrm{C}$ values found in young specimens follow the total number of chambers rather than the size of the specimens.

It is reasonable to expect that proloculus size varies from place to place and through time. Ecological theory predicts larger young where juvenile mortality is high or unpredictable, or where there is size-selective predation against small individuals (Stearns 1976). Moreover several empirical studies of Neogloboquadrina pachyderma have shown geographic variation in the number of chambers in the final whorl (Kennett 1968, Vilks 1975). Using the model derived here, these might be interpreted as variations in proloculus size. 


\subsection{Literature cited}

Aksu, A.E. and G. Vilks. Stable isotopes in planktonic and benthic foraminifera from Arctic Ocean surface sediments. Canadian Journal of Earth Sciences 25:701-709.

Arnold, A.J. 1982. Techniques for biometric analysis of foraminifera. Proceedings of the Third North American Paleontological Convention.

Berger, W.H. 1969. Planktonic foraminifera: Basic morphology and ecologic implications. Journal of Paleontology 43(6):1369-1383.

Berger, W.H., J.S. Killingley, and E. Vincent. 1978. Stable isotopes in deep-sea carbonates: Box Core ERDC-92, West Equatorial Pacific. Oceanologica Acta 1(2):203-216.

Bookstein, F.L. 1978. The measurement of biological shape and shape change. Lecture Notes in Biomathematics 24:1-191.

Curry, W.B. and R.K. Matthews. 1981. Equilibrium ${ }^{18} \mathrm{O}$ fractionation in small size fraction planktic foraminifera: Evidence from Recent Indian Ocean sediments. Marine Micropaleontology 6:327:337.

Emiliani, C. 1954. Depth habitats of some species of pelagic foraminifera as indicated by oxygen isotope ratios. American Journal of Science 252:149-158.

Emiliani, C. 1971. Depth habitats of growth stages of pelagic foraminifera: Science 173:11221124.

Hemleben, C., M. Spindler, I. Breitinger, and W.G. Deuser. 1985. Field and laboratory studies on the ontogeny and ecology of some globorotaliid species from the Sargasso Sea off Bermuda. Journal of Foraminiferal Research 15(4):254-272.

Keigwin, L.D., and E.A. Boyle, in press. Late quaternary paleochemistry of high-latitude surface waters. Paleogeography, Paleoclimatology, Paleoecology.

Kennett, J.P., 1968. Latitudinal variation in Globigerina pachyderma (Ehrenberg) in surface sediments of the southwest Pacific Ocean. Micropaleontology 14(3):305-318.

Kennett, J.P., 1976. Phenotypic variation in some Recent and Late Cenozoic planktonic foraminifera. pp.111-166 in Hedley, R.H., and C.G. Adams (eds) Foraminifera volume 2. Academic Press, London.

Reynolds, L.A. and R.C. Thunell, 1986. Seasonal production and morphologic variation of Neogloboquadrina pachyderma (Ehrenberg) in the northeast Pacific. Micropaleontology $32(1): 1-18$.

Stearns, S.C. 1976. Life-history tactics: A review of the ideas. Quarterly Review of Biology $51(1): 1-47$.

Vilks, G. 1975. Comparison of Globorotalia pachyderma (Ehrenberg) in the water column and sediments of the Canadian Arctic. Journal of Foraminiferal Research 5(4):313-325. 


\subsection{Appendix A. Computer programs for the measurement of foraminiferal ontogeny}

Four computer programs were used to create and manipulate this data set. Photos were digitized using the program 2D, the outlines of the shapes were digitized using program BUILD, suture points were marked on the digitized outlines using program LANDMARK, and chambers refit to the shapes using program FITCIR. All programs operate on IBM microcomputers using any of a variety of graphics boards. 


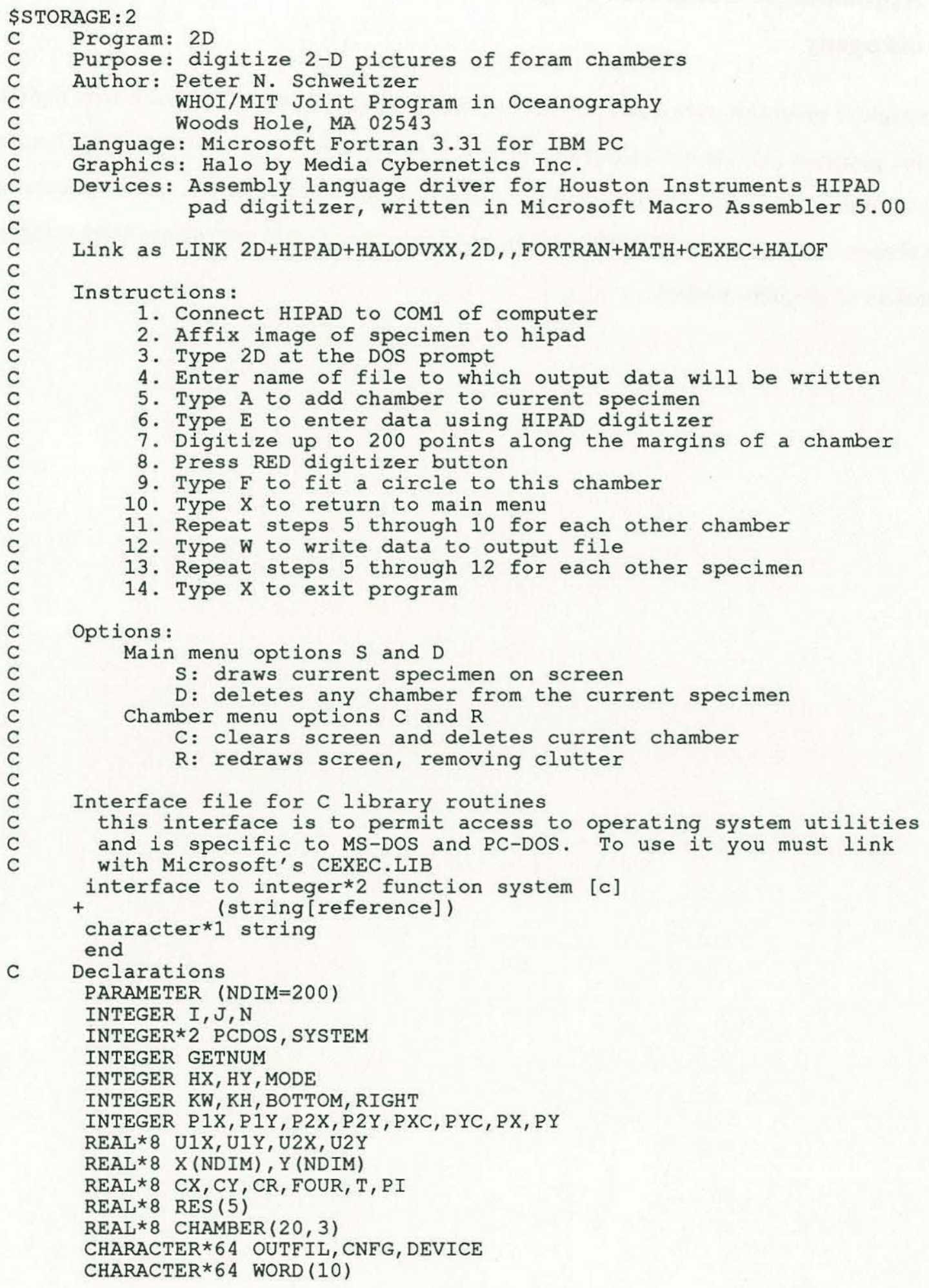




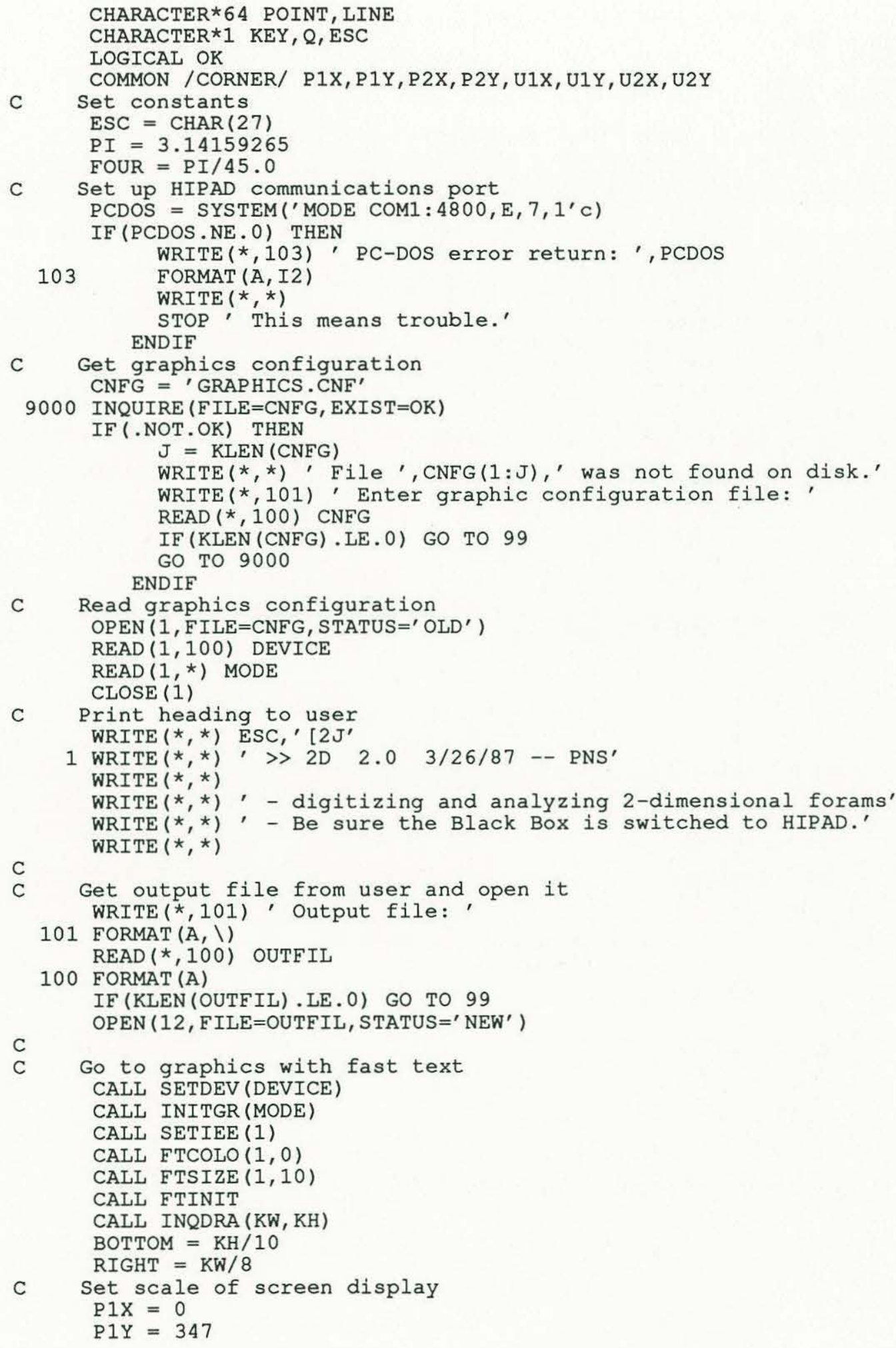




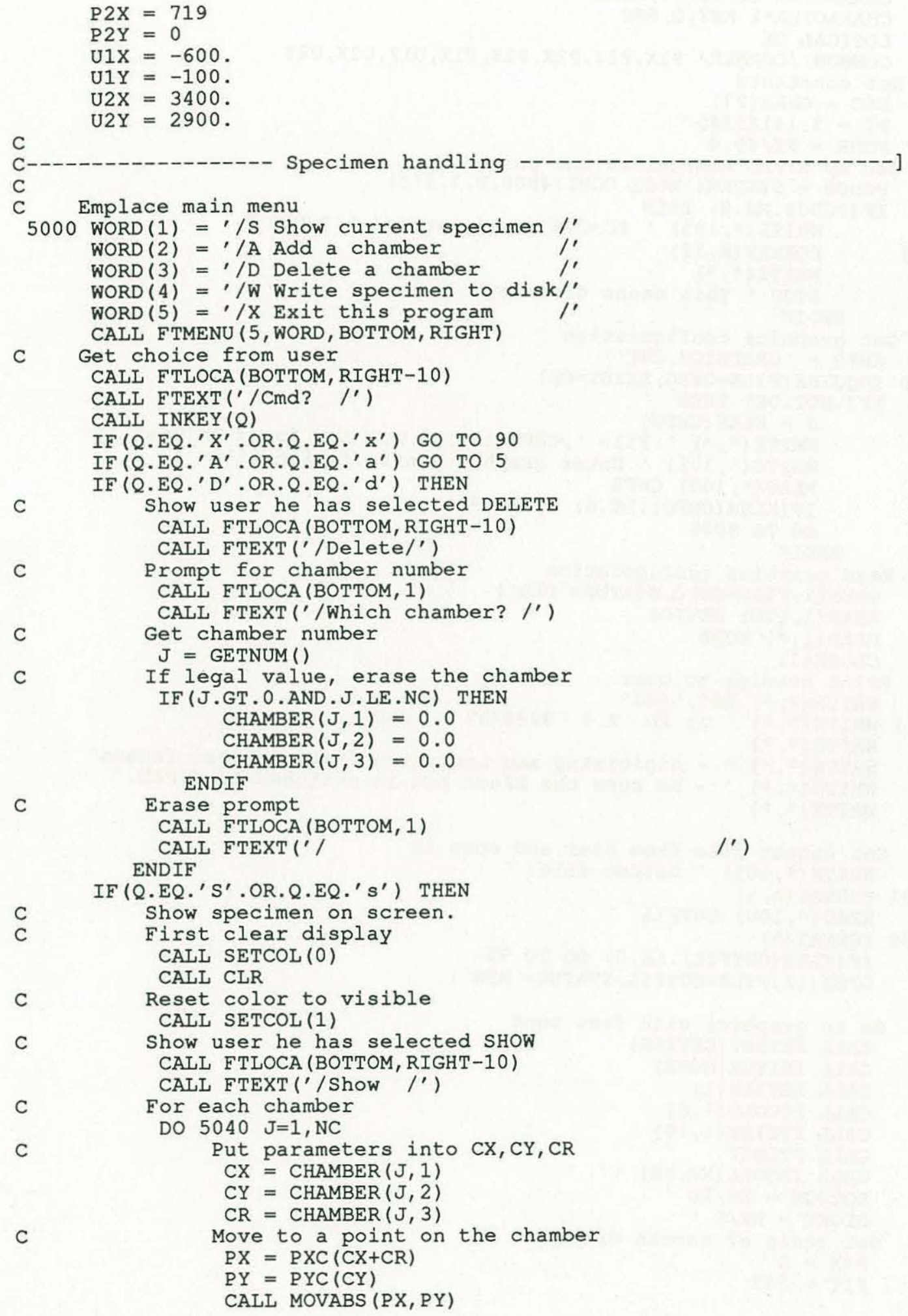


C 
Read HIPAD input; ignore errors

READ (POINT, 301, ERR=10) KEY, HX, HY

C

FORMAT (A1, 2I6)

If red button was pressed, escape from ADD

C

IF (KEY.EQ.' B') GO TO 15

If not, store this point

$I=I+1$

C

...unless you can't; in that case, squawk and exit ADD IF (I.GT.NDIM) THEN

CALL FTLOCA (BOTTOM, 1)

CALL FTEXT('/Error: too many input points

$\mathrm{N}=\mathrm{I}-1$

ENDIF

C

store point

$X(I)=\operatorname{DBLE}(\mathrm{HX})$

$Y(I)=\operatorname{DBLE}(\mathrm{HY})$

C display coods on screen

210 FORMAT (A, A, 2F7.0, A)

IR $=1+\operatorname{MOD}(I-1$, BOTTOM $)$

$I C=1+20 *((I-1) /$ BOTTOM $)$

CALL FTLOCA (IR, IC)

CALL FTEXT (LINE)

C

Find screen coords

$\mathrm{PX}=\mathrm{PXC}(\mathrm{X}(I))$

$\mathrm{PY}=\mathrm{PYC}(\mathrm{Y}(\mathrm{I}))$

C

move to point if it is the first, otherwise draw

IF (I.EQ.1) CALL MOVABS (PX,PY)

IF (I.NE.1) CALL LNABS (PX,PY)

C and get another point

GO TO 10

C prepare to exit $A D D$. Store number of points collected

$15 \quad \mathrm{~N}=\mathrm{I}$

C and erase the prompt

CALL FTLOCA (BOTTOM, 1)

CALL FTEXT (')

ENDIF

C

IF (Q.EQ.' R' OR.Q.EQ.' $r^{\prime}$ ) THEN

Clear screen

CALL SETCOL (0)

CALL CLR

C

Tell user he's in REDRAW

CALL FTLOCA (BOTTOM, RIGHT-10)

CALL FTEXT ('/Redraw/')

C

set color for visible drawing

CALL SETCOL (1)

C

Move to first point

$\mathrm{PX}=\mathrm{PXC}(\mathrm{X}(1))$

$\mathrm{PY}=\mathrm{PYC}(\mathrm{Y}(1))$

CALL MOVABS (PX, PY)

C

Draw to all the others

DO $20 \quad I=1, N$

$\mathrm{PX}=\mathrm{PXC}(\mathrm{X}(\mathrm{I}))$

$P Y=P Y C(Y(I))$

CALL LNABS (PX, PY)

20 CONTINUE

ENDIF

C

IF (Q.EQ.' $F^{\prime}$. OR.Q.EQ.' $f^{\prime}$ ) THEN

Tell user what's happening

CALL FTLOCA (BOTTOM, RIGHT-10) 


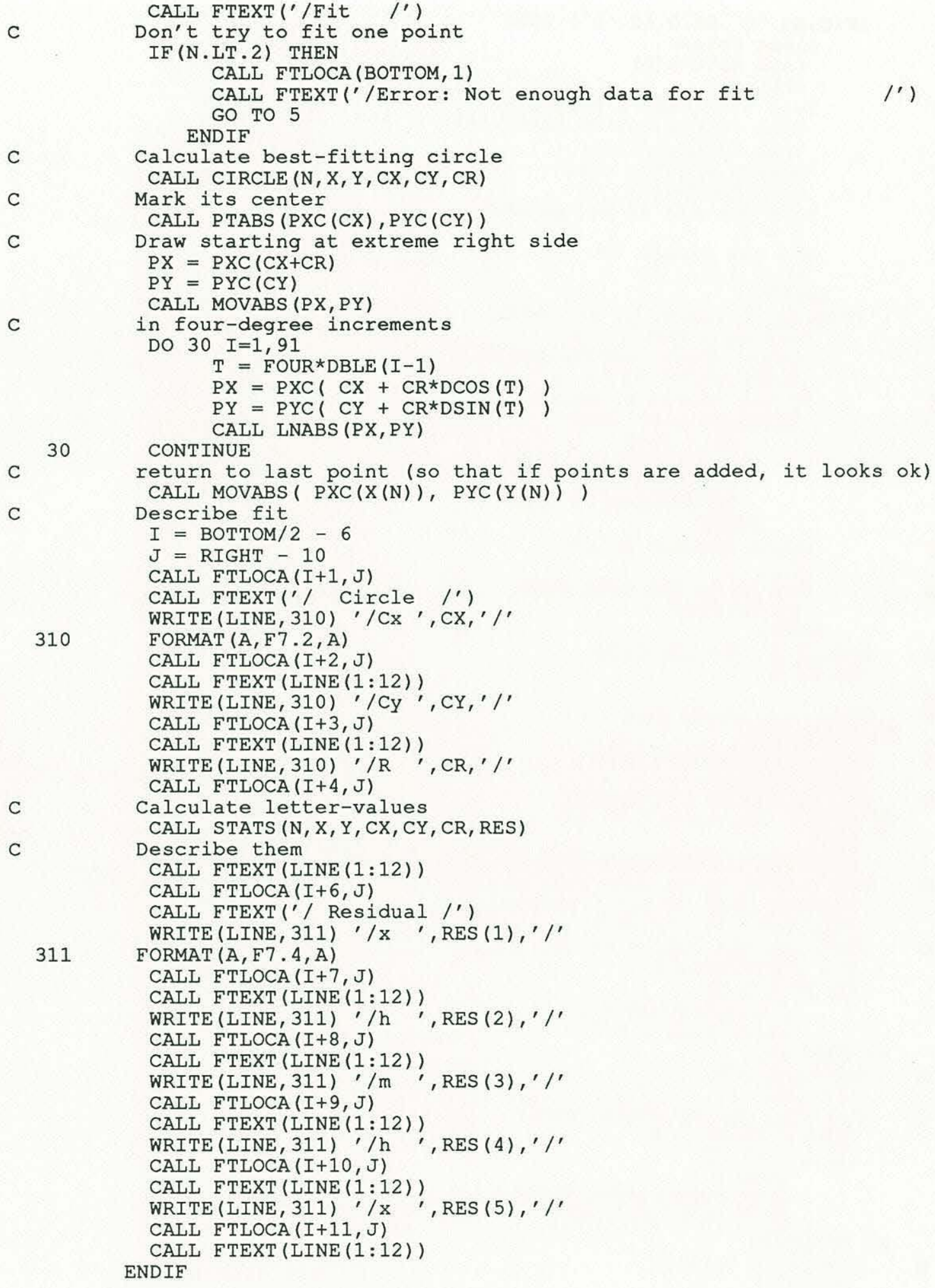




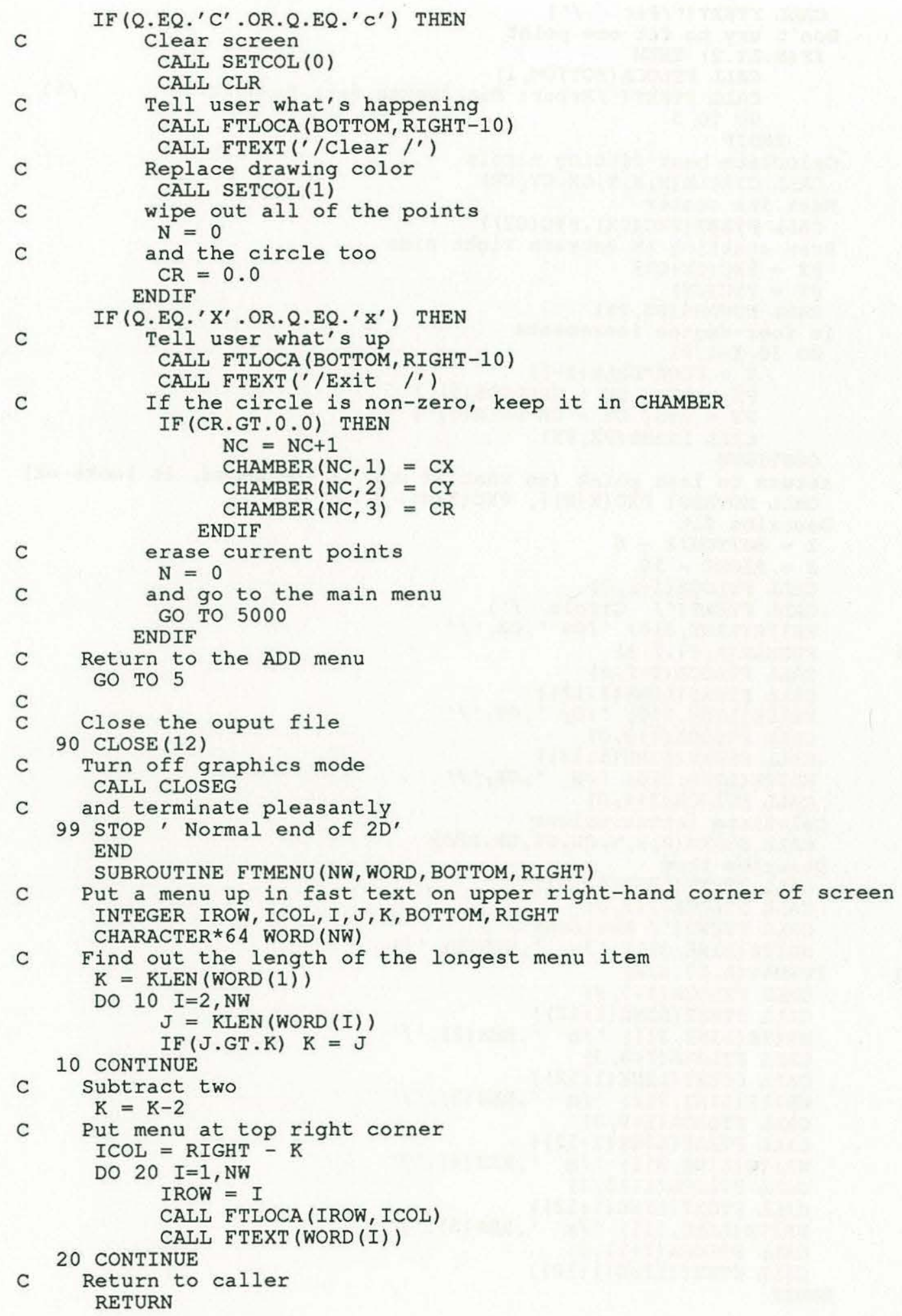




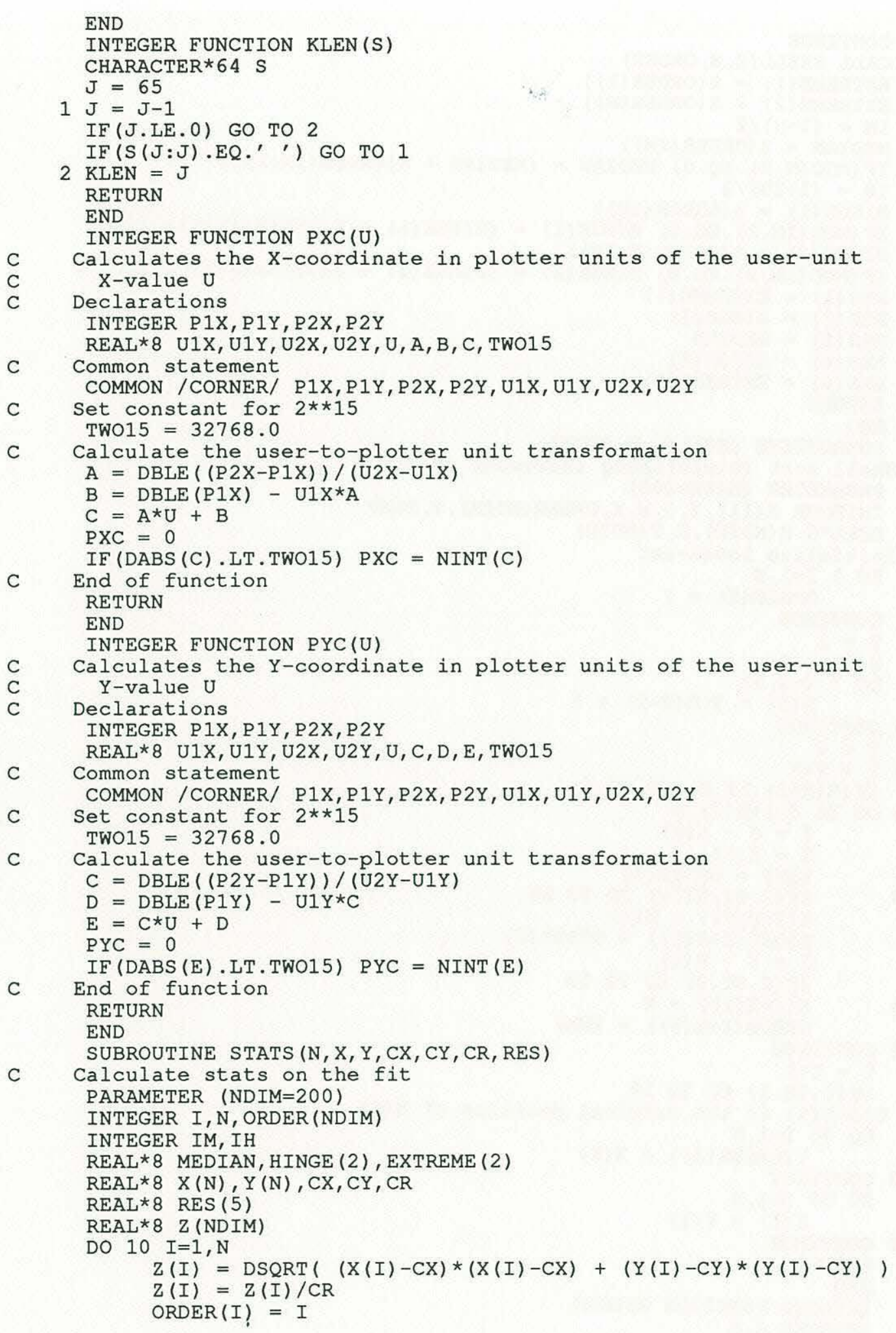


10 CONTINUE

CALL SHELL ( $Z, N$, ORDER)

EXTREME (1) $=\mathrm{Z}(\operatorname{ORDER}(1))$

$\operatorname{EXTREME}(2)=\mathrm{Z}(\operatorname{ORDER}(\mathrm{N}))$

$I M=(1+\mathrm{N}) / 2$

MEDIAN $=Z(O R D E R(I M))$

$\operatorname{IF}(\operatorname{MOD}(\mathrm{N}, 2) \cdot \mathrm{EQ} \cdot 0) \operatorname{MEDIAN}=(\operatorname{MEDIAN}+\mathrm{z}(\operatorname{ORDER}(\operatorname{IM}+1))) / 2 \cdot 0$

$I H=(1+I M) / 2$

$\operatorname{HINGE}(1)=\mathrm{Z}(\mathrm{ORDER}(\mathrm{IH}))$

$\operatorname{IF}(\operatorname{MOD}(\operatorname{IM}, 2) \cdot \operatorname{EQ} \cdot 0)$ HINGE $(1)=(\operatorname{HINGE}(1)+z(\operatorname{ORDER}(\operatorname{IH}+1))) / 2 \cdot 0$

$\operatorname{HINGE}(2)=\mathrm{Z}($ ORDER $(\mathrm{N}-\mathrm{IH}))$

$\operatorname{IF}(\operatorname{MOD}(\operatorname{IM}, 2) \cdot \mathrm{EQ} \cdot 0) \operatorname{HINGE}(2)=(\operatorname{HINGE}(2)+\mathrm{Z}(\mathrm{ORDER}(\mathrm{N}-\mathrm{IH}+1))) / 2 \cdot 0$

$\operatorname{RES}(1)=\operatorname{EXTREME}(1)$

$\operatorname{RES}(2)=\operatorname{HINGE}(1)$

$\operatorname{RES}(3)=$ MEDIAN

$\operatorname{RES}(4)=\operatorname{HINGE}(2)$

$\operatorname{RES}(5)=$ EXTREME (2)

RETURN

END

SUBROUTINE SHELL ( $\mathrm{X}, \mathrm{N}$, ORDER)

C Shell sort (Diminishing increment sort)

PARAMETER (NDIM $=200$ )

INTEGER H (11) , I, J, M, N , ORDER (NDIM) , T, TEMP

C Initialize index-set

DO 1 I=1, N

1 CONTINUE

$$
\operatorname{ORDER}(I)=I
$$

$\mathrm{T}=1$

$\mathrm{H}(1)=1$

DO $5 \mathrm{~T}=2,11$

5 CONTINUE

$$
\mathrm{H}(\mathrm{T}) \stackrel{11}{=} 3 \star \mathrm{H}(\mathrm{T}-1)+1
$$

$T=0$

$6 \mathrm{~T}=\mathrm{T}+1$

IF $(\mathrm{H}(\mathrm{T}+2)$. IT.N) GO TO 6

10 DO $30 \mathrm{~J}=1+\mathrm{H}(\mathrm{T}), \mathrm{N}$

$I=J-H(T)$

$\mathrm{K}=\mathrm{X}(\mathrm{J})$

15 IF(K.GT.X(I)) GO TO 20

TEMP $=\operatorname{ORDER}(\mathrm{J})$

$X(I+H(T))=X(I)$

$\operatorname{ORDER}(I+H(T))=\operatorname{ORDER}(I)$

$I=I-H(T)$

$20 \quad$ IF(I.GT.O) GO TO 15

$20 \quad X(I+H(T))=K$

30 CONTINUE

$\operatorname{ORDER}(I+H(T))=T E M P$

$\mathrm{T}=\mathrm{T}-1$

IF(T.GE.1) GO TO 10

C Order(i) is the original position of $X(i)$

DO $40 \quad I=1, N$

40 CONTINUE

$$
\mathrm{Y}(\mathrm{ORDER}(I))=\mathrm{X}(\mathrm{I})
$$

DO $50 \quad I=1, N$

$X(I)=Y(I)$

50 CONTINUE

RETURN

END

INTEGER FUNCTION GETNUM

INTEGER J,K 


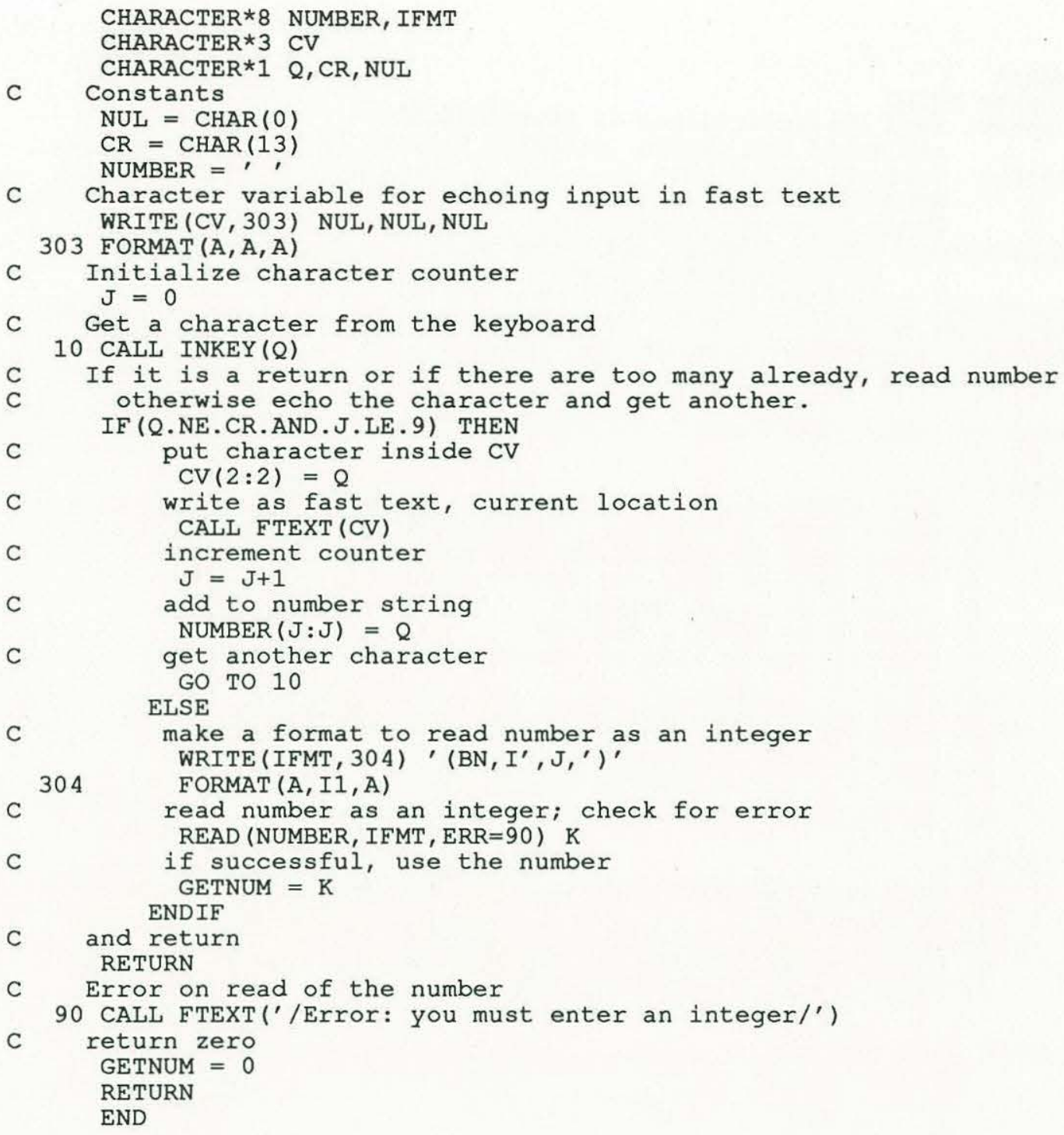




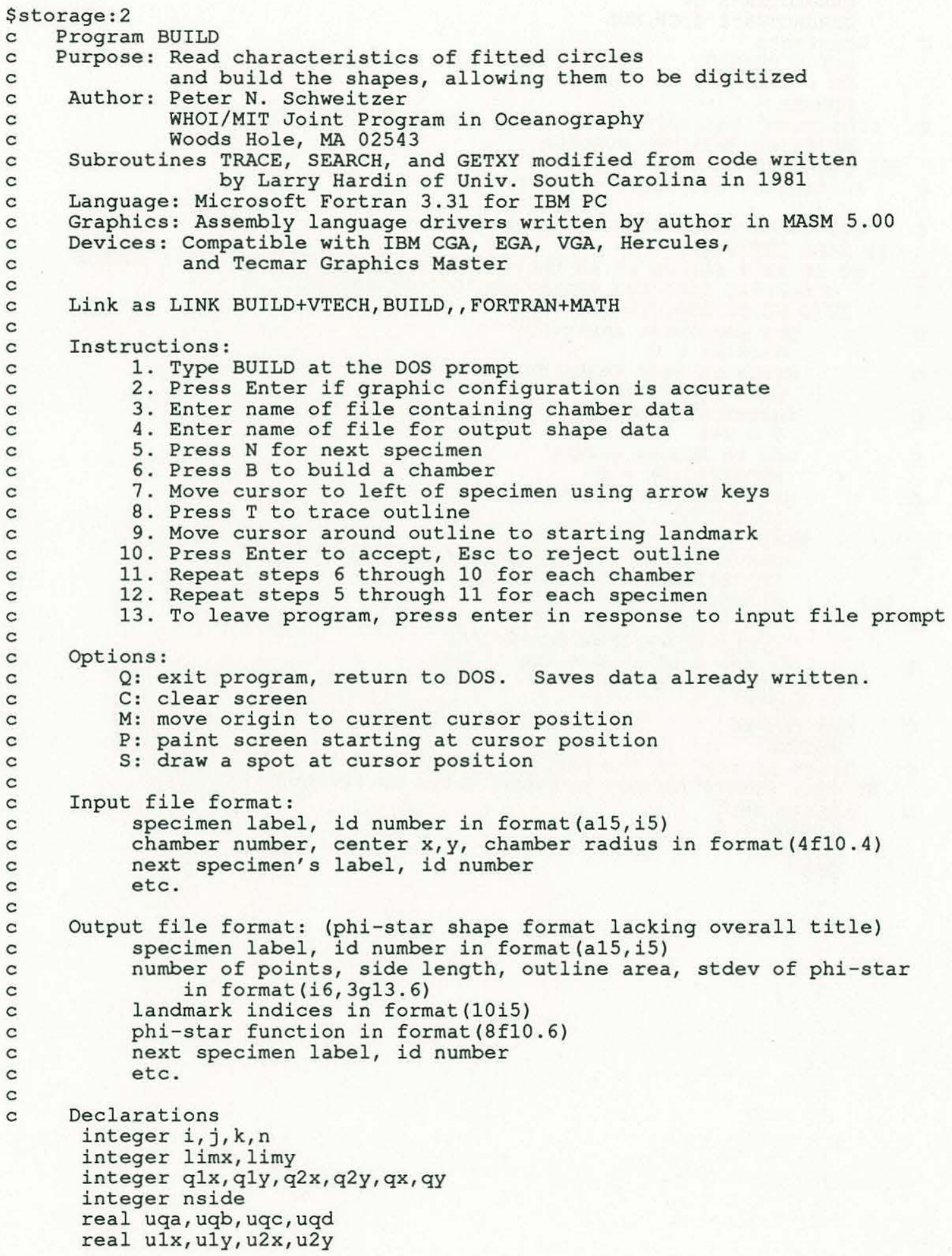




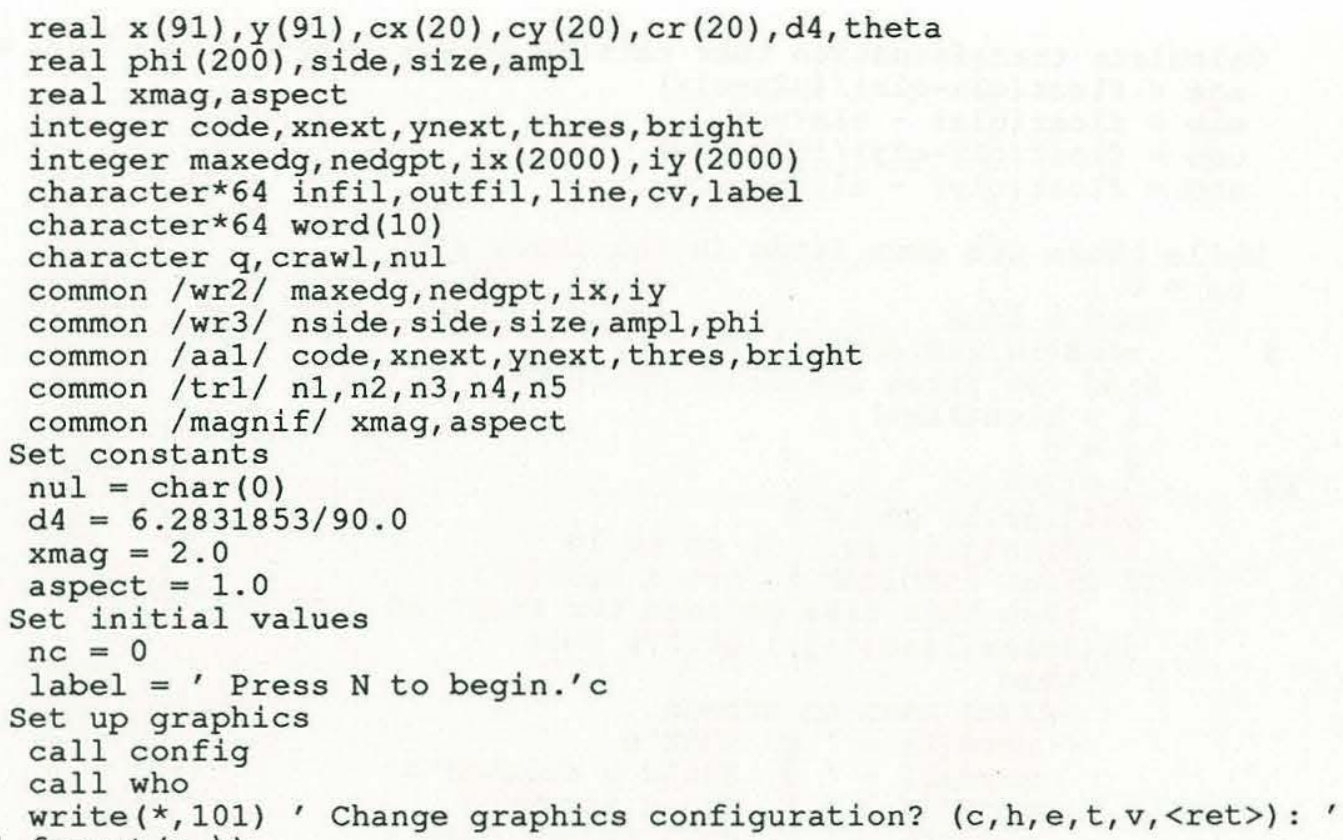




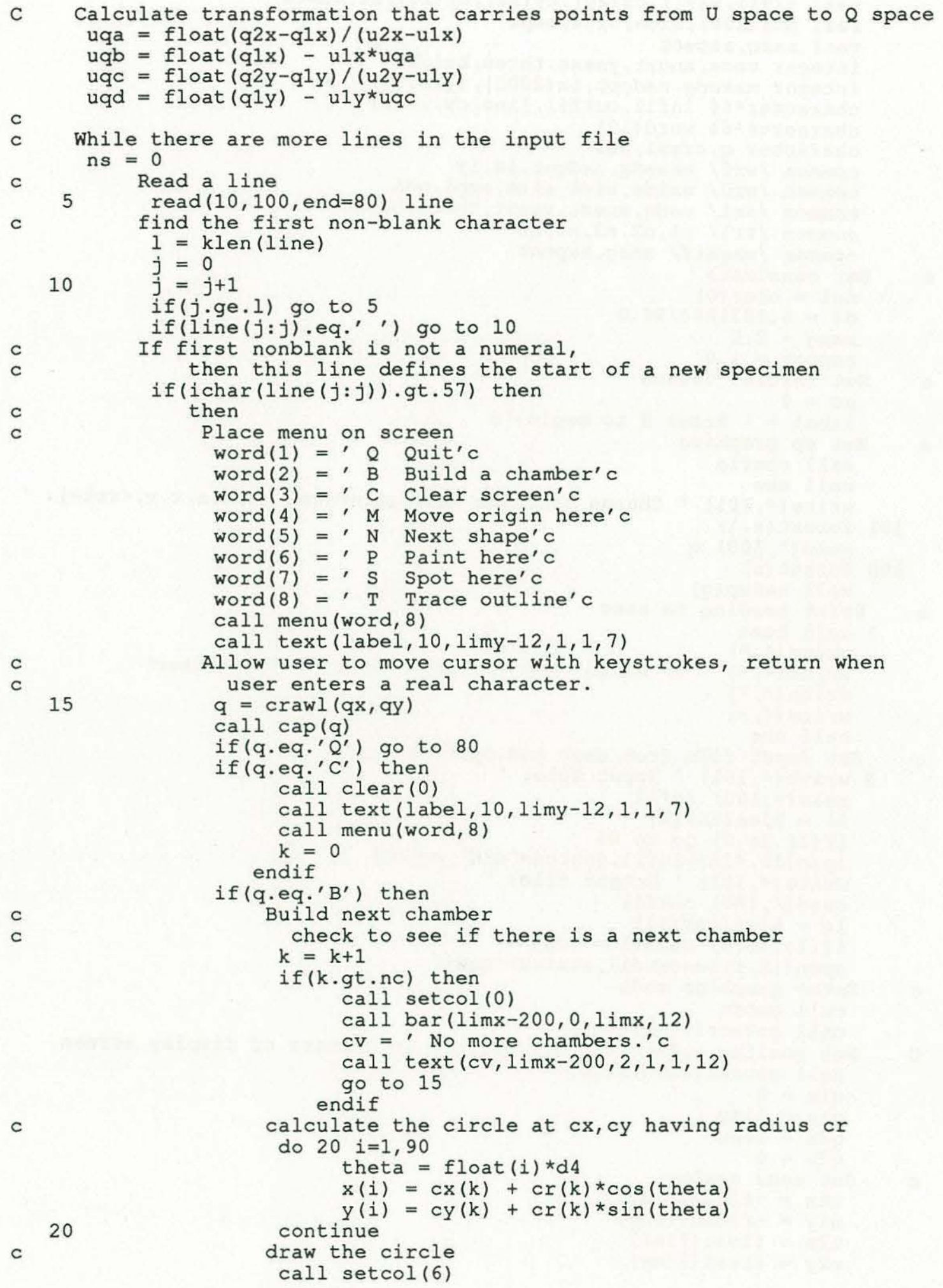




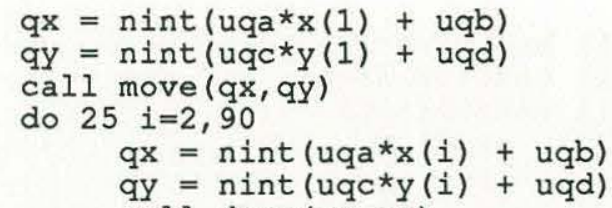


30

302

c

205.

206

207

208

c

c

c End-while

C Close input file and get next

80 call clear $(0)$

call tmode

close (10)

close (12)

go to 1

c

End of program

86 stop' Okay'

end

integer function klen(s)

character*64 s

$j=65$

$1 j=j-1$

if $(j . l e .0)$ go to 2

if $(s(j: j)$.eq.' ') go to 1

$2 \mathrm{klen}=j$

return

end

character function $\operatorname{crawl}(\mathrm{x}, \mathrm{y})$

integer limx, limy

integer $j, x, y$, step

character $q$

call getscr(limx, limy)

step $=4$

10 call cursor $(x, y)$ 
$\operatorname{call} \operatorname{key}(q, j)$

if $(j$. eq. -1$)$ then

$\mathrm{k}=\operatorname{ichar}(\mathrm{q})$
if $(\mathrm{k} \cdot$ eq. 83$)$ step $=$ step -1
if $(\mathrm{k} \cdot$ eq. 82$)$ step $=$ step +1

step $=\max 0($ step, 1)

step $=\min 0($ step, 100)

if (k.1t.71.or.k.gt.81) go to 10

if (k.eq.71.or.k.eq.72.or.k.eq.73) y $=y$ - step

if (k.eq.79.or.k.eq.80.or.k.eq.81) $y=y+$ step

if (k.eq.71.or.k.eq.75.or.k.eq.79) $\mathrm{x}=\mathrm{x}$ - step

if (k.eq.73.or.k.eq.77.or.k.eq.81) $\mathrm{x}=\mathrm{x}+$ step

if $(x . l t .0) \quad x=x+\lim x$

if $(y \cdot l t .0) y=y+l i m y$

if $(x \cdot g t \cdot \lim x) \quad x=\lim x-x$

if (y.gt.limy) $y=$ limy $-y$ go to 10

endif

crawl $=\mathrm{g}$

call cursor (limx, limy)

return

end

SUBROUTINE TRACE ( $i x, i y)$

INTEGER XOLD, YOLD, XBEG, YBEG, XNEXT, YNEXT, CODE, DIRECT

INTEGER NDIR, X(2000), Y (2000), SUMDIR, DX, DY, TRYNO, THRES

LOGICAL FOUND, BRIGHT

COMMON /WR2/ MAXEDG, NEDGPT, X, Y

COMMON /AAI/ CODE, XNEXT, YNEXT, THRES, BRIGHT

C

TR1 USED IN: TRACE, SEARCH, GETXY

COMMON /TR1/ XOLD, YOLD, TRYNO, FOUND, DIRECT

MAXEDG $=2000$

call getscr (ixbnd, iybnd)

c

set current point at $\mathrm{dx}, \mathrm{dy}$

xold $=i \mathrm{x}$

yold $=i y$

C Set threshold value at 1

bright $=$.true.

thres $=1$

C Highlight outline

CALL SETCOL (14)

C Here begins the trace routine

DIRECT $=0$

C $O$ DIRECTION MEANS SEARCH THE POINT SENT

C While point searched is on screen

10

Search current point

IF (FOUND) GO TO 20

C if not found, move to right and repeat search XOLD $=$ XOLD +1

IF (XOLD.LE. IXBND) GO TO 10

C End-while

C ERROR - NO EDGE FOUND

GO TO 130

C

STORE COORDS OF STARTING POINT

$20 \mathrm{XBEG}=\mathrm{XOLD}$

YBEG $=$ YOLD

NEDGPT $=1$

$\mathrm{X}(\mathrm{NEDGPT})=\mathrm{XBEG}$

$Y(N E D G P T)=Y B E G$

C CHOOSE PATTERN HERE

C ONLY CURRENT PATTERN IS L-SHAPE 


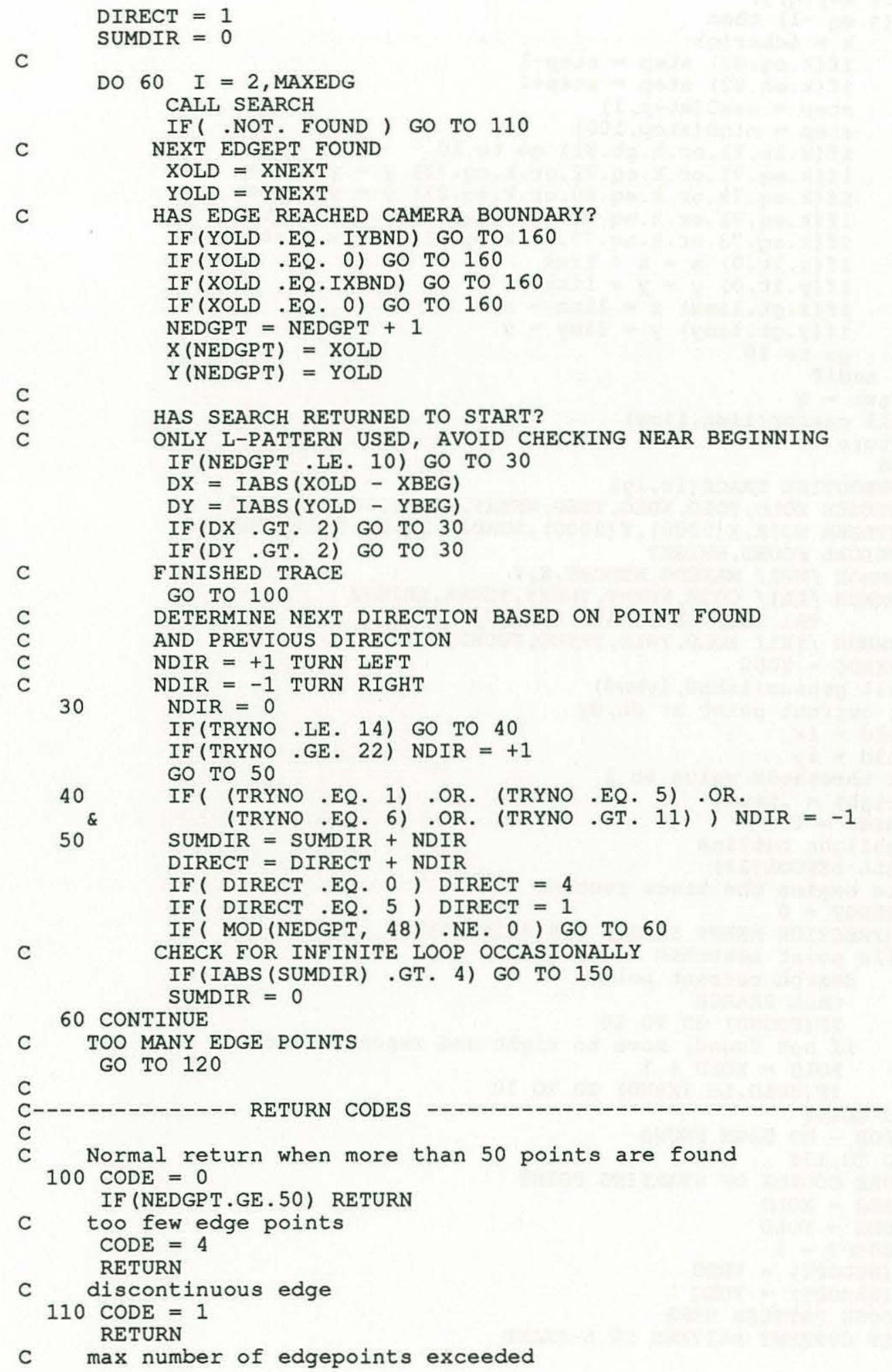




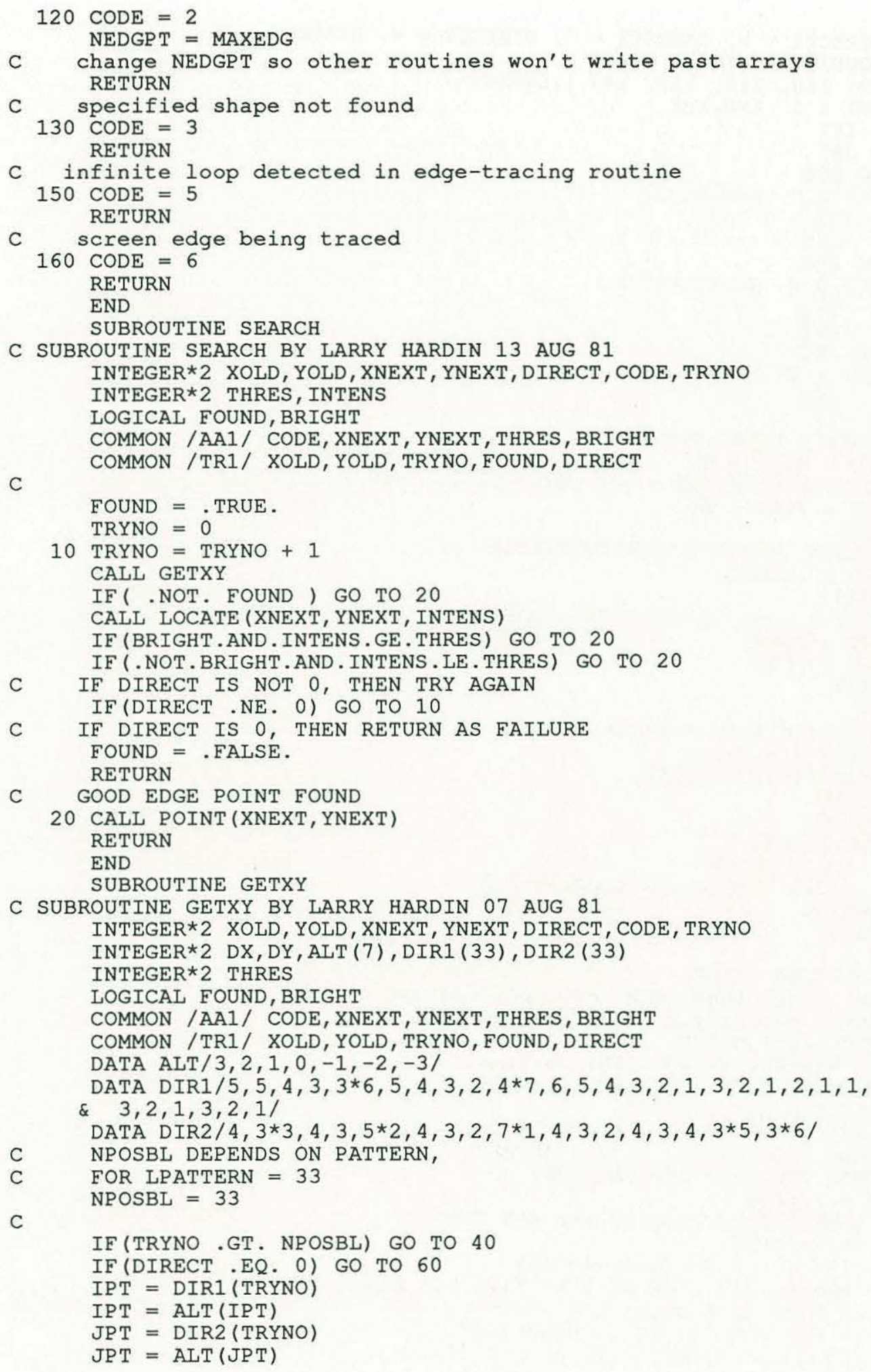




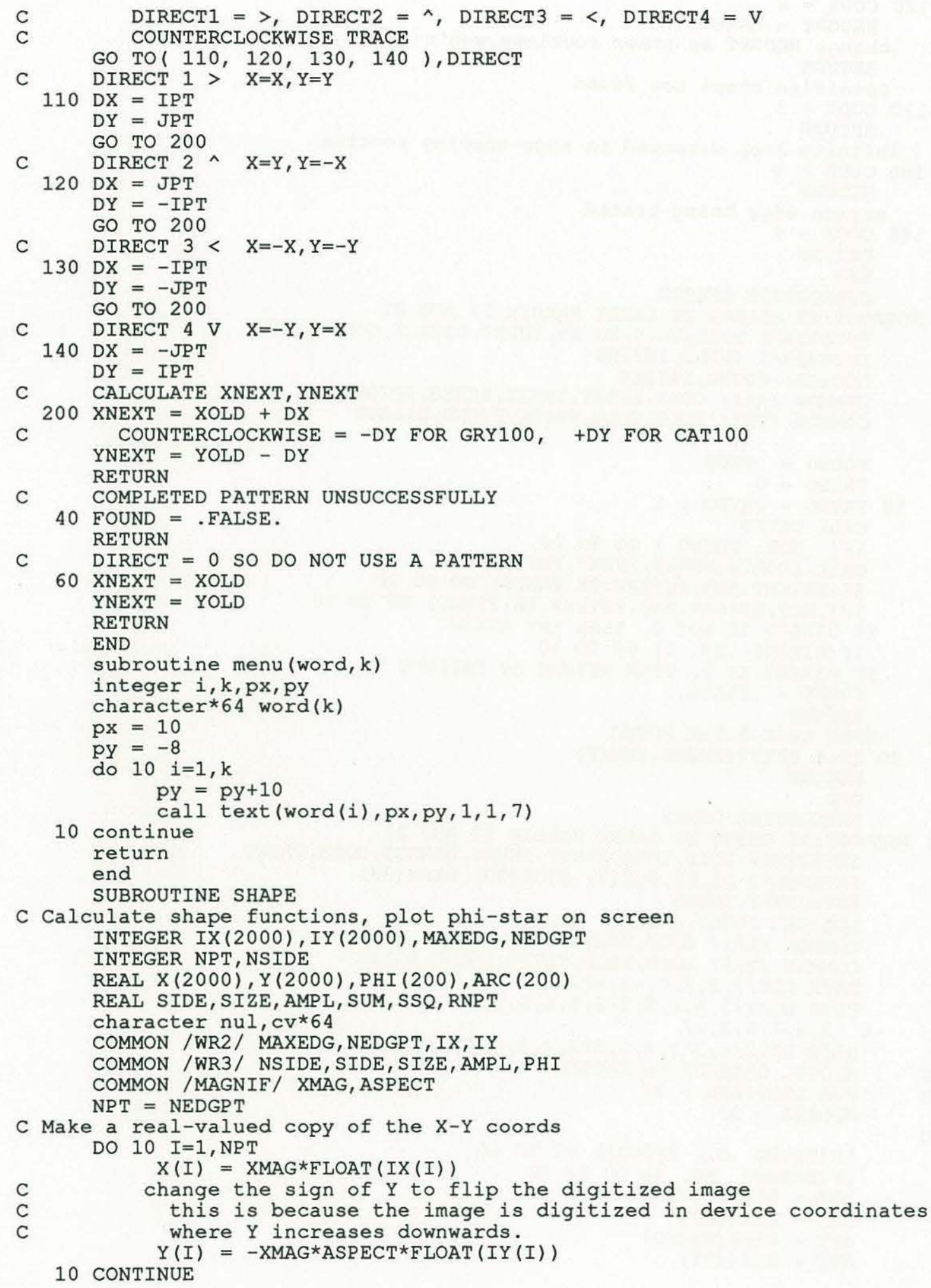




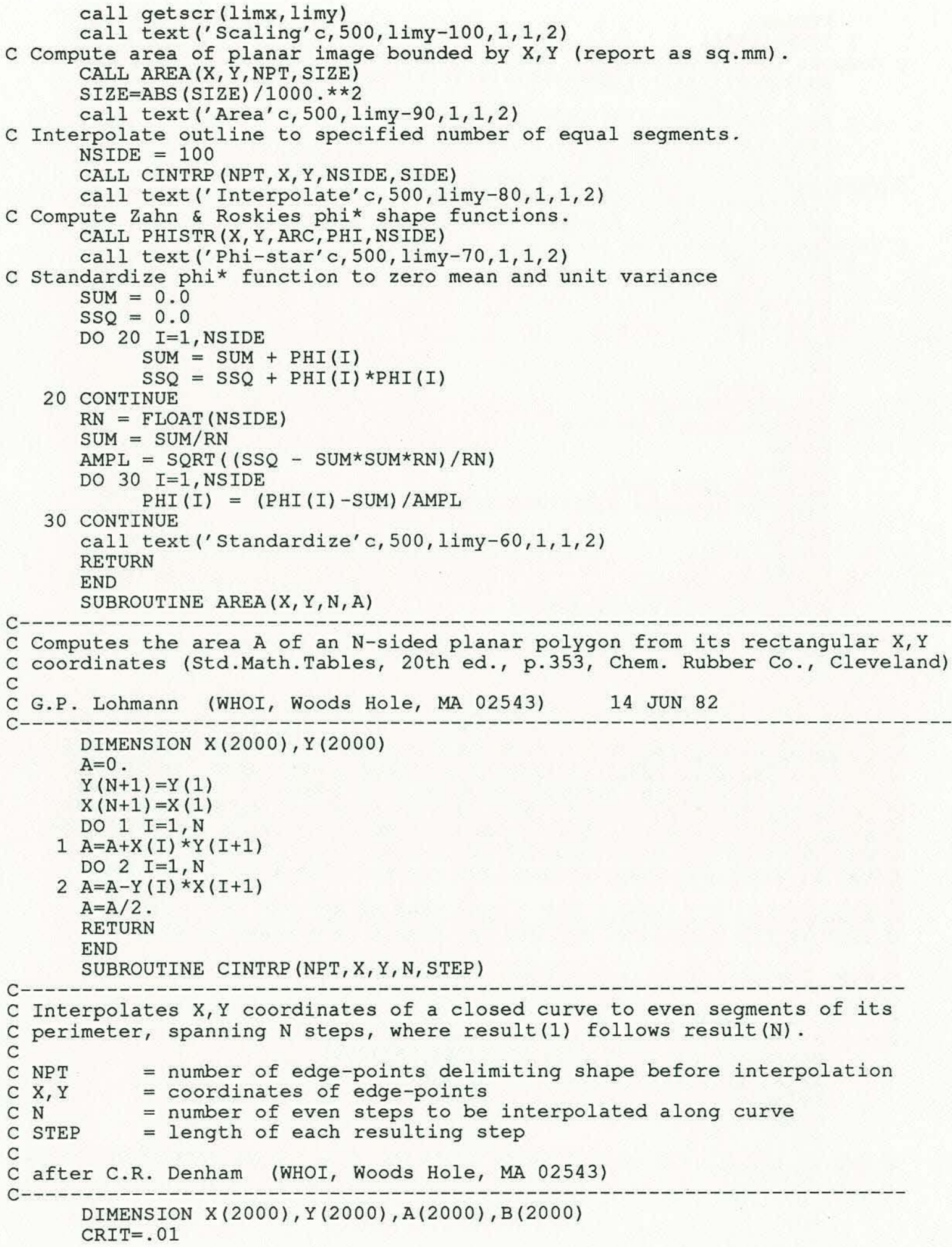


$I T E R=0$

1 ITER=ITER+1

C Compute perimeter length

$\mathrm{SUM} 2=\mathrm{SQRT}((\mathrm{X}(1)-\mathrm{X}(\mathrm{NPT})) \star \star 2+(\mathrm{Y}(1)-\mathrm{Y}(\mathrm{NPT})) \star \star 2)$

DO $2 I=2, N P T$

2 SUM2 $=S U M 2+S Q R T((X(I)-X(I-1)) \star \star 2+(Y(I)-Y(I-1)) \star \star 2)$

STEP $=$ SUM $2 /$ FLOAT $(\mathrm{N})$

IF (ITER. LE.2) GO TO 3

C Test for convergence (stop criterion is $1 \%$ change)

DIFF $=($ SUM1-SUM2) $/$ SUM1

IF (DIFF.LT.CRIT) RETURN

C Interpolate perimeter to $\mathrm{N}$ equal segments

3 SUM1=SUM2

DO $4 \quad I=1, N P T$

$A(I)=X(I)$

$4 B(I)=Y(I)$

$M 2=1$

$\mathrm{S} 2=0$.

DO $7 \mathrm{~J}=2, \mathrm{~N}$

DIST $=S T E P$ * $(\mathrm{J}-1)$

5 IF (DIST.LE.S2) GO TO 6

$\mathrm{M} 1=\mathrm{M} 2$

$\mathrm{M} 2=\mathrm{M} 2+1$

IF (M2.GT.NPT) M2 $=1$

$\operatorname{SIDE}=\operatorname{SQRT}((\mathrm{A}(\mathrm{M} 2)-\mathrm{A}(\mathrm{M} 1)) * \star 2+(\mathrm{B}(\mathrm{M} 2)-\mathrm{B}(\mathrm{M} 1)) \star \star 2)$

$\mathrm{S} 1=\mathrm{S} 2$

$\mathrm{S} 2=\mathrm{S} 2+\mathrm{SIDE}$

GO TO 5

$6 \mathrm{~F}=(\mathrm{DIST}-\mathrm{S} 1) / \mathrm{SIDE}$

$\mathrm{X}(\mathrm{J})=\mathrm{A}(\mathrm{M} 1)+\mathrm{F}^{*}(\mathrm{~A}(\mathrm{M} 2)-\mathrm{A}(\mathrm{M} 1))$

$7 \mathrm{Y}(\mathrm{J})=\mathrm{B}(\mathrm{M} 1)+\mathrm{F} *(\mathrm{~B}(\mathrm{M} 2)-\mathrm{B}(\mathrm{M} 1))$

$\mathrm{NPT}=\mathrm{N}$

GO TO 1

END

SUBROUTINE PHISTR(X, Y, ARC, PHI, NPT)

C Computes PHI* shape function of Zahn and Roskies (1972) IEEE Trans.

C C-21(3):269-281. PHI* represents a closed plane curve "as a function

$C$ of arc length by the accumulated change in direction of the curve

C since the starting point". Phi is the net amount of angular bend

$C$ around its perimeter. PHI* is normalized by removing a circle from

C PHI, such that PHI* $(0)$ and PHI* $(2 \mathrm{PI})=0$. Thus, "PHI* measures the

$C$ way in which the shape in question differs from a circular shape".

C

$C \mathrm{X}$ and $\mathrm{Y}$ are the integer $\mathrm{X}, \mathrm{Y}$ coordinates of NPT edge-points.

$C$ PHI* is the normalized net angular change as a function of ARC

C

C G.P. Lohmann (WHOI, Woods Hole, MA 02543) 18 Oct 81

C After a program written in PL/1 by Zahn and Roskies.

DIMENSION X $(200), Y(200), \operatorname{ARC}(200)$, PHI $(200)$

IF (X(1).EQ.X (NPT) . AND.Y(1).EQ.Y(NPT)) GO TO 1

$\mathrm{NPT}=\mathrm{NPT}+1$

$\mathrm{X}(\mathrm{NPT})=\mathrm{X}(1)$

$\mathrm{Y}(\mathrm{NPT})=\mathrm{Y}(1)$

C Arc length is the cumulative point-to-point distance around perimeter.

$1 \operatorname{ARC}(1)=0$

$\operatorname{PHI}(1)=0$

$\mathrm{P}=0$

DO $2 I=2, \mathrm{NPT}$ 


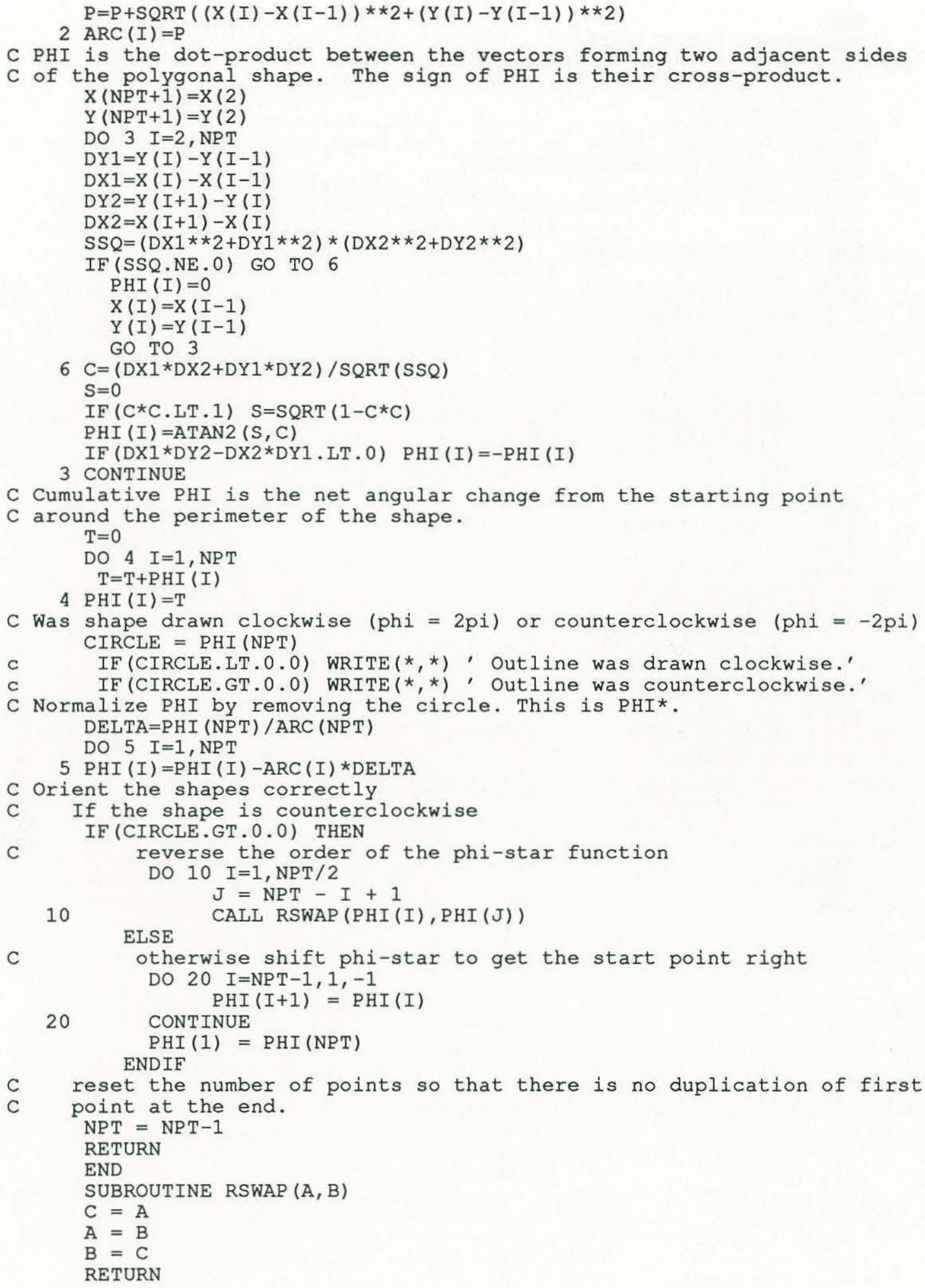


END

SUBROUTINE SETPT1(ier)

$C$ set the starting point by using the mouse INTEGER IX (2000), IY (2000), MAXEDG, NEDGPT INTEGER IZ(2000)

CHARACTER $* 1$ Q, esC

LOGICAL BRIGHT

COMMON /WR2 / MAXEDG, NEDGPT, IX, IY

esc $=\operatorname{char}(27)$

$\mathrm{K}=14$

$\mathrm{J}=1$

2 call cursor $(i x(j), i y(j))$

call key $(q, i)$

if (i.eq. -1 ) then

$\mathrm{k}=\operatorname{ichar}(\mathrm{q})$

if (k.eq. 71 ) $j=j-10$

if (k.eq. 73) $j=j+10$

if (k.eq.75) $j=j-1$

if (k.eq.77) $j=j+1$

if (j.gt.nedgpt) $j=j-$ nedgpt

if $(j$. le.0 $) j=$ nedgpt $+j$

go to 2

endif

ier $=1$

if (q.eq.esc) return

$\mathrm{K}=\mathrm{J}$

DO $10 I=1$, NEDGPT

10

$I Z(I)=I X(I)$

DO $11 \mathrm{I}=1$, NEDGPT

$\mathrm{J}=\mathrm{K}+\mathrm{I}-1$

IF ( $J$.GT.NEDGPT) $J=J-$ NEDGPT

$I X(I)=I Z(J)$

11 CONTINUE

DO $20 \mathrm{I}=1$, NEDGP T

$20 \operatorname{IZ}(I)=I Y(I)$

DO $21 \mathrm{I}=1$, NEDGPT

$\mathrm{J}=\mathrm{K}+\mathrm{I}-1$

IF (J.GT.NEDGPT) $\mathrm{J}=\mathrm{J}-$ NEDGPT

21 CONTINUE

$I Y(I)=I Z(J)$

ier $=0$

RETURN

END 


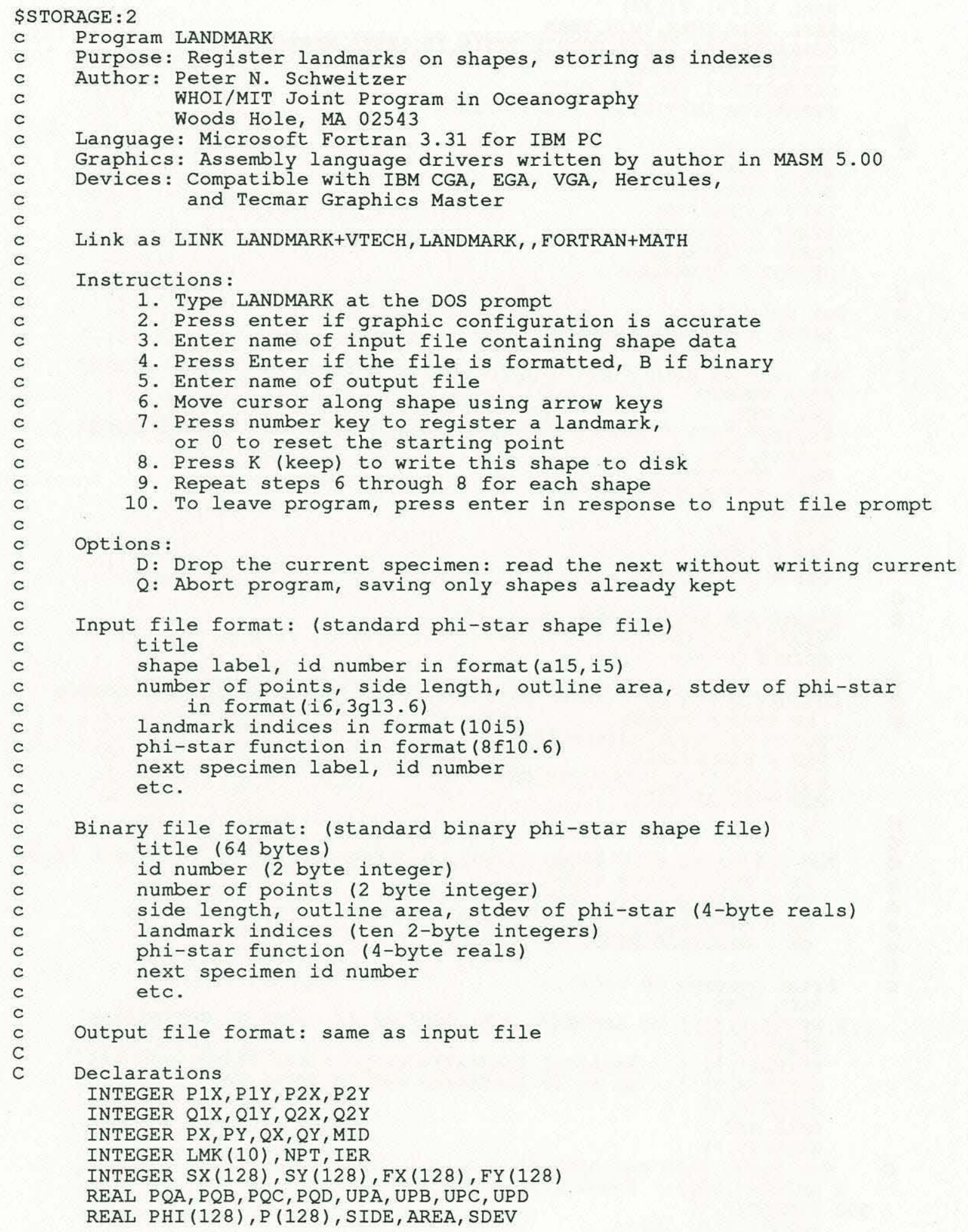




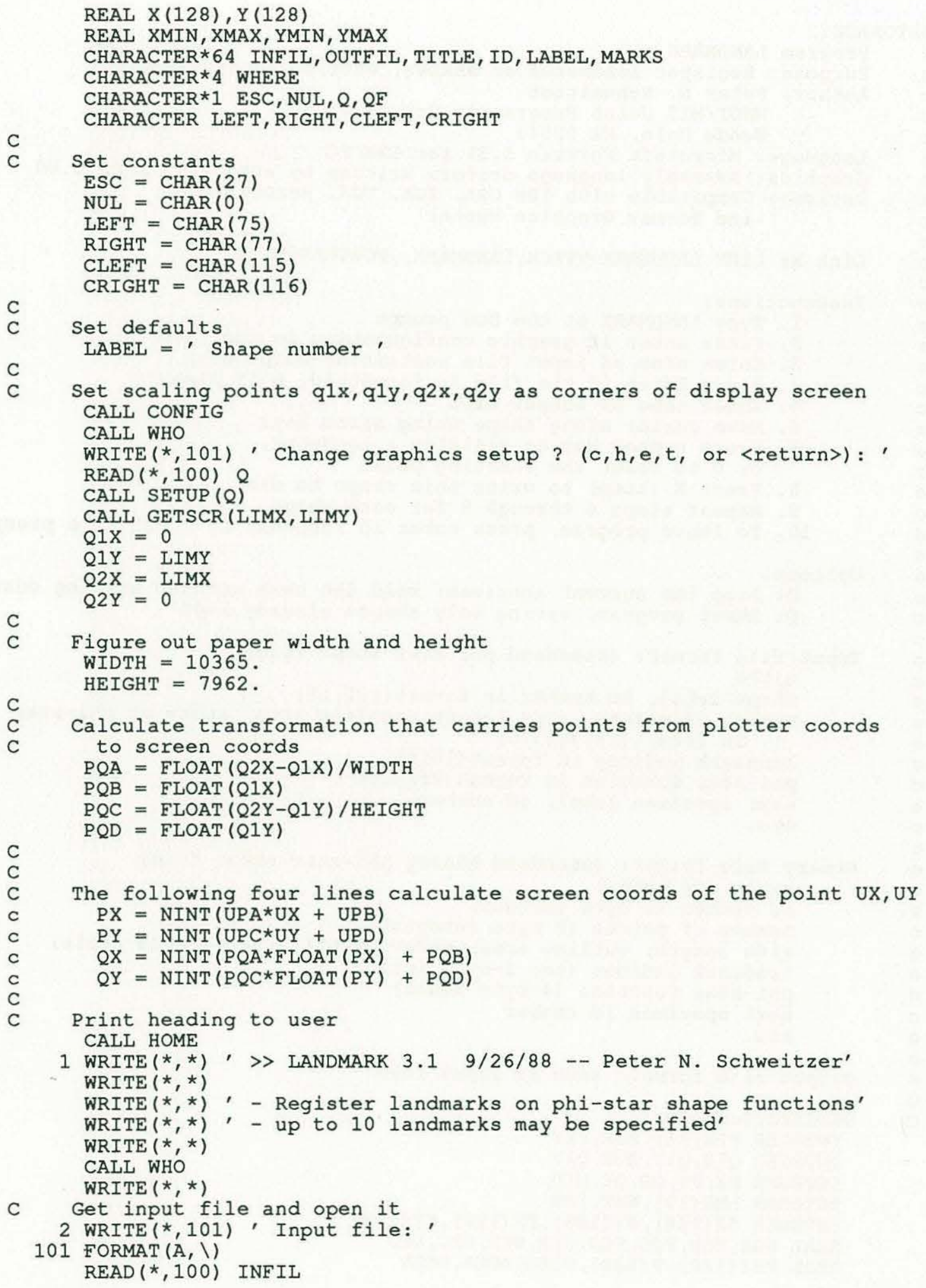




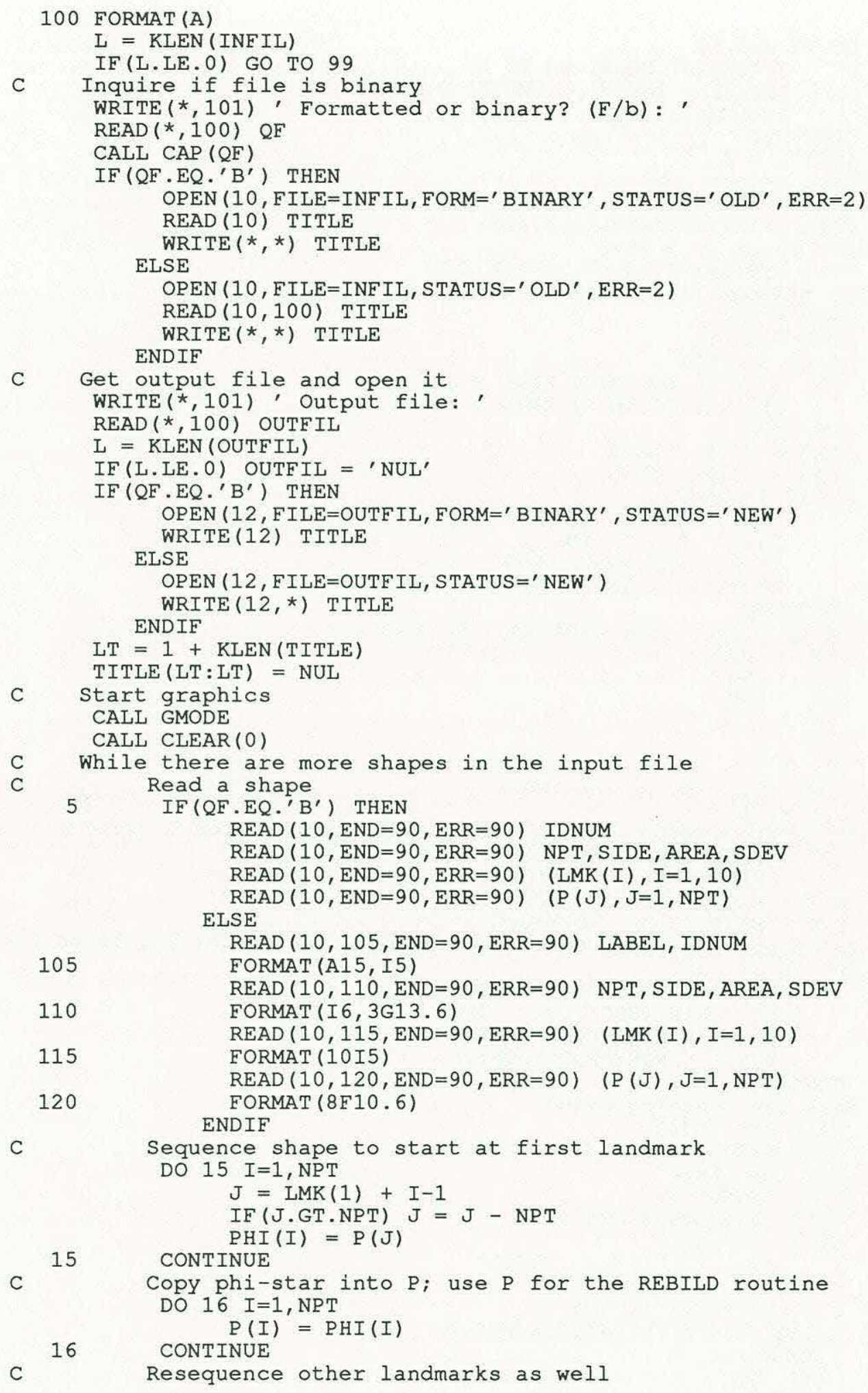




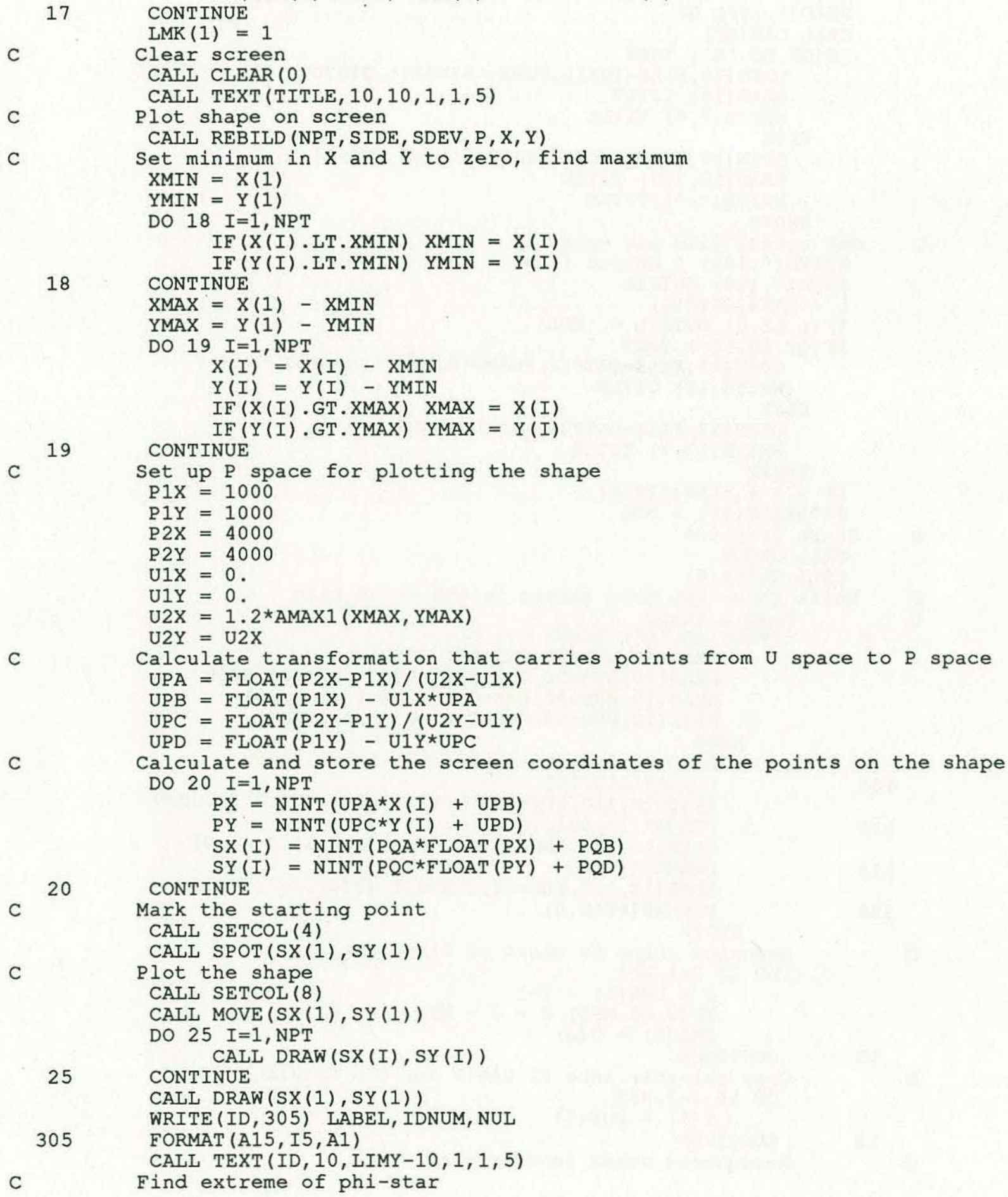


YMAX $=$ ABS $($ PHI (1))

DO $27 I=1$, NPT IF (ABS (PHI(I)) , GT. YMAX) YMAX = ABS (PHI(I))

C

Set up $P$ space for plotting the phi-star function

$\mathrm{P} 1 \mathrm{X}=3000$

$\mathrm{P} 1 \mathrm{Y}=4000$

$\mathrm{P} 2 \mathrm{X}=9000$

$\mathrm{P} 2 \mathrm{Y}=7000$

$\mathrm{U} 1 \mathrm{X}=0$.

$\mathrm{U} 1 \mathrm{Y}=-\mathrm{YMAX}$

$\mathrm{U} 2 \mathrm{X}=$ FLOAT $(\mathrm{NPT}+1)$

$\mathrm{U} 2 \mathrm{Y}=+\mathrm{YMAX}$

C

Calculate transformation that carries points from $U$ space to $P$ space $\mathrm{UPA}=$ FLOAT $(\mathrm{P} 2 \mathrm{X}-\mathrm{P} 1 \mathrm{X}) /(\mathrm{U} 2 \mathrm{X}-\mathrm{U} 1 \mathrm{X})$

$U P B=F L O A T(P 1 X)-U 1 X * U P A$

$\mathrm{UPC}=$ FLOAT $(\mathrm{P} 2 \mathrm{Y}-\mathrm{P} 1 \mathrm{Y}) /(\mathrm{U} 2 \mathrm{Y}-\mathrm{U} 1 \mathrm{Y})$

$\mathrm{UPD}=$ FLOAT $(\mathrm{P} 1 \mathrm{Y})-\mathrm{U} 1 \mathrm{Y} * \mathrm{UPC}$

C

Calculate and store the screen coordinates of the phi-star function DO $30 \quad I=1$, NPT

$P X=N I N T(U P A * F L O A T(I)+U P B)$

$P Y=N I N T(U P C \star P H I(I)+U P D)$

$\mathrm{FX}(I)=\operatorname{NINT}(P Q A * F L O A T(P X)+P Q B)$

30 CONTINUE

C

Frame the Phi-star function

CALL SETCOL (3)

$Q 1 X=$ NINT $(P Q A * F L O A T(P 1 X)+P Q B)$

$Q 1 Y=$ NINT $(P Q C \star F L O A T(P 1 Y)+P Q D)$

$\mathrm{Q} 2 \mathrm{X}=\operatorname{NINT}(\mathrm{PQA}$ *FLOAT $(\mathrm{P} 2 \mathrm{X})+\mathrm{PQB})$

$Q 2 Y=N I N T(P Q C * F L O A T(P 2 Y)+P Q D)$

CALL MOVE ( $Q 1 X, Q 1 Y$ )

CALL DRAW (Q1X, Q2Y)

CALL MOVE (Q2X, Q2Y)

CALL DRAW (Q2X, Q1Y)

CALL BAR ( $Q 1 X, Q 2 Y, Q 2 X, Q 2 Y-1)$

CALL BAR ( $Q 1 X, Q 1 Y, Q 2 X, Q 1 Y+1)$

C

Draw a zero line

CALL SETCOL (2)

$\mathrm{MID}=(Q 2 \mathrm{Y}+\mathrm{Q} 1 \mathrm{Y}) / 2$

CALL MOVE (Q1X, MID)

CALL DRAW (Q2X, MID)

C

Plot the phi-star function on this box

CALL SETCOL (6)

CALL MOVE (FX(1), FY (1))

DO $35 \mathrm{I}=1$, NPT

CALL DRAW(FX(I), FY (I))

c CONTINUE

35

Display locations of current landmarks

DO $36 \quad I=1,10$

$\mathrm{K}=\mathrm{I}-1$

WRITE (MARKS, 410) K, LMK(I), NUL

$\mathrm{QX}=10$

$Q Y=30+10 * K$

36 CONTINUE

C

Prompt user to move cursor

CALL TEXT ('<- Move Cursor ->' $c, Q 1 X, \operatorname{LIMY}-30,1,1,10$ )

CALI TEXT ('0-9 set Landmark', , Q1X, LIMY-20,1, 1, 10)

CALL TEXT (' $\mathrm{K}=$ Keep, $\mathrm{D}=$ Drop, $Q=$ Quit' $^{\prime}, Q 1 \mathrm{X}, \mathrm{LIMY}-10,1,1,10$ )

C

set cursor on first landmark 


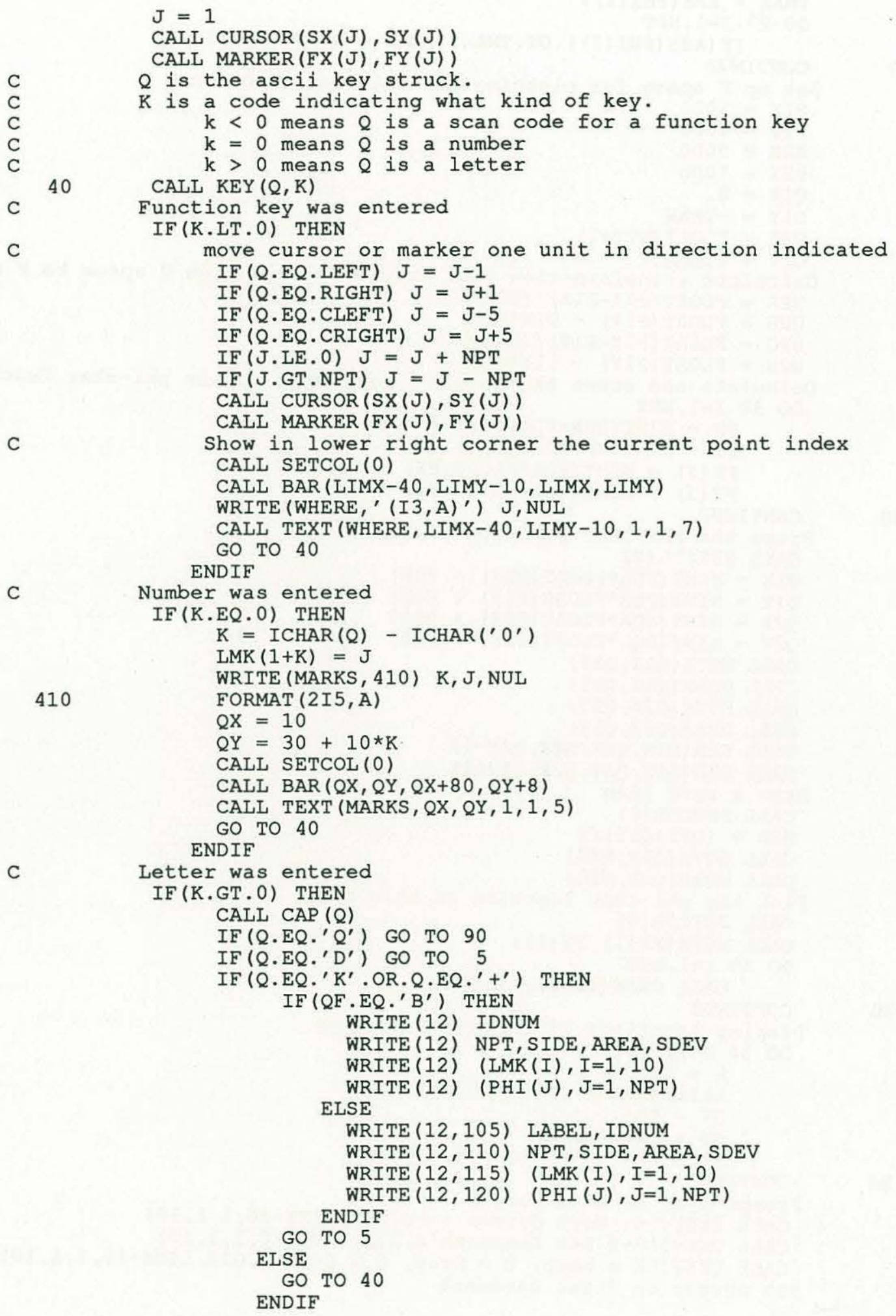




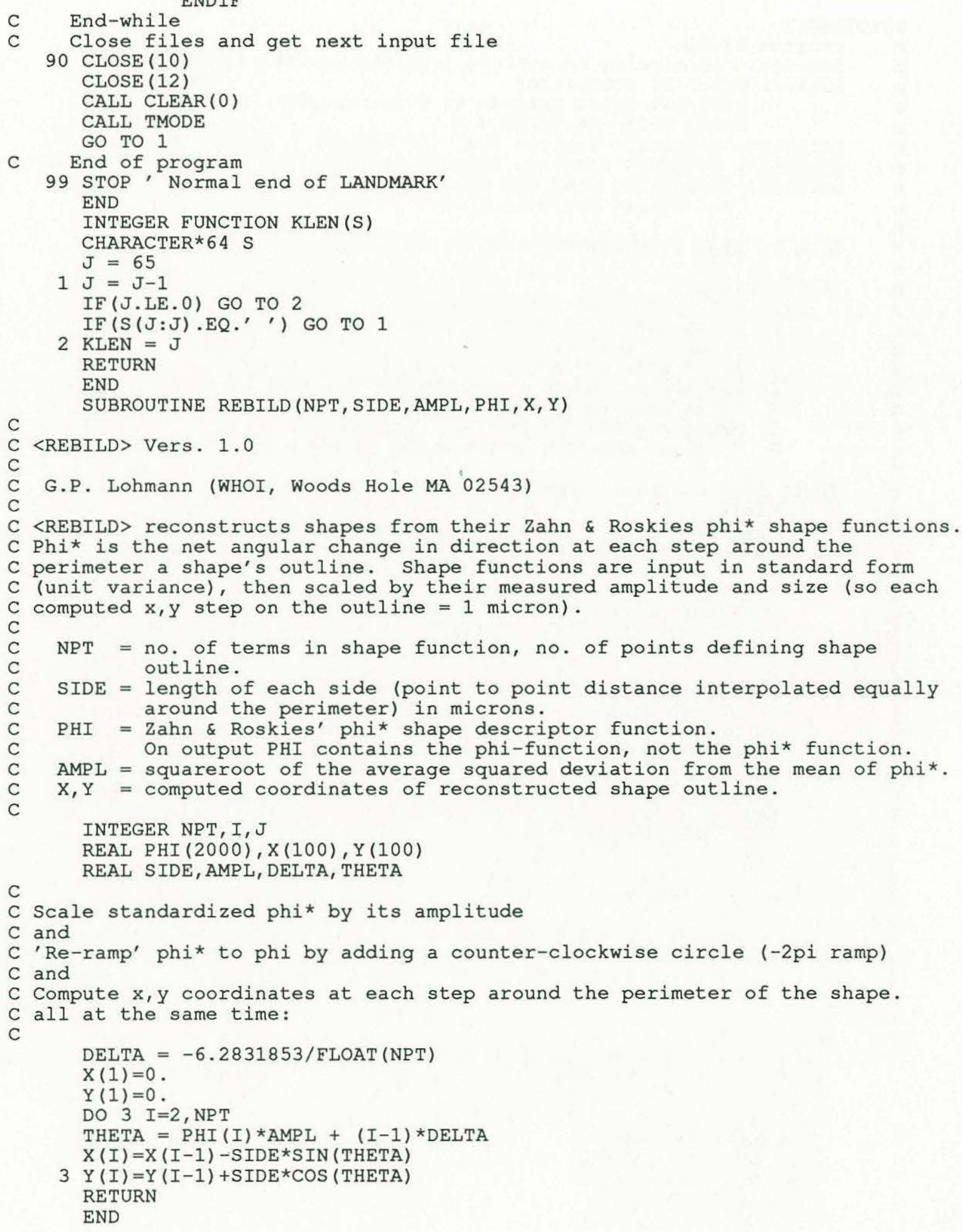


\$STORAGE : 2

Program FitCir

Purpose: Fit circles to outline segments between landmarks

Author: Peter N. Schweitzer

WHOI/MIT Joint Program in Oceanography

Woods Hole, MA 02543

Language: Microsoft Fortran 3.31 for IBM PC

Graphics: Assembly language drivers written by author in MASM 5.00

Devices: Compatible with IBM CGA, EGA, VGA, Hercules, and Tecmar Graphics Master

Link as LINK FITCIR+VTECH, FITCIR, , FORTRAN+MATH

Instructions:

1. Type FITCIR at the DOS prompt

2. Press enter if graphic configuration is accurate

3. Enter $Y$ to pause after each specimen is processed

4. Enter name of input file containing shape data

5. Press Enter if the file is formatted, B if binary

6. Enter name of output file

7. Press any key to read each specimen

8. To leave program, press enter in response to input file prompt

Input file format: (standard phi-star shape file)

title

shape label, id number in format $(a 15,15)$

number of points, side length, outline area, stdev of phi-star in format $(i 6,3 g 13.6)$

landmark indices in format(10i5)

phi-star function in format $(8 \mathrm{f} 10.6)$

next specimen label, id number

etc.

Binary file format: (standard binary phi-star shape file)

title (64 bytes)

id number ( 2 byte integer)

number of points ( 2 byte integer)

side length, outline area, stdev of phi-star (4-byte reals)

landmark indices (ten 2-byte integers)

phi-star function (4-byte reals)

next specimen id number

etc.

Output file format:

title

shape label, idnumber, number of chambers in format $(a 15,15, f 10.4)$

chamber center $x, y$, radius, number of points along arc, angle of arc, angle/median for this specimen in format $(6 f 10.4)$ next shape label, etc.

Declarations

INTEGER I, J, K, M, NPT , LMK (10), IDNUM, K1, K2, NK, NDIM, MDIM

INTEGER MARKER, OUTLINE

INTEGER P1X, P1Y, P2X, P2Y, PX, PY

INTEGER Q1X, Q1Y, Q2X, Q2Y, QX, QY

INTEGER LIMX, LIMY

REAL UPA, UPB, UPC, UPD

REAL PQA, PQB, PQC, PQD

REAL WIDTH, HEIGHT

REAL U1X, U1Y, U2X, U2Y 
REAL X (201), Y (201), PHI (201), SIDE, AREA, SD

REAL XMIN, XMAX, YMIN, YMAX, LOW, HIGH, RANGE

REAL Z (201), W (201, 3), $\operatorname{COEFF~(3),~A3X3~(3,~3),~A3~(3)~}$

REAL A, B, C, RADIUS

REAL CX (64), CY (64), DELTA, T

REAL CCX (11), $\mathrm{CCY}(11), \mathrm{CR}(11), \mathrm{CN}(11), \operatorname{ANGLE}(11), \mathrm{CH}(11), \mathrm{TCH}$

CHARACTER $\star 64$ TITLE

CHARACTER *64 INFIL, OUTFIL, CV

CHARACTER $* 15$ LABEL

CHARACTER $* 2$ MARK

CHARACTER * 1 Q, NUL

C

LOGICAL F, QPAUSE

C

Set constants

NDIM $=201$

MDIM $=3$

NUL $=\operatorname{CHAR}(0)$

DELTA $=6.2831853 / 60$.

MARKER $=6$

OUTLINE $=3$

CALL CONFIG

$\mathrm{pi}=3.14159265$

$r 2 \mathrm{~d}=180 \cdot / \mathrm{pi}$

C

Set scaling points $q 1 x, q 1 y, q 2 x, q 2 y$ as corners of display screen

CALL GETSCR (LIMX, LIMY)

$\mathrm{Q} 1 \mathrm{X}=0$

QIY $=$ LIMY

Q2X $=$ LIMX

$\mathrm{Q} 2 \mathrm{Y}=0$

C

Figure out paper width and height

WIDTH $=10365$.

HEIGHT $=7962$.

C

Calculate transformation that carries points from plotter coords to screen coords

$\mathrm{PQA}=$ FLOAT $(Q 2 \mathrm{X}-\mathrm{Q} 1 \mathrm{X}) / \mathrm{WIDTH}$

$\mathrm{PQB}=$ FLOAT $(Q 1 \mathrm{X})$

$\mathrm{PQC}=$ FLOAT $(Q 2 \mathrm{Y}-\mathrm{Q} 1 \mathrm{Y}) / \mathrm{HEIGHT}$

$\mathrm{PQD}=\mathrm{FLOAT}(\mathrm{Q} 1 \mathrm{Y})$

C

The following four lines calculate screen coords of the point UX, UY $P X=N I N T(U P A * U X+U P B)$

$P Y=N I N T(U P C \star U Y+U P D)$

$Q X=N I N T(P Q A * F L O A T(P X)+P Q B)$

$Q Y=N I N T(P Q C * F L O A T(P Y)+P Q D)$

Print heading to user

CALL HOME

WRITE $(*, *)$ ' $>$ FitCir $2.13 / 11 / 89$-- Peter N. Schweitzer'

$\operatorname{WRITE}(*, *)$

WRITE $(*, *)$ ' - Plot foram shapes and fit circles to chambers'

WRITE $(*, *)$ ' - Formatted or binary input'

WRITE $(*, *)$

C

CALL WHO

C Get correct hardware setup from user write $(*, *)$

write $(*, *)$ ' Using C for IBM Color Graphics,' write (*,*) ' E for IBM Enhanced Graphics,' 


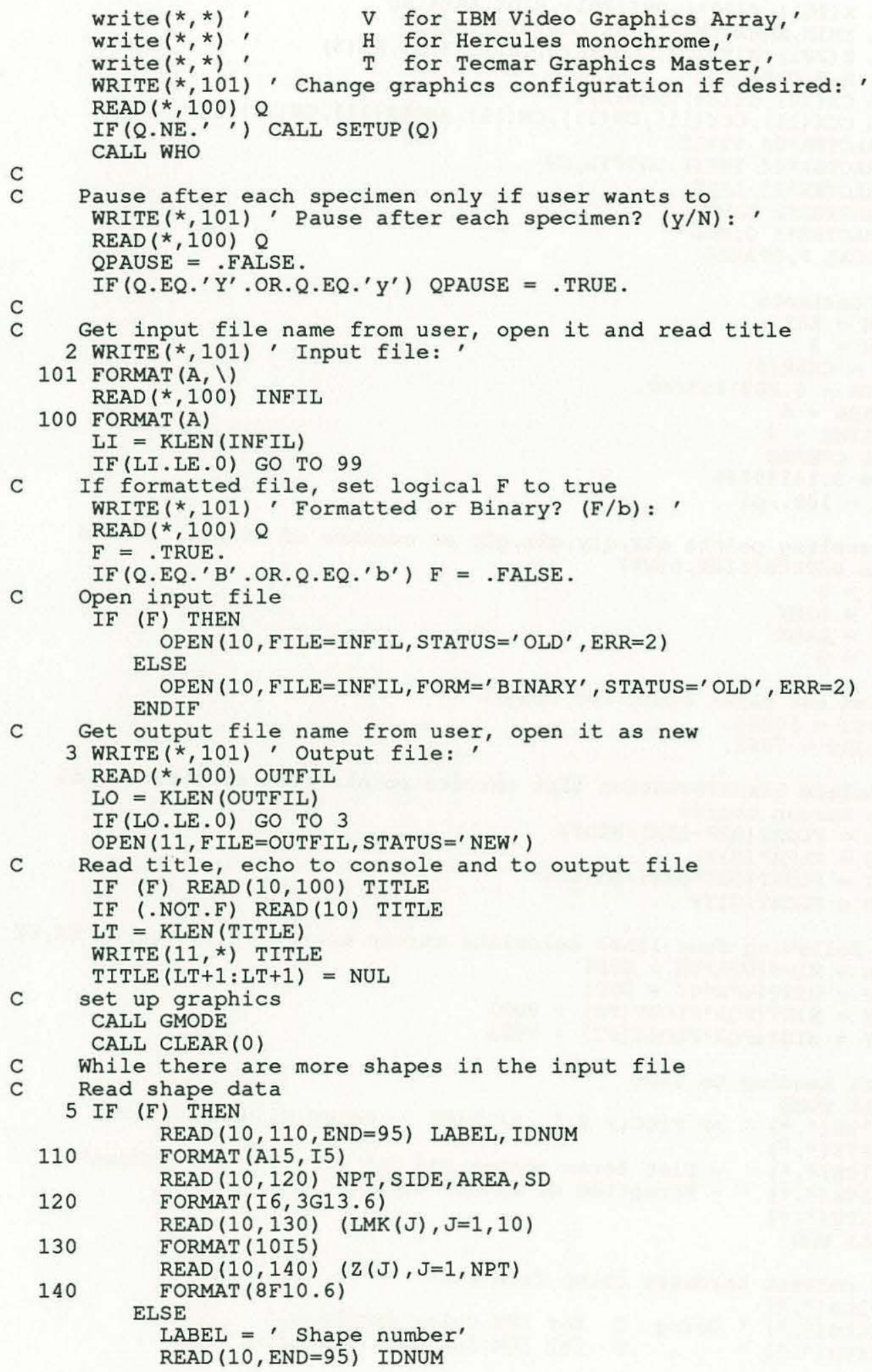




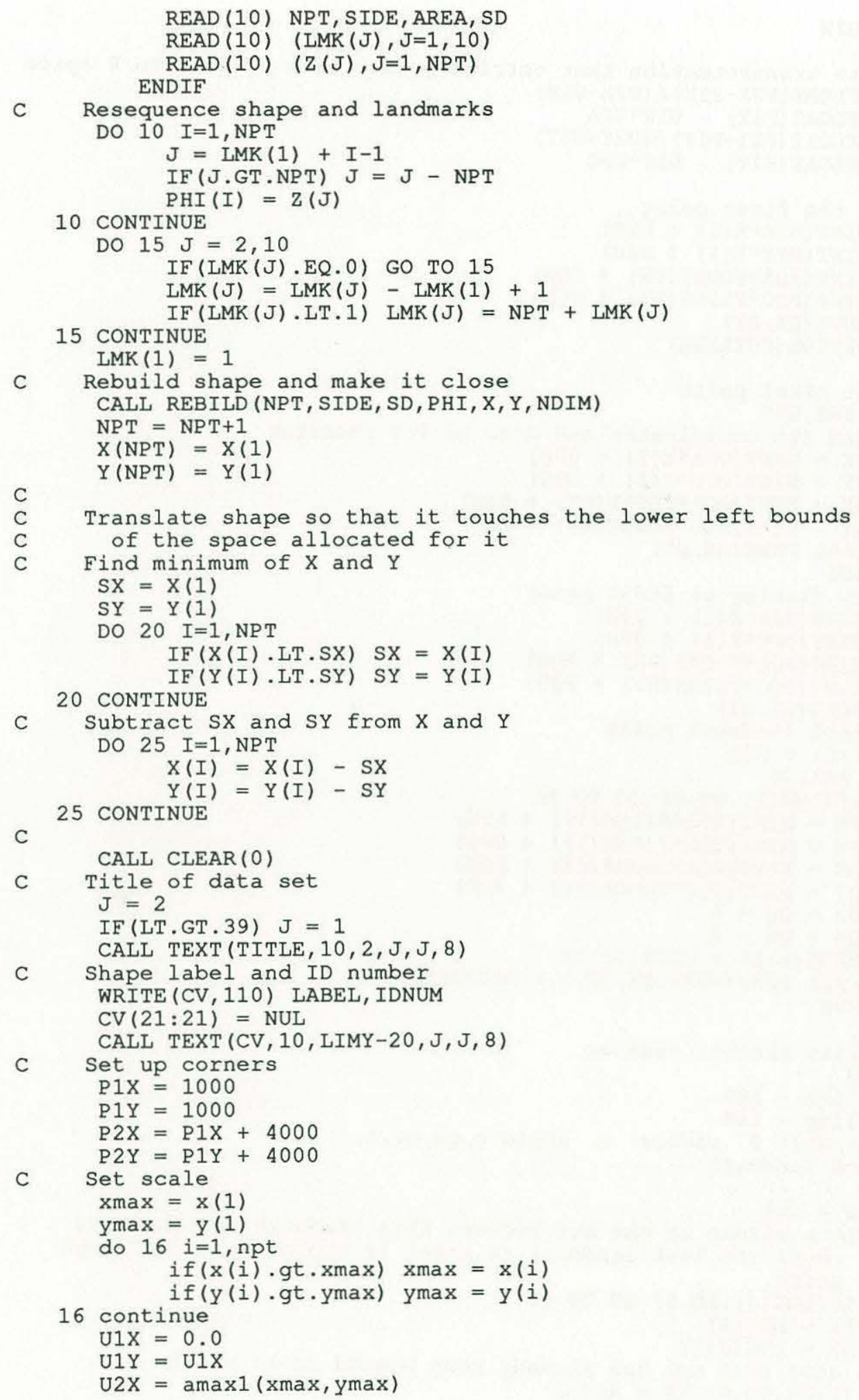




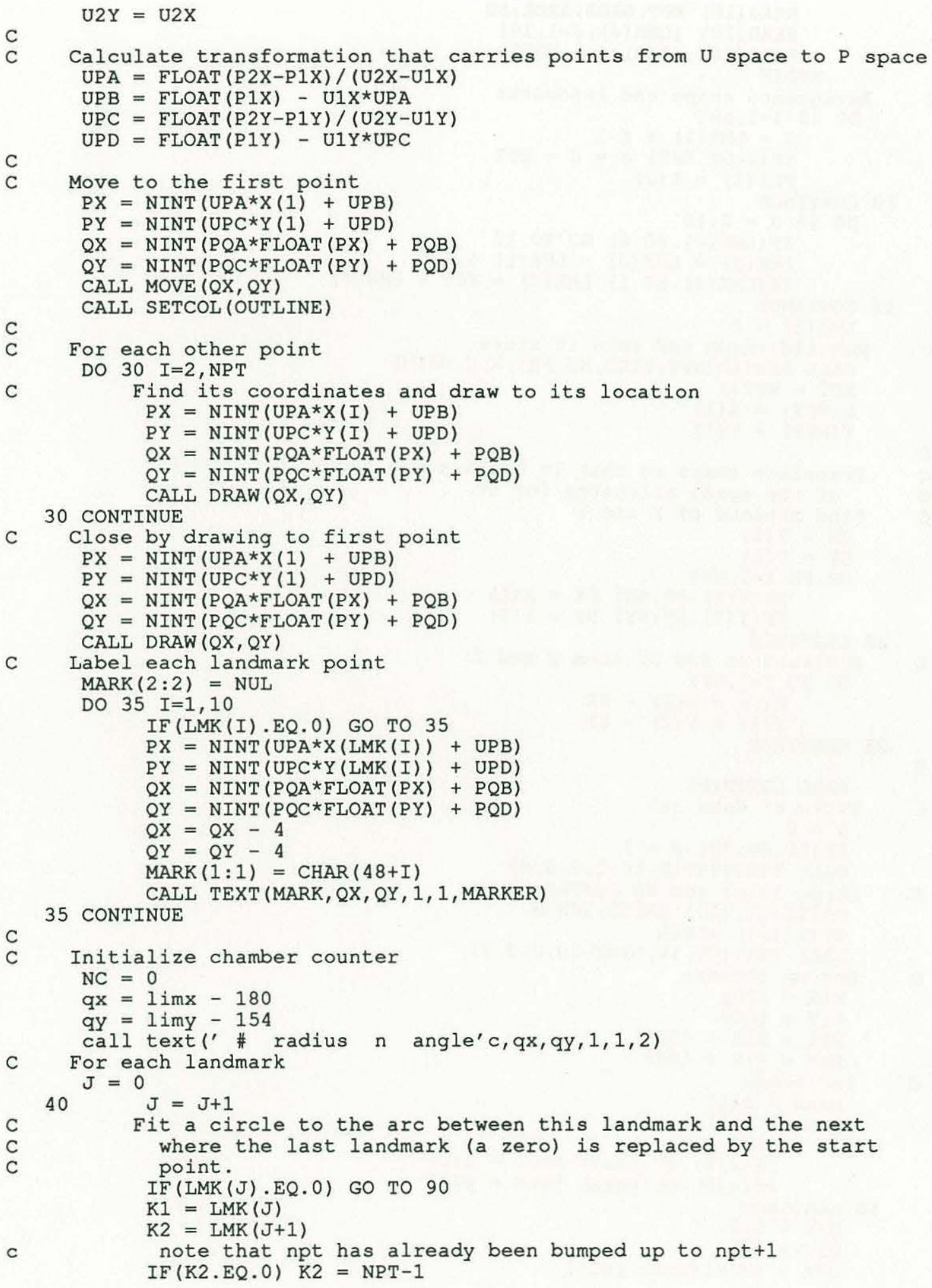


C

C

C

C

45

C

C

C

C

CD

$C D$

CD

CD

C

50

55

IF (K1.GT.K2) CALL ISWAP (K1,K2)

If too few points, don't try to fit

$\mathrm{NK}=\mathrm{K} 2-\mathrm{K} 1+1$

IF (NK.LT.3) GO TO 40

Calculate $\mathrm{Z}=\mathrm{X} * \star 2+\mathrm{Y} * \star 2$

Write $X, Y, 1$ to a matrix $W$

DO $45 \mathrm{I}=1$, NK

$M=K 1+I-1$

$W(I, 1)=X(M)$

$W(I, 2)=Y(M)$

$W(I, 3)=1.0$

CONTINUE

$\mathrm{Z}(\mathrm{I})=\mathrm{X}(\mathrm{M}) * \mathrm{X}(\mathrm{M})+\mathrm{Y}(\mathrm{M}) * \mathrm{Y}(\mathrm{M})$

Invoke routine REGR to calculate multiple regression coefficients $M=3$

CALL REGR (NDIM, NK, M, W, Z, COEFF, RSSQ, A3X3, MDIM, A3)

Connect old circle center with new one, in green

CALL SETCOL (2)

$\mathrm{PX}=\mathrm{NINT}\left(\mathrm{UPA}^{\star} \mathrm{A}+\mathrm{UPB}\right)$

$P Y=N I N T(U P C * B+U P D)$

$Q X=N I N T(P Q A * F L O A T(P X)+P Q B)$

$Q Y=N I N T(P Q C * F L O A T(P Y)+P Q D)$

IF (J.GT.1) CALL MOVE (QX,QY)

Divide coefficients $A$ and $B$ by two to get circle's center

$A=\operatorname{COEFF}(1) / 2$.

$\mathrm{B}=\operatorname{COEFF}(2) / 2$.

$\mathrm{PX}=\mathrm{NINT}(\mathrm{UPA} * \mathrm{~A}+\mathrm{UPB})$

$P Y=N I N T(U P C * B+U P D)$

$Q X=N I N T(P Q A * F L O A T(P X)+P Q B)$

$Q Y=N I N T(P Q C \star F L O A T(P Y)+P Q D)$

IF (J.LE. 1) CALL MOVE (QX, QY)

IF (J.GT.1) CALL DRAW (QX, QY)

$\mathrm{C}=\operatorname{COEFF}(3)$

Calculate radius as $\mathrm{Rsq}=\mathrm{C}+\mathrm{Asq}+\mathrm{Bsq}$

RADIUS $=S Q R T(C+A * A+B * B)$

Print to console circle center, radius, and residual SSQ

WRITE $(*, *)$, Circle center: , , A, B

WRITE $(*, *)$ ' Radius: ', RADIUS

WRITE $(*, *)$ ' Residual SSQ: ', RSSQ

WRITE $(*, *)$ ' Number of points along arc: ',NK

Plot the fitted circle

DO $50 \mathrm{I}=1,61$

$\mathrm{T}=$ FLOAT $(I-1) *$ DELTA

$C X(I)=$ RADIUS*COS $(T)+A$

CONTINUE

CALL SETCOL (6)

$\mathrm{PX}=\operatorname{NINT}\left(\mathrm{UPA}^{\star} \mathrm{CX}(1)+\mathrm{UPB}\right)$

$P Y=N I N T\left(U P C{ }^{\star} C Y(1)+U P D\right)$

$Q X=N I N T(P Q A * F L O A T(P X)+P Q B)$

$Q Y=N I N T(P Q C \star F L O A T(P Y)+P Q D)$

CALL MOVE ( $Q X, Q Y)$

DO $55 I=2,61$

$\mathrm{PX}=\mathrm{NINT}\left(\mathrm{UPA}{ }^{*} \mathrm{CX}(\mathrm{I})+\mathrm{UPB}\right)$

$P Y=N I N T\left(U P C{ }^{*} C Y(I)+\right.$ UPD $)$

$Q X=N I N T(P Q A * F L O A T(P X)+P Q B)$

$Q Y=N I N T(P Q C \star F L O A T(P Y)+P Q D)$

CALL DRAW (QX, QY)

CONTINUE

Calculate the angle subtended by the arc

$\mathrm{NC}=\mathrm{NC}+1$ 
91 CONTINUE

write (cv, 311) tch,' chambers'c

311 format ( $f 10.2, a)$

$\mathrm{qx}=\lim \mathrm{x}-180$

$q y=1$ limy $-136+n c \star 10$

call text (cv, qx, qy, 1, 1, 12)

IF (QPAUSE) CALL KEY $(Q, I)$

IF (Q.EQ.' $Q$ ' . OR.Q.EQ.' ' ' ') GO TO 95

$C$ Write the label of the shape to the output file WRITE $(11,210)$ LABEL, IDNUM, TCH

210 FORMAT (A15, I5, F10.4)

C Write the circles' parameters to the output file WRITE $(11,215)$ (CCX (I) , CCY (I) , CR (I) , CN (I), ANGLE (I) , CH (I), I=1, NC)

215 FORMAT (6F10.4) GO TO 5

C End-while more shapes

C Close files

95 CLOSE (10)

CLOSE (11)

CALL CLEAR(0)

CALL TMODE

C Repeat if desired

GO TO 2

C End of program

99 STOP ' Normal end of FitCir'

END

SUBROUTINE ISWAP $(\mathrm{J}, \mathrm{K})$

$\mathrm{L}=\mathrm{J}$

$\mathrm{J}=\mathrm{K}$

$\mathrm{K}=\mathrm{L}$

RETURN

END

SUBROUTINE REBILD (NPT, SIDE, AMPL, PHI, X, Y, NDIM)

C

C $\langle$ REBILD $>$ Vers. 1.1

C

C G.P. Lohmann (WHOI, Woods Hole MA 02543)

C $\langle$ REBILD> reconstructs shapes from their Zahn \& Roskies phi* shape functions. 


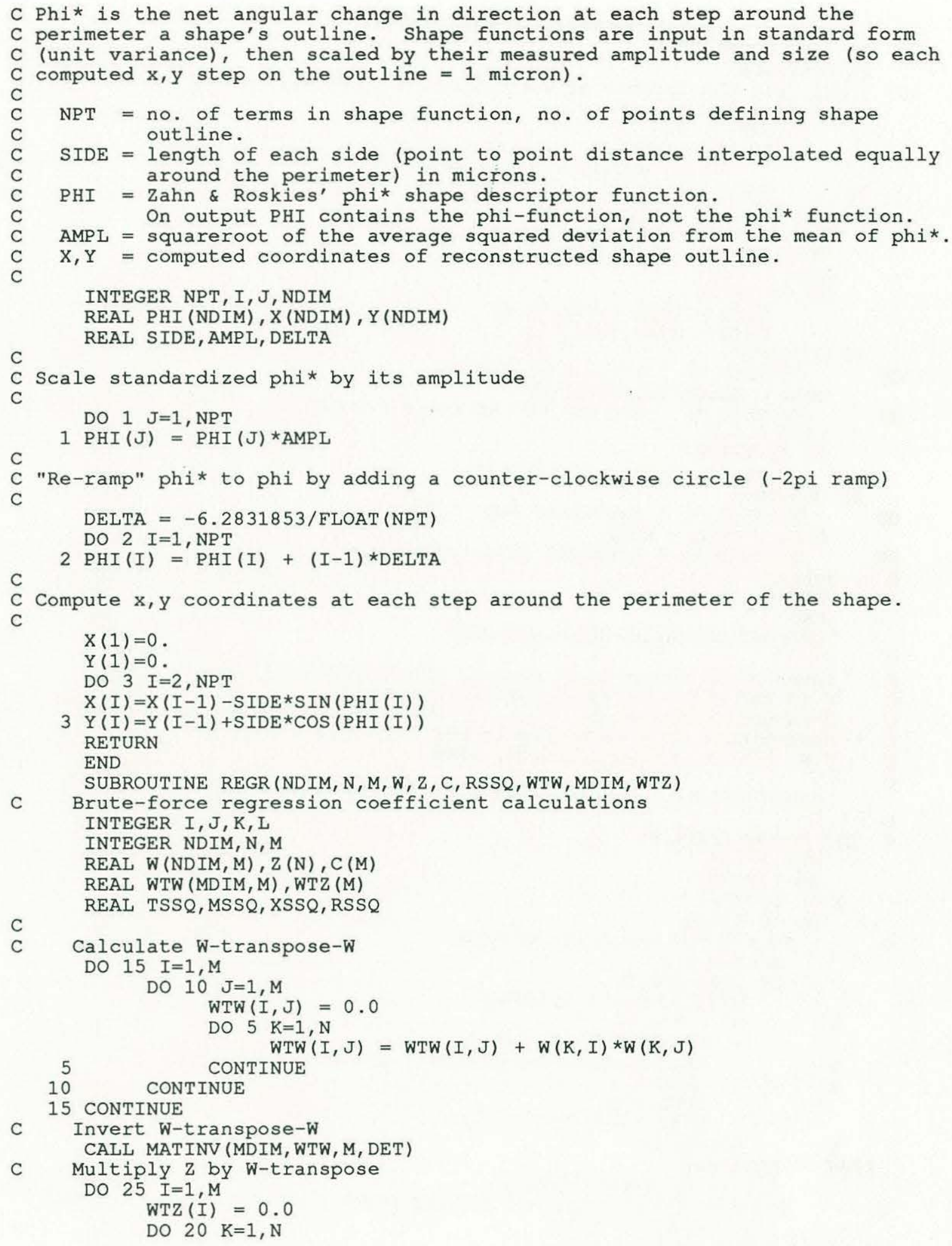




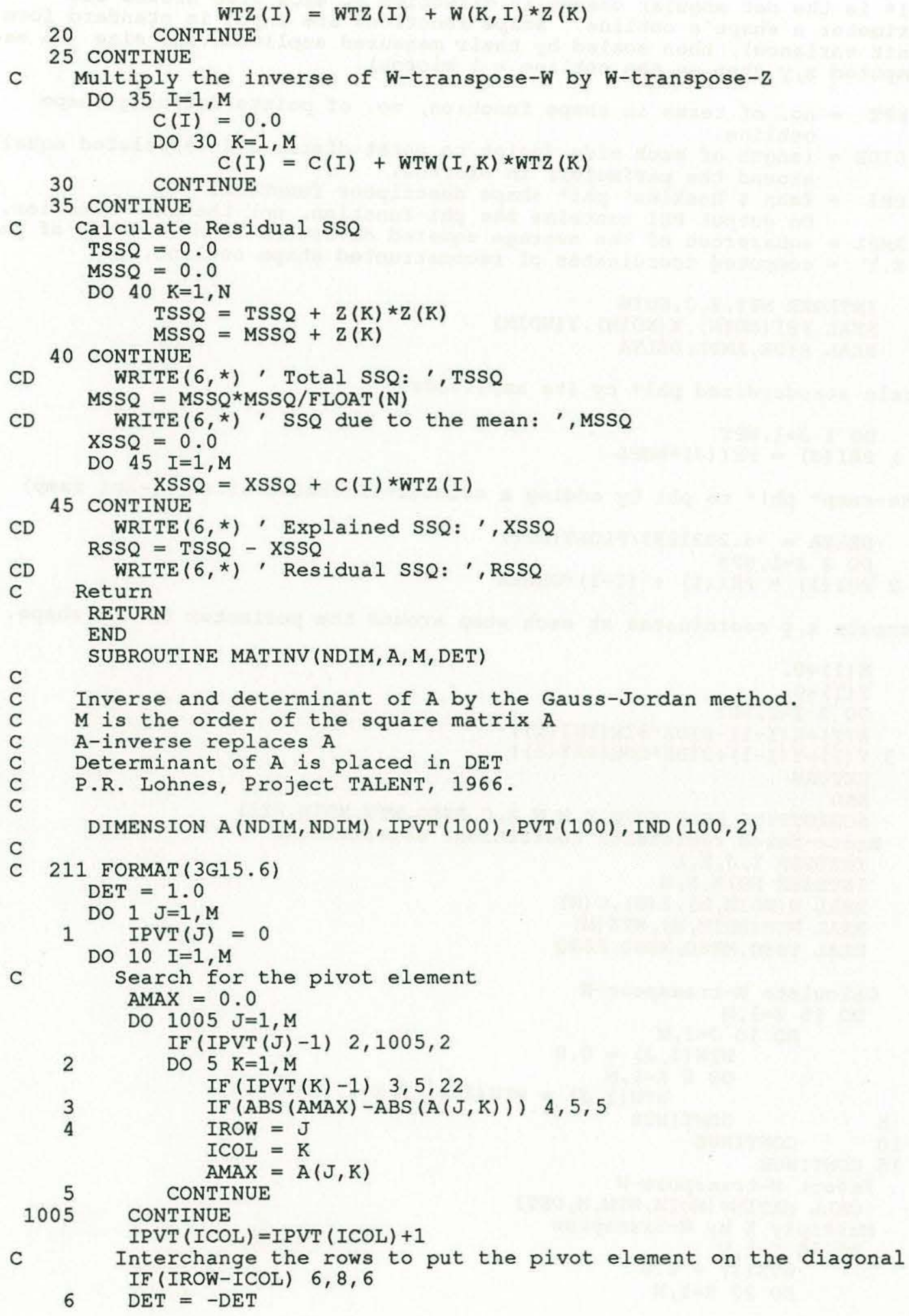




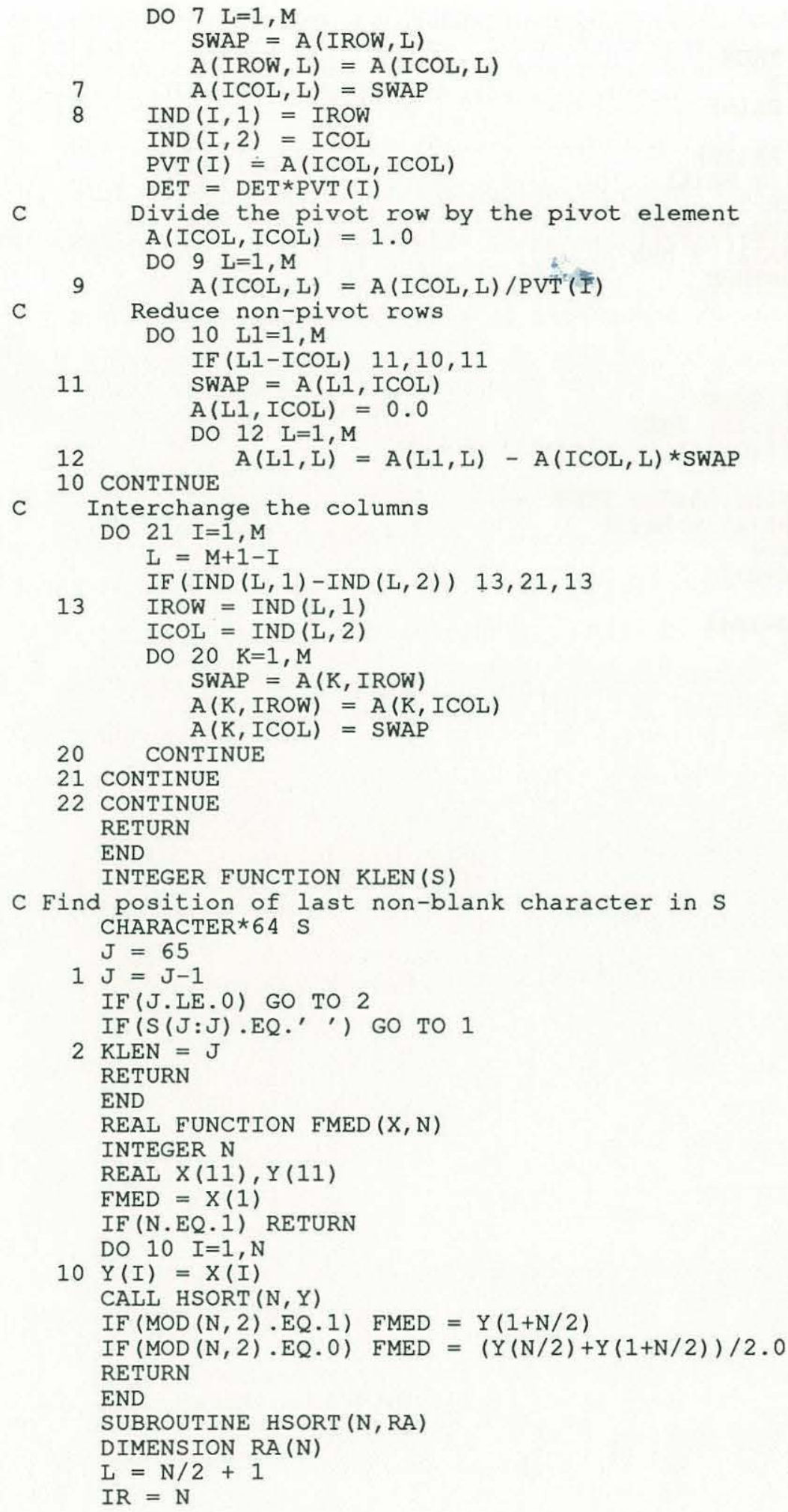


10 CONTINUE

IF (L.GT.1) THEN

$\mathrm{L}=\mathrm{L}-1$

$R R A=R A(L)$

ELSE

$R R A=R A(I R)$

$\mathrm{RA}(\mathrm{IR})=\mathrm{RA}(1)$

$I R=I R-1$

IF (IR.EQ.1) THEN $\mathrm{RA}(1)=\mathrm{RRA}$

ENDIF

ENDIF RETURN

$I=L$

$\mathrm{J}=\mathrm{L}+\mathrm{L}$

20

IF (J.LE.IR) THEN

IF (J.LT.IR) THEN

ENDIF

$\operatorname{IF}(R A(J) \cdot L T \cdot R A(J+1)) \quad J=J+1$

IF (RRA.LT.RA(J)) THEN

$\mathrm{RA}(\mathrm{I})=\mathrm{RA}(\mathrm{J})$

$I=J$

ELSE

$\mathrm{J}=\mathrm{J}+1$

$J=I R+1$

GO TO 20

ENDIF

$R A(I)=R R A$

GO TO 10

END 